Aus dem Institut für Pflanzenpathologie und Pflanzenschutz der Georg-August-Universität Göttingen

\title{
Entwicklung eines schlagspezifischen und schadensbezogenen Prognosemodells zur Bekämpfung von Sclerotinia sclerotiorum an Winterraps
}

\author{
Dissertation \\ zur Erlangung des Doktorgrades \\ der Fakultät für Agrarwissenschaften \\ der Georg-August-Universität zu Göttingen
}

vorgelegt von

Simone Koch

geboren in Alfeld

Göttingen, im Dezember 2005 
D7

Referent: Prof. Dr. Andreas von Tiedemann

Korreferent: Prof. Dr. Heiko Becker

Tag der mündlichen Prüfung: 02. Februar 2006 
1 Einleitung 1

2 Material und Methoden 9

2.1 Chemikalien 9

2.2 Nährmedien und Pufferlösungen 10

2.3 Herkunft und Bezeichnung der Pilzisolate 14

2.4 Sklerotienproduktion 15

2.5 Apothezieninduktion 15

2.6 Pilzanzucht 16

2.7 Datenerhebung aus Feldversuchen 16

2.7.1 Anlage von Sklerotiendepots 16

$\begin{array}{ll}2.7 .2 \text { Erfassung des Vorjahresbefalls } & 17\end{array}$

$\begin{array}{ll}\text { 2.7.3 Erfassung des Erstauftretens von Apothezien } & 17\end{array}$

$\begin{array}{ll}2.7 .4 \text { Erfassung schlagspezifischer Daten } & 18\end{array}$

2.7.5 Erfassung des Knospenstadiums (BBCH 55) 19

$\begin{array}{ll}2.7 .6 \text { Bonituren } & 19\end{array}$

2.8 Entnahme von Blütenblättern im Feld 19

2.9 Feldversuche zur Überprüfung des Prototyps SkleroPro und $\begin{array}{ll}\text { des Modells SKLERO } & 20\end{array}$

2.10 Implementierung von SkleroPro in die Praxis 21

2.11 Gewächshaus- und Klimakammerversuche 22

2.11.1 Pflanzenanzucht 22

2.11.2 Künstliche Inokulation der Pflanzen 22

2.11.3 Herstellung von Ascosporensuspensionen 23

2.11.4 Boxentest 23

$2.12 \mathrm{pH}$-Indikator-Test zum Nachweis von S. sclerotiorum auf Blütenblättern $\quad 24$

2.13 ELISA zum Nachweis von S. sclerotiorum auf Blütenblättern 26

2.13.1 Herstellung des Antiserums 26

2.13.2 Biotinylierung der Antikörper 26

2.13.3 Aufbereitung von Pilzmaterial 26

$\begin{array}{ll}\text { 2.13.4 Aufbereitung von Pflanzenmaterial } & 27\end{array}$ 
$\begin{array}{ll}\text { 2.13.5 Proteinbestimmung } & 27\end{array}$

2.13.6 Standardisierung des ELISA 28

2.14 PCR 29

2.14.1 Isolierung genomischer DNA aus filamentösen Pilzen 29

2.14.2 DNA-Konzentrationsbestimmung 30

2.14.3 DNA-Gelelektrophorese und Geldokumentation 30

2.14.4 Standardisierung des PCR-Protokolls 30

2.15 Real-time PCR zum Nachweis von S. sclerotiorum auf Blütenblättern 32

2.15.1 Herstellung von linearem Polyacrylamid 32

2.15.2 Isolierung genomischer DNA aus Ascosporen 33

2.15.3 Isolierung genomischer DNA aus Blütenblättern vom Feld 33

2.16 Verrechnung der Schlagdaten aus den einzelnen Bundesländern 34

2.17 Bereitstellung der Wetterdaten 35

2.18 Wirtschaftlichkeitsuntersuchung zur Überprüfung der Modelle 36

2.19 Beschreibung des Modells SKLERO 37

2.20 Statistik 40

3 Ergebnisse $\quad 41$

3.1 Witterungsverlauf im Untersuchungszeitraum 2002-2005 41

3.2 Befallshäufigkeiten im Untersuchungszeitraum 2002-2005 45

3.3 Nachweis von S. sclerotiorum auf Blütenblättern mittels pH-Indikator-Test $\quad 47$

3.3.1 Befall der Blütenblattproben in den Jahren 2003 und $2004 \quad 48$

3.3.2 Vergleich der abgefallenen und festen Blütenblätter vom Feld 50

3.3.3 Vergleich des pH-Indikator-Tests mit dem Befall im Feld 51

3.4 ELISA 53

3.4.1 Ermittlung der optimalen Antikörperverdünnung 53

3.4.2 Ermittlung der Nachweisgrenze für S. sclerotiorum 54

3.4.3 Spezifität des Nachweises von S. sclerotiorum 55

3.4.4 Nachweis von S. sclerotiorum in künstlich infizierten Blütenblättern 56

3.4.5 Bestimmung des Befalls von $S$. sclerotiorum auf Blütenblättern vom Feld und Vergleich mit dem Befall im Feld 57

$\begin{array}{ll}3.5 \text { PCR } & 60\end{array}$

$\begin{array}{ll}\text { 3.5.1 Optimierung der PCR } & 60\end{array}$ 
3.5.1.1 Magnesiumchloridkonzentration

3.5.1.2 Annealingtemperatur

3.5.1.3 Spezifität des Primerpaares

3.6 Real-time PCR

3.6.1 Überprüfung der Spezifität gegenüber verschiedenen Sclerotinia-Isolaten 63

3.6.2 Überprüfung der Spezifität gegenüber anderen Pathogenen 64

3.6.3 Ermittlung der Nachweisgrenze $\quad 65$

3.6.4 Bestimmung des Befalls von S. sclerotiorum auf Blütenblättern und $\begin{array}{ll}\text { Vergleich mit dem Befall im Feld } & 67\end{array}$

$\begin{array}{ll}3.7 \text { Boxentest } & 69\end{array}$

3.7.1 Ermittlung der Minimumtemperatur für eine Ascosporeninfektion 69

3.8 Einfluss von Standortfaktoren und pflanzenbaulichen Maßnahmen auf den Befall mit S. sclerotiorum $\quad 71$

3.8.1 Analyse der schlagspezifischen Daten aus dem gesamten Datensatz 71

3.8.2 Analyse der schlagspezifischen Daten aus den einzelnen

Datensätzen der Pflanzenschutzdienste der Länder 74

3.9 Multiple Varianzanalysen zur Berechnung des Varianzanteils der Einflussgrößen nach Bundesländern $\quad 76$

3.10 Validierung von SKLERO anhand vorhandener Versuchsdaten 78

3.10.1 Vorhersagegenauigkeit des Erscheinens der Apothezien 78

3.10.2 Vorhersagegenauigkeit der Befallshäufigkeit 79

3.10.3 Vorhersagegenauigkeit der Rapsentwicklung während der Blüte $\quad 80$

3.11 Beschreibung des Modells SkleroPro 81

3.12 Erstellung des Modells SkleroPro und Veränderungen zu SKLERO 84

3.12.1 Berechnung der Rapsentwicklung 85

3.12.2 Berechnung der infektionsgünstigen Stunden 88

3.12.3 Integration der Fruchtfolge als schlagspezifischer Faktor 90

3.12.4 Integration der Berechnung einer Schadensschwelle für S. sclerotiorum 91

3.13 Validierung von SkleroPro in Feldversuchen der

Pflanzenschutzdienste der Länder 93

3.13.1 Vorhersagegenauigkeit der Befallshäufigkeit 93

3.13.2 Vorhersagegenauigkeit der Rapsentwicklung 93

3.14 Vorhersage des optimalen Applikationstermins für die Blütenbehandlung anhand von Wetterdaten 
3.15 Erste Überprüfung des Modellprototyps SkleroPro in Feldversuchen im Jahr 2004

3.15.1 Vorhersagegenauigkeit der Behandlungsentscheidung

3.16 Implementierung von SkleroPro in ISIP und erste Überprüfung im Feld im Versuchsjahr 2005

3.16.1 Vorhersagegenauigkeit der Behandlungsentscheidung 99

3.16.2 Wirtschaftlichkeit 100

3.17 Wirtschaftlichkeit durch exakte Terminierung der Blütenbehandlung 101

3.18 Retrospektive Wirtschaftlichkeitsuntersuchung von SkleroPro aus den Jahren 1994-2005

3.18.1Vorhersagegenauigkeit der Behandlungsentscheidung

3.18.2 Reduktion des Fungizideinsatzes durch SkleroPro im Vergleich zur Routinebehandlung

3.19 SkleroPro als Entscheidungsmodell auf der Internet Plattform des Informationssystems integrierte Pflanzenproduktion (ISIP)

4.1 Nachweisverfahren für S. sclerotiorum auf Blütenblättern

4.1.1 Nachweis von $S$. sclerotiorum mittels pH-Indikator-Test

4.1.2 Nachweis von S. sclerotiorum mittels ELISA

4.1.3 Nachweis von S. sclerotiorum mittels Real-time PCR

4.2 Einfluss schlagspezifischer Parameter auf den Befall mit S. sclerotiorum

4.3 Prognosemodelle und Beratungssysteme im Pflanzenschutz

4.4 Erstellung des Modells SkleroPro

4.5 Validierung von SkleroPro

4.6 Bewertung verschiedener Verfahren zur Abschätzung der

Behandlungsnotwendigkeit von S. sclerotiorum im Hinblick auf SkleroPro 


\section{Abkürzungsverzeichnis}

Abb.

AG

AK

BBA

$\mathrm{BH}$

$\mathrm{BBCH}$

bp

BS

bzw.

$\mathrm{cm}$

$\mathrm{Ct}$

CTAB

CPDP

DNA

dNTP

dpi

DWD

E

ELF

EDTA

$\mathrm{Fa}$.

g

h

ha

IgG

ISIP

$\operatorname{Inh}_{\mathrm{i}}$

INFEKT

k.D.

$\mathrm{kg}$

$\mathrm{km}$
Abbildung

Antigen

Antikörper

Biologische Bundesanstalt

Befallshäufigkeit

Entwicklungsstadien im Raps

Basenpaar

Befallsstärke

beziehungsweise

Zentimeter

Threshold Cycle

Cetyltrimethylammoniumbromid

Czapek Dox - Medium + Pepton

Desoxyribonukleinsäure

Desoxyribonukleotid-5'-Triphosphat

days post inoculation (Tage nach Inokulation)

Deutscher Wetterdienst

Extinktion

Entwicklungsfunktion

Ethylendiamintetraessigsäure

Firma

Gramm

Stunde

Hektar

Immunoglobulin G

Informationssystem integrierte Pflanzenproduktion

schlagsspezifischer Schwellenwert der infektionsgünstigen

Stunden

infektionsgünstige Stunde

keine Daten

Kilogramm

Kilometer 
Liter

$\mathrm{m}$

Meter

$\mathrm{m}^{2}$

Quadratmeter

$\mathrm{mM}$

Millimol

$\mathrm{mm}$

Millimeter

$\min$

$\mathrm{NaOH}$

NPZ

NUV

$\mathrm{nm}$

ng

n.s.

OD

PEG

PCR

PDA

PVP

PVPP

$r$

$\mathrm{r}^{2}$

rel.

RFU

RLF

RSA

RT

SD

SDS

Ss

StrAP

Taq

$\mathrm{t}$

Tab.

TE

TES

Minute

Natriumhydroxid

Norddeutsche Pflanzenzucht

Nah Ultra Violett

Nanometer

Nanogramm

nicht signifikant

optische Dichte

Polyethylenglykol

„polymerase chain reaction“

Potato Dextrose Agar

Polyvinylpyrrolidone

Polyvinylpolypyrrolidone

Korrelationskoeffizient

Bestimmtheitsmaß

relativ

relative fluorescence units

relative Luftfeuchte im Rapsbestand

Rinderserumalbumin

Raumtemperatur

Standardabweichung

Natriumdodecylsulfat

Sclerotinia sclerotiorum Isolat

Streptavidin-Alkalische-Phosphatase

Thermus aquaticus

Tonne

Tabelle

Tris-EDTA

Temperatursummenfunktion 
TRIS

TSF

TTRA

ver.

z.B.

z.T.

$\mu \mathrm{g}$

$\mu 1$

$\%$

${ }^{\circ} \mathrm{C}$

$\mathrm{w}: \mathrm{v}$
Tris(Hydroxymethyl)-ammoniumethan

Temperatursummenfunktion

Temperatur im Rapsbestand

verdünnt

zum Beispiel

zum Teil

Mikrogramm

Mikroliter

Prozent

Grad Celsius

weight per volume (Gewichtsanteil zu Volumenanteil) 


\section{Einleitung}

Der Anbau von Ölsaaten hat in den letzten 30 Jahren im Vergleich zu anderen Kulturpflanzen weltweit stetig an Bedeutung gewonnen. Insbesondere in den europäischen Ländern ist die Rapsproduktion von 2,8 Mio. t im Jahr 1976 auf 15,2 Mio. t im Jahr 2004 angestiegen (MiELKE, 2005). Davon wurden allein in Deutschland im Jahr 2004 5,3 Mio. $\mathrm{t}$ Raps (Brassica napus ssp. oleifera) produziert. Mit einer Anbaufläche von 1,3 Mio. ha konnte damit die bisher größte Rapsanbaufläche in Deutschland erreicht werden. Dies entspricht ungefähr 11\% der gesamten nutzbaren Ackerfläche (RAPOOL, 2005; UFOP, 2005). Der zweitgrößte Produzent in der Europäischen Union ist nach Deutschland Frankreich (4,0 Mio. t), gefolgt vom Großbritannien (1,6 Mio. t), Polen (1,5 Mio. t) und Tschechien (0,43 Mio. t). Weltweit sind China (12 Mio. t), Kanada (7,7 Mio. t) und Indien (6,6 Mio. t) die wichtigsten Anbauländer für Raps (MiELKE, 2005).

Die Hauptgründe für die Ausdehnung der Rapsanbaufläche in Deutschland sind einerseits in einer steigenden Nachfrage nach Speiseöl (REUTER, 2003) andererseits aber auch in der steigenden Bedeutung der Rapspflanze als Biodiesel zu sehen (BOCKEY, 2003). Zudem kommt seit 1993 dem Anbau von Raps als nachwachsender Rohstoff auf Stilllegungsflächen eine große Bedeutung zu (PARKHOMENKO, 2003). Zudem spielt die verbesserte Preis- und Marktsituation der Kulturpflanze eine große Rolle bei der Fruchtfolgegestaltung in den landwirtschaftlichen Betrieben. Ein weiterer Vorteil der Rapspflanze gegenüber anderen Kulturpflanzen ist der sehr gute Vorfruchtwert, gekennzeichnet durch die lange Bodenbedeckung und die gute Durchwurzelung des Bodens (Christen \& Siebling, 1999; HonERMEIER et al., 2002). Ebenso fördern ein hohes Leistungspotential der Sorten und eine hohe Ertragssicherheit die Attraktivität dieser Pflanze (DIEPENBROCK et al., 1999).

Die traditionellen Anbauregionen mit den stärksten Anbaudichten in Deutschland sind Mecklenburg-Vorpommern, Thüringen, Sachsen und Schleswig-Holstein (REUTER, 2003). Durch die zum Teil sehr engen Fruchtfolgen und hohen Anbaudichten in diesen Regionen nehmen vor allem die bodenbürtigen Pilzkrankheiten, wie Sclerotinia sclerotiorum und Verticillium longisporum, aber auch die stoppelbürtigen Krankheiten wie Phoma lingam bzw. seine sexuelle Form Leptosphaeria maculans zu (GARBE, 1999). Die Weißstängeligkeit, verursacht durch den Erreger S. sclerotiorum, ist eine der weltweit wichtigsten Krankheiten an Raps. Der Erreger besitzt einen sehr weiten 
Wirtspflanzenkreis, zu dem insgesamt 64 Pflanzenfamilien und 361 Spezies gehören. Neben den Brassicaceae werden auch Solanaceae, Chenopodiaceae und Apiaceae sowie zahlreiche andere Arten befallen (PURDY, 1979; Boland \& HALL, 1994). Das Auftreten des Schaderregers kann je nach Witterung, Jahr und Anbauregion stark schwanken und bei epidemischem Auftreten zu erheblichen Ertragsausfällen führen. Nicht selten können in einigen Jahren und Regionen Ertragsverluste von über 50\% entstehen (POPE et al., 1989).

S. sclerotiorum (Lib.) de Bary gehört zur Abteilung der Ascomyceten und hier zur Klasse der Discomycetes (BÖRNER, 1996). Bei S. sclerotiorum handelt es sich um einen monozyklischen Erreger, der keine Konidienformen bildet. Mit Hilfe von Dauerorganen, den Sklerotien, kann der Schaderreger bis zu 10 Jahre im Boden überleben (ADAMS \& AYERS, 1979) (Abb. 1).

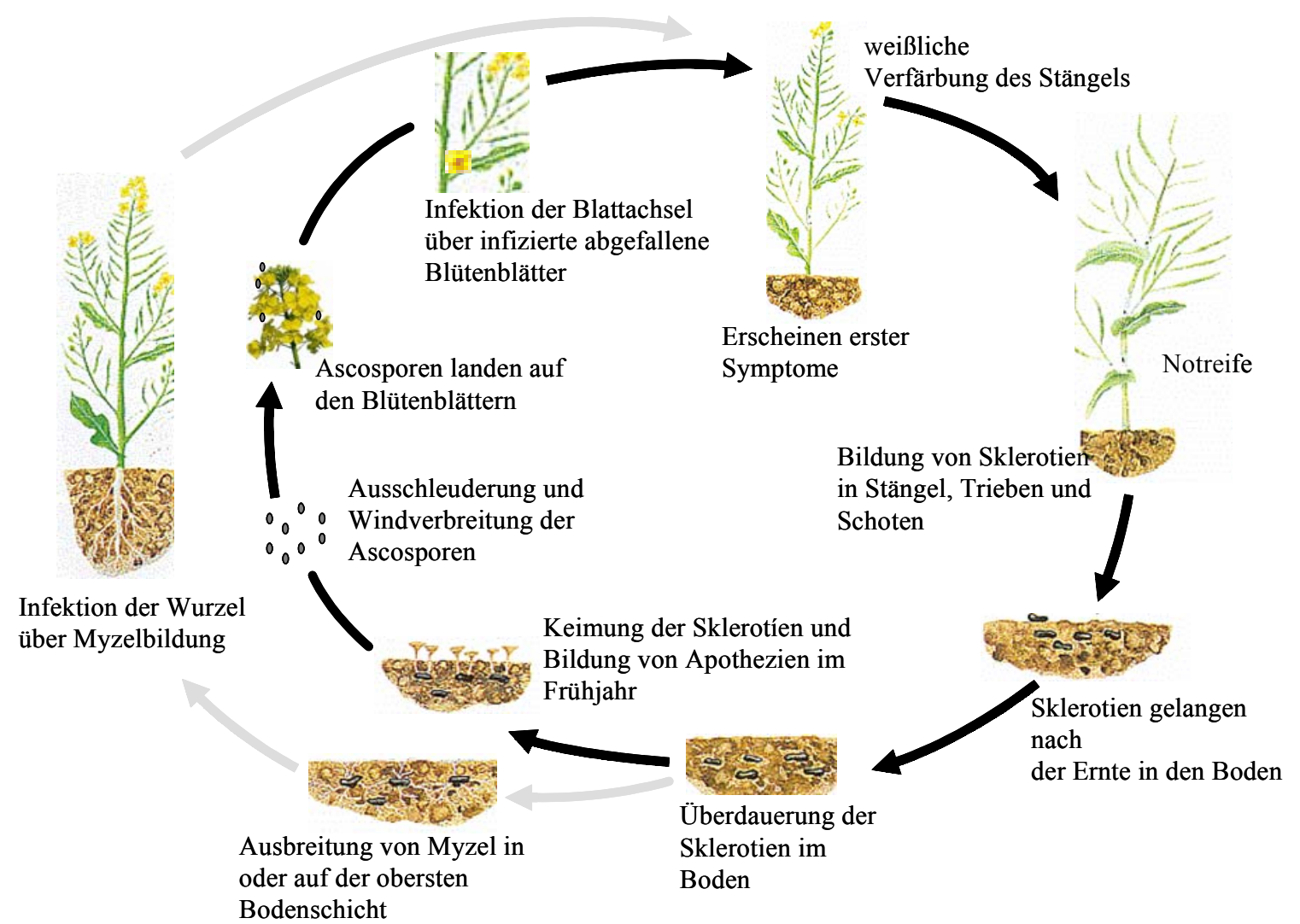

Abb. 1: Entwicklungszyklus von S. sclerotiorum an Raps verändert nach PAUL (2003)

Bei geeigneten Witterungsbedingungen und Lage der Sklerotien können diese im Frühjahr karpogen keimen und ein bis mehrere tellerförmige, hellbraune Apothezien ausbilden. 
Dabei kann sich eine zunehmende Ablagetiefe hemmend auf die Keimung der Sklerotien auswirken (Mitchell \& WHEELER, 1990; KRÜGER, 1975a). Eine Verlagerung der Sklerotien im Boden kann auch durch die Bodenbearbeitung herbeiführt werden. Williams et al. (1995) stellten fest, dass das tiefe Eingraben der Sklerotien bei der konventionellen Bodenbearbeitung zu einer Verringerung der Keimung und damit zu einer geringeren Apothezienbildung führt. Weitere Standortfaktoren wie die Bodenart und die Stickstoffdüngung üben keinen Einfluss auf das Auskeimen der Sklerotien aus (KRÜGER, 1977; Singh \& Singh, 1983). Neben den Standortbedingungen spielen besonders die Witterungsfaktoren, wie Temperatur und Bodenfeuchte, eine wichtige Rolle bei der Keimung. Die optimalen Temperaturen für eine Apothezienkeimung liegen im Bereich von $7-11^{\circ} \mathrm{C}$, während bei Temperaturen von durchschnittlich $18^{\circ} \mathrm{C}$ und tiefen Temperaturen zwischen $4-8^{\circ} \mathrm{C}$ sowie nach kurzen Frostperioden von $-15^{\circ} \mathrm{C}$, keine Entwicklung der Apothezien bzw. eine Hemmung der Keimung beobachtet werden konnte (KRÜGER, 1977; ABAWI \& GROGAN, 1979). Je höher die Bodenfeuchte ist, desto höher ist auch die Keimungungsrate der Sklerotien (FERRAZ et al., 1999). SINGH \& SingH (1983) berichten, dass sich eine Bodenfeuchte von 30\% besonders günstig auswirkt.

In den aufwachsenden Apothezien befinden sich die Ascusschläuche, die jeweils acht einzellige, elliptische Ascosporen enthalten (KoHN, 1979). Erst wenn die Apothezien eine bestimmte Größe erreicht haben, schleudern sie die Ascosporen in Stößen aus (SAUR, 1983). Bis zu 30 Millionen Sporen können von jedem gebildeten Apothezium entlassen werden (VenetTe, 1998). Die ausgeschleuderten und mit dem Wind verbreiteten Ascosporen können so auf die Blütenblätter des Rapses gelangen und dort unter günstigen Bedingungen auskeimen. Nach KRÜGER (1975) stellen die Blütenblätter eine wichtige Nährstoffquelle für die keimenden Sporen dar. Auch JAMAUX et al. (1995) konnten mit Hilfe elektronenmikroskopischer Aufnahmen feststellen, dass die Sporen von $S$. sclerotiorum nur in Gegenwart von Blütenblättern in der Lage sind, den Stängel bzw. die Laubblätter zu infizieren. Fallen die infizierten Blütenblätter in die Blattachsel der Pflanze, können sie von dort den Stängel infizieren. Die Infektion des Stängels und die weitere Verbreitung im Stängel erfolgt ausschließlich über Myzelwachstum.

Die Witterungsbedingungen gehören $\mathrm{zu}$ den wichtigsten Einflussfaktoren für eine erfolgreiche Infektion durch Ascosporen. Von entscheidender Bedeutung für ein hohes Befallsniveau, ist das Zusammentreffen des Ascosporenfluges mit dem Herabfallen der Blütenblätter. ABAWI \& GROGAN (1979) berichten, dass Ascosporen bis zu 12 Tage 
überleben können. Die Temperaturen für eine Infektion durch Ascosporen liegen im Bereich von $8-27^{\circ} \mathrm{C}$ (Young et al., 2004; AHLERs \& Hindorf, 1987), wobei $16-20^{\circ} \mathrm{C}$ optimal sind (ABAwi \& GRogan, 1979). CAESAR \& PEARSON (1983) beobachteten, dass sich Temperaturen von über $25^{\circ} \mathrm{C}$ schädlich auf das Überleben der Ascosporen auswirken. Relative Luftfeuchten von 83\% stellen die unterste Grenze einer Keimung der Ascosporen dar (AHLERS, 1987). Nach KRÜGER (1979) liegen die optimalen Luftfeuchten für eine Infektion bei 84-92\%. In Arbeiten von JAMAUX et al. (1995) konnte mit Hilfe von elektronenmikroskopischen Aufnahmen der Infektionsweg der Ascosporen über das Blütenblatt in das Rapsblatt genau beschrieben werden. Nach der Sporenkeimung erfolgte die Penetration des Blütenblattes nach 20-30 Stunden bei einer Luftfeuchte von 100\% und bei Raumtemperatur. Nach drei bis vier Tagen konnten erste Symptome auf der Oberfläche des Laubblattes beobachtet werden.

Der Schaderreger besitzt zwei Möglichkeiten, die Pflanze zu befallen. Neben der karpogenen Keimung durch Freisetzung von Ascosporen wird teilweise auch über eine direkte Infektion der unterirdischen Pflanzenteile durch das im Boden wachsende Myzel berichtet (LE TOURNEAU, 1979). Diese Art der Infektion ist jedoch nur bei direktem Kontakt von Sklerotium und Wurzel über Ausscheidung von Wurzelexsudaten möglich (MCQuiLCKen et al., 1994). Vom Befall der Pflanze bis zu den ersten sichtbaren Symptomen können je nach Witterung 10 - 14 Tage liegen. Der Befall äußert sich in weißen bis gelblichen Läsionen an Haupt- und Seitentrieben, während sich im Stängelinneren weißes wattiges Myzel mit gräulichen bis schwarzen Sklerotien befindet. Durch die Zerstörung der Leitbahnen und Gefäße werden die Pflanzenteile, die sich oberhalb der infizierten Stelle befinden, notreif und sterben vorzeitig ab. Bei der Ernte fallen die Sklerotien aus den Stängeln heraus und werden bei der nachfolgenden Bodenbearbeitung zusammen mit den Ernteresten in den Boden eingearbeitet (PAUL, 2003).

Die Schwierigkeiten bei der Bekämpfung von S. sclerotiorum liegen darin, dass zum optimalen Spritzzeitpunkt (während des Infektionsgeschehens zum Zeitpunkt der Blüte) die Befallssymptome an der Pflanze in der Regel noch nicht zu sehen sind und daher nicht als Grundlage für eine Behandlungsentscheidung herangezogen werden können. Zudem wird die Behandlung gegen die Weißstängeligkeit durch die nur begrenzte kurative und protektive Wirkung der Fungizide erschwert (PAUL et al., 2000; PAUL, 2005). Eine direkte Bekämpfung der Krankheit ist derzeit mit entsprechenden chemischen Fungiziden zum 
Zeitpunkt der Blüte oder mit dem biologischen Präparat Contans WG® (Prophyta GmbH) nach der Rapsernte auf die Stoppeln möglich (VON TIEDEMANN et al., 2001). Bei der Blütenbehandlung ist kein genauer Spritzzeitpunkt vorgegeben, in den letzten Jahren hat sich aber besonders in den traditionellen Anbaugebieten der prophylaktische Einsatz zum Zeitpunkt der Vollblüte (BBCH 65) durchgesetzt. Aufgrund des jährlich unterschiedlich starken Auftretens von S. sclerotiorum erweist sich eine Behandlung nicht in jedem Jahr als wirtschaftlich. WAHMHOFF (2000) konnte in seinen Auswertungen aus den Jahren 1981 und 1991 zeigen, dass sich nur ein durchschnittlicher Ertragsgewinn von 2,96 dt/ha durch eine Blütenbehandlung gegen S. sclerotiorum ergab. In der gleichen Studie konnte für den gleichen Zeitraum ein Anteil von 73\% unwirtschaftlicher Fungizidmaßnahmen gegen $S$. sclerotiorum ermittelt werden. Durch den sehr hohen Anteil an unwirtschaftlichen Fungizidapplikationen gegen die Weißstängeligkeit und im Hinblick auf die sich ständig verändernden Rahmenbedingungen in der Landwirtschaft, kommt einer umweltverträglichen und standortgerechten Bearbeitung der landwirtschaftlichen Flächen eine immer größer werdende Bedeutung zu. Im Pflanzenschutzgesetz vom 15. September 1986, § 6 Absatz 1, wurden die Grundsätze des Integrierten Pflanzenschutzes erstmalig vom Gesetzgeber berücksichtigt. Diese sind auch heute noch im geltenden Pflanzenschutzgesetz ( $§ 2 \mathrm{a}$, Absatz 1) im Zusammenhang mit der guten fachlichen Praxis berücksichtigt. Nach der Definition des Integrierten Pflanzenschutzes wird unter vorrangiger Berücksichtigung biologischer, biotechnischer und pflanzenzüchterischer sowie anbau- und kulturtechnischer Maßnahmen die Begrenzung der Anwendung chemischer Pflanzenschutzmittel auf das notwendige Maß gefordert. An die Stelle von prophylaktischen Behandlungen sollen gezielte Spritzungen treten, die auf der Grundlage von Befalls-Verlust-Relationen, Diagnose- und Prognoseverfahren beruhen (BURTH et al., 1994).

Erste Ansätze zur Abschätzung der Behandlungswürdigkeit von S. sclerotiorum in der Praxis basieren auf einem von AHLERS (1989) entwickelten Fragebogen. Zur Bewertung einer möglichen Infektion durch Sclerotinia sind der vorjährige Befall, die Fruchtfolge, der Gefährdungsgrad der Lage, das Erscheinen der Apothezien und insbesondere die Witterungsverhältnisse während der Blütezeit des Rapses von besonderem Interesse (Ahlers, 1989). Dabei wird jeder Parameter mit einer bestimmten Anzahl an Punkten bewertet und zu drei verschiedenen Terminen während der Blüte (BBCH 63, 65 und 69) erhoben. Die Bekämpfungsmaßnahme richtet sich nach der erreichten Gesamtpunktzahl 
und nach Befallslage. In dem untersuchten Zeitraum wird die Zuverlässigkeit der Fragebogenmethode mit etwa $60 \%$ angegeben, wobei ein Überschätzen der Bekämpfungswürdigkeit vorherrscht. Auf gleicher Grundlage wie der Fragebogen von AHLERS (1989), wurde in Schweden eine Risiko-Punkt-Tabelle entwickelt (TWENGSTRÖM et al., 1998). Neben der Fruchtfolge, dem Krankheitsauftreten in der letzten Wirtspflanze und der Bestandesdichte werden auch die Apothezienentwicklung und verschiedene Witterungsparameter mit erfasst. Je nach Überschreiten einer gewissen Gesamtpunktzahl wird eine Behandlung gegen S. sclerotiorum empfohlen. Die Ergebnisse zeigten, dass sich für den Wertebereich zwischen 40 und 50 Punkten eine sehr unsichere Prognose ergibt. In einer Weiterentwicklung der Bewertungstabellen wurde von AHLERS (1986) ein mathematisches Verfahren, basierend auf einer Diskriminanzanalyse, erarbeitet, welches ausgehend von einem Schwellenwert von $10 \%$ tolerierbarem Befall die Bekämpfungswürdigkeit zum Zeitpunkt der Blüte feststellt. Als nachteilig erweist sich die Anlage und Auswertung von Sklerotiendepots und Sporenfallen. Der hohe Zeitaufwand der Datengewinnung ist aus heutiger Sicht nicht praktikabel. Die ersten Untersuchungen im Feld lieferten keine ausreichenden Ergebnisse für einen großflächigen praktischen Einsatz (AHLERS \& HINDORF, 1987). Eine weitere Möglichkeit zur Vorhersage des Befallsauftretens von S. sclerotiorum besteht in der Anlage von Sklerotiendepots, an denen die Heranreifung von Apothezien verfolgt wird (NORDIN et al., 1992).

Das agrarmeteorologische Simulationsmodell SKLERO des Deutschen Wetterdienstes berechnet die Infektionswahrscheinlichkeit auf der Basis des Mikroklimas im Bestand, verschiedener meteorologischer Faktoren, des Rapsentwicklungsstadiums und einer 5tägigen Wettervorhersage (FrIESLAND, 1998 und 2000). Das Bestandesklima wird dabei aus stündlich gemessenen Größen wie der Bodenfeuchte, rel. Luftfeuchte und Lufttemperatur simuliert, um aufwändige direkte Messungen im Bestand zu umgehen. Im Weiteren wird das Erscheinen der Apothezien und der Ascosporenflug vorhergesagt und erst wenn diese Faktoren ermittelt werden konnten, berechnet das Modell ab Blühbeginn die stündlichen Infektionswahrscheinlichkeiten. Auf der Grundlage von Infektionsstunden und -druck wird der „meteorologische Infektionsdruck“ täglich auf einer Skala von „keiner“ bis „extrem hoch“ eingestuft.

Neben der Erarbeitung von Prognoseverfahren zum Befallsauftreten von S. sclerotiorum anhand von Wetterdaten und verschiedenen schlagspezifischen Daten können auch unterschiedliche quantitative Testmethoden als eine zusätzliche Möglichkeit zur Erfassung 
des voraussichtlichen Befalls dienen. Einen Ansatzpunkt $\mathrm{zu}$ einer verbesserten quantitativen Befallsvorhersage bietet der im kanadischen Sommerrapsanbau praktizierte Petaltest. Hierbei werden zu drei Entwicklungsstadien im Raps (Blühbeginn, Vollblüte und Blühende) Blütenblätter aus dem Bestand entnommen und mit einem spezifischen AgarTest auf Kontamination bzw. Infektion mit S. sclerotiorum untersucht (GUGEL \& MORALL, 1986). Die Blütenblattkontamination spiegelt dabei die vorhergehende Apothezienbildung, den Ascosporenflug und die bis zum Zeitpunkt der Probenahme herrschenden Infektionsbedingungen wieder. Je später der Termin der Probenentnahme lag, desto besser war die Vorhersagegenauigkeit. Multiple Regressionen aus Blüteblattinfektion und Bestandesdichteparametern (Blattflächenindex, Lichtdurchlässigkeit des Bestandes, Pflanzenhöhe) erklärten den späteren Befall zu 55-98\%. Unter praktischen Bedingungen konnte eine Verbesserung der Vorhersagegenauigkeit des Petaltests mit zunehmend günstigen Infektionsbedingungen zur Zeit der Blüte festgestellt werden (TURKINTON \& MORRALL, 1993).

Eine weitere Möglichkeit zur Unterstützung von Prognosemodellen stellen serologische Nachweisverfahren des Erregers dar. Der Nachweis und die Befallsquantifizierung mittels ELISA für phytopthogene Pilze in Raps wurden bereits für Verticillium dahliae (ForTnAgel, 1994; CERnUSKO, 1995; HePPNER, 1994) und für S. sclerotiorum (JAMAUX \& SPIRE, 1994) durchgeführt. Eine andere Alternative zur frühzeitigen Diagnose des Blütenblattbefalls kann ferner auch die PCR-Technik sein. In Arbeiten von FREEMAN et al. (2002) wurden bereits spezifische Primer zum Nachweis von S. sclerotiorum auf Blütenblätter entwickelt. Bis jetzt kam es noch zu keiner praktischen Anwendung dieser PCR. Eine weitere Entwicklung der konventionellen PCR stellt die Real-time PCR dar. Diese relativ neue Technik in der Phytomedizin ermöglicht im Gegensatz zur konventionellen PCR auch einen quantitativen Nachweis des Erregers (BATES et al., 2001; SALM \& GEIDER, 2004).

Obwohl in der Literatur zahlreiche Modellansätze und Nachweismethoden zur frühen Ermittlung des Befalls beschrieben worden sind, steht zurzeit noch kein geeignetes Prognosemodell zur Einschätzung der Bekämpfungswürdigkeit von S. sclerotiorum im Winterraps zur Verfügung. Die vorliegende Arbeit hatte das Ziel, ein solches Prognoseverfahren zu entwickeln und dies als Entscheidungshilfe für den Fungizideinsatz in der Praxis nutzbar zu machen. In Zusammenarbeit mit den Pflanzenschutzdiensten der Länder, der ZEPP (Zentralstelle der Länder für EDV-gestützte Entscheidungshilfen und 
Programme im Pflanzenschutz), ISIP (Informationssystem integrierte Pflanzenproduktion) und dem DWD (Deutschen Wetterdienst) wurde das bereits vorhandene Prognosesystem SKLERO (FRIESLAND, 1998) als Arbeitsmodell mit einbezogen und ein erweitertes Prognosemodell auf diesem aufgebaut. In einem ersten Arbeitsschritt wurde das Modell SKLERO anhand von Feldversuchen ausführlich validiert. Insbesondere wurde hier eine regional- und jahresspezifische Auswertung und die Bewertung von Grenzen und Schwächen des Modells vorgenommen. Schwerpunkt dieser Untersuchungen war eine Überprüfung der Vorhersagegenauigkeit von SKLERO in Bezug auf das Erscheinen der Apothezien und der Relation von vorhergesagter Infektionswahrscheinlichkeit zur tatsächlich eingetretenen Befallshäufigkeit in Abhängigkeit von Standort, Witterung und Befallsdruck.

Des Weiteren wurde anhand von Datenerhebungen aus Feldversuchen der Pflanzenschutzdienste der Länder der letzten 10 Jahre eine umfassende statistische Auswertung zur Überprüfung des Einflusses verschiedener schlagspezifischer Faktoren und deren Wechselbeziehungen auf den Befall mit S. sclerotiorum vorgenommen. Die bewerteten Faktoren wurden anschließend in das Prognosemodell integriert.

Die Erstellung eines komplexen schlagspezifischen, befalls- und schadensbezogenen Prognosemodells erfolgte durch die Verknüpfung mit der Berechnung schlagspezifischer Schadensschwellen, die aus Befalls-Verlust-Relationen entwickelt wurden (DUNKER, 2004).

Zur Unterstützung der Behandlungsentscheidung durch das Prognosemodell wurden verschiedene Methoden wie der ELISA, der pH-Indikator-Test und eine Real-time PCR für den Nachweis von S. sclerotiorum auf befallenen Blütenblättern überprüft. Ziel war eine möglichst schnelle, präzise und zuverlässige Methode für den Befall von S. sclerotiorum auf Blütenblättern zu entwickeln. 


\section{Material und Methoden}

\subsection{Chemikalien}

Außer den unten aufgeführten Chemikalien wurden nur Standardchemikalien der Firma Merck, Damstadt mit dem Reinheitsgrad „p.a“" oder „reinst“ verwendet.

Acrylamid 40\%

Bacto Agar

Agarose

Bengalrosa

Biotin-X-NHS

Bromkresolgrün

Casein

Chloramphenicol

Chlortetracyclin

Coomassie Blue

CTAB

Czapek-Dox Broth

Diethanolamin

Dimethylformamid

DNA-Marker: pUC Marker Mix dNTP

Loading Dye (BJ)

Lambada DNA

$\mathrm{MgCl}_{2}$

Streptomycinsulfat

Nonidet P-40

4-Nitrophenylphosphat

10x PCR-Puffer

Potato Dextrose Both

Proteinase $\mathrm{K}$

Pepton
FLUKA Chemie GmbH, Neu-Ulm

SCHARLAU Chemie, Barcelona

MERCK $\AA$, Darmstadt

MERCK ${ }^{\circledR}$, Darmstadt

SIGMA ALDRICH Chemie GmbH, Deisenhofen

MERCK ${ }^{\circledR}$, Darmstadt

SERVA Feinchemikalien, Heidelberg

SERVA Feinchemikalien, Heidelberg

SIGMA ALDRICH Chemie GmbH, Deisenhofen

SERVA Feinchemikalien, Heidelberg

CARL ROTH®, Karlsruhe

SCHARLAU Chemie, Barcelona

SERVA Feinchemikalien, Heidelberg

SIGMA ALDRICH Chemie GmbH, Deisenhofen

MBI-Fermentas, St. Leon-Roth

BIOLINE GmbH, London

MBI-Fermentas, St. Leon-Roth

MBI-Fermentas, St. Leon-Roth

BIOLINE GmbH, London

FLUKA Chemie GmbH, Neu-Ulm

FLUKA Chemie GmbH, Neu-Ulm

SERVA Feinchemikalien, Heidelberg

BIOLINE GmbH, London

SCHARLAU Chemie, Barcelona

CARL ROTH ${ }^{\circledR}$, Karlsruhe

CARL ROTH ${ }^{\circledR}$, Karlsruhe 


$\begin{array}{ll}\text { PVPP } & \text { SERVA Feinchemikalien, Heidelberg } \\ \text { Rinderserum albumin Fraktion V } & \text { SERVA Feinchemikalien, Heidelberg } \\ \text { SybrGreen } & \text { Applied Biosystems }{ }^{\circledR}, \text { Kalifornien, USA } \\ \text { StrAP } & \text { ROCHE Diagnostics GmbH, Mannheim } \\ \text { Taq-Polymerase } & \text { MBI-Fermentas, St. Leon-Roth } \\ \text { Triton X-100 } & \text { MBI-Fermentas, St. Leon-Roth } \\ \text { Tween } 20 & \text { FLUKA Chemie GmbH, Neu-Ulm }\end{array}$

\subsection{Nährmedien und Pufferlösungen}

Die beschriebenen Nährmedien wurden z.T. sowohl als Flüssig- wie auch als Festmedium verwendet. Für die Verfestigung der Medien wurde 1,5\% Bacto Agar zugesetzt. Die sterilisierten Medien wurden vor dem Ausplattieren auf ca. $50^{\circ} \mathrm{C}$ im Wasserbad gekühlt und anschließend in Polystyrolpetrischalen (9 cm Durchmesser, Fa. Greiner) ausplattiert. Im Folgenden wird die Zusammensetzung der Nährmedien $(1000 \mathrm{ml})$ angegeben.

Potato Dextrose Agar (PDA): $\mathrm{pH}$ 6,0

$\begin{array}{ll}\text { Potato Dextrose Broth (PDB) } & 20 \mathrm{~g} \\ \text { Bacto-Agar } & 15 \mathrm{~g} \\ \text { Streptomycinsulfat } & 200 \mathrm{mg} / 1 \\ \mathrm{H}_{2} \mathrm{O}_{\text {bidest }} & \text { ad } 1000 \mathrm{ml}\end{array}$

Czapek Dox-Medium (CPD): $\mathrm{pH}$ 5,5

$$
\begin{array}{ll}
\text { Czapek-Dox-Broth } & 33,4 \mathrm{~g} \\
\mathrm{H}_{2} \mathrm{O}_{\text {bidest }} & \text { ad } 1000 \mathrm{ml}
\end{array}
$$

CPD+P: $\quad$ Czapek Dox-Medium mit 0,1\% Pepton (aus Casein)

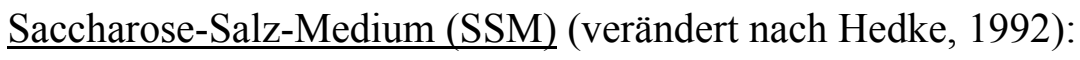

$\begin{array}{lr}\text { Agar } & 15 \mathrm{~g} \\ \text { Saccharose } & 40 \mathrm{~g} \\ \mathrm{NH}_{4} \mathrm{NO}_{3} & 1 \mathrm{~g} \\ \mathrm{KH}_{2} \mathrm{PO}_{4} & 0,7 \mathrm{~g}\end{array}$




$\begin{array}{lc}\mathrm{MgSO}_{4} \times 7_{2} \mathrm{O} & 0,2 \mathrm{~g} \\ \mathrm{KCl} & 0,14 \mathrm{~g} \\ \mathrm{CaCO}_{3} \text { (variiert) } & 2-8 \mathrm{~g} \\ \text { Triton } & 2 \mathrm{ml} \\ \text { Bromkresolgrün } & 80 \mathrm{mg} \\ \text { Bengalrosa } & 60 \mathrm{mg} \\ \text { Chloramphenicol } & 60 \mathrm{mg} \\ \text { Streptomycin } & 60 \mathrm{mg} \\ \text { Chlortetracyclin } & 20 \mathrm{mg} \\ \text { Spurenelementstammlösung } & 2 \mathrm{ml} \\ \mathrm{H}_{2} \mathrm{O}_{\text {bidest }} & \mathrm{ad} 1000 \mathrm{ml}\end{array}$

Spurenelementstammlösung $1000 \mathrm{ml}$ davon enthalten:

$\begin{array}{ll}\mathrm{FeSO}_{4} \times 7 \mathrm{H}_{2} \mathrm{O} & 1 \mathrm{~g} \\ \mathrm{ZnCl}_{2} & 1 \mathrm{~g} \\ \mathrm{MgCl}_{2} \times 7 \mathrm{H}_{2} \mathrm{O} & 0,6 \mathrm{~g} \\ \mathrm{H}_{2} \mathrm{O}_{\text {bidest }} & \text { ad } 1000 \mathrm{ml}\end{array}$

Phosphatgepufferte physiologische Kochsalzlösung (PPK): pH 7,2-7,4 (nach CASPER \& MEYER, 1981)

$\begin{array}{ll}\mathrm{NaCl} & 8,0 \mathrm{~g} \\ \mathrm{KH}_{2} \mathrm{PO}_{4} & 0,2 \mathrm{~g} \\ \mathrm{Na}_{2} \mathrm{HPO}_{4} \times 12 \mathrm{H}_{2} \mathrm{O} & 2,9 \mathrm{~g} \\ \mathrm{KCl} & 0,2 \mathrm{~g} \\ \mathrm{H}_{2} \mathrm{O}_{\text {bidest }} & \text { ad } 1000 \mathrm{ml}\end{array}$

PPK-Tween: $\quad$ PPK $+0,05 \%$ Tween

Konjugatpuffer (nach CASPER \& MEYER, 1981):

PPK-Tween $+0,2 \%$ RSA 
Waschpuffer (nach CASPER \& MEYER, 1981):

$1 / 2$ PPK-Tween

Extraktionspuffer (nach CASPER \& MEYER, 1981):

PPK-Tween + 0,2\% PVP

Extraktionspuffer (nach HEPPNER, 1995):

$\begin{array}{ll}\text { Tris/HCl } & 100 \mathrm{mM} \\ \mathrm{NaCl} & 2 \mathrm{M} \\ \text { EDTA } & 20 \mathrm{mM} \\ \text { Triton X-100 } & 0,1 \% \\ \text { Casein } & 1,0 \%\end{array}$

Beschichtungspuffer pH 9,6 (nach CASPER \& MEYER, 1981):

$\begin{array}{ll}\mathrm{NaHCO}_{3} & 2,93 \mathrm{~g} \\ \mathrm{Na}_{2} \mathrm{CO}_{3} & 1,59 \mathrm{~g} \\ \mathrm{NaN}_{3} & 2 \mathrm{~g} \\ \mathrm{H}_{2} \mathrm{O}_{\text {bidest }} & \text { ad } 1000 \mathrm{ml}\end{array}$

Substratpuffer pH 9,8 (nach CLARK \& ADAMS, 1977):

$\begin{array}{ll}\text { Diethanolamin } & 97 \mathrm{ml} \\ \mathrm{H}_{2} \mathrm{O}_{\text {bidest }} & \text { ad } 1000 \mathrm{ml}\end{array}$

TES-Puffer: $\quad \mathrm{pH} 8,0$

$\begin{array}{lc}\text { Tris/HCl } & 100 \mathrm{mM} \\ \text { EDTA } & 20 \mathrm{mM} \\ \text { SDS } & 1 \% \\ \mathrm{H}_{2} \mathrm{O}_{\text {bidest }} & \text { ad } 1000 \mathrm{ml}\end{array}$

TE-Puffer: $\quad \mathrm{pH} 8,0$

$\begin{array}{lc}\text { Tris } / \mathrm{HCl} & 10 \mathrm{mM} \\ \text { EDTA } & 1 \mathrm{mM} \\ \mathrm{H}_{2} \mathrm{O}_{\text {bidest }} & \text { ad } 1000 \mathrm{ml}\end{array}$


Carbonatpuffer: $\quad \mathrm{pH} 7,5$

$\begin{array}{ll}\mathrm{NaCl} & 10 \mathrm{~g} \\ \mathrm{NaHCO}_{3} & 10 \mathrm{~g} \\ \mathrm{H}_{2} \mathrm{O}_{\text {bidest }} & \text { ad } 1000 \mathrm{ml}\end{array}$

\section{PEG:}

Polyethylenglykol 6000

$30 \%$

$\mathrm{NaCl}$

$10,5 \mathrm{~g}$

50x TAE:

$\mathrm{pH} \mathrm{8,5}$

Tris

$0,04 \mathrm{M}$

$\mathrm{Na}_{2}$ EDTA x $2 \mathrm{H}_{2} \mathrm{O}$

$2 \mathrm{mM}$

$\mathrm{H}_{2} \mathrm{O}_{\text {bidest }}$ ad $1000 \mathrm{ml}$

Saline:

$\mathrm{NaCl}$

$8,5 \mathrm{~g}$

$\mathrm{H}_{2} \mathrm{O}_{\text {bidest }}$

ad $1000 \mathrm{ml}$

Proteinase K: $\quad 20 \mathrm{mg} / \mathrm{ml}$ gelöst in sterilem, $\mathrm{H}_{2} \mathrm{O}_{\text {bidest, }}$ aloquiert und bei $-20^{\circ} \mathrm{C}$ gelagert.

CTAB:

in $0,7 \mathrm{M} \mathrm{NaCl}$ und TE-Puffer

$\underline{\text { SDS: }}$

SDS in $\mathrm{H}_{2} \mathrm{O}_{\text {bidest }}$ lösen und pH-Wert mit konz. $\mathrm{HCl}$ auf 7,2 einstellen. 


\subsection{Herkunft und Bezeichnung der Pilzisolate}

Für die Erprobung eines quantitativen Nachweises von S. sclerotiorum auf Blütenblättern wurden folgende in Tabelle 1 aufgeführte Pilzisolate verwendet.

Tab. 1: Bezeichnung und Herkunft der verwendeten Pilzisolate (- = nicht bekannt)

\begin{tabular}{|c|c|c|c|c|c|}
\hline Pilzart & $\begin{array}{l}\text { Be- } \\
\text { zeichnung }\end{array}$ & Wirt & Herkunft & Land & Jahr \\
\hline Sclerotinia sclerotiorum & Ss 1.1 & Brassica napus & Biestow & $\mathrm{D}$ & 1998 \\
\hline Sclerotinia sclerotiorum & Ss $1.1 \mathrm{a}$ & Brassica napus & Petschow & $\mathrm{D}$ & 1998 \\
\hline Sclerotinia sclerotiorum & Ss 1.2 & Brassica napus & Sildemow & $\mathrm{D}$ & 1998 \\
\hline Sclerotinia sclerotiorum & Ss 1.3 & Brassica napus & Wölschendorf & $\mathrm{D}$ & 1997 \\
\hline Sclerotinia sclerotiorum & Ss 1.5 & Brassica napus & Biestow & $\mathrm{D}$ & 1997 \\
\hline Sclerotinia sclerotiorum & Ss 1.6 & Brassica napus & Diedrichshagen & $\mathrm{D}$ & 1997 \\
\hline Sclerotinia sclerotiorum & Ss 2.4 & Helianthus annuus & Biestow & $\mathrm{D}$ & 1997 \\
\hline Sclerotinia sclerotiorum & Ss 3.4 & Vica faba $L$. & PM-Institut GWH & $\mathrm{D}$ & 1997 \\
\hline Sclerotinia sclerotiorum & Ss 4.5 & $\begin{array}{l}\text { Crambe abyssinica } \\
\text { L. }\end{array}$ & Biestow & $\mathrm{D}$ & 1997 \\
\hline Sclerotinia sclerotiorum & Ss 5.5 & Camelina sativa & Biestow & $\mathrm{D}$ & 1997 \\
\hline Sclerotinia sclerotiorum & Ss 6.12 & Cannabis sativa & Malchow/Poel & $\mathrm{D}$ & 1997 \\
\hline Sclerotinia sclerotiorum & Ss 11.4 & - & - & - & - \\
\hline $\begin{array}{l}\text { Verticillium } \\
\text { longisporum }\end{array}$ & V1 82 & Brassica napus & Mecklenburg & $\mathrm{D}$ & 1997 \\
\hline $\begin{array}{l}\text { Verticillium } \\
\text { longisporum }\end{array}$ & V1 83 & Brassica napus & Mecklenburg & $\mathrm{D}$ & - \\
\hline $\begin{array}{l}\text { Verticillium } \\
\text { longisporum }\end{array}$ & V1 84 & Brassica napus & Mecklenburg & $\mathrm{D}$ & - \\
\hline Phoma lingam & P1 IB 23 & Brassica napus & Polen & POL & - \\
\hline Phoma lingam & P1 IB 39 & Brassica napus & Deutschland & $\mathrm{D}$ & - \\
\hline Phoma lingam & P1 IB 42 & Brassica napus & Frankreich & $\mathrm{F}$ & - \\
\hline Phoma lingam & P1 IB 2 & Brassica napus & Deutschland & $\mathrm{D}$ & 1986 \\
\hline Botrytis cinerea & $\mathrm{Bc} 1.0$ & Helianthus annuus & Forchheim & $\mathrm{D}$ & 1986 \\
\hline Botrytis cinerea & $\mathrm{Bc} 1.1$ & Vica faba $L$. & - & - & - \\
\hline Fusarium culmorum & Fc 33 & Triticum aestivum & Italien & $\mathrm{I}$ & - \\
\hline Fusarium oxysporum & Fo 36 & - & - & - & - \\
\hline Fusarium graminearum & Fg 35 & Triticum aestivum & Göttingen & $\mathrm{D}$ & 1975 \\
\hline Verticillium albo-atrum & Vaa 1.0 & Solanum tuberosum & Wisconsin & USA & - \\
\hline Verticillium dahliae & $\mathrm{Vd} 76$ & - & - & - & - \\
\hline Verticillium dahliae & $\mathrm{Vd} 3$ & Fragaria ananassa & Münsterland & $\mathrm{D}$ & 1997 \\
\hline Rhizoctonia solani & Rs AG 2-1 & - & - & - & - \\
\hline Alternaria brassicae & $\mathrm{Ab} 4$ & Brassica napus & Göttingen & $\mathrm{D}$ & 1988 \\
\hline
\end{tabular}




\subsection{Sklerotienproduktion}

Die Anzucht von Sklerotien erfolgte nach einer modifizierten Methode von SCHMIDT (1990) in $1000 \mathrm{ml}$ Erlenmeyerkolben auf einem Sand-Substrat-Gemisch. Die Erlenmeyerkolben wurden mit $300 \mathrm{~g}$ grobem, auf $1 \mathrm{~mm}$ gesiebten Quarzsand gefüllt. Dazu kamen 30 g gemahlene Vollkern-Haferflocken und 40-50 ml demineralisiertes Wasser. Nach sorgfältiger Durchmischung und Homogenisierung wurden die Kolben mit Alufolie verschlossen und zweimal im Abstand von 24 Stunden 40 min autoklaviert.

Die Sclerotinia-Isolate wurden in Petrischalen auf Potato-Dextrose-Agar (PDA) angezogen. Die Schalen wurden bei $18-22^{\circ} \mathrm{C}$ bei Tageslicht etwa 5 Tage inkubiert, bis deutlicher Myzelbewuchs und erste Exsudattröpfchen zu sehen waren. Erst dann erfolgte die Überimpfung von zwei gut zerkleinerten PDA-Kulturen in die Kolben. Die Inkubation erfolgte bei $18-22^{\circ} \mathrm{C}$ und Tageslicht. $\mathrm{Ab}$ dem Zeitpunkt deutlich erkennbaren Myzelwachstums wurden die Kolben ein bis zweimal pro Woche kräftig geschüttelt, um die Sklerotienbildung zu fördern. Die Ernte konnte nach 6-8 Wochen erfolgen. Dazu wurden die Kolben auf ein $1 \mathrm{~mm}$ Rundsieb ausgegossen und unter fließendem Leitungswasser kräftig ausgespült. Die geernteten Sklerotien wurden für mehrere Tage auf Filterpapier getrocknet und danach bei $4^{\circ} \mathrm{C}$ in einem geschlossenen Gefäß gelagert.

\subsection{Apothezieninduktion}

Für die Apothezieninduktion nach HEDKE (1992) wurden durchsichtige Quarkschalen (10 x 8 x 4,5 cm) mit 100 g gedämpfter und autoklavierter, auf 4 mm gesiebter Komposterde gefüllt. Auf die Komposterde wurden $19 \mathrm{ml}$ autoklaviertes Leitungswasser mit einer Dispensette verteilt, um einen einheitlichen Feuchtegehalt von 54\% Feldkapazität (w/w) einzustellen. Nach Durchmischen und Einebnen der Bodenoberfläche wurden in jede Quarkschale 6 Sklerotien des jeweiligen Isolats mit einer Pinzette 0,5 - $1 \mathrm{~cm}$ tief eingelegt. Die Schalen wurden verschlossen, wobei die Deckel mit Löchern versehen wurden, um eine ständige Luftzufuhr zu gewährleisten.

Zur Konditionierung der Sklerotien kamen die Schalen zunächst in einen Klimaschrank mit einer Wechseltemperatur von 12 Stunden bei $15^{\circ} \mathrm{C}$ bzw. $10^{\circ} \mathrm{C}$ und durchgehender Dunkelheit. Der Feuchtegehalt der Schalen wurde wöchentlich kontrolliert und gegebenenfalls durch Zugabe von autoklaviertem Wasser entsprechend dem Ausgangsgewicht nachjustiert. 
Nach vier Wochen wurden die Quarkschalen für weitere 4 Wochen bis zum Auskeimen der Apothezien unter Wechsel-NUV-Licht von 12 Stunden NUV-Licht und 12 Stunden Dunkelheit pro Tag bei einer Temperatur von $18^{\circ} \mathrm{C}$ inkubiert. Das Auskeimen der Apothezien wurde täglich kontrolliert.

\subsection{Pilzanzucht}

In $1000 \mathrm{ml}$ Erlenmeyerkolben wurden jeweils $200 \mathrm{ml}$ Czapek-Dox-Flüssigmedium autoklaviert und anschließend mit 200 ppm Streptomycin und einem mit Pilz bewachsenem Agarblock beimpft. Unter Schütteln auf dem Horizontalschüttler (Gyrotory Water Bath Shaker, G 67, New Brunswick Scientific, New York, USA) wurde das Pilzmyzel für 5-7 Tage bei $18^{\circ} \mathrm{C}$ inkubiert. Das Myzel wurde anschließend in einem Büchnertrichter, der mit einem Papierfilter (Durchmesser $15 \mathrm{~cm}$, Schleicher Schuell, Dassel) ausgelegt wurde, unter Unterdruck durch eine Wasserstrahlpumpe geerntet. Anschließend wurde zweimal mit demineralisiertem Wasser gespült. Das Myzel wurde für zwei Tage in einer Gefriertrocknung getrocknet. Das getrocknete Myzel wurde bei $-20^{\circ} \mathrm{C}$ aufbewahrt.

\subsection{Datenerhebung aus Feldversuchen}

Für die Datenerhebungen waren die Kontrollparzellen der Versuchsstandorte der Pflanzenschutzdienste vorgesehen. Die Datenerhebung fand in den Jahren 2002-2005 auf insgesamt 87 verschiedenen Flächen statt (Abb. 2). Insgesamt haben sich zehn Bundesländer und elf Pflanzenschutzdienste an dem Projekt beteiligt (Tab. 2).

\subsubsection{Anlage von Sklerotiendepots}

Die Anlage der Sklerotiendepots erfolgte in allen Versuchsjahren im Herbst (Oktober). In den Jahren 2002-2004 wurden an insgesamt 28 Versuchsstandorten Sklerotiendepots angelegt. Je Depot wurden 70 Sklerotien von unterschiedlicher Größe (aus Göttingen, gesammelt vom Rapsfeld 1998 und 1999) in 2-3 cm Bodentiefe auf einer Fläche von 0,25 $\mathrm{m}^{2}$ ausgelegt. Das Depot wurde in unmittelbarer Nähe der Versuchsanlage mit möglichst gleichen Schlagcharakteristika angelegt. 
Tab. 2: Beteiligung der Bundesländer, Biologischen Bundesanstalt und Pflanzenschutzdienste am Projekt Sclerotinia-Prognose

\begin{tabular}{|c|c|}
\hline Bundesland & Biologische Bundesanstalt und Landwirtschaftsämter \\
\hline Niedersachsen & Biologische Bundesanstalt (BBA) Braunschweig \\
\hline Mecklenburg-Vorpommern & Pflanzenschutzamt Mecklenburg-Vorpommern, Rostock \\
\hline Schleswig-Holstein & Amt für ländliche Räume Kiel \\
\hline \multirow[t]{2}{*}{ Niedersachsen } & $\begin{array}{l}\text { Landwirtschaftskammer (LWK) Hannover: } \\
\text { Bezirksstelle Northeim, Braunschweig, Niendorf und } \\
\text { Hannover }\end{array}$ \\
\hline & LWK Weser-Ems, Oldenburg \\
\hline Brandenburg & $\begin{array}{l}\text { Landesanstalt für Verbraucherschutz und Landwirtschaft, } \\
\text { Wünsdorf }\end{array}$ \\
\hline Sachsen-Anhalt & $\begin{array}{l}\text { Landesanstalt für Landwirtschaft und Gartenbau, } \\
\text { Magdeburg }\end{array}$ \\
\hline Sachsen & Sächsische Landesanstalt für Landwirtschaft, Dresden \\
\hline Thüringen & Thüringer Landesanstalt für Landwirtschaft, Kühnhäuser \\
\hline Nordrhein-Westfalen & LWK Nordrhein-Westfalen, Bonn \\
\hline Rheinland-Pfalz & $\begin{array}{l}\text { Dienstleistungszentrum ländlicher Raum Rheinhessen- } \\
\text { Nahe-Hunsrück, Westpfalz, Mosel, Westerwald, Osteifel }\end{array}$ \\
\hline Bayern & Bayerisches Landesanstalt für Landwirtschaft, München \\
\hline
\end{tabular}

\subsubsection{Erfassung des Vorjahresbefalls}

Der Vorjahresbefall (Befall in \% befallener Pflanzen pro Parzelle (geschätzt) des letzten Rapses auf dem Standort) wurde in vier Befallsklassen eingestuft:

Klasse 0 : geringer Befall $=1-7 \%$

Klasse $1:$ mittlerer Befall $=8-20 \%$

Klasse 2 : hoher Befall $=21-40 \%$

Klasse $3:$ sehr hoher Befall $=>40 \%$

\subsubsection{Erfassung des Erstauftretens von Apothezien}

Die Feststellung des Termins des ersten Erscheinens der Apothezien (tellerförmige Gestalt) in den Sklerotiendepots erfolgte durch regelmäßige Begehung und visuelle Bonitur ab Anfang April. 


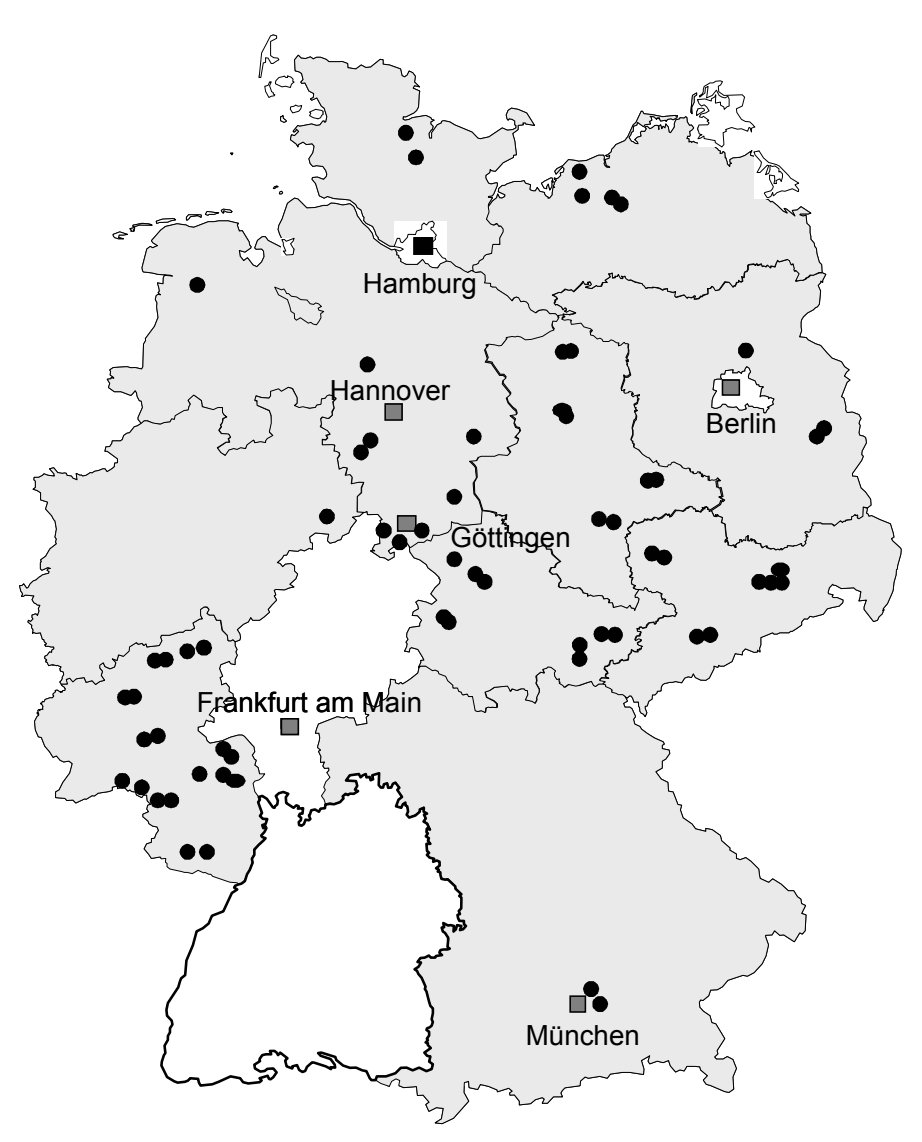

Abb. 2: Standorte der Feldversuche in Kooperation mit den Pflanzenschutzdiensten der Länder in 2002-2004.

Grau schattiert $=$ Teilnahme des jeweiligen Bundeslandes am Projekt

\subsubsection{Erfassung schlagspezifischer Daten}

Folgende Daten wurden bei Auswertung der Versuchsberichte und bezüglich der Versuchsstandorte erfasst:

- Schlaglage

- Angaben zur Fruchtfolge (Anteil Raps in der Fruchtfolge) in \%

- Aussaattermin

- Auflauftermin

- Saattiefe in cm

- Bodenbearbeitung

- Bodenart

- Sorte

- Entfernung der Wetterstation in $\mathrm{km}$

- Bestandesdichte im Frühjahr (Pflanzen $/ \mathrm{m}^{2}$ ) 
- N-Düngung ( $\mathrm{kg}$ oder $1 / \mathrm{ha})$

\subsubsection{Erfassung des Knospenstadiums (BBCH 55)}

Die Feststellung des Termins des Knospenstadiums (BBCH 55) erfolgte in allen Jahren durch visuelle Bonitur. Laut WeBER \& BLEIHOLDER (1990) ist das Knospenstadium BBCH 55 erreicht, wenn die Einzelblüten der Hauptinfloreszenz sichtbar (geschlossen) sind, das heißt, dass der Blütenstand die Blattebene überragt hat und sich die Einzelblüten voneinander trennen.

\subsubsection{Bonituren}

Die Bewertung des Befalls mit S. sclerotiorum erfolgte in den Versuchsjahren durch die Ermittlung des Anteils befallener Pflanzen (\%) pro Parzelle zum BBCH 75-79.

\subsection{Entnahme von Blütenblättern im Feld}

Die Probenahme erfolgte diagonal gleichmäßig verteilt in jeder Kontrollparzelle/ Wiederholung oder auf Praxisschlägen an drei verschiedenen Punkten. An jedem der drei Punkte wurden vier Rapspflanzen zufällig ausgesucht. Von jeder der vier Pflanzen wurden jeweils 10 abgefallene Blütenblätter mit der Pinzette abgenommen und 5 Blüten mit der Schere abgeschnitten. Für jede Probeentnahmestelle wurden alle abgefallenen und alle festen Blütenblätter separat in jeweils einem Plastikröhrchen (Firma Sarstedt) gesammelt, so dass pro Parzelle 6 Röhrchen benötigt wurden (Abb. 3). Nach der Probeentnahme wurden die Röhrchen mit den Blütenblättern sofort in einer Kühlhaltebox aufbewahrt und spätestens nach 24 Stunden bei $4^{\circ} \mathrm{C}$ im Kühlschrank gelagert. Der Postversand erfolgte jeweils am Wochenanfang nach Göttingen, um einen zügigen Transport zu gewährleisten und eine eventuelle Lagerung unter ungünstigen Bedingungen während des Wochenendes auf der Post zu verhindern. 
Die Entnahme der Blütenblätter erfolgte zu drei Terminen während der Rapsblüte:

1. BBCH 62 (20\% der Blüten am Haupttrieb offen)

2. BBCH 65 (Vollblüte, $50 \%$ der Blüten am Haupttrieb offen; erste Blütenblätter fallen bereits ab)

3. BBCH 69 (Ende der Blüte)

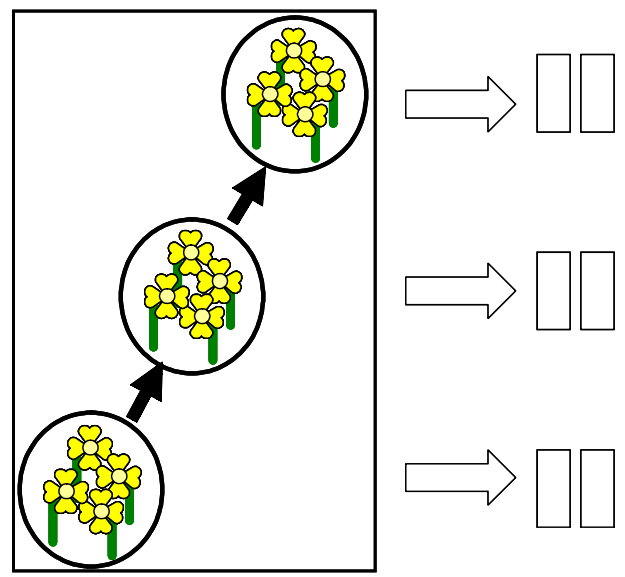

Abb. 3: Entnahmepunkte der Blütenblattproben am Beispiel einer Variante und Wiederholung am Versuchsstandort. Je Entnahmepunkt wurden 5 feste Blüten und 10 abgefallene Blütenblätter von vier Rapspflanzen genommen. Die Rechtecke zeigen die Anzahl der Proberöhrchen pro Wiederholung. An jedem Probenentnahmepunkt wurde ein Röhrchen für abgefallene Blütenblätter und ein Röhrchen für feste Blütenblätter genommen.

\subsection{Feldversuche zur Überprüfung des Prototyps SkleroPro und des Modells SKLERO}

In dem Jahr 2003/04 fand in den Versuchen der Pflanzenschutzämter und der Biologischen Bundesanstalt eine erste Überprüfung des Modellprototyps SkleroPro statt. Bei diesem Prototyp handelte es sich zu diesem Zeitpunkt um eine eingeschränkte schlagspezifische Vorhersage, bei der die Berechnung einer flexiblen schlagspezifischen Schadensschwelle fehlte. Anhand verschiedener Literaturangaben (AHLERS, 1986; KRÜGER \& STOLTENBERG, 1986) wurde eine feste Schadensschwelle von 15\% Befallshäufigkeit angenommen, welche insgesamt 60 günstigen Infektionsstunden entspricht. 
In der folgenden Tabelle (Tab. 3) ist der Versuchsplan für das Jahr 2003/04 aufgeführt. Die Überprüfung des Prototyps fand auf 21 Versuchsstandorten statt. Es wurden eine unbehandelte Kontrolle und eine praxisübliche Variante mit routinemäßigem Applikationstermin zur Vollblüte (BBCH 65) angelegt. Des Weiteren wurde ein Vergleich des vorhandenen Modells (SKLERO) mit dem neuen Prototyp SkleroPro vorgenommen. In den Varianten 2-4 wurde je nach Behandlungsempfehlung das Fungizid Cantus ${ }^{\circledR}$ (BASF; Aufwandmenge 0,5 1/ha) eingesetzt. Im Versuchsjahr 2003/04 wurden in allen Varianten (1-4) keine weiteren Herbst- bzw. Frühjahrsbehandlungen durchgeführt. Insektizide wurden je nach Bedarf eingesetzt.

Tab. 3: Versuchsplan (2003/04) zur Überprüfung des Prototyps SkleroPro im Vergleich zum Modell SKLERO, zur unbehandelten Kontrolle und einer praxisüblichen Variante im Feld.

\begin{tabular}{|c|l|c|c|c|}
\hline & Versuchsglieder & $\begin{array}{c}\text { Aufwand- } \\
\text { menge 1/ha }\end{array}$ & $\begin{array}{c}\text { Applikationstermin } \\
\text { BBCH }\end{array}$ & $\begin{array}{c}\text { Sonstige } \\
\text { Behandlungen }\end{array}$ \\
\hline 1. & Unbehandelte Kontrolle & - & \multicolumn{1}{|c|}{-} & - \\
\hline 2. & SKLERO & 0,5 Cantus & $\begin{array}{l}\text { nach Prognoseempfehlung } \\
\text { SKLERO }\end{array}$ & - \\
\hline 3. & Prototyp & 0,5 Cantus & $\begin{array}{l}\text { nach Prognoseempfehlung } \\
\text { SkleroPro }\end{array}$ & - \\
\hline 4. & Praxisüblich & 0,5 Cantus & BBCH 65 & - \\
\hline
\end{tabular}

\subsection{Implementierung von SkleroPro in die Praxis}

Im Versuchsjahr 2004/05 fand die Praxiseinführung des Modells SkleroPro in ISIP anhand von 32 Versuchen der Pflanzenschutzdienste der Länder und der Biologischen Bundesanstalt statt. Der Versuchsplan ist der Tabelle $4 \mathrm{zu}$ entnehmen. Neben der Variante in der nach der Prognoseempfehlung von SkleroPro behandelt wurde, wurden eine praxisübliche Variante mit Behandlungstermin zur Vollblüte und eine Kontrolle in den Versuchsplan aufgenommen. In allen Varianten wurde eine Frühjahrsbehandlung zum BBCH 51-53 mit Folicur ${ }^{\circledR}$ (Bayer; Aufwandmenge 0,75 1/ha) appliziert, um ein Auftreten anderer Pathogene in den Varianten zu vermeiden. Insektizide wurden je nach Bedarf eingesetzt. In den Varianten 2 und 3 wurde je nach Behandlungsempfehlung das Fungizid Cantus ${ }^{\circledR}(B A S F ;$ Aufwandmenge 0,5 1/ha) eingesetzt. 
Tab. 4: Versuchsplan (2005) zur Praxiseinführung des Modells SkleroPro mit zwei Vergleichsvarianten, der Routinebehandlung zur Vollblüte und der Kontrolle.

\begin{tabular}{|c|l|c|c|c|}
\hline & Versuchsglieder & $\begin{array}{c}\text { Aufwand- } \\
\text { menge 1/ha }\end{array}$ & $\begin{array}{c}\text { Applikationstermin } \\
\text { BBCH }\end{array}$ & $\begin{array}{c}\text { Sonstige } \\
\text { Behandlungen }\end{array}$ \\
\hline 1. & Kontrolle & - & - & Frühjahrsbehandlung \\
\hline 2. & SkleroPro & 0,5 Cantus & $\begin{array}{l}\text { nach Prognoseempfehlung } \\
\text { SkleroPro (in ISIP) }\end{array}$ & Frühjahrsbehandlung \\
\hline 3. & Praxisüblich & 0,5 Cantus & BBCH 65 & Frühjahrsbehandlung \\
\hline
\end{tabular}

\subsection{Gewächshaus- und Klimakammerversuche}

\subsubsection{Pflanzenanzucht}

Die Aussaat erfolgte in Pikierschalen in einem Gemisch aus Komposterde, Torf und Sand in einem Verhältnis von 2:1:1 (v:v:v) bei $18^{\circ} \mathrm{C}$. Die 2-3 Tage alten vorgekeimten Rapssamen von Rapid cycling Raps wurden in Plastiktöpfe $(9 \times 19 \mathrm{~cm})$ mit einer Bodenmischung bestehend aus 2 Teilen gedämpfter Komposterde, 1 Teil Sand und 1 Teil Einheitserde ausgepflanzt. Die Anzucht erfolgte im Gewächshaus bei einer Tageslänge von $16 \mathrm{~h}$ und $18^{\circ} \mathrm{C}$ und einer rel. Luftfeuchte von $65-75 \%$. Nach ungefähr 6-8 Wochen hatte der Raps das BBCH 65 erreicht, so dass zu diesem Zeitpunkt alle Pflanzen inokuliert werden konnten.

\subsubsection{Künstliche Inokulation der Pflanzen}

Von fünf verschiedenen Sclerotinia-Isolaten (Ss 1.1; Ss 1.2; Ss 1.3; Ss 1.5; Ss 1.6) wurde wie in Kapitel 2.6 Myzel in Flüssigkultur angezogen. Nach einer Woche Kulturdauer wurde das Myzel nach der Methode von GIEFFERS (2001) von der übrigen Nährlösung getrennt, dreimal mit sterilem (autoklaviertem) Wasser gewaschen, in ein Sieb (Teesieb) zum Abtropfen überführt und dann gewogen und mit 60\% sterilem Wasser versetzt. Danach wurde das Myzel/Wasser Gemisch mit dem Ultra-Turrax 30 s lang bei 1300 U/min homogenisiert. Die Myzelsuspensionen der verschiedenen Isolate wurden mit einem Zerstäuber, der an einen Kompressor angeschlossen war, auf die Blütenblätter von Rapspflanzen im Stadium BBCH 65 aufgesprüht. 
Die Pflanzen wurden nach der Sprühinokulation bei einer Temperatur von $20^{\circ} \mathrm{C}$, einer Luftfeuchtigkeit von ca. 80\% und einer Lichtdauer von 16 Stunden kultiviert. Das Ernten der Blütenblätter erfolgte nach 1, 2, 3, 4, 5 und 6 Tagen. Dabei wurden sowohl abgefallene Blütenblätter als auch fest an der Blüte sitzende Blütenblätter entnommen und anschließend zur Optimierung des ELISA-Tests und pH-Indikator-Tests eingesetzt.

\subsubsection{Herstellung von Ascosporensuspensionen}

Die Apothezien wurden wie in Kapitel 2.5 angezogen. Nach dem Aufwachsen der Fruchtkörper wurde ein 1,5 ml Eppendorfgefäß umgekehrt auf die noch jungen Apothezien aufgesetzt. Schon durch das leichte Berühren beim Aufsetzen der Eppendorfgefäße fand ein Ausschleudern der Sporen statt. Dies konnte sehr gut an der Sporulationswolke und am Beschlagen des Eppendorfgefäßes beobachtet werden. Danach wurden die Gefäße vom Apothezium entfernt und mit $500 \mu \mathrm{l}$ sterilem Wasser versetzt. Für die Konservierung von Sporensuspensionen wurden diese mit $1 / 2$ Volumen Glycerin versetzt und bei $-20^{\circ} \mathrm{C}$ eingefroren. Die Sporendichte wurde mit Hilfe der Thoma-Zählkammer unter dem Mikroskop ausgezählt. Zur künstlichen Infektion der Pflanzen wurde eine Sporendichte von $5 \times 10^{4}$ Sporen $/ \mathrm{ml}$ hergestellt.

\subsubsection{Boxentest}

Der Boxentest diente der Bestimmung des Schwellenwertes der Temperatur, an dem eine Infektion mit $S$. sclerotiorum beginnt. Für die Durchführung des Tests wurde die Sommerrapssorte Heros (Saaten-Union) verwendet. Zur Keimung wurden die Rapssamen in einer Schale mit einem Erde-Sand-Gemisch ausgelegt und bei Raumtemperatur für einige Tage vorgekeimt. Nach vier Tagen wurden die Keimlinge in einer Bodenmischung, bestehend aus 2 Teilen gedämpfter Komposterde, 1 Teil Sand und 1 Teil Einheitserde, in Töpfe der Größe 11,5 cm x 11,5 cm ausgepflanzt. Für den Infektionsversuch wurden insgesamt 100 Töpfe verwendet. In jeden Plastiktopf kam jeweils ein Rapskeimling. Für die Inokulation mit den fünf Sclerotinia-Isolaten standen jeweils 20 Rapspflanzen zur Verfügung. Die Pflanzen wurden im Gewächshaus unter normalen Bedingungen $\left(18^{\circ} \mathrm{C}\right.$, 65\% Luftfeuchte und 16 h Licht) angezogen. Für die Untersuchung des Schwellenwertes der Temperatur wurden nur Pflanzen, die sich im Entwicklungsstadium 65 (Vollblüte) 
befanden genommen. Von jeder Pflanze wurde ein Stängelstück mit Seitentrieben (Länge 8 $\mathrm{cm})$ aus $30 \mathrm{~cm}$ Höhe herausgetrennt. Zwölf Boxen (24 x 34 x 13,5 cm) mit einem luftdichten Deckel wurden für die Inkubation benötigt. In jede Box wurde ein Gitter in 1 cm Höhe hineingestellt, in welches die Stängelstücke aufrecht gesteckt wurden. Es wurden jeweils sechs Stängel pro Box zwischen den Gitterstäben befestigt. Bei drei Stängeln wurde die Sporensuspension von $10 \mu \mathrm{l}$ auf ein Blütenblatt gegeben, welches vorher in die Blattachsel gelegt wurde. Die Blattachseln der anderen drei Stängel wurden direkt mit der Sporensuspension beimpft. Um eine konstante Luftfeuchtigkeit von 99\% in allen Boxen zu gewährleisten wurde in jede Box 11 Wasser hineingefüllt. Die Boxen wurden bei unterschiedlichen Temperaturen von $6-28^{\circ} \mathrm{C}$ in $2^{\circ} \mathrm{C}$ Schritten aufbewahrt. Alle Temperaturbedingungen wurden in 2 facher Wiederholung getestet. Die Pflanzen wurden täglich auf Infektionen kontrolliert und nach 14 Tagen ausgewertet.

\subsection{2 pH-Indikator-Test zum Nachweis von $S$. sclerotiorum auf Blütenblättern}

Ein Nachweis von S. sclerotiorum auf Blütenblättern ist durch die Verwendung eines $\mathrm{pH}$ Indikatormediums möglich. Bei dem nach HEDKE (1992) entwickelten SSM-Medium handelt es sich um ein Agarmedium mit Bromkresolgrün als Indikator. Die oxalsäurebildenden Pilze, zu denen auch S. sclerotiorum gehört, können so durch den Farbumschlag des Mediums von blau zu gelb-orange identifiziert werden (CESSNA et al., 2000). Mit Hilfe des pH-Tests sollte der Befall der Blütenblätter im Feld untersucht werden, um daraus den späteren Befall im Feld ableiten zu können und so entweder als Entscheidungshilfe für den Fungizideinsatz oder zur Überprüfung der Aussagen des Prognosemodells genutzt zu werden.

In einem ersten Ansatz wurden myzelbewachsene PDA-Stückchen, die jeweils mit verschiedenen Sclerotinia-Isolaten (Ss 1.1, Ss 1.2, Ss 1.3, Ss 1.5 und Ss 1.6) überwachsen waren, auf das pH-Indikatormedium ausgelegt. Des Weiteren wurden myzelbewachsene PDA-Stückchen von verschiedenen Pathogenarten auf das Agarmedium überimpft und auf eventuellen Farbumschlag untersucht. Um die Nachweisempfindlichkeit des Mediums für S. sclerotiorum zu optimieren, wurden verschiedene Versuchsreihen mit unterschiedlichen Calciumcarbonatgehalten angesetzt: 2, 3, 4 und $5 \mathrm{~g} / 1 \mathrm{CaCO}_{3}$. In einem zweiten Ansatz wurde der Befall mit S. sclerotiorum an künstlich infizierten Blütenblättern überprüft. 
Hierfür wurden drei infizierte Blütenblätter auf einer Petrischale ausgelegt und täglich auf Farbveränderung kontrolliert.

Die von den Feldversuchen 2003 gesammelten Blütenblattproben (Kapitel 2.3) wurden zunächst eingefroren und später auf dem $\mathrm{pH}$-Indikator-Medium auf Befall mit $S$. sclerotiorum untersucht. Von jeder Kontrollfläche wurden insgesamt 36 feste und 36 abgefallene Blütenblätter auf 24 Petrischalen verteilt und unter Wechsel-NUV-Licht (12 h) bei $18^{\circ} \mathrm{C}$ aufbewahrt. Die Petrischalen wurden jeden Tag auf Myzelwachstum, Verfärbung des Mediums und Sklerotienbildung kontrolliert. Die Bonitur erfolgte nach Anzahl befallener Blütenblätter pro Petrischale. Je nachdem wie viel Blütenblätter befallen waren, wurden verschiedene Klassifizierungen und Befallseinstufungen ermittelt (Tab. 5).

Da die Untersuchungen aus dem Versuchsjahr 2003 keine zufriedenstellenden Ergebnisse lieferten, wurde die Methode insofern verbessert, dass im Jahr 2004 nur noch frisch geerntetes Pflanzenmaterial untersucht wurde.

Tab. 5: Einteilung der mittels $\mathrm{pH}$-Indikator-Test untersuchten Blütenblätter nach Befall und Klassifizierung. Es wurden jeweils drei Blütenblätter pro Petrischale untersucht, bewertet und der durchschnittliche Befall ermittelt.

\begin{tabular}{|c|c|c|}
\hline $\begin{array}{c}\text { Anzahl befallener } \\
\text { Blütenblätter pro } \\
\text { Petrischale }\end{array}$ & Klassifizierung & Befallseinstufung \\
\hline kein Befall der Blütenblätter & 0 & kein \\
\hline ein Blütenblatt befallen & 1 & schwach \\
\hline zwei Blütenblätter befallen & 2 & mittel \\
\hline drei Blütenblätter befallen & 3 & stark \\
\hline
\end{tabular}




\subsection{ELISA zum Nachweis von $S$. sclerotiorum auf Blütenblättern}

\subsubsection{Herstellung des Antiserums}

Das Antiserum für S. sclerotiorum wurde im Institut für Pflanzenpathologie und Pflanzenschutz von der Arbeitsgruppe von Herrn Prof. Dr. G.A. Wolf hergestellt und freundlicherweise zur Verfügung gestellt. Die Immunisierung der Kaninchen erfolgte in der Arbeitsgruppe von Herrn Dr. Huth an der Biologischen Bundesanstalt Braunschweig.

\subsubsection{Biotinylierung der Antikörper}

Aufgrund der geringen Menge an biotinylierten Antikörpern wurden diese während des Untersuchungszeitraums neu hergestellt. Zur Markierung der Antikörper wurden diese mit Biotin gebunden. Die Biotinylierung der gereinigten IgG erfolgte weitgehend nach der Methode von BIEBER (1990). Hierbei wurden die gereinigten Immunoglobuline (IgG) des Rohserums zur vollständigen Entfernung von freien Ammonium-Verbindungen über Nacht gründlich gegen eisgekühlten Carbonatpuffer dialysiert (24 h, dreimaliger Pufferwechsel). Die Dialyse wurde in einem 1,5 ml Eppendorf-Reaktionsgefäß durchgeführt, welches mit einer Membran (Visking, Serva) verschlossen wurde. Unmittelbar vor der Kopplung wurde Biotin X-NHS in wasserfreiem Dimethylformamid zu $1 \mathrm{mg} / \mathrm{ml}$ gelöst und davon $50 \mu \mathrm{l} / \mathrm{ml}$ zu $1 \mathrm{ml} \mathrm{IgG} \mathrm{gegeben.} \mathrm{Nach} 30$ min Inkubation bei Raumtemperatur wurde die Reaktion durch $50 \mu 11 \mathrm{M}$ Tris/HCl (pH 7,5) pro ml Lösung gestoppt.

Die konjugierten Antikörper wurden über Nacht gegen $0,85 \% \mathrm{NaCl}$ bei zweimaligem Pufferwechsel dialysiert, um die freien Biotinmoleküle zu entfernen. Zur Stabilisierung und Verbesserung der Haltbarkeit der biotinylierten IgG wurden 1\% RSA und 50\% Glycerin zugegeben. Die Aufbewahrung erfolgte bei $-20^{\circ} \mathrm{C}$.

\subsubsection{Aufbereitung von Pilzmaterial}

Nach Anzucht der in Tab. 1 dargestellten Pilzisolate in Flüssigkultur wurde das Myzel wie in Kapitel 2.6 geerntet. Das gefriergetrocknete Myzel wurde mit dem 2-fachen ihres Gewichts mit Extraktionspuffer und Quarzsand im Porzellanmörser homogenisiert und anschließend in einem Verhältnis von 1:10 (w/v) mit Extraktionspuffer versetzt. Die 
Proben wurden über Nacht im Kühlraum bei $6^{\circ} \mathrm{C}$ auf dem Schüttler aufbewahrt. Anschließend erfolgte die Proteinbestimmung nach BRADFORD (1976).

\subsubsection{Aufbereitung von Pflanzenmaterial}

Die frisch geernteten Blütenblattproben von den Kontrollflächen der angelegten Feldversuche wurden bei $-10^{\circ} \mathrm{C}$ aufbewahrt. Von den 12 Proben pro Kontrollfläche wurden von jeder Probe jeweils 5 Blütenblätter entnommen und in eine Mikrotiterplatte mit $2 \mathrm{ml}$ Vertiefung (Fa. NUNC; immuno Platte; Brand Produkt) aufgetragen. Anschließend wurden die Proben mit Extraktionspuffer im Verhältnis 1:10 (w/v) extrahiert und über Nacht im Kühlraum bei $6^{\circ} \mathrm{C}$ auf dem Schüttler aufbewahrt.

Aufgrund eines $\mathrm{zu}$ hohen Anteils falsch positiver Reaktionen mit abgefallenen Blütenblättern durch störende Bodeninhaltsstoffe aus dem ersten Versuchsjahr wurde nach anderen Extraktionsverfahren gesucht. Die abgefallenen Blütenblätter wurden danach mit einem von HEPPNER (1995) entwickelten Puffer extrahiert.

\subsubsection{Proteinbestimmung}

Die Bestimmung der Proteingehalte erfolgte mit der Methode nach BRADFORD (1976), bei der Rinderserumalbumin als Standard eingesetzt wird. Die Durchführung erfolgt in Mikrotiterplatten (Typ 3595, Fa. Costar, Cambridge) mit einer nach UnGER (1989) abgewandelten Variante. Die Bradford-Stammlösung wurde folgendermaßen hergestellt: $100 \mathrm{mg}$ Coomassie Brillant Blue G-250 wurde in $50 \mathrm{ml}$ Ethanol (70\%) gelöst und mit 100 $\mathrm{ml}$ Phosphorsäure (85\%) versetzt.

Die Stammlösung wurde zur Herstellung der Bradfordreagenz 1:6,6 mit $\mathrm{H}_{2} \mathrm{O}$ bidest. verdünnt und anschließend durch einen Glasfaserrundfilter (Schleicher und Schüll, Dassel) filtriert. Je $30 \mu$ l Eichlösung (20-120 $\mu \mathrm{g} / \mathrm{ml}$; Rinderserumalbumin als Standard) bzw. Probe wurden in Mikrotiterplatten mit $350 \mu$ Kavitäten (Typ 3595, Fa. Costar, Cambridge) pipettiert und mit $300 \mu \mathrm{l}$ Bradfordreagenz versetzt. Die Messung erfolgte nach $10 \mathrm{~min}$ Inkubation bei RT im Photometer (Spectra II, SLT, Österreich) bei $592 \mathrm{~nm}$ und einer Referenzwellenlänge von $492 \mathrm{~nm}$. 


\subsubsection{Standardisierung des ELISA}

Zum Nachweis von S. sclerotiorum auf Blütenblättern wurde aufgrund der höheren Spezifität der direkte ELISA mit biotinylierten Detektionsantikörpern angewendet (DASELISA). Dabei erfolgt der Nachweis über ein Streptavidin-Phosphatase-Konjugat, das mit Biotin in eine nichtkovalente Bindung mit hoher Affinität eingeht. Dadurch kann die Empfindlichkeit des ELISA wesentlich erhöht werden.

Die Erprobung und Optimierung des ELISA führte zu folgendem Protokoll:

- Beschichten der Mikrotiterplatten mit je $100 \mu$ spezifischen Antikörpern (1: 1000 verd.; Beschichtungspuffer); Inkubation über Nacht bei $4^{\circ} \mathrm{C}$.

- 3 x 3 min waschen mit Waschpuffer

- Blocken mit $200 \mu \mathrm{l}$ 0,2\% RSA in Beschichtungspuffer, $1 \mathrm{~h}$ bei $37^{\circ} \mathrm{C}$

- 3 × 3 min waschen mit Waschpuffer

- Auftragen von extrahierter Pflanzenprobe (1:10 verd., Extraktionspuffer); Inkubation über Nacht bei $4^{\circ} \mathrm{C}$

- 3 x 3 min waschen mit Waschpuffer

- Zugabe von $100 \mu \mathrm{l}$ biotinylierten Antikörpern (1:1000 verd., PPK/Tween + 0,2\% RSA); Inkubation über Nacht bei $4^{\circ} \mathrm{C}$ oder $4 \mathrm{~h}$ bei $37^{\circ} \mathrm{C}$.

- Zugabe von $100 \mu \mathrm{l}$ Streptavidin-alkalischem Phosphatase-Konjugat, (1:10000 verd., Konjugatpuffer); Inkubation $1 \mathrm{~h}$ bei $37^{\circ} \mathrm{C}$.

- 3 x 3 min waschen mit Waschpuffer

-Zugabe von $100 \mu \mathrm{l}$ Substratlösung (2-Nitrophenylphosphat 1mg/ml; Substratpuffer); Inkubation bei Raumtemperatur im Dunkeln

- Messung erfolgte bei $405 \mathrm{~nm}$ und einer Referenzwellenlänge von $592 \mathrm{~nm}$ nach 120, 180, und $240 \mathrm{~min}$

Der Elisa wurde in Mikrotiterplatten aus Polystyrol (Fa. NUNC U 96 Maxisorb; immuno Platte; Brand Produkt) durchgeführt. Jede Probe wurde in zweifacher Wiederholung angelegt und der Mittelwert wurde in die Auswertung übernommen. Die zweite und dritte Reihe wurden als Porteinstandard verwendet. Die Extinktionen wurden durch ein Mehrstrahlphotometer (Spektra II, SLT Labinstruments) bei einer Wellenlänge von 405nm und einer Referenzwellenlänge von 592 nm gegen einen Leerwert (ohne Probenextrakt) gemessen. Die Auswertung des ELISA variierte je nach Signalstärke von 1 bis 4 Stunden. 


\subsection{PCR}

\subsubsection{Isolierung genomischer DNA aus filamentösen Pilzen}

Die verwendete Methode stellte eine modifizierte Form der Isolierung von Gesamt-DNA nach MurRAY und THOMPSON (1980) und Lis und SCHLEIF (1975) dar. Für die DNAIsolierung wurden die Pilzisolate in Czapek Dox-Flüssigmedium angezogen. Das gefriergetrocknete Myzel wurde zerkleinert und in einem Mörser mit etwas Sand zu einem feinen Pulver zerrieben. Anschließend wurde das Myzelpulver in $50 \mathrm{ml}$ chloroformbeständige Falkonröhrchen (Fa. Sarstedt GmbH) mit $10 \mathrm{ml}$ TES-Puffer und 0,2 $\mathrm{ml}$ Proteinase $\mathrm{K}$ überführt und unter gelegentlichem Mischen $45 \mathrm{~min}$ bei $45^{\circ} \mathrm{C}$ inkubiert. $\mathrm{Zu}$ dem Myzel-TES Gemisch wurden 3,9 $\mathrm{ml}$ einer $5 \mathrm{M} \mathrm{NaCl}$ Lösung zugegeben und vermischt. Proteine und Polysaccharide wurden durch Zugabe von 1,4 ml einer 10\%igen CTAB-Lösung und einer zehnminütigen Inkubation bei $65^{\circ} \mathrm{C}$ komplexiert. Zur Abtrennung von Nukleinsäuren aus proteinhaltigen Lösungen wurde eine ChloroformExtraktion durchgeführt. Zur Entfernung der Proteine wurde eine Extraktion mit $10 \mathrm{ml}$ Chloroform-Isoamylalkohol $(24: 1 \mathrm{v} / \mathrm{v})$ bei $30 \mathrm{~min}$ im Eiswasserbad durchgeführt. Die Phasentrennung wurde durch eine fünfzehnminütige Zentrifugation bei $4500 \mathrm{U} / \mathrm{min}$ und $5^{\circ} \mathrm{C}$ herbeigeführt. Die Nukleinsäuren blieben aufgrund ihrer hydrophilen Gruppen in der oberen wässrigen Phase gelöst, während sich die enthaltenen Proteine zwischen beiden Phasen, in der sogenannten Interphase, anordneten. Nach fünfzehnminütiger Zentrifugation bei $4500 \mathrm{U} / \mathrm{min}$ bei $5^{\circ} \mathrm{C}$ wurde die obere wässrige Phase vorsichtig abgenommen und in ein neues Reaktionsgefäß überführt. Die DNA wurde durch Zugabe von $10 \mathrm{ml}$ Isopropanol gefällt und durch Zentrifugation sedimentiert (10 min bei $4200 \mathrm{U} / \mathrm{min}$, RT). Nach anschließendem Spülen in 70\%igem Ethanol und Trocknen für 10 min in der Speed-vac (Fa. Eppendorf, Hamburg) wurde die DNA in 4,5 ml TE resuspendiert. Von der DNALösung wurde eine $10 \mu \mathrm{l}$ Probe aufgehoben und mit dem Rest eine PEG-Fällung durchgeführt. $\mathrm{Zu}$ der restlichen DNA-Lösung wurde 0,5 $\mathrm{ml}$ einer $5 \mathrm{M} \mathrm{NaCl}$ Lösung und 1,5 ml einer 30\%igen (w/v) PEG-3000 zugegeben und gründlich vermischt. Nach einer Stunde bei Raumtemperatur wurde die DNA durch Zentrifugation (30 min, $4500 \mathrm{U} / \mathrm{min}$, RT) sedimentiert. Anschließend wurde das Pellet nochmals in 70\%igem Ethanol gespült, für $10 \mathrm{~min}$ in der Speed-vac (Fa. Eppendorf, Hamburg) getrocknet und in $1 \mathrm{ml} \mathrm{TE}$ aufgenommen. 


\subsubsection{DNA-Konzentrationsbestimmung}

Die Konzentration einer DNA-Lösung wurde im Agarosegel abgeschätzt. Nach Auftrennung der DNA in der Gelmatrix und Anfärbung durch Ethidiumbromid konnte die Fluoreszenz der DNA-Probe mit der Hilfe von Molekulargewichtmarkern aus Lambda DNA (MBI, Fermentas), die eine DNA-Konzentration von 25, 50 und 100 ng DNA nach einer Gelelektrophorese charakterisieren, verglichen werden. Entsprechend der festgestellten Konzentration wurde die notwendige Menge der Ausgangslösung für die Analysen festgesetzt.

\subsubsection{DNA-Gelelektrophorese und Geldokumentation}

Zur analytischen Auftrennung der DNA wurden Agarosegelelektrophoresen in Flachbettgelkammern durchgeführt. Für die Elektrophorese wurden 0,8 - 1,7\% Agarose $(\mathrm{w} / \mathrm{v})$ in 1x TAE Puffer verwendet. Vor dem Auftragen wurden die Proben mit 0,2 Volumen Loading Dye beschwert. Die Dauer der Gelelektrophorese ist abhängig von der verwendeten Gelkammer. Die Elektrophorese wurde bei einer Spannung von 60-80 V in 1x TAE-Puffer durchgeführt. Zum Anfärben der DNA-Banden wurde das Gel für ca. 10 min in einem Ethidiumbromid (EtBr)-Färbe-Bad $\left(2 \mu 1 \mathrm{EtBr} / 1000 \mathrm{ml} \mathrm{H} \mathrm{H}_{2} \mathrm{O}\right)$ getränkt. EtBr ist ein interkalierender Farbstoff, der sich zwischen die DNA einlagert und nach der Anregung mit UV-Licht eine rötliche Fluoreszenz (590 nm) aufweist. Anschließend wurde das Gel für ca. 10 min in einem Wasserbad getränkt, um überschüssiges EtBr aus dem Gel $\mathrm{zu}$ entfernen. Mit einem Geldokumentator (Fa. Biorad, Hagen) ließ sich die die Fluoreszenz über eine Videokamera erfassen und mittels spezieller Software (Molekular Analyst, Fa. Biorad Hagen) auswerten.

\subsubsection{Standardisierung des PCR-Protokolls}

Als Amplifikationsproben wurden zur Optimierung der PCR Gesamt-DNA verschiedener Pilzisolate verwendet (siehe Tab.1 in Kapitel 1.1). Die spezifischen Primer-Sequenzen von S. sclerotiorum wurden von FREEMAN et. al (2002) entwickelt und übernommen. 
Es wurde folgendes Primerpaar eingesetzt:

SSFWD 5 '-GCTGCTCTTCGGGGCCTTGTATGC-3’ und

SSREV 5'-TGACATGGACTCAATACCAAGCTG-3'

Der zu amplifizierende Abschnitt ist 278 bp groß. Die Bedingungen für die Amplifikation wurden optimiert. Hierbei wurden vor allem die Parameter Annealingtemperatur und Magnesiumkonzentration variiert. Die ermittelten Konzentrationen für das PCRReaktionsgemisch mit einem Gesamtvolumen von $25 \mu$ l setzte sich wie in Tabelle 6 dargestellt zusammen.

Die Ansätze wurden gemischt und im PCR Block 2 min bei $94^{\circ} \mathrm{C}$ denaturiert. Es schlossen sich 30 Zyklen der folgenden Temperaturzyklen an:

Denaturierung $\quad 30 \mathrm{~s} / 94^{\circ} \mathrm{C}$

Annealing $\quad 20 \mathrm{~s} / 68^{\circ} \mathrm{C}$

Elongation $\quad 1 \mathrm{~min} / 72^{\circ} \mathrm{C}$

Nach dem letzten Zyklus wurde noch ein Extensionsschritt von $5 \mathrm{~min} / 72^{\circ} \mathrm{C}$ angehängt, um nur teilweise verlängerte Produkte zu vervollständigen.

Tab. 6: Reaktionsansatz für die PCR

\begin{tabular}{lcc}
\hline Komponenten & Endkonzentration/Reaktion & Volumen/Reaktion \\
\hline $\mathrm{MgCl}_{2}(25 \mathrm{mM})$ & $2.0 \mathrm{mM}$ & $1 \mu \mathrm{l}$ \\
$\mathrm{dNTP}(2 \mathrm{mM})$ & $0.2 \mathrm{mM}$ & $2.5 \mu \mathrm{l}$ \\
Puffer $10 \mathrm{x}$ & $1 \mathrm{x}$ & $2.5 \mu \mathrm{l}$ \\
Primer SSFWD $(5 \mathrm{pmol} / \mu \mathrm{l})$ & $0.2 \mu \mathrm{M}$ & $1 \mu \mathrm{l}$ \\
Primer SSREV $(5 \mathrm{pmol} / \mu \mathrm{l})$ & $0.2 \mu \mathrm{M}$ & $1 \mu \mathrm{l}$ \\
Template $(1 \mathrm{ng} / \mu \mathrm{l})$ & $1 \mathrm{ng} / 25 \mu \mathrm{l}$ & $1 \mu \mathrm{l}$ \\
$\mathrm{H}_{2} \mathrm{O}_{\text {bidest }}$ & $\mathrm{ad} 25 \mu \mathrm{l}$ & $15.9 \mu \mathrm{l}$ \\
Taq-Polymerase $(5 \mathrm{U} / \mu \mathrm{l})$ & $0.7 \mathrm{U} / 25 \mu \mathrm{l}$ & $0.14 \mu \mathrm{l}$ \\
\hline
\end{tabular}




\subsection{Real-time PCR zum Nachweis von $S$. sclerotiorum auf Blütenblättern}

Die Real-time PCR bietet im Gegensatz zur konventionellen PCR den Vorteil, dass die Quantität des zu amplifizierenden Produktes direkt abgelesen werden kann und der Aufwand durch Einsparung des Gelschritts deutlich geringer ist. Als Detektionshilfsmittel für die Amplifikationsmenge wurde der fluoreszierende Farbstoff SybrGreen ${ }^{\circledR}$ (Applied Biosystems, Californien) eingesetzt. Alle Amplifikationsansätze wurden im iCycler IQ (BioRad Laboratories, Californien) durchgeführt. Als Amplifikationsproben wurde genomische DNA aus filamentösen Pilzen, Ascosporen sowie Blütenblättern verwendet. Die Quantifizierung des Amplifikationsproduktes basiert auf der Software-gestützten Berechnung eines Fluoreszenzschwellenwertes. Der Zyklus, in dem eine zu untersuchende Probe diesen berechneten Fluoreszenzschwellenwert signifikant überschreitet, wird als Schwellenwertzyklus („Threshold cycle“ oder Ct-Wert) der jeweiligen Probe zugewiesen. Der Schwellenwert ist umso schneller erreicht, je mehr DNA der Amplifikationsprobe eingesetzt wird. Die Quantifizierung der Proben erfolgte über den Vergleich des ermittelten Ct-Wertes der jeweiligen Probe mit den Ct-Werten des amplifizierten DNAStandards (Sporenstandard und Myzelstandard), die in jedem Ansatz parallel mitliefen. Am Ende der PCR wurde zusätzlich eine Schmelzpunktanalyse durchgeführt, dabei wurde durch kontinuierliches Erhitzen über ein vorgegebenes Temperaturintervall, die während der Amplifikation gebildete doppelsträngige DNA getrennt. Bei der Trennung lag das gebundene SybrGreen ${ }^{\circledR}$ wieder frei in der Lösung vor und die gemessene Fluoreszenz nahm kontinuierlich wieder ab. Betrachtet man die Ableitung Zeit $\rightarrow$ Fluoreszenz $(\mathrm{d}(\mathrm{RFU}) / \mathrm{dt})$ so stellten sich unterschiedliche Amplifikate durch unterschiedliche Peaks dar.

\subsubsection{Herstellung von linearem Polyacrylamid}

Um die Ausbeute der DNA-Konzentration aus Sporenmaterial zu erhöhen, wurde lineares Polyacrylamid für die DNA-Isolierung aus Sporen verwendet. Zur Herstellung des linearen Polyacrylamids wurde eine 5\% Acrylamid-Lösung ohne Bisacrylamid in $40 \mathrm{mM}$ Tris/ $\mathrm{HCl}$ (pH 8), $20 \mathrm{mM}$ Natriumacetat und $1 \mathrm{mM}$ EDTA hergestellt. Durch Zugabe von Ammoniumpersulfat wurde eine Endkonzentration von $0,1 \%$ eingestellt. Die Polymerisation des Acryls erfolgte nach Zugabe von 0,001\% TEMED und einer Inkubation von 30 min bei RT. Zum Ausfällen des linearen Acrylamids wurde die viskose Lösung mit 2,5 Volumina Ethanol versetzt. Nach anschließender Zentrifugation (10 min, 
$4500 \mathrm{U} / \mathrm{min}, \mathrm{RT}$ ) wurde der Überstand verworfen und das Pellet in $10 \mathrm{mM}$ Tris/HCl und 1 $\mathrm{mM}$ EDTA zu einer Endkonzentration von $5 \mathrm{mg} / \mathrm{ml}$ gelöst. Die Aufbewahrung des linearen Acrylamids erfolgte bei $-20^{\circ} \mathrm{C}$.

\subsubsection{Isolierung genomischer DNA aus Ascosporen}

Nach Auszählung der Ascosporen mit der Thoma-Zählkammer wurde eine Ausgangskonzentration von 50.000 Sporen $/ \mathrm{ml}$ mit $\mathrm{H}_{2} \mathrm{O}$ bidest. eingestellt. Anhand dieser Stammkonzentration wurde eine Verdünnungsreihe mit 50mM Tris/ $\mathrm{HCl}, 0,1 \%$ Nonidet und 20mM EDTA hergestellt (50.000, 25.000, 10.000, 5000, 2500, 1000, 500, 250, 100, 50, 5 Sporen $/ \mathrm{ml}$ ). Jede Sporensuspension wurde mit einem Rapsblütenblatt und 3 Wolframcarbit-Kugeln (Fa. Retsch, Düsseldorf) versehen und in einer Kugelmühle (Fa. Retsch, Düsseldorf) für 4 min geschüttelt. Nach anschließender Zentrifugation (10 min bei $4200 \mathrm{U} / \mathrm{min}, \mathrm{RT}$ ) wurde der Überstand abgenommen und mit 20-50 $\mu \mathrm{g}$ 5\%igem linearem Polyacrylamid versetzt. Die DNA wurde durch Zugabe von $700 \mu 1$ Isopropanol und $200 \mu 1$ Acrylamid bei einer Inkubationszeit von 20 min bei RT gefällt und durch Zentrifugation sedimentiert. Nach anschließendem Spülen in 70\%igem Ethanol und Trocknen wurde die DNA in $50 \mu 1$ TE-Puffer resuspendiert.

\subsubsection{Isolierung genomischer DNA aus Blütenblättern vom Feld}

Die frisch geernteten Blütenblattproben aus den Kontrollflächen der Versuchsstandorte wurden bei $-10{ }^{\circ} \mathrm{C}$ eingefroren und aufbewahrt. Für den Nachweis von S. sclerotiorum auf Blütenblättern mittels Real-time PCR wurde eine Mischprobe aus den drei Röhrchen der festen Blütenblätter jeder Wiederholung angelegt, so dass insgesamt 4 Proben pro Kontrollfläche analysiert wurden. Für die Mischprobe wurden von jeder der drei Proben pro Wiederholung fünf Blütenblätter entnommen. Die Gesamtmenge pro Wiederholung betrug somit 15 Blütenblätter. Diese Anzahl an Blütenblättern wurde in ein $2 \mathrm{ml}$ Eppendorf Gefäß überführt und mit $1 \mathrm{ml}$ Puffer (50mM Tris/HCl, 0,1\% Nonidet und 20mM EDTA) versetzt. Zusätzlich wurden $\mathrm{zu}$ jeder Probe 4 Wolframcarbit-Kugeln (Fa. Retsch, Düsseldorf) getan und in einer Kugelmühle (Fa. Retsch, Düsseldorf) für 4 min geschüttelt. Nach anschließender Zentrifugation (10 min bei $4200 \mathrm{U} / \mathrm{min}, \mathrm{RT}$ ) wurde der Überstand abgenommen und mit 20-50 $\mu \mathrm{g}$ linearem Polyacrylamid versetzt. In einem ersten 
Aufreinigungsschritt erfolgte die Extraktion mit Phenol/Chloroform/Isoamylalkohol. Bei dieser Reinigung wurde die DNA-Lösung nacheinander mit einem Volumen Phenol und einem Volumen Chloroform/Isoamylalkohol (24:1) versetzt. Zwischen den beiden Arbeitsschritten wurde die Lösung zentrifugiert, dabei bildeten sich drei Phasen, die obere wässrige Phase, die Interphase/organische Phase und die Phenolphase. Durch diese Methode wurden Verschmutzungen denaturiert und sammelten sich in der organischen Phase an, während die Nukleinsäure in der oberen Phase verblieb. Nach der Zentrifugation wurde jeweils die obere wässrige Phase in ein neues Eppendorf Gefäß überführt. Die DNA wurde durch Zugabe von $700 \mu$ I Isopropanol und $200 \mu$ Ammoniumacetat bei einer Inkubationszeit von 20 min bei RT gefällt und durch Zentrifugation sedimentiert. Nach anschließendem Spülen mit 70\%igem Ethanol und Trocknen wurde die DNA in $50 \mu 1$ TEPuffer resuspendiert.

\subsection{Verrechnung der Schlagdaten aus den einzelnen Bundesländern}

Durch eine umfassende statistische Analyse sollte der Einfluss pflanzenbaulicher und standortbedingter Faktoren und deren Wechselbeziehungen auf das Auftreten der Weißstängeligkeit ermittelt und quantifiziert werden. Grundlage für die statistische Auswertung der Schlagdaten waren Befallserhebungen aus der Versuchstätigkeit der einzelnen Pflanzenschutzämter und der Biologischen Bundesanstalt aus den zurückliegenden Jahren (1994-2004). Da in den einzelnen Datensätzen der verschiedenen Ländern zum Teil unterschiedliche Schlagdaten für die Befallserhebung ermittelt wurden, wurde bei der Verrechnung der Daten zum einen das gesamte Datenmaterial mit 811 Versuchsstandorten betrachtet und zum anderen die Datensätze einzeln analysiert (Tab. 7). Es wurden dabei folgende Faktoren berücksichtigt: Jahr, Aussaattermin, Sorte, Bestandesdichte, Fruchtfolge, Vorfrucht, N-Düngung, Bodenbearbeitung, Bodenart. 
Tab. 7: Anzahl der Feldversuche der Pflanzenschutzdienste der Länder, eingeteilt nach Bundesländern und Jahren, für die Auswertung des Einflusses von schlagspezifischen Faktoren auf den Befall mit S. sclerotiorum.

\begin{tabular}{|l|c|c|}
\hline Gebiete & $\begin{array}{c}\text { Anzahl Versuche } \\
\text { (n) }\end{array}$ & Jahre \\
\hline Mecklenburg-Vorpommern & 125 & $1994-2004$ \\
\hline Schleswig-Holstein & 40 & $1994-2004$ \\
\hline Sachsen-Anhalt & 590 & $1994-2004$ \\
\hline $\begin{array}{l}\text { Sonstige Länder (Thüringen, Sachsen, Bayern, } \\
\text { Rheinland-Pfalz und Niedersachsen }\end{array}$ & 56 & $1999-2004$ \\
\hline Insgesamt & 811 & $1994-2004$ \\
\hline
\end{tabular}

\subsection{Bereitstellung der Wetterdaten}

Voraussetzung für die Anwendung der Prognosemodelle SKLERO und SkleroPro war die Bereitstellung von Wetterdaten. In Abbildung 4 ist der Datenfluss der einzelnen Wetterdaten dargestellt. Für die Validierung der Modelle wurden sowohl Wetterstationen vom DWD als auch agrarmeteorologische Stationen der Pflanzenschutzdienste genutzt. Die Bereitstellung der Daten vom DWD erfolgte über die Zentralstelle in Offenbach. Von hier wurden täglich aktuelle Wetterdaten der letzten 24 Stunden sowie eine dreitägige Wettervorhersage online zur ZEPP in Bad Kreuznach übertragen (KLEINHENZ \& Rossberg, 2000). Über die ZEPP wurden je nach Bedarf die Datenpakete der Wetterstationen an das Institut für Pflanzenpathologie und Pflanzenschutz Göttingen online weitergeleitet. Die Wetterdaten aus den agrarmeteorologischen Stationen der einzelnen Pflanzenschutzdienste wurden direkt an das Institut in Göttingen geschickt. Die Daten beinhalten die Stunden- und Tageswerte der Temperatur $\left({ }^{\circ} \mathrm{C}\right)$ gemessen in $2 \mathrm{~m}$ Höhe, der relativen Luftfeuchte (\%) und des Niederschlags (mm). In das Modell fließen dabei jeweils die stündlich gemessenen Daten ein. Insgesamt wurden von über 100 Wetterstationen in Deutschland Wetterdaten für die Jahre 1994-2005 angefordert und verarbeitet. Von den untersuchten Feldversuchen lagen 80\% innerhalb eines Radius von 20 $\mathrm{km}$ von der nächstgelegenen Wetterstation. Im Versuchsjahr 2004 wurden für die tägliche Prognose der Exaktversuche täglich die aktuell gemessenen Wetterdaten der DWD- 
Stationen mit einer simulierten 3-tägigen Vorhersage aus Bad Kreuznach angefordert. Zusätzlich wurden Wetterdaten der letzten 24 Stunden der eigenen Stationen der Pflanzenschutzdienste direkt von diesen online zum Institut geleitet.

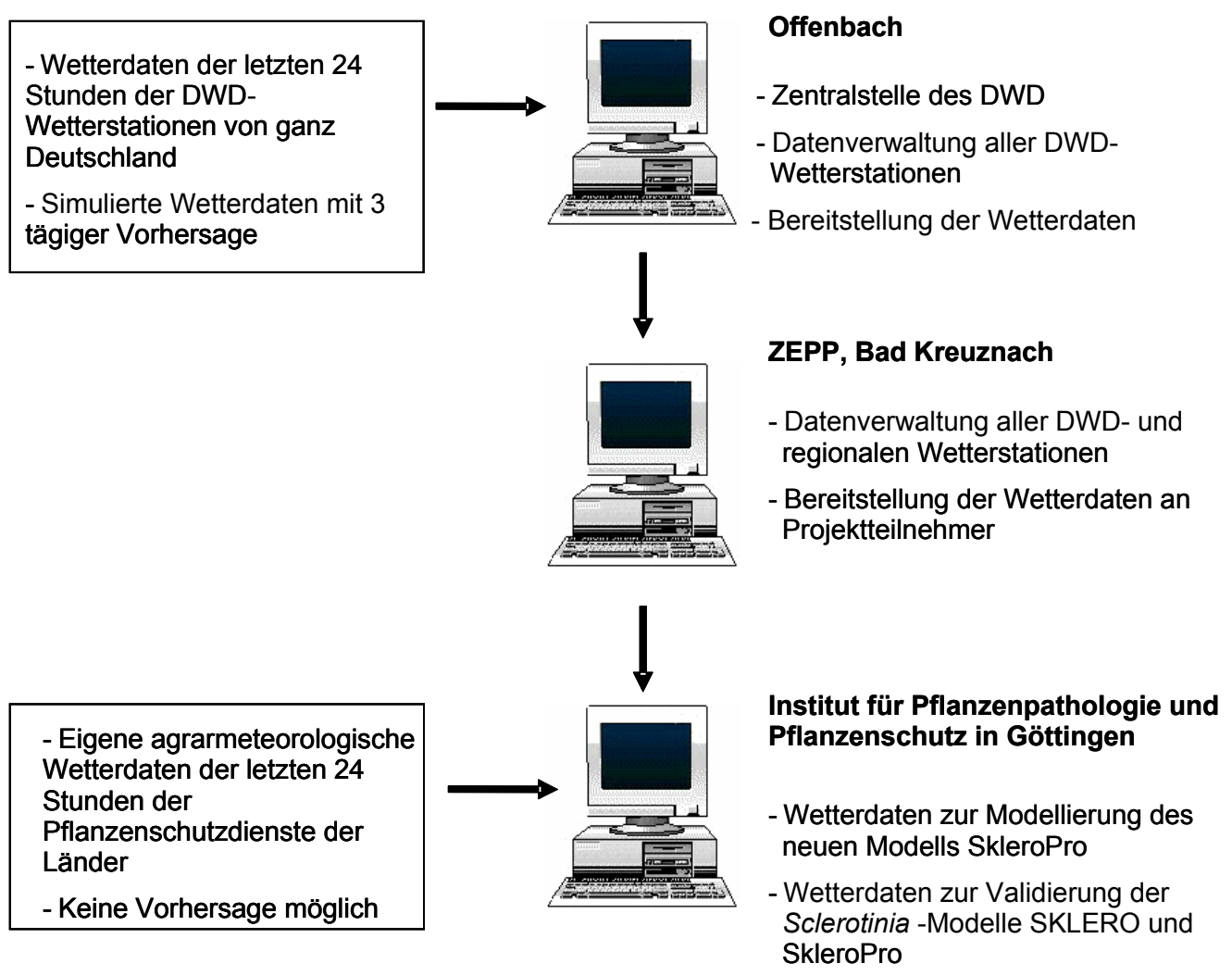

Abb. 4: Herkunft und Bereitstellung der Wetterdaten für die Modellierung und Validierung der Prognosemodelle SKLERO und SkleroPro am Institut für Pflanzenpathologie und Pflanzenschutz der Universität Göttingen.

\subsection{Wirtschaftlichkeitsuntersuchung zur Überprüfung der Modelle}

Anhand von 108 Feldversuchen der amtlichen Pflanzenschutzdienste der Länder (Mecklenburg-Vorpommern, Schleswig-Holstein, Sachsen-Anhalt, Brandenburg, Sachsen, Thüringen, Niedersachsen, Rheinland-Pfalz und Bayern) aus den Jahren 1994-2005 wurde durch eine rückwirkende Anwendung des Modells SkleroPro die Wirtschaftlichkeit der Behandlungsentscheidungen zur Blüte im Vergleich zur Routinebehandlung untersucht. 
Die Applikationskosten beinhalten Fungizidkosten, Überfahrtsverluste und den Rapspreis. Die Berechnung der variablen Applikationskosten basiert auf der Datenbank des Kuratoriums für Technik und Bauwesen in der Landwirtschaft (KTBL) und beinhaltet die Maschinenkosten (Standard Traktor, 75-92 kW, mit einer Anhängespritze mit einem Fassungsvermögen von 10001 und 15 m Arbeitsbreite) und die Arbeitskosten (Grundlage der Arbeitszeit: 200 1/ha Applikationsfläche, Feldgröße von 2 ha, Lohnkosten). Die Fungizidkosten der verschiedenen Jahre wurden den Preislisten der Raiffaisen Hauptgenossenschaft Nord entnommen. Ertragsverluste aufgrund von Durchfahrten während der Vollblütenbehandlung wurden mit 2,6\%/ha angenommen. Beim Rapspreis wurde der mittlere Rapspreis des jeweiligen Jahres zugrunde gelegt.

\subsection{Beschreibung des Modells SKLERO}

Als Grundlage für die Erstellung eines neuen Sclerotinia-Prognosemodells diente das vom Deutschen Wetterdienst von Herrn Friesland entwickelte Modell SKLERO (FRIESLAND, 2000). Das Prognosemodell SKLERO gehört zu den sehr komplexen und umfangreichen Modellen, welches mit einer hohen Anzahl an Parametern und mathematischen Gleichungen epidemiologische Prozesse in Abhängigkeit externer Parameter wie der Witterung berechnen kann. Im Folgenden werden der Aufbau und die einzelnen Berechnungen im Modell beschrieben und in Abbildung 5 dargestellt.

Für die Modellberechnung werden stündlich die rel. Luftfeuchte und die Temperatur (jeweils gemessen in $2 \mathrm{~m}$ Höhe) und der Niederschlag aus den nahe liegenden Wetterstationen des DWD erfasst. Aus den Wetterdaten erfolgt ab dem 1. Februar die Berechnung des Mikroklimas im Raps (FrIESLAND, 2000). Ergebnis dieser sehr komplexen Berechnung ist die Bodentemperatur, -feuchte, Lufttemperatur, -feuchte sowie die Blattbenetzung durch Regen oder Tau.

In einem weiteren Schritt wird die Sklerotienkeimung berechnet. Diese ist abhängig von der Bodenfeuchte und -temperatur sowie nach dem Aufwachsen der Apothezien, von der Lufttemperatur. Je nach Jahrestag, Nässe und Trockenheit in der oberen Bodenschicht wird die Sklerotienkeimung gefördert oder gehemmt. Die Berechnung des Bodennässeindex erfolgt über die Niederschlagsmenge und über das Entwicklungsstadium des Rapses. Dieser Index kann Werte zwischen 0 und 1 annehmen. Der Tag des Erscheinens der ersten 
Apothezien wird mit Hilfe einer Temperatursummenfunktion simuliert und wird erst dann vom Modell herausgegeben, wenn der Schwellenwert der Temperatursumme überschritten wurde. Bodentemperaturen von über $11^{\circ} \mathrm{C}$ fördern die Keimung wesentlich, dagegen verläuft die Keimung unterhalb dieser Temperatur deutlich langsamer ab. Ebenfalls erfolgt ein verzögertes Aufwachsen der Apothezien, wenn der vorhergegangene Winter starke Frostperioden oder sogar Kahlfröste zu verzeichnen hatte. Die Berechnung für das Aufwachsen neuer oder wieder frisch gewordener Apothezien nach Trockenheit oder Frost erfolgt über eine Warteschleife. Erst wenn nach einer Trocken- oder Frostperiode 12 Stunden lang eine bestimmte Feuchte vorhanden ist, sind die Apothezien wieder frisch. Die Apothezien erfrieren, wenn die Bodentemperatur unter $-1,5^{\circ} \mathrm{C}$ liegt. Ebenso vertrocknen die Apothezien nach 8 Tagen Trockenheit.

Die Entwicklung des Rapses wird erst nach Eingabe des Knospenstadiums berechnet und ist abhängig von der Temperatur und vom Jahrestag. Mit steigender Temperatur verläuft auch die Entwicklung des Rapses zügiger. Mit zunehmendem Alter der Pflanzen verzögert sich aber die Entwicklung und verläuft trotz steigender Temperaturen langsamer.

Nur wenn die ersten Apothezien erschienen sind, wird die Sporulation intern im Modell prognostiziert. Diese ist abhängig von der Bodentemperatur, Luftfeuchte und der Bodenässe. Die optimale Luftfeuchte zur Sporenausschleuderung beträgt $84 \%$. Die Bodentemperatur bei der noch bis zu 50\% der Sporen entlassen werden, liegt in einem sehr breiten Bereich von $4-26^{\circ} \mathrm{C}$, wobei das Optimum bei einer Bodentemperatur von $14^{\circ} \mathrm{C}$ erreicht ist. Durch Frost oder längere Trockenheit kann die Sporulation gehemmt werden. Zudem können Niederschläge nach längerer Trockenheit eine Intensität des Sporenfluges hervorrufen. Die Überlebenszeit der Ascosporen ist abhängig von der rel. Luftfeuchte. Bei einem Absinken der rel. Luftfeuchte unter 70\%, wird ein Absterben der Sporen von dem Modell prognostiziert.

Weiterhin werden nach dem Erscheinen der Apothezien und nach dem Erreichen des BBCH 60 (Anfang Blüte) stündlich die Infektionswahrscheinlichkeiten für eine Infektion berechnet. Die Berechnung der Infektionswahrscheinlichkeit ergibt sich aus den infektionsgünstigen Stunden und dem Infektionsdruck. Infektionsgünstige Stunden sind eine Kombination von Lufttemperatur, relativer Luftfeuchte und Dauer der Blattbenetzung. Die optimale Temperatur für eine Infektion mit Ascosporen liegt in dem Modell bei $15^{\circ} \mathrm{C}$ und einer rel. Luftfeuchte von $>94 \%$. Die Minimumtemperatur für eine infektionsgünstige Stunde liegt bei $3^{\circ} \mathrm{C}$ in Verbindung mit einer rel. Luftfeuchte von $92 \%$. 
Ebenfalls wird eine infektionsgünstige Stunde bei einem Minimum an rel. Luftfeuchte von $80 \%$ und einer damit verbundenen Temperatur von $8{ }^{\circ} \mathrm{C}$ erreicht. Die Infektionswahrscheinlichkeiten können einen Wert zwischen 0 (keine Infektionsbedingungen) und 1 (optimale Infektionsbedingungen) annehmen. Durch hohe Niederschlagsmengen können die infektionsgünstigen Stunden durch ein Abwaschen der Sporen vom Stängel/Blütenblatt gemindert werden.

\begin{tabular}{|c|}
\hline $\begin{array}{c}\text { Wetterdaten } \\
\text { (Niederschlag, Luftfeuchte, Temperatur) }\end{array}$ \\
\hline $\begin{array}{c}\text { Berechnung des Bestandesklimas } \\
\text { (Niederschlag, Luftfeuchte, Temperatur im Rapsbestand) }\end{array}$ \\
\hline $\begin{array}{l}\text { Bestimmung des Erstauftretens } \\
\text { der Apothezien (Jahrestag) }\end{array}$ \\
\hline $\begin{array}{l}\text { Bestimmung des Bodennässeindex (0-1) } \\
\text { (abh. von Niederschlag) }\end{array}$ \\
\hline $\begin{array}{l}\text { Berechnung des Entwicklungsstadiums des Rapses } \\
\qquad(\mathrm{BBCH})\end{array}$ \\
\hline $\begin{array}{l}\text { Berechnung des Sporenflugs } \\
\qquad(\mathrm{Ja} / \mathrm{Nein})\end{array}$ \\
\hline $\begin{array}{c}\text { Bestimmung neuen Apothezienwachstums } \\
\text { nach Frost- oder Trockenheit }\end{array}$ \\
\hline $\begin{array}{l}\text { Berücksichtigung von Frosteinwirkung } \\
\qquad\left(12 \mathrm{~h} \text { Temperatur }<-1,5^{\circ} \mathrm{C}\right)\end{array}$ \\
\hline $\begin{array}{l}\text { Berücksichtigung von Trockenheit } \\
\text { (8 Tage ohne Niederschlag) }\end{array}$ \\
\hline $\begin{array}{l}\text { Überlebensdauer der Sporen } \\
\quad(<17 \mathrm{~h} \text { Trockenheit })\end{array}$ \\
\hline $\begin{array}{l}\text { Berechnung der infektionsgünstigen Stunden (INST) und des } \\
\text { Infektionsdrucks (INDR) }\end{array}$ \\
\hline
\end{tabular}

\section{Abb. 5: Funktionalitäten und Parameter im Prognosemodell SKLERO}

Für eine gelungene Infektion müssen mindestens 22 ununterbrochen infektionsgünstige Stunden vorliegen. Die zweite Bedingung für das Gelingen einer Infektion ist der Infektionsdruck. Dieser berechnet sich aus der Anzahl der infektionsgünstigen Stunden 
und der gemittelten Infektionswahrscheinlichkeit über diese Periode. Erst wenn der Infektionsdruck den Wert von 5 erreicht hat und mindestens 22 ununterbrochen infektionsgünstige Stunden vorliegen, ist eine Infektion gelungen und wird vom Modell berechnet. Je nach dem, wie hoch der Infektionsdruck ist, wird eine schwache, mäßige, hohe oder sehr hohe Infektion herausgegeben.

\subsection{Statistik}

Die statistischen Berechnungen zur Überprüfung des Einflusses schlagspezifischer Faktoren auf den Befall mit S. sclerotiorum aus den Datensätzen der einzelnen Länder erfolgten mit Hilfe des Programms „,R“ (Version 1.7.1, GENTELMAN \& IHAKA, 1997). Die statistische Analyse des gesamten Datensatzes erfolgte mit dem Programmpaket STATGRAPHICS (Version 5.0). Im Rahmen der Untersuchungen erwies es sich als notwendig, eine Klassifizierung der erfassten Primärdaten nach bestimmten sachlogischen Gesichtspunkten vorzunehmen. Um den Einfluss der gewählten klassifizierten Faktoren auf den Befall festzustellen, wurde eine nichtparametrische Varianzanalyse durchgeführt. Zur Absicherung der signifikanten Mittelwertsdifferenzen diente der F-Test. Als Irrtumswahrscheinlichkeit (p) wurde $\mathrm{p} \leq 0,05$ zugrunde gelegt. In den Tabellen und Abbildungen wurden Signifikanzen wie folgt gekennzeichnet:

* für $\mathrm{p} \leq 0,05 ; * *$ für $\mathrm{p} \leq 0,01 ; * * *$ für $\mathrm{p} \leq 0,001$

Für die Untersuchung von Wechselwirkungen zwischen den ausgewählten Faktoren wurde eine multiple Varianzanalyse durchgeführt. Für die Programmierung, Modellierung und Parameterschätzung des Modellprototyps SkleroPro wurde das Simulationsprogramm ModelMaker, Version 4.0, verwendet (WALKER, 1997). Für die Kalibrierung und Erstellung des Modells SkleroPro wurden Befallserhebungen aus den Feldversuchen der amtlichen Pflanzenschutzdienste und der Biologischen Bundesanstalt (BBA) aus den Jahren 1999-2004 herangezogen und zusammen mit den simulierten Ergebnissen der Modelle graphisch mit einfachen Regressionsgeraden dargestellt. Die Beziehung zwischen Simulation und Befallsdaten wurde mit Hilfe des Programmpaketes STATGRAPHICS (Version 5.0) ermittelt. 


\section{Ergebnisse}

\subsection{Witterungsverlauf im Untersuchungszeitraum 2002-2005}

Das Auflaufen der Winterrapsbestände war durch die Trockenheit im September 2001 geprägt. Die früh gesäten Rapssamen konnten aufgrund der Niederschläge im Juli und August sehr gut auflaufen, demgegenüber liefen die Rapssamen, die nach dem 20. August gesät wurden, aufgrund der örtlichen Trockenheit nur ungleichmäßig auf. Nach dem milden Winter begann das Jahr 2002 weiterhin mit milden Temperaturen und wechselnden Niederschlägen. Das feucht-warme Klima im Frühjahr führte zu einem zügigen und üppigen Wachstum des Winterrapses. In der ersten Aprilhälfte führte die trocken-kühle Witterung mit erheblichen Nachtfrösten wieder zu einer stagnierenden Entwicklung der Bestände. Ab Ende April konnte ein Anstieg der Temperaturen registriert werden. In der Abbildung 6 sind die Witterungsbedingungen zum Zeitpunkt der Blüte vom 15. April (Erreichen des Knospenstadiums) bis zum 25. Mai (Ende der Blüte) am Beispiel der Wetterstation vom DWD in Göttingen dargestellt. Für die Berechnung einer infektionsgünstigen Stunde im Modell SkleroPro sind Mindesttemperaturen von $7^{\circ} \mathrm{C}$ verbunden mit einer Luftfeuchte von 86\% notwendig oder eine Mindestluftfeuchte von $80 \%$ und damit verbundenen Temperaturen von über $11^{\circ} \mathrm{C}$. In der zweiten Aprilhälfte konnten nur an vereinzelten Tagen Temperaturen von über $10^{\circ} \mathrm{C}$ erreicht werden, während in den ersten Maiwochen die Temperaturen kontinuierlich über $11^{\circ} \mathrm{C}$ lagen. Die Rapsblüte war durch sich abwechselnde Niederschläge und damit verbundenen hohen Luftfeuchten gekennzeichnet. Aus diesem Grund wurden an sehr vielen Tagen Luftfeuchten von über $80 \%$ erreicht. Im Mittel lagen die Temperaturen vom 15. April bis zum 25. Mai bei $12^{\circ} \mathrm{C}$ und die Luftfeuchten bei $81 \%$.

In den Monaten Mai bis September 2002 lagen die Jahresniederschläge und Temperaturen deutlich über dem langjährigen Mittel. Durch die sehr warmen Temperaturen und die sich abwechselnden Niederschläge im Spätsommer konnte die Rapsernte frühzeitig und zügig auflaufen. Die stärksten Temperaturschwankungen im Frostbereich waren im Dezember zu verzeichnen. Diese Kältewelle setzte sich auch über den Jahreswechsel fort. 


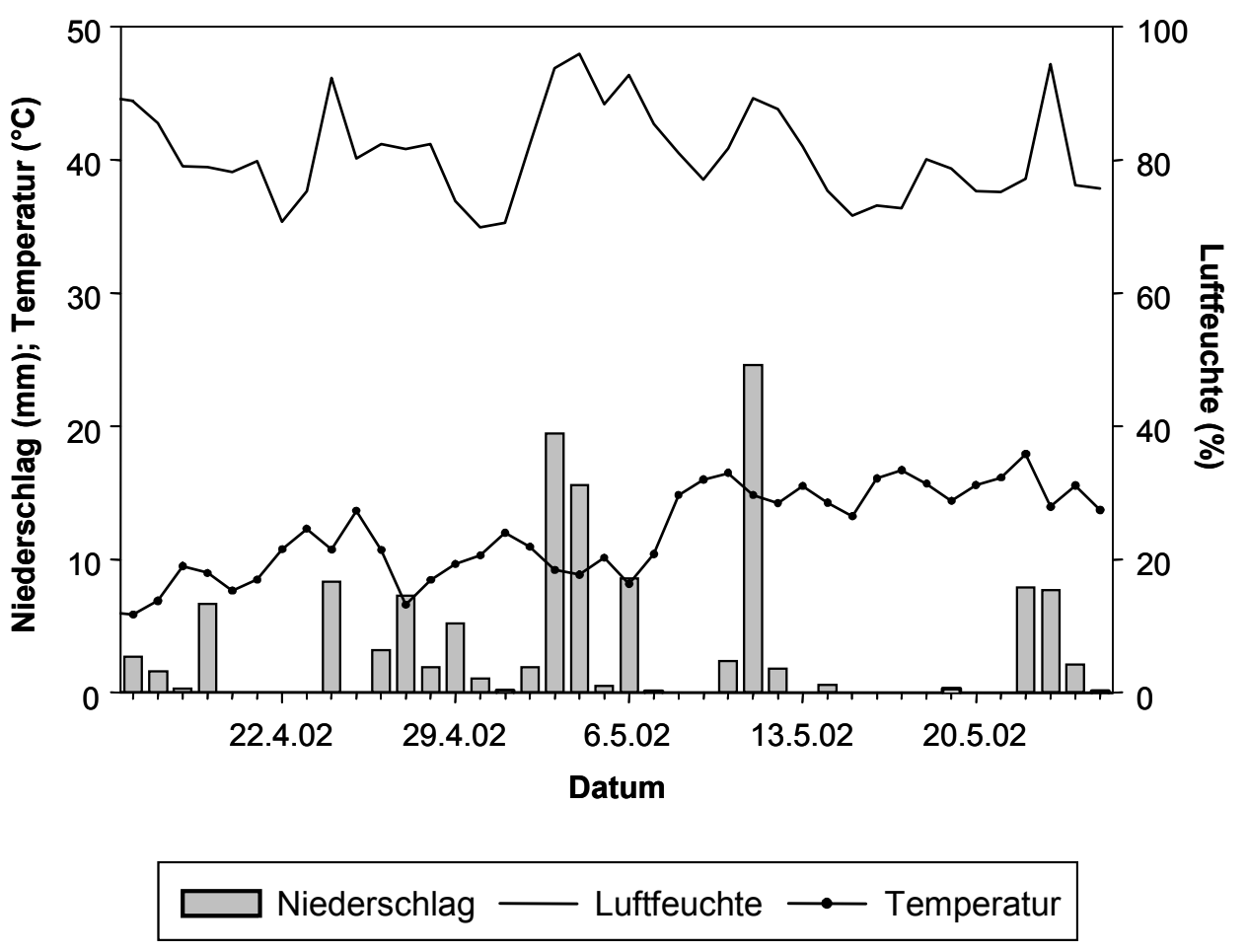

\begin{abstract}
Abb. 6: Witterungsverlauf (Niederschlag (mm); Temperatur $\left({ }^{\circ} \mathrm{C}\right)$; Luftfeuchte (\%)) in Göttingen von Mitte April bis Mitte Mai 2002. Datenaufzeichnung von der Messstation Göttingen des Deutschen Wetterdienstes (DWD).
\end{abstract}

Nach einem kalten Winter mit zum Teil starken Frostperioden wurde der Vegetationsbeginn der Kulturarten erst spät erreicht. Vielerorts konnten extreme Auswinterungsschäden im Raps beobachtet werden, die sich aber nach zunehmendem Temperaturanstieg im März zum Teil wieder erholen konnten. Von April bis August wurden nahezu kontinuierlich überdurchschnittliche Temperaturen mit geringen Niederschlägen registriert. Besonders die Rapsblüte war durch eine trockene und warme Witterung mit geringen Luftfeuchten gekennzeichnet (Abb. 7). Die durchschnittlichen Temperaturen und Luftfeuchten lagen vom 15. April bis zum 25 . Mai bei $12,9^{\circ} \mathrm{C}$ und 70,5\%. Bei Betrachtung der einzelnen Tageswerte wird deutlich, dass nur an sehr wenigen Tagen die Mindestluftfeuchte für eine Infektion von $80 \%$ überschritten wurde, dabei lagen die Temperaturen kontinuierlich über $11^{\circ} \mathrm{C}$.

Das Jahresmittel der Lufttemperatur lag im Jahr 2003 über dem langjährigen Durchschnitt. Dies führte vielerorts zu extremen Trockenschäden und einer frühzeitigen Ernte des Winterrapses. Mit Ausnahme der Monate Januar und Oktober lagen die Niederschlagshöhen in allen übrigen Monaten unter dem langjährigen Durchschnitt. 


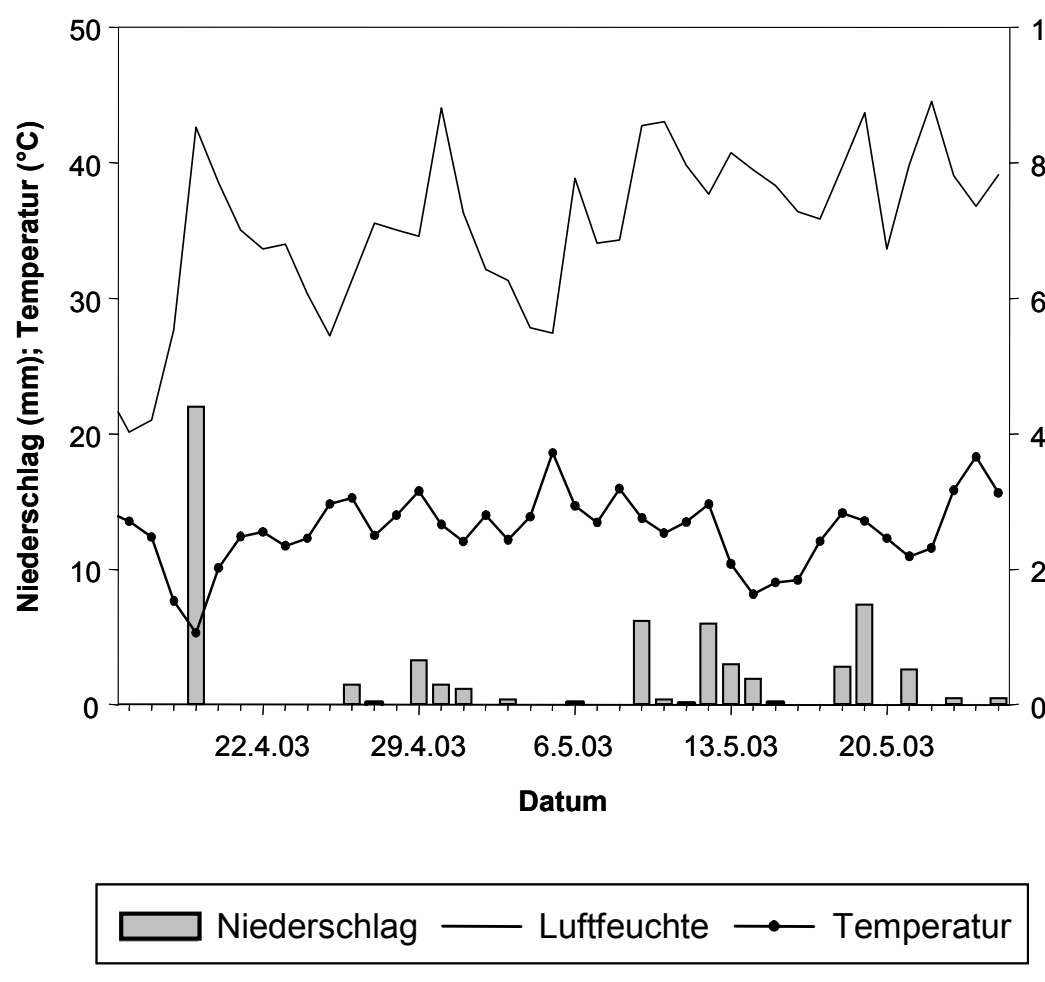

Abb. 7: Witterungsverlauf (Niederschlag (mm); Temperatur $\left({ }^{\circ} \mathrm{C}\right)$; Luftfeuchte $\left.(\%)\right)$ in Göttingen von Mitte April bis Mitte Mai 2003. Datenaufzeichnung von der Messstation Göttingen des Deutschen Wetterdienstes (DWD).

Durch die extreme Trockenheit im Jahr 2003 liefen die Rapsbestände nur sehr lückig auf, erst durch die Niederschläge im September konnten die übrigen Rapssamen auflaufen. Das Jahr 2004 begann mit einer ungewöhnlich milden Witterung, so dass der Vegetationsbeginn schon sehr früh eintrat. Nach kurzen Frostperioden im März, stiegen die Temperaturen im April wieder an. Der April war durch zeitweise kalte Abschnitte gekennzeichnet. Zum Monatsende konnte aber vielerorts die Rapsblüte beobachtet werden. Die Rapsblüte und auch der Juni zeichneten sich durch überwiegend kühle Witterungsabschnitte und nur wenige warme Tage aus (Abb. 8). Im Mittel lagen die Temperaturen während der Rapsblüte (vom 15. April bis zum 25. Mai) bei $11,1^{\circ} \mathrm{C}$ und die Luftfeuchten bei $76,3 \%$. Obwohl die Temperaturen fast täglich bei $11^{\circ} \mathrm{C}$ lagen, erreichte die Luftfeuchte nur an vereinzelten Tagen $80 \%$. Nur in dem Zeitraum zwischen 6. Mai bis 16. Mai lagen die Luftfeuchten beständig über $80 \%$.

Insgesamt waren die Sommermonate Juni bis September durch häufige Niederschläge und geringe Temperaturen gekennzeichnet. 


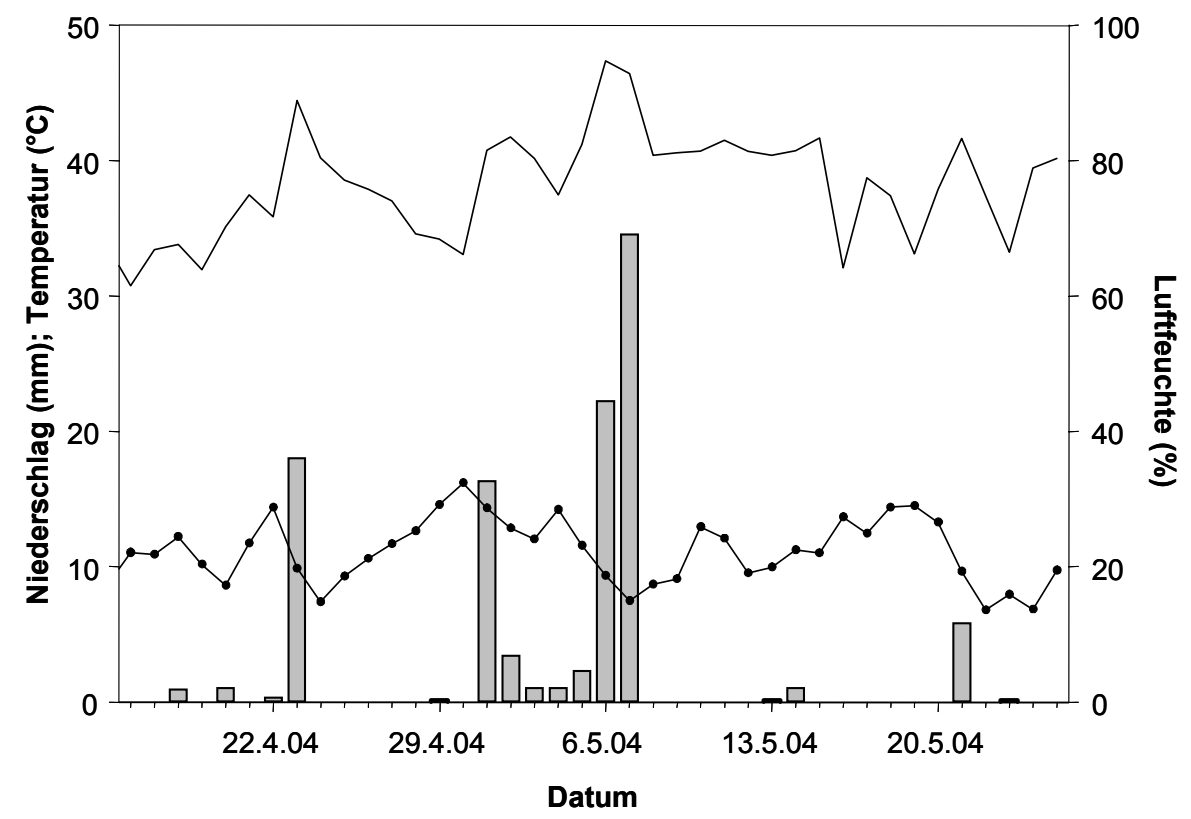

Niederschlag $\longrightarrow$ Luftfeuchte $\longrightarrow$ Temperatur

Abb. 8: Witterungsverlauf (Niederschlag (mm); Temperatur $\left({ }^{\circ} \mathrm{C}\right)$; Luftfeuchte $\left.(\%)\right)$ in Göttingen von Mitte April bis Mitte Mai 2004. Datenaufzeichnung von der Messstation Göttingen des Deutschen Wetterdienstes (DWD).

Nach milden Wintermonaten 2004/05 war besonders der Februar zum Teil mit häufigen Frostperioden gekennzeichnet, so dass der Vegetationsbeginn erst sehr spät eintrat. Der April war gekennzeichnet durch eine kühle Witterung von häufig unter $10^{\circ} \mathrm{C}$. Nur in dem Zeitraum vom 30. April bis 4. Mai und zum Ende der Blüte konnten Temperaturen von über $10^{\circ} \mathrm{C}$ registriert werden, in diesem Zeitraum lag jedoch die Luftfeuchte unter $80 \%$. Ende April begann vielerorts die Rapsblüte. Aufgrund der fortschreitenden kühlen Witterung bis Ende Mai konnte eine sehr lange Rapsblüte beobachtet werden. Während der Rapsblüte vielen nur vereinzelt Niederschläge, so dass die Luftfeuchte häufig unterhalb von $80 \%$ blieb (Abb. 9). Die durchschnittlichen Temperaturen und Luftfeuchten lagen in Göttingen vom 15 . April bis zum 25 . Mai bei $10,6^{\circ} \mathrm{C}$ und $76 \%$.

Der darauf folgende Juni war zum Teil durch extrem warme Temperaturen gekennzeichnet. Zum Zeitpunkt der Ernte in den Monaten Juli und August traten vielerorts häufige Niederschläge auf, so dass die Ernte nur verzögert ablaufen konnte. 


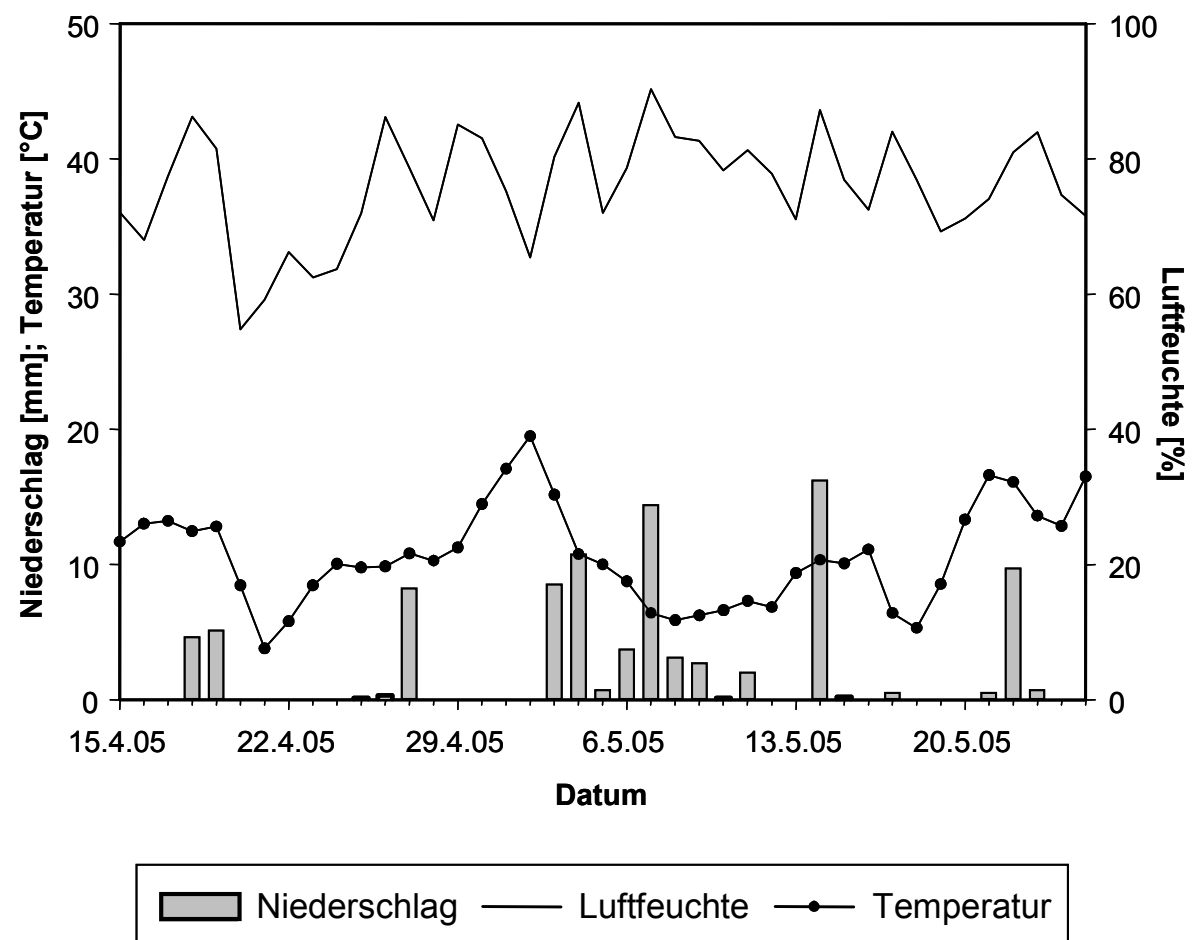

Abb. 9: Witterungsverlauf (Niederschlag (mm); Temperatur $\left({ }^{\circ} \mathrm{C}\right)$; Luftfeuchte $(\%)$ ) in Göttingen von Mitte April bis Mitte Mai 2005. Datenaufzeichnung von der Messstation Göttingen des Deutschen Wetterdienstes (DWD).

\subsection{Befallsentwicklung im Untersuchungszeitraum 2002-2005}

In der Abbildung 10 sind die Befallshäufigkeiten von S. sclerotiorum im Mittel über alle Versuchsstandorte der einzelnen Bundesgebiete für die Jahre 2002-2005 dargestellt. Die feucht-warmen Witterungsbedingungen während der Rapsblüte im Jahr 2002 führten vielerorts $\mathrm{zu}$ sehr hohen Befallshäufigkeiten. Besonders in den traditionellen Anbaugebieten, in denen der Raps in dreijähriger oder engerer Fruchtfolge steht, wie zum Beispiel in Mecklenburg-Vorpommern, Sachsen und Thüringen, wurden Befallshäufigkeiten von 25-40\% beobachtet. Eine Ausnahme stellte Schleswig-Holstein dar, hier traten im Mittel der Standorte nur Befallshäufigkeiten von 11\% auf. In den Bundesländern, in denen der Winterraps nur eine geringere Verbreitung findet, wie dies in Brandenburg und Bayern der Fall ist, lag die Befallshäufigkeit im Jahr 2002 insgesamt auf einem sehr geringen Niveau. In den Bundesländern Niedersachsen und Rheinland-Pfalz lagen im Jahr 2002 keine Feldversuche zur Sclerotinia-Bekämpfung vor. Aus diesem Grund konnte hier keine Aussage über die Befallshäufigkeit vorgenommen werden. 


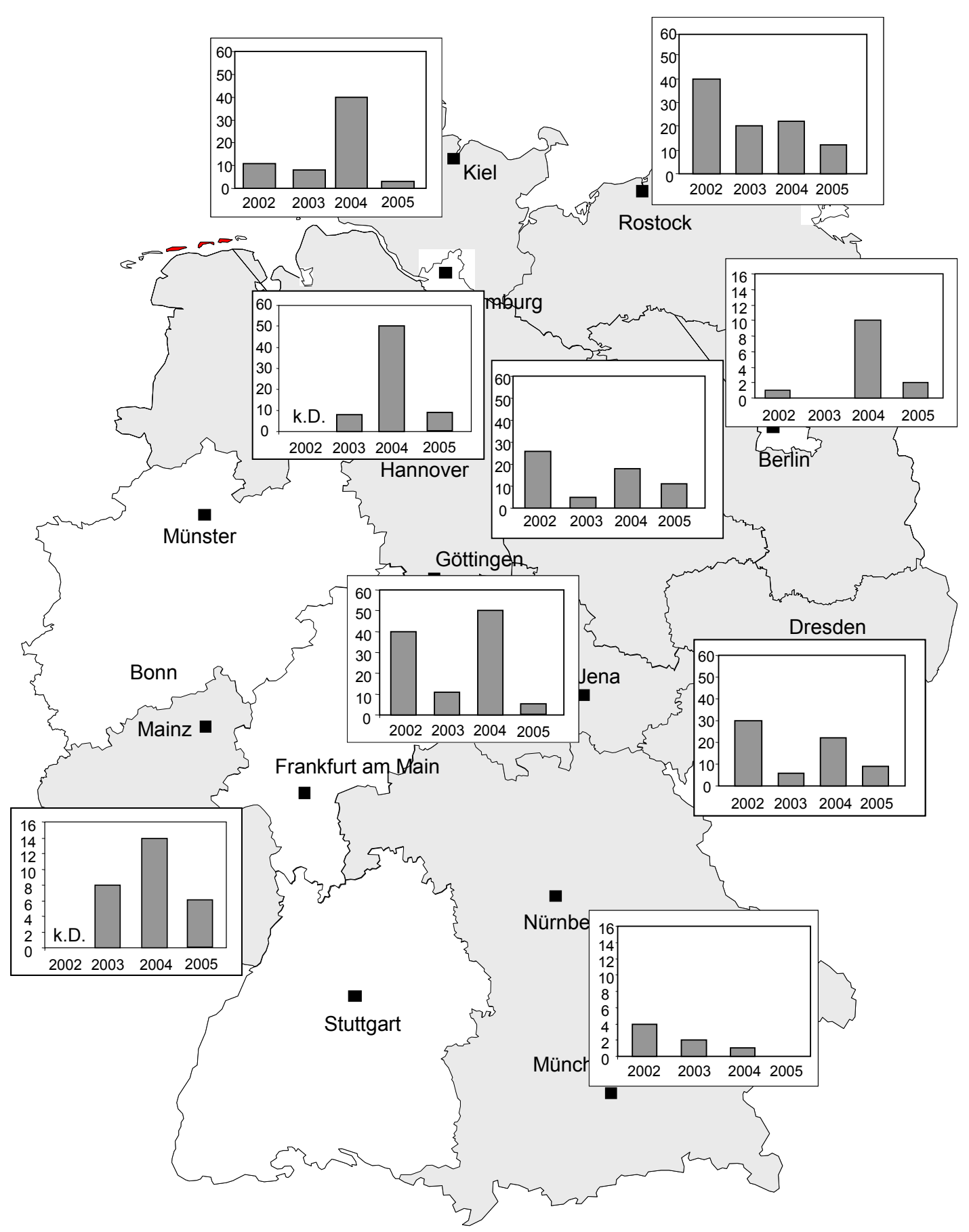

Abb. 10: Durchschnittliche Befallshäufigkeiten (\% befallene Pfl. $\left./ \mathrm{m}^{2}\right)$ von S. sclerotiorum in den Kontrollflächen der Fungizidversuche der amtlichen Pflanzenschutzdienste in den einzelnen Bundesgebieten in den Jahren 2002-2005; k.D.= keine Daten vorhanden; grau unterlegt $=$ Teilnahme des Bundeslandes an dem Sclerotinia-Projekt.

Auf der y-Achse sind die Jahre, auf der x-Achse die Befallshäufigkeiten (\%) dargestellt.

Durch die extrem trockene Witterung im Jahr 2003 verbunden mit sehr geringen Luftfeuchten während der Rapsblüte konnten in fast allen Bundesländern nur wenige Symptome der Weißstängeligkeit beobachtet werden. Nur vereinzelt wie in Mecklenburg- 
Vorpommern trat stärkerer Befall von 20\% auf. Insgesamt blieben die Befallshäufigkeiten unter $11 \%$ befallene Pflanzen $/ \mathrm{m}^{2}$.

Im Gegensatz zur extremen Trockenheit im Jahr 2003 führten die feucht-mäßig bis kühlen Witterungsbedingungen während der Rapsblüte im Jahr 2004 in fast allen Bundesgebieten zu einem Anstieg des Sclerotinia-Befalls. In einigen Regionen (Niedersachsen, Thüringen, Schleswig-Holstein) wurden Befallshäufigkeiten von 40-50\% ermittelt. Eine Ausnahme stellte wiederum Bayern dar, hier konnte nur ein sehr geringer bis gar kein Befall festgestellt werden. Die ersten Symptome der Weißstängeligkeit traten in 2004 in vielen Gebieten jedoch erst sehr spät im Bestand auf, oft erst vier bis fünf Wochen nach der Rapsblüte.

Das Jahr 2005 war insgesamt durch ein sehr geringes Auftreten von S. sclerotiorum gekennzeichnet. Aufgrund der sehr kühlen Temperaturen während der Blüte lag der Befall im Durchschnitt bei 10\%. Nur in vereinzelten Feldversuchen konnten Befallshäufigkeiten von $25 \%$ beobachtet werden.

\subsection{Nachweis von $S$. sclerotiorum auf Blütenblättern mittels pH-Indikator-Test}

Beim Überimpfen von myzelbewachsenen PDA-Stücken von verschiedenen SclerotiniaIsolaten und anderen Pathogenen wie Alternaria alternata, Botrytis cinerea, Phoma lingam, Verticillium dahliae, $V$. longisporum, Fusarium culmorum, F. graminearum und $F$. oxysporum auf pH-Indikator-Medium konnten durchweg alle Sclerotinia-Isolate durch Farbveränderung von blau zu orange diagnostiziert werden (Abb. 11).
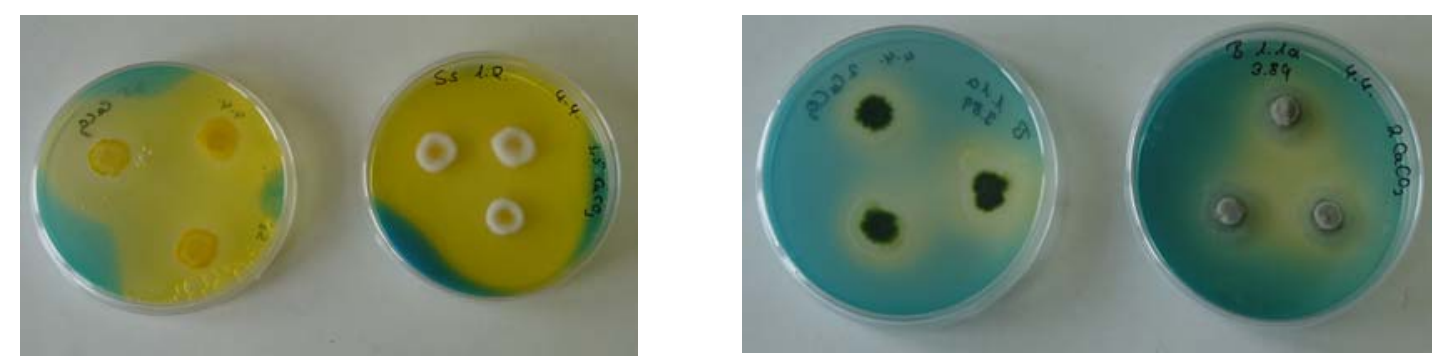

Abb. 11: Farbnachweis am Beispiel von drei mit Myzel von S. sclerotiorum und Botrytis cinerea bewachsenen PDA-Stücken auf dem $\mathrm{pH}$-Indikatormedium nach 7 Tagen. 
Die Verfärbung zeigte sich nach drei Tagen. Nach ungefähr 12 Tagen hatte sich die gesamte Petrischale bei allen Sclerotinia-Isolaten gelb verfärbt und die ersten Sklerotien waren sichtbar. Bei den anderen Pathogenen konnte nur bei Botrytis cinerea eine leichte Verfärbung des Agarmediums beobachtet werden.

Die Calciumcarbonatmenge musste so optimiert werden, dass der Test möglichst schnell zu genauen Ergebnissen führt und gleichzeitig andere schwach säurebildende Pilze, wie zum Beispiel Botrytis cinerea, ausgeschlossen werden konnten. Die Optimierung zeigte, dass sich für den Nachweis von $S$. sclerotiorum ein Calciumcarbonatgehalt von $3 \mathrm{~g} / \mathrm{l}$ $\mathrm{CaCO}_{3}$ empfiehlt (Abb. 12). Nach 3-4 Tagen konnte bei Gehalten mit 2 und $3 \mathrm{~g} / \mathrm{CaCO}_{3}$ eine Verfärbung festgestellt werden. Bei einem Gehalt von 4 und $5 \mathrm{~g} / 1 \mathrm{CaCO}_{3}$ zeigten sich die ersten Verfärbungen erst nach 8-10 Tagen.

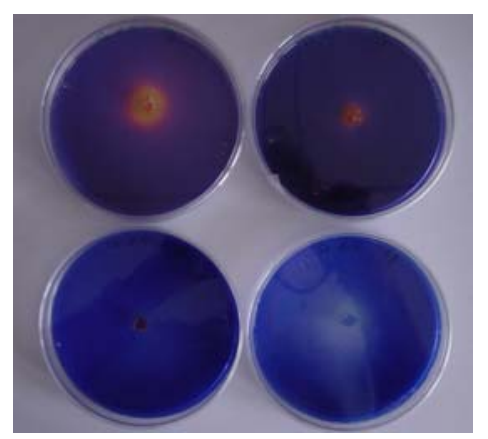

\begin{abstract}
Abb. 12: Farbumschlag auf $\mathrm{pH}$-Indikatormedium bei unterschiedlichen Calciumcarbonatgehalten (von oben links bis unten rechts 2, 3, 4 und $5 \mathrm{~g} / 1 \mathrm{CaCO}_{3}$ ) zum Nachweis von S. sclerotiorum (nach 3 Tagen).
\end{abstract}

\title{
3.3.1 Befall der Blütenblattproben in den Jahren 2003 und 2004
}

Ein großflächiger Einsatz dieser Methode mit den geernteten Blütenblattproben von Versuchsfeldern aus dem Jahr 2003 zeigte kein zufrieden stellendes Ergebnis. Bei keiner untersuchten Probe konnte S. sclerotiorum nachgewiesen werden. Zwar trat in einigen Fällen ein Farbumschlag ein, dieser konnte aber nicht eindeutig S. sclerotiorum zugeordnet werden. Durch Kontamination mit einigen schwach säurebildenden Penicillium-Arten und mit Botrytis cinerea bestand die Gefahr einer Verfälschung der Ergebnisse. Eine mögliche Erklärung dafür, dass kein Befall mit S. sclerotiorum nachgewiesen werden konnte, bestand darin, dass durch das lange Einfrieren der Blütenblätter die Sporen bzw. das gewachsene Myzel abgestorben waren und somit nicht mehr fähig waren, auf dem 
Agarmedium auszukeimen bzw. zu wachsen. Aus diesem Grund wurden im dritten Versuchsjahr (2004) die frischen Blütenblattproben direkt mit dem pH-Indikator-Test auf Befall mit S. sclerotiorum untersucht. In Abbildung 13 ist der Befall von drei Blütenblättern vom Versuchsstandort Börry aus dem Jahr 2004 auf dem pHIndikatormedium dargestellt. Durch die Farbveränderung des Agarmediums konnte der Befall deutlich S. sclerotiorum zugeordnet werden, zudem waren nach 7 Tagen Exsudattropfen und erste Sklerotienbildung sichtbar.
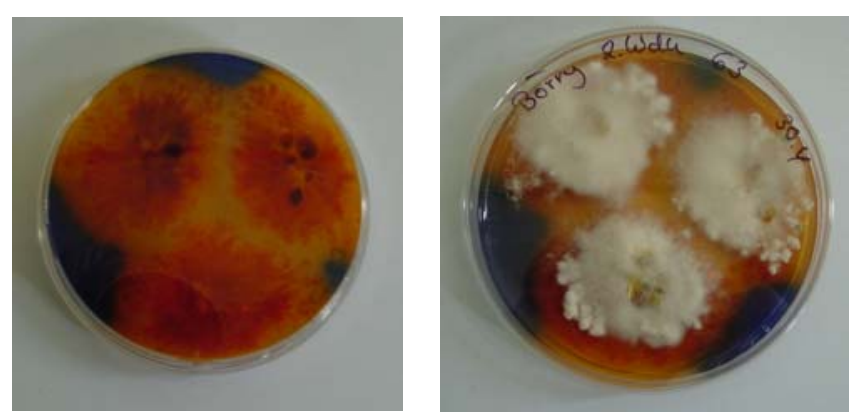

Abb. 13: Nachweis von S. sclerotiorum auf drei Blütenblättern vom Feld mittels $\mathrm{pH}-$ Indikatormedium am Beispiel von Proben vom Versuchsstandort Börry zum BBCHStadium 63 im Jahr 2004 nach 7 dpi.

In Abbildung 14 ist der Befall der Blütenblätter $\mathrm{zu}$ den drei Probeentnahmeterminen (Anfang, Mitte und Ende Blüte) an den einzelnen Versuchsstandorten in ganz Deutschland dargestellt. Zu Beginn der Blüte konnte an den meisten Standorten nur ein geringer bis gar kein Befall der Blütenblätter festgestellt werden. Nur in Niedersachsen, Sachsen-Anhalt und Thüringen konnte ein mittlerer bis starker Befall zum BBCH 63 nachgewiesen werden. Mit zunehmendem Blütenblattfall nahm auch die Kontamination mit $S$. sclerotiorum auf den Blütenblättern zu. Zu diesem Zeitpunkt konnte nur noch an den Blütenblattproben von einigen Standorten in Rheinland-Pfalz und Sachsen-Anhalt kein Befall festgestellt werden. In den übrigen Blütenblattproben variierte der Befall von gering bis stark. Ähnlich wie schon zu Blühbeginn zeigte sich auch zum Zeitpunkt der Vollblüte der höchste Befall in der Mitte Deutschlands (an den Versuchsstandorten Niedersachsen, Sachsen-Anhalt und Thüringen). Zum Ende der Blüte schwächte sich der Befall insgesamt wieder ab. Aber auch zu diesem Zeitpunkt konnte an vereinzelten Standorten in Niedersachsen und Thüringen noch ein starker Sclerotinia-Befall auf den Blütenblättern nachgewiesen werden. Weiterhin konnte mit abnehmender Blüte eine leichte Verschiebung 
des Infektionsgeschehens in den nördlichen Teil Deutschlands beobachtet werden, wie Emden, Brandenburg und Stendal.

BBCH 63

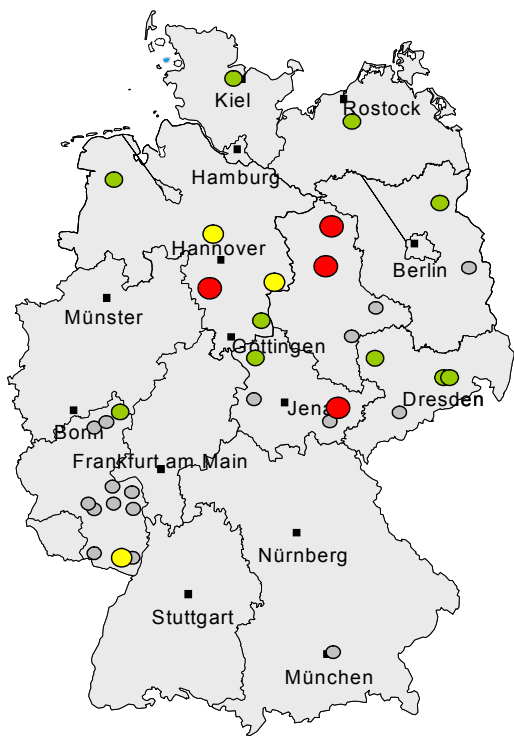

BBCH 65

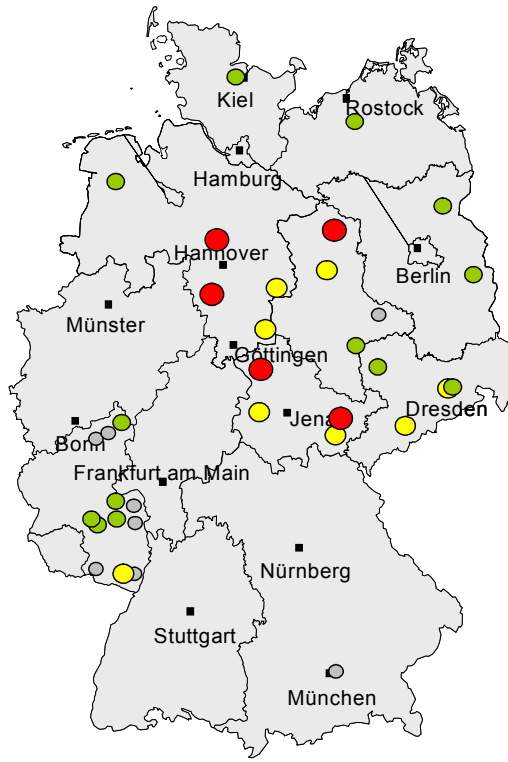

BBCH 69

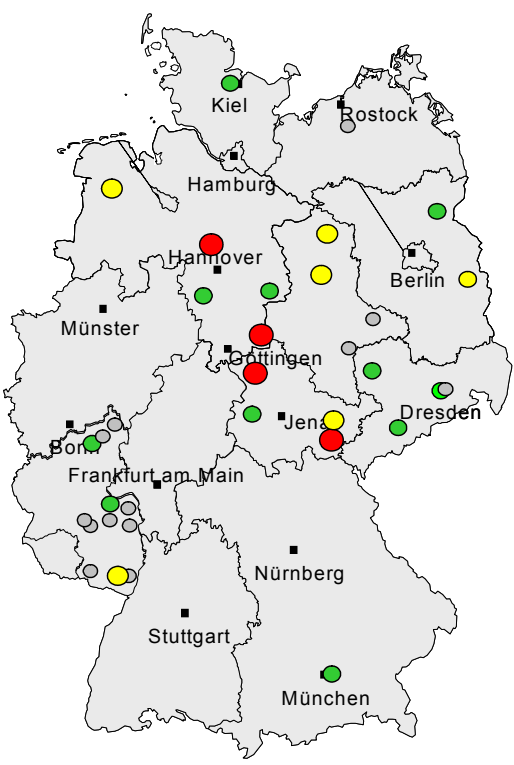

$\circ$ Kein Befall $\bigcirc$ Geringer Befall $\bigcirc$ Mittlerer Befall $\bigcirc$ Starker Befall

Abb. 14: Ergebnis der Blütenblattuntersuchung der festen Blütenblätter mit dem $\mathrm{pH}-$ Indikator-Test anhand von Frischmaterial, welches zu drei Probeentnahmeterminen (BBCH 63, 65 und 69) an den einzelnen Versuchsstandorten der Pflanzenschutzämter im Jahr 2004 gesammelt wurde; der Befall der Blütenblätter mit $S$. sclerotiorum wurde in vier Stufen eingeteilt (kein, geringer, mittlerer und starker Befall)

Kein Befall $\quad=0 \%$ Befall der Blütenblätter

Geringer Befall $=1-10 \%$ Befall der Blütenblätter

Mittlerer Befall $=11-25 \%$ Befall der Blütenblätter

Starker Befall $=>25 \%$ Befall der Blütenblätter

\subsubsection{Vergleich der abgefallenen und festen Blütenblattproben vom Feld}

In der Literatur sind zwei Wege der Infektion durch Ascosporen beschrieben, zum einen können die Ascosporen direkt abgestorbene Blätter oder Stängel des Rapses befallen, zum anderen erfolgt die Infektion über bereits abgefallene Blütenblätter, die sich in der Blattachsel befinden (PAUL, 2003). Dabei wird dem Infektionsweg über die Blütenblätter eine größere Bedeutung beigemessen (JAMAUX et al., 1995; KRÜGER, 1975). Aufgrund dieser Annahme wurden sowohl abgefallene als auch fest an der Blüte haftende 
Blütenblattproben vom Feld entnommen und auf den Befall mit Ascosporen untersucht. Das Ergebnis zeigt, dass eine gute Übereinstimmung zwischen dem Ergebnis der festen und abgefallenen Blütenblätter besteht. Weiterhin konnte festgestellt werden, dass im Mittel über alle Probenahmetermine bei den abgefallenen Blütenblättern eine geringere Kontamination mit Ascosporen beobachtet werden konnte, als bei den festen Blütenblättern (Abb. 15).

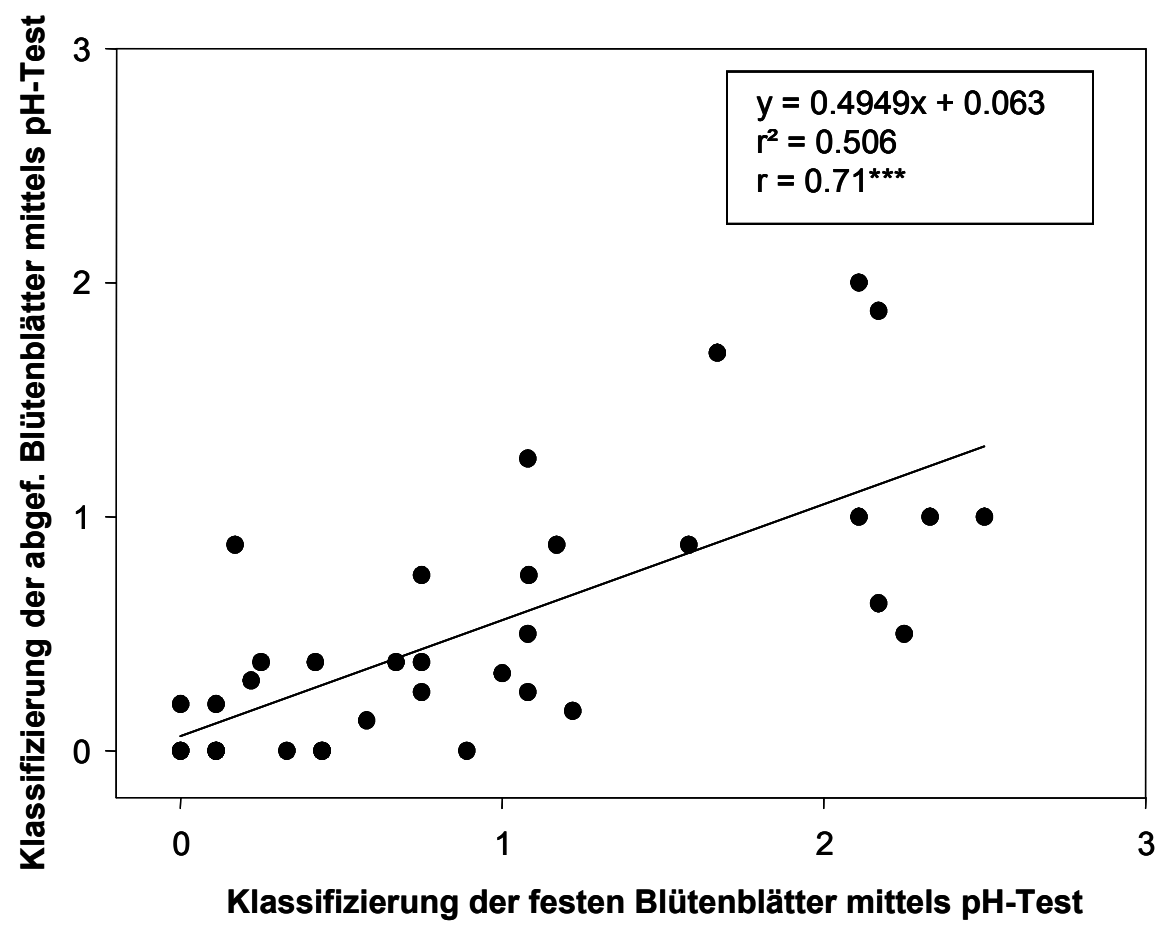

Abb. 15: Vergleich der Ergebnisse des pH-Tests der festen und abgefallenen Blütenblattproben von den Versuchsstandorten der Pflanzenschutzämter der Bundesländer im Mittel über alle drei Probenahmetermine im Jahr 2004.

$\mathrm{r}^{2}$ : Bestimmtheitsmaß; $\mathrm{r}=$ Korrelationskoeffizient

\subsubsection{Vergleich des pH-Indikator-Tests mit dem Befall im Feld}

Eine Quantifizierung des Ergebnisses des pH-Indikator-Tests ist insofern schwierig, als das man nur einen Farbumschlag des Agarmediums visuell messen kann. Eine photometrische Messung zur genaueren Quantifizierung des Pathogens ist nicht möglich. Die einzige Möglichkeit zur Abschätzung der ungefähr zu erwartenden Befallshäufigkeit ist die Quantifizierung der Menge an befallenen Blütenblättern. In Abbildung 16 sind die 
Mittelwerte des pH-Indikator-Tests der drei Probeentnahmetermine im Vergleich zum Sclerotinia-Befall zum Zeitpunkt der Ernte dargestellt. Anhand des Ergebnisses wird deutlich, dass mit steigendem Befall der Blütenblätter beim pH-Test auch der aktuelle Befall im Feld zunimmt. Aufgrund der geringen Menge an untersuchtem Pflanzenmaterial ist jedoch die Möglichkeit einer exakten Aussagekraft der zur erwartenden Befallshäufigkeit nicht möglich. Bei einem geringen pH-Test Ergebnis zwischen 0 und 1.2 lag der anschließende Befall in einem sehr weiten Bereich zwischen 0 und 30\%.

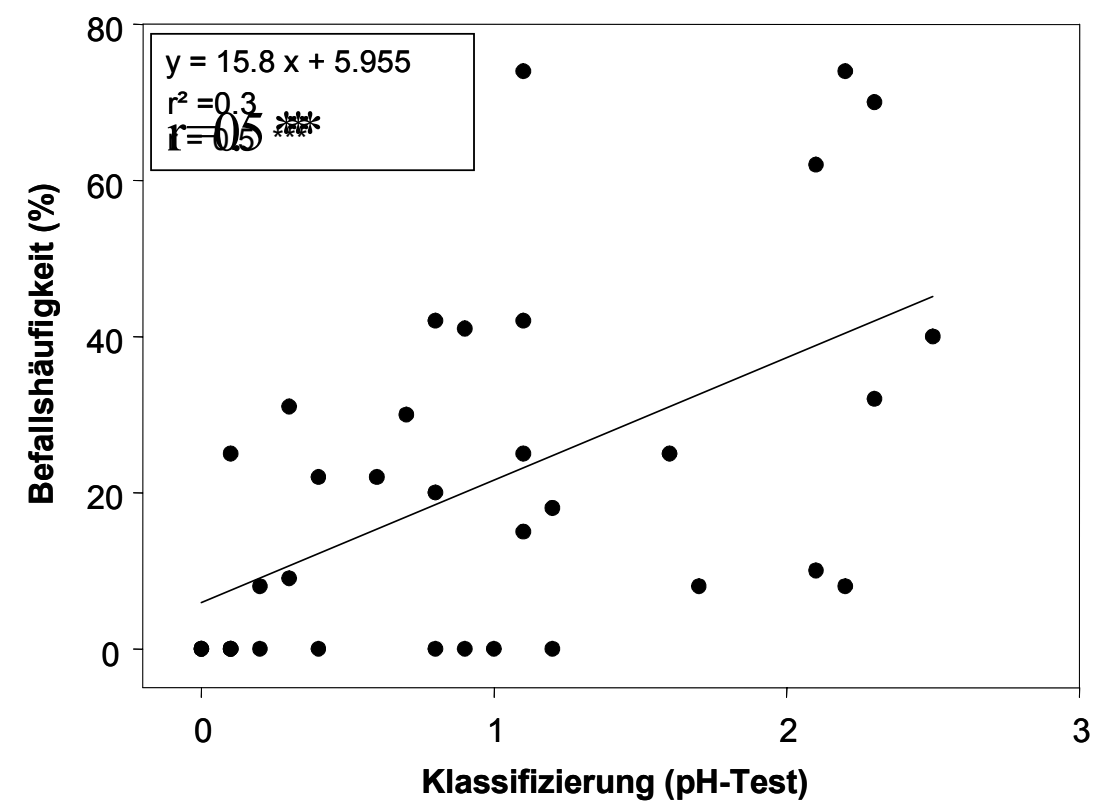

\begin{abstract}
Abb. 16: Vergleich des Ergebnisses der untersuchten festen Blütenblätter mit dem $\mathrm{pH}$ Indikator-Test im Mittel über alle Probenahmetermine (BBCH 63, 65 und 69) von 36 Versuchsstandorten der Pflanzenschutzdienste der Länder und dem aktuellen Befall der Kontrollflächen zum Zeitpunkt der Ernte (2004)

$\mathrm{y}$ : Regressionsgleichung, $\mathrm{r}^{2}$ : Bestimmtheitsmaß r: Korrelationskoeffizient
\end{abstract}




\subsection{ELISA}

\subsubsection{Ermittlung der optimalen Antikörperverdünnung}

Um ein empfindliches Nachweisverfahren von S. sclerotiorum $\mathrm{zu}$ erhalten, ist es notwendig die Antikörperkonzentrationen so $\mathrm{zu}$ optimieren, dass trotz sparsamen Verbrauchs des Antiserums eine maximale Empfindlichkeit bei gleichzeitig minimalen falsch positiven Reaktionen erreicht wird. Dies kann sowohl durch Veränderung der Konzentration der Antikörper als auch der biotinylierten Antikörper beeinflusst werden.

Um einen sicheren Nachweis zu erzielen, wurden 7 verschiedene Verdünnungsreihen und vier Antigenverdünnungen ausgewählt und unter Verwendung von Kultur-Filtrat Antigen getestet. Die in Tabelle 8 dargestellten Antikörperverdünnungen zeigen, dass sowohl der Verdünnungsgrad der Antikörper (IgG) als auch der biotinylierten Antikörper (bio IgG) den ELISA stark beeinflussen können. Je höher die Konzentration der Antikörper oder auch der biotinylierten Antikörperkonzentrationen ist, desto stärker nehmen auch die Extinktionswerte zu. Die höchsten Extinktionswerte wurden bei einem Verdünnungsgrad von 1:500 Antikörper und 1:1000 biotinylierte Antikörper und einem Verdünnungsgrad von 1:1000 Antikörper und 1:500 biotinylierte Antikörper erreicht.

Tab. 8: Einfluss der Verdünnung von Antikörpern ( $\operatorname{IgG})$ und biotinylierten Antikörpern (bio $\mathrm{IgG}$ ) auf die Reaktion im ELISA $\left(\mathrm{E}_{405} \mathrm{~nm}\right)$ bei $16 \mathrm{ng} / \mathrm{ml}, 250 \mathrm{ng} / \mathrm{ml}, 500 \mathrm{ng} / \mathrm{ml}$ und $1000 \mathrm{ng} / \mathrm{ml}$ Protein von S. sclerotiorum.

\begin{tabular}{|c|c|c|c|c|}
\hline \multirow{3}{*}{$\begin{array}{c}\text { Verdünnungsgrad } \\
\text { der Antikörper } \\
\text { IgG/ bio IgG }\end{array}$} & \multicolumn{4}{|c|}{ Antigenkonzentration } \\
\hline & $\begin{array}{c}16 \\
n g / m L\end{array}$ & $\begin{array}{c}250 \\
n g / m L\end{array}$ & $\begin{array}{c}500 \\
\mathrm{ng} / \mathrm{mL}\end{array}$ & $\begin{array}{c}1000 \\
\mathrm{ng} / \mathrm{mL}\end{array}$ \\
\hline & \multicolumn{4}{|c|}{ OD $\left(E_{405} \mathrm{~nm}\right)$} \\
\hline $1: 500 / 1: 1000$ & 1,8 & 2 & 2,1 & 2,3 \\
\hline $1: 500 / 1: 2000$ & 1,1 & 1,2 & 1,4 & 1,5 \\
\hline $1: 1000 / 1: 500$ & 1,8 & 2,2 & 2,2 & 2,5 \\
\hline 1:1000 / 1:1000 & 1,2 & 1,4 & 1,5 & 1,6 \\
\hline $1: 1000 / 1: 2000$ & 0,8 & 0,9 & 1 & 1,1 \\
\hline $1: 2000 / 1: 500$ & 1 & 1,2 & 1,3 & 1,5 \\
\hline $1: 2000 / 1: 2000$ & 0,4 & 0,5 & 0,6 & 0.6 \\
\hline
\end{tabular}


Für einen routinemäßigen Gebrauch des ELISA ist jedoch eine Verdünnung von 1:1000 $(1 \mu 1 / \mathrm{ml})$ für beide Antikörpertypen ausreichend.

\subsubsection{Ermittlung der Nachweisgrenze für $S$. sclerotiorum}

Die Empfindlichkeit des Tests gilt als wichtigstes Kriterium bei der Beurteilung des ELISA. Gerade bei S. sclerotiorum auf Blütenblättern muss davon ausgegangen werden, dass der Befall der Blütenblätter sehr gering ist und somit die Empfindlichkeit des Tests sehr hoch sein muss. Als Maß für die Empfindlichkeit dient die Nachweisgrenze, d.h. die Antigenmenge, die unter den verwendeten Testbedingungen noch nachgewiesen werden kann.

Zur Überprüfung der Nachweisgrenze des $S$. sclerotiorum-Antiserums wurde eine Verdünnungsreihe des Kulturfiltratantigens von 1000, 500, 250, 125, 64, 32, 16, 8, 4 und 2 ng Pilzprotein/ml hergestellt und bei einer Antikörper- und biotinylierten Antikörperverdünnung von 1:1000 im ELISA untersucht (Abb. 17). Die Nachweisgrenze des ELISA lag bei einer Proteinkonzentration von $2 \mathrm{ng} / \mathrm{ml}\left(\mathrm{OD}_{405 \mathrm{~nm}}=0,1\right)$ nach $240 \mathrm{~min}$.

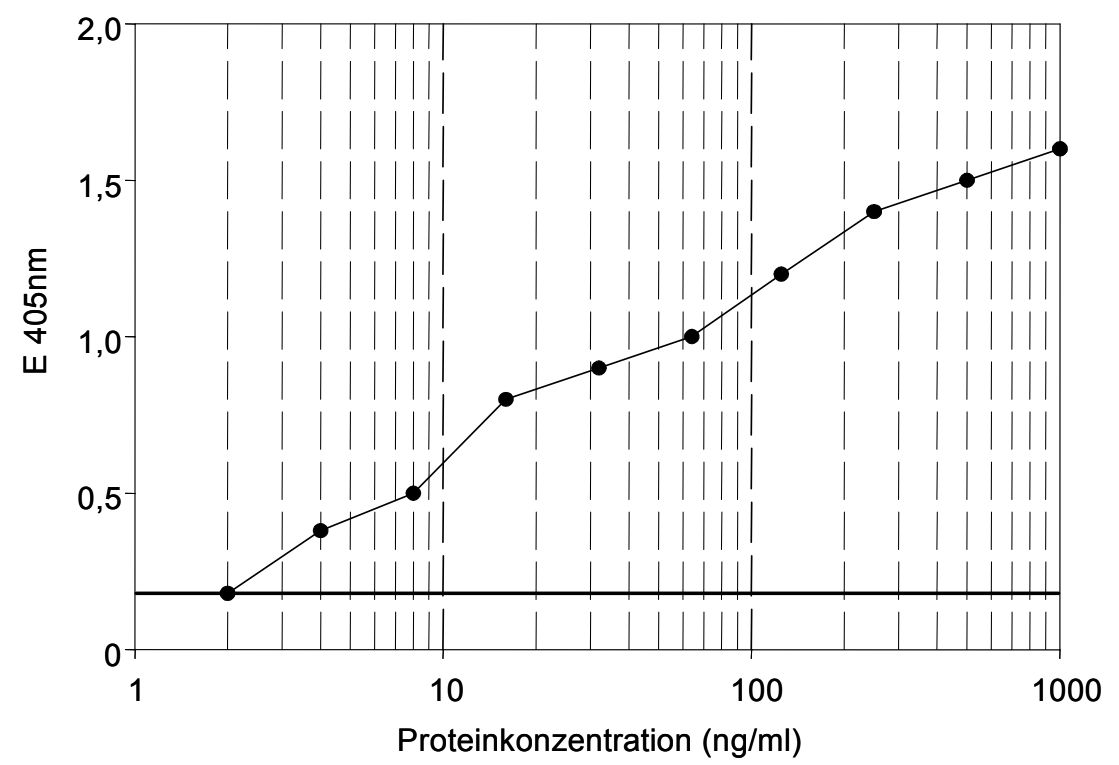

\footnotetext{
Abb. 17: Ermittlung der Nachweisgrenze im ELISA in Abhängigkeit von der Proteinkonzentration von $S$. sclerotiorum nach logarithmischer Auftragung der Messwerte.
} 


\subsubsection{Spezifität des Nachweises von $S$. sclerotiorum}

Vor einem routinemäßigem Einsatz des ELISA für $S$. sclerotiorum musste überprüft werden, ob die Antikörper mit pflanzlichen Inhaltstoffen oder mit anderen Pilzarten kreuzreagieren. Im Einzelnen sind dabei die Pilzarten interessant, die auf Raps vorkommen. Zur Ermittlung der Kreuzreaktion wurden Myzelextrakte von verschiedenen wichtigen Pathogenen sowie bodenbürtigen saprophytischen Pilzen mit Proteingehalten von $1 \mu \mathrm{g} / \mathrm{ml}$ eingesetzt. Die Überprüfung pilzlicher rapspathogener Schaderreger aus in vitro Kulturen ergab, dass keine Kreuzreaktionen auftraten, da die Extinktion $\left(\mathrm{E}_{405 \mathrm{~nm}}\right)$ bei einer Proteinmenge von $1 \mu \mathrm{g} / \mathrm{ml}$ unterhalb der festgesetzten Nachweisgrenze von 0,1 lag (Tab. 9). Aufgrund dieser Ergebnisse waren Kreuzreaktionen in planta nicht zu erwarten.

Tab. 9: Überprüfung der Spezifität des Antiserums im ELISA an Isolaten verschiedener Pathogene und von S. sclerotiorum sowie einem unbehandelten Blütenblatt als Kontrolle. Einsetzt wurden jeweils $1 \mu \mathrm{g}$ Protein/ml.

\begin{tabular}{|l|c|lc|}
\hline \multicolumn{1}{|c|}{ Pilz (Antigen) } & Isolat & \multicolumn{2}{l|}{ OD (E (405nm) $^{\prime}$} \\
\hline Fusarium culmorum & Fc 33 & 0 & - \\
\hline Fusarium graminearum & Fg 35 & 0 & - \\
\hline Fusarium oxysporum & Fo 36 & 0 & - \\
\hline Rhizoctonia solani & Rs AG 2-1 & 0,015 & - \\
\hline Botrytis cinerea & 1.0 & 0 & - \\
\hline Botrytis cinerea & 9 & 0 & - \\
\hline Verticillium longisporum & 84 & 0 & - \\
\hline Verticillium longisporum & 82 & 0 & - \\
\hline Verticillium dahliae & Vd 3 & 0 & - \\
\hline Alternaria alternata & 4.13 & 0 & - \\
\hline Alternaria alternata & 64 & 0,0135 & - \\
\hline Alternaria alternata & 228 & 0 & - \\
\hline Phoma lingam & 39 & 0 & - \\
\hline Phoma lingam & 23 & 0,01 & - \\
\hline Kontrolle (unbeh.Blütenblatt) & & 0 & - \\
\hline Sclerotinia sclerotiorum & Ss 1,3 & 0,15 & + \\
\hline Sclerotinia sclerotiorum & Ss 1,1 & 0,5 & + \\
\hline Sclerotinia sclerotiorum & Ss 1,6 & 1,0 & + \\
\hline Sclerotinia sclerotiorum & Ss 1,2 & 1,2 & + \\
\hline Sclerotinia sclerotiorum & Ss 11,4 & 4,7 & ++ \\
\hline Sclerotinia sclerotiorum & Ss 1,5 & 6,6 & +++ \\
\hline
\end{tabular}

[Antigengewinnung der verschiedenen Pilzisolate mittels gefriergetrockneten Myzels, anschließender Extraktion der Proteine und Bestimmung der Proteinmenge nach Bradford] 
Weiterhin zeigte sich bei dieser Überprüfung, dass die verschiedenen Isolate von $S$. sclerotiorum unterschiedlich hohe Extinktionswerte hatten. Das Sclerotinia-Isolat Ss 1.5 erreichte mit 6,6 den höchsten Extinktionswert.

\subsubsection{Nachweis von $S$. sclerotiorum in künstlich infizierten Blütenblättern}

Zur Überprüfung des ELISA an Pflanzenmaterial (Blütenblättern) wurden jeweils zehn blühende Rapspflanzen mittels Sprühmyzelinokulation mit fünf Sclerotinia-Isolaten infiziert. Nach einer Inkubationsdauer von 72 dpi wurden die Blütenblätter geerntet und eine Mischprobe aus den zehn Blütenblättern eines Isolates hergestellt. Bezüglich der ermittelten Proteinkonzentrationen konnten alle Proben jeden Isolates mit Hilfe des ELISA nachgewiesen werden (Abb. 18). Den stärksten Nachweis zeigten die Pflanzen die mit dem Isolat Ss 1.1 infiziert wurden. Die ermittelte Proteinkonzentration lag hier bei $150 \mathrm{ng}$. Die Pflanzen, die mit den anderen Sclerotinia-Isolaten künstlich infiziert wurden, lagen im Bereich von 95-130 ng Protein $/ \mathrm{ml}$.

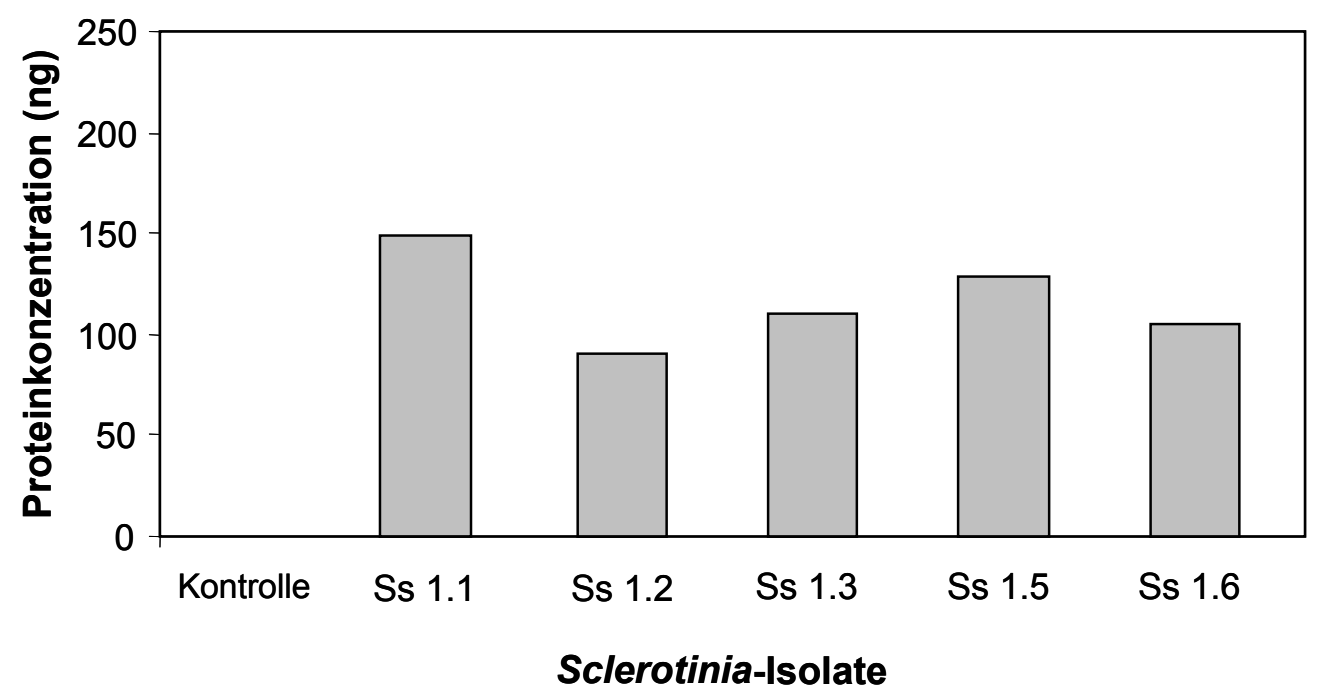

Abb. 18: ELISA Nachweis von verschiedenen Isolaten von S. sclerotiorum auf Rapsblütenblättern mit einer gesunden Blütenblattprobe als Kontrolle. 


\subsubsection{Bestimmung des Befalls von $S$. sclerotiorum auf Blütenblättern und Vergleich mit dem Befall im Feld}

Die ersten Symptome der Weißstängeligkeit sind meist erst zum Ende der Blüte im Bestand sichtbar. Eine visuelle Bonitur zum Zeitpunkt der Infektion ist daher nicht möglich. Um den Befall der Blütenblätter mit S. sclerotiorum frühzeitig im Feld nachzuweisen, wurden zu drei verschiedenen BBCH-Terminen Blütenblattproben von den Kontrollparzellen der Versuchsfelder gesammelt und auf Kontamination mit $S$. sclerotiorum untersucht. In dem ersten Versuchsjahr wurden sowohl feste als auch abgefallene Blütenblätter mit dem ELISA untersucht. Es stellte sich aber heraus, dass die Extinktionen der abgefallenen Blütenblätter erheblich höher waren als bei den festen Blütenblättern. Aufgrund der zum Teil starken Verschmutzung der abgefallenen Blütenblätter mit Bodenpartikeln wurden daraufhin in weiterführenden Tests verschiedene Bodenproben genommen und mit dem ELISA untersucht. In allen Bodenproben konnten starke positive Reaktionen gemessen werden. Um die störende Wirkung von Fremdstoffen zu unterbinden und die falsch-positiven Reaktionen so gering wie möglich zu halten, wurden die abgefallenen Blütenblätter mit einem von HEPPNER (1995) entwickelten Puffer, zum Nachweis von Verticillium dahliae im Boden, über Nacht extrahiert. Anhand der Ergebnisse zeigte sich, dass eine starke Verringerung aller Reaktionen eintrat. Nicht nur die falsch positiven Reaktionen, sondern auch die richtig positiven Reaktionen der Standardreihe und der Positivkontrolle wurden stark reduziert. In Anbetracht dieser Wirkung wurde auf eine weitere Verwendung des Puffers verzichtet. Im weiteren Untersuchungsverlauf wurden nur noch die festen Blütenblätter, die visuell keine Verunreinigungen mit Bodenpartikeln aufwiesen, zum Nachweis von S. sclerotiorum eingesetzt.

In Tabelle 10 ist die mittels ELISA gemessene Proteinmenge (ng/ml) zu drei verschiedenen Probenahmeterminen am Beispiel von 28 Versuchsstandorten im Jahr 2003 dargestellt. Insgesamt konnte bei allen untersuchten Blütenblattproben nur ein geringer Proteingehalt $(\mathrm{ng} / \mathrm{ml})$ nachgewiesen werden. Der geringste Sclerotinia-Befall zeigte sich $\mathrm{zu} \mathrm{BBCH}$ 63. Nur bei $10 \%$ aller Versuchsstandorte konnte $\mathrm{zu}$ diesem Zeitpunkt eine Kontamination festgestellt werden. Es zeigte sich weiterhin, dass mit zunehmendem Entwicklungsstadium des Rapses auch der Befall der Blütenblätter zunahm. 
Tab. 10: Ergebnis der Blütenblattuntersuchung mittels ELISA in Protein $(\mathrm{ng} / \mathrm{ml})$ an drei Probenahmeterminen $(\mathrm{BBCH}$ 63, 65, 69) im Vergleich zum Befall (\%) im Feld am Beispiel von 28 Versuchsstandorten in dem Jahr 2003.

\begin{tabular}{||l|c|c|c|c||}
\hline \multirow{2}{*}{ Standort } & BBCH 63 & BBCH 65 & BBCH 69 & Befall (\%) \\
\cline { 2 - 5 } & \multicolumn{2}{|c|}{ Protein (ng/ml) } & Feld \\
\hline \hline Senneckerode & 0 & 8 & 0 & 5 \\
\hline Vogelsang & 0 & 8 & 0 & 15 \\
\hline Hannover & 0 & 0 & 0 & 0 \\
\hline BBA (Elan) & 0 & 0 & 0 & 0 \\
\hline BBA (Zenith) & 0 & 0 & 0 & 0 \\
\hline Weißenburg & 0 & 0 & 0 & 15 \\
\hline Magdeburg & 0 & 7 & 0 & 0 \\
\hline Dessau & 0 & 0 & 0 & 0 \\
\hline Stendal & 0 & 15 & 2,6 & 0 \\
\hline Altenburg & 0 & 0 & 0 & 13 \\
\hline Großenstein & 6,4 & 0 & 0 & 5 \\
\hline Burkersdorf & 0 & 8 & 0,3 & 2 \\
\hline Deutsch-Niendorf & 0 & 0 & 0 & 1 \\
\hline Birkenmoor & 0 & 1,3 & 0 & 16 \\
\hline München (Capitol) & 12 & 11 & 0 & 0 \\
\hline München (Pronto) & 1,5 & 0 & 0 & 0 \\
\hline Lichtenhagen & 0 & 0 & 0 & 10 \\
\hline Laage & 0 & 0 & 0 & 23 \\
\hline Biestow & 0 & 0 & 0 & 31 \\
\hline Chemnitz & 0 & 0 & 0 & 0 \\
\hline Nossen & 0 & 0 & 35 & 2 \\
\hline Limbach & 0 & 1,3 & 0 & 10 \\
\hline Albrechtshain & 0 & 0 & 0 & 7 \\
\hline Bad Kreuznach & 0 & 0 & 0 & 0 \\
\hline Bingen & 0 & 0 & 0 & 0 \\
\hline Bingen 1 & 0 & 0 & 0 & 14 \\
\hline Bingen 2 & 0,8 & 0 & 23 & 22 \\
\hline Wahlbach & & & & \\
\hline
\end{tabular}

Die meisten und auch stärksten Infektionen konnten zur Mitte und zum Ende der Blüte nachgewiesen werden. Die Standorte mit den höchsten Proteinkonzentrationen waren Senneckerode, Vogelsang, Stendal, Magdeburg, Burkersdorf, Nossen, Wahlbach und München. Vergleicht man die im ELISA gemessenen Proteingehalte mit den Befallshäufigkeiten im Feld so kann man keinen Zusammenhang zwischen den beiden erhobenen Parametern erkennen. Betrachtet man die Versuchsstandorte Bingen 2 und Biestow, an denen die höchsten Befallshäufigkeiten im Feld festgestellt werden konnten, 
so konnte mittels ELISA kein oder nur ein sehr geringer Sclerotinia-Befall der Blütenblätter nachgewiesen werden. Im Gegensatz dazu zeigten Versuchsstandorte an denen ein höherer Blütenblattbefall mittels ELISA festgestellt werden konnte, wie z.B. Stendal und Nossen, keinen späteren Befall im Feld.

Um die Ergebnisse des ELISA besser bewerten zu können, wurden im Folgenden die mit der visuellen Bonitur ermittelten Befallshäufigkeiten zum Zeitpunkt der Ernte mit dem von den Blütenblattproben im ELISA ermittelten Befall aus den Jahren 2003-2004 verglichen (Abb. 19). Insgesamt wurden Proben und Befallshäufigkeit von 100 Standorten erhoben. Die ermittelten Befallswerte im ELISA zeigten keinen Zusammenhang mit den erhobenen Befallshäufigkeiten im Feld. Insgesamt blieben die gemessenen Extinktionen der Blütenblattproben in einem Bereich zwischen 0 und 3. Obwohl bei den meisten Blütenblattproben nur eine Extinktion von bis zu 0,5 gemessen werden konnte, lagen die beobachteten Befallshäufigkeiten zwischen 0-70\%. Da die Nachweisgrenze bei dem ELISA bei einer Extinktion von 0,25 erreicht ist, lagen ein Großteil der Blütenblattproben Demgegenüber konnte an einigen Standorten kein visueller Befall festgestellt werden, dennoch wurden bei diesen Blütenblattproben Extinktionen von bis zu 0.17 gemessen.

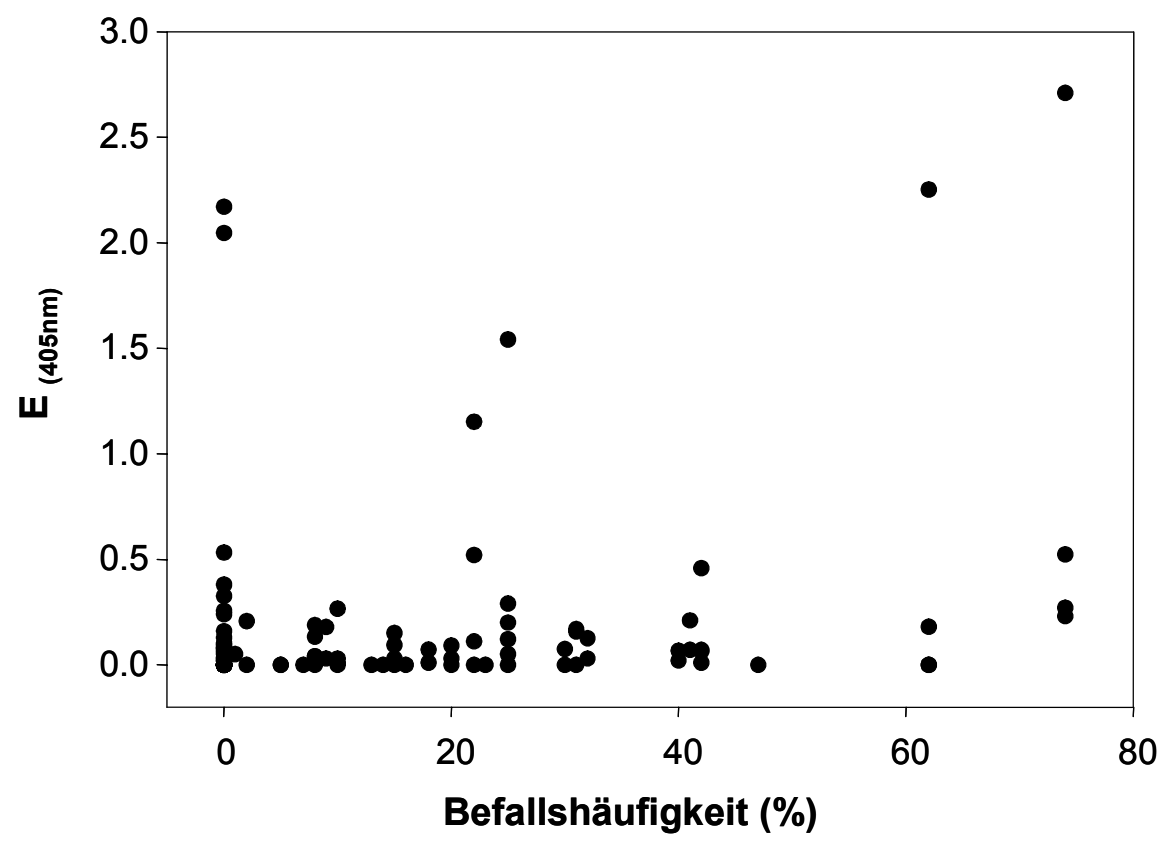

\begin{abstract}
Abb. 19: Vergleich zwischen ELISA (E 405nm) und Befallshäufigkeit (\%) zum Zeitpunkt der Ernte im Feld anhand von 100 Versuchsstandorten der Pflanzenschutzdienste der Länder in den Jahren 2003 und 2004.
\end{abstract}




\subsection{PCR}

Die Etablierung der Real-time PCR für den Nachweis von $S$. sclerotiorum auf Blütenblättern erforderte einige Vorversuche zur Optimierung der verschiedenen Reaktionsparameter, um konstante Amplifikationsprodukte und damit reproduzierbare Ergebnisse zu gewährleisten. Zunächst erfolgte die Optimierung des Reaktionsansatzes und die erste Überprüfung der Primerpaare auf Spezifität und Sensitivität in der konventionellen PCR. Erst danach wurde mit der Entwicklung der Real-time PCR begonnen.

\subsubsection{Optimierung der PCR}

\subsubsection{Magnesiumchloridkonzentration}

Magnesium-Ionen sind Cofaktoren der Polymerase. Sie beeinflussen das Primerannealing, die Trennung der Stränge bei der Denaturierung und die Produktspezifität. Die optimale Magnesiumkonzentration sollte für jede PCR neu bestimmt werden. Die Primerpaare wurden mit verschiedenen Magnesiumchloridkonzentrationen von 1; 1,5;2 und 2,5 mM getestet. Die Ausbeuten des spezifischen Amplifikates wurden durch hohe $(2,5 \mathrm{mM})$ und niedrige Magnesiumkonzentrationen $(1 \mathrm{mM})$ negativ beeinflusst. Aus der Abbildung 21 wird ersichtlich, dass eine Magnesiumkonzentration von $2 \mathrm{mM}$ für das Primerpaar optimal ist.

\subsubsection{Annealingtemperatur}

Die Annealingtemperatur richtet sich nach den eingesetzten Primern. Je nachdem, wo die Schmelztemperatur der Primer liegt, ist die Annealingtemperatur einzuordnen. Um die optimale Temperatur des Primerpaares festzustellen, wurden diese in einem AnnealingTemperaturgradient von $58-70^{\circ} \mathrm{C}$ in $2^{\circ} \mathrm{C}$ Schritten überprüft. Spezifische Amplifikationen mit einer guten Ausbeute wurden in einem Temperaturbereich von $66-70^{\circ} \mathrm{C}$ erreicht. Die optimale Annealingtemperatur wurde bei $68^{\circ} \mathrm{C}$ gewählt (Abb. 20). 


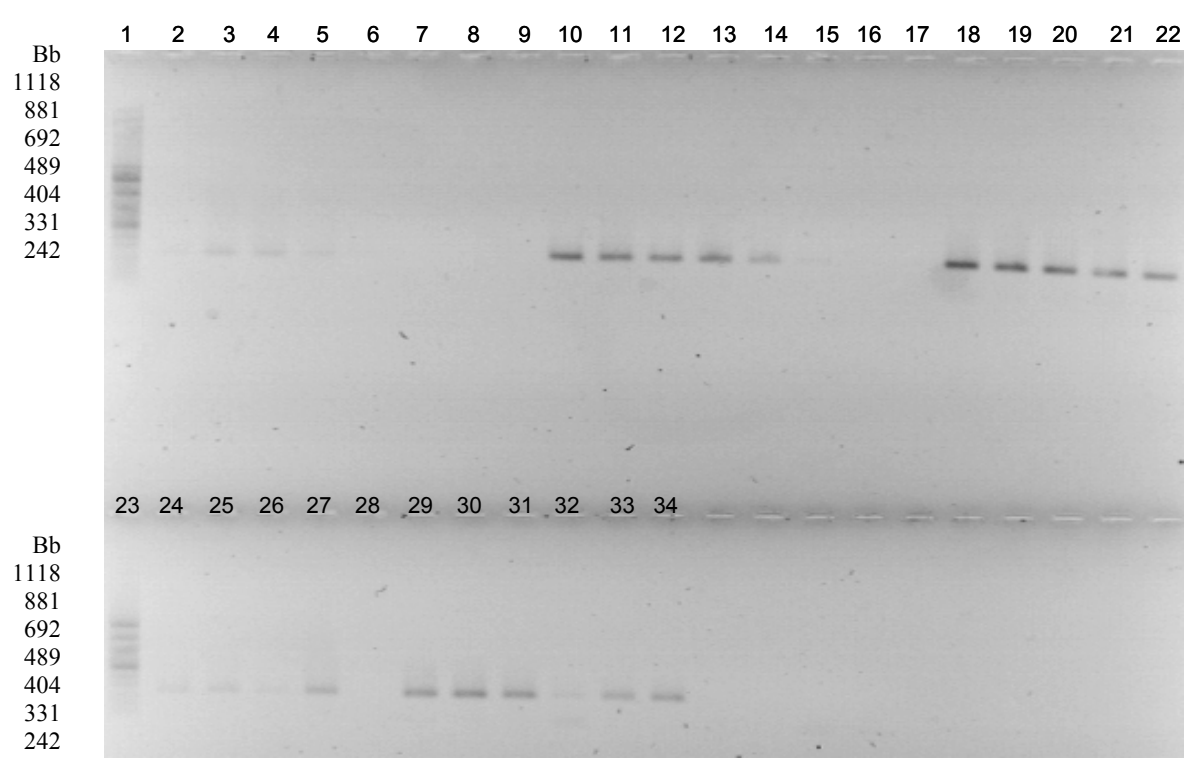

Abb. 20: Überprüfung des Primerpaars SSREW/SSREV mit DNA von S. sclerotiorum (Ss 1.6) bei verschiedenen Magnesiumchloridkonzentrationen und AnnealingTemperaturen 1) und 23) pUC 8 Marker Mix 2-9) $1.0 \mathrm{mM} \mathrm{MgCl}_{2}$ und 70-56 ${ }^{\circ} \mathrm{C}$; 10-17) $1.5 \mathrm{mM} \mathrm{MgCl}_{2}$ und $\left.70-56^{\circ} \mathrm{C}_{\text {; }} 18-26\right) 2.0 \mathrm{mM} \mathrm{MgCl}_{2}$ und $\left.70-56^{\circ} \mathrm{C}_{\text {; }} 27-34\right) 2.5 \mathrm{mM} \mathrm{MgCl}_{2}$ und $70-56^{\circ} \mathrm{C}$.

\subsubsection{Spezifität des Primerpaares}

Die Sicherheit eines Nachweisverfahrens ist dann gewährleistet, wenn eine breite Erfassung verschiedener Isolate des Erregers nachgewiesen werden kann. Die Spezifität des Primerpaares wurde mit 9 verschiedenen Sclerotinia-Isolaten aus unterschiedlichen geographischen Regionen bestimmt. In Abbildung 22a sind die gelelektrophoretische Auswertung der Isolate sowie eine Negativkontrolle dargestellt. In allen Fällen wurde ein Amplifikationsprodukt mit einer Fragmentgröße von 287 Bb gebildet (Abb. 21).

Die Spezifität der Amplifikation ist eine grundlegende Voraussetzung für den Einsatz der PCR. Für die Überprüfung der Spezifität wurden 16 verschiedener pathogener Pilzarten, die auf Rapspflanzen vorkommen können, gewählt. Aus der Abbildung 22b wird ersichtlich, dass mit der DNA aus den Isolaten der Arten Botrytis, Fusarium, Verticillium, Alternaria, Rhizoctonia und Phoma keine Amplifikation erfolgte. Nur bei den beiden Positivkontrollen der Sclerotinia-Isolate Ss 1.5 und Ss 1.6 wurde ein Amplifikationsprodukt gebildet. Die Eignung der Primer für den Nachweis von $S$. sclerotiorum wurde damit bewiesen. 

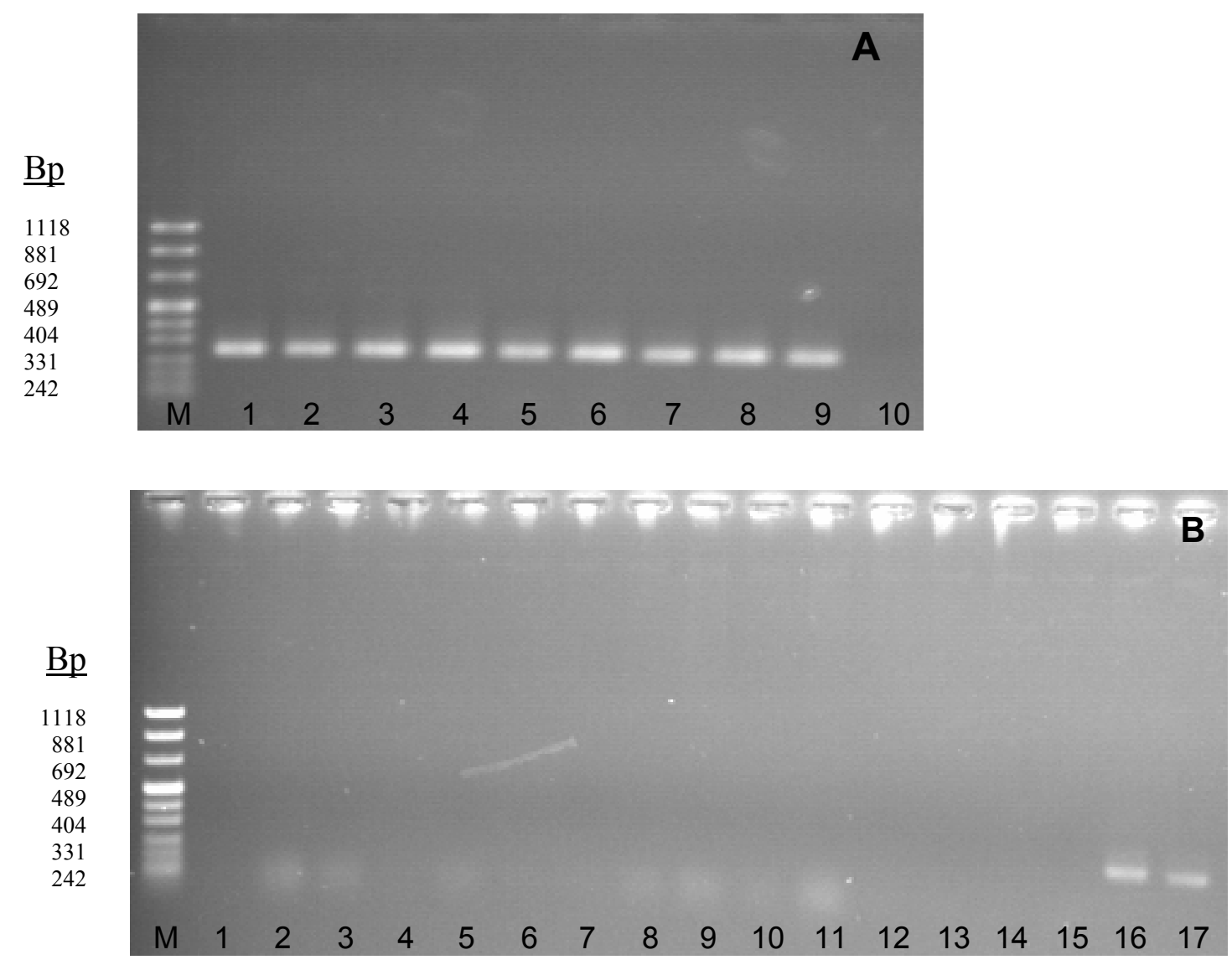

Abb. 21: Spezifität des Primerpaares SSREW/SSREV mit

A) DNA aus verschiedenen Sclerotinia-Isolaten M: Größenstandard pUC Marker Mix 8 1) Ss 1.1 ; 2) Ss 1.3 ; 3) Ss 1.5 ; 4) Ss 2.4 ; 5) Ss 3.4 ; 6) Ss 4.5; 7) Ss 5.5; 8) Ss 6.12; 9) Ss 11.4; N: Negativkontrolle.

B) mit DNA aus verschiedenen Pathogenen (M: Größenstandard pUC Marker Mix 8 1) $V$. longisporum 82; 2) $V$. longisporum 83 ; 3) $V$. longisporum 84; 4) $V$. dahliae 3 ; 5) $V$. dahliae 76; 6) $V$. albo-atrum; 7) A. brassicae; 8) P. lingam 24; 9) $P$. lingam 2 ; 10) $P$. lingam 23 ; 11) $R$. solani; 12) B. cinerea; 13) F. graminearum; 14) $F$. oxysporum; 15) $F$. culmorum; 16) S. sclerotiorum 1.5; 17) S. sclerotiorum 1.6.

\subsection{Real-time PCR}

Um eine verbesserte quantitative Aussage über den Befall der zu untersuchenden Blütenblattproben geben zu können, wurde auf der Grundlage der konventionellen PCR eine Real-time PCR zum Nachweis von S. sclerotiorum entwickelt. Diese Methode bietet im Gegensatz zur herkömmlichen PCR den Vorteil, dass eine aufwändige Auswertung der Ergebnisse mittels Agarose-Gelelektrophorese entfällt und somit sehr viel zeitsparender ist, 
zum anderen ist diese Methode sensitiver, so dass auch noch ein Nachweis von sehr geringen DNA-Mengen möglich ist. Die Durchführung der Real-time PCR erfolgte mit dem Thermocycler der Firma BioRad. Als interkalierender Farbstoff wurde SYBRGreen ${ }^{\circledR}$ (Applied Biosystems) eingesetzt. In einem ersten Schritt mussten einige Parameter für die Real-time PCR überprüft und optimiert werden, bevor ein großflächiger Einsatz mit Feldmaterial stattfinden konnte.

\subsection{1 Überprüfung der Spezifität gegenüber verschiedenen Sclerotinia- Isolaten}

Für die Überprüfung der Spezifität der Primer SSFWD und SSREV wurde DNA von verschiedenen Sclerotinia-Isolaten von unterschiedlicher geographischer Herkunft getestet. In der Abbildung 22 ist das abgeleitete Schmelzkurvenprofil (-(dRFU) / dTemp ${ }^{\circ} \mathrm{C}$ ) von 12 verschiedenen Sclerotinia-Isolaten dargestellt. Von allen Isolaten wurde 1ng DNA eingesetzt. Alle getesteten Isolate konnten mit dem Primerpaar amplifiziert werden. Die spezifischen Amplifikationsprodukte haben eine Schmelztemperatur von $89^{\circ} \mathrm{C}$. Die Wasserkontrolle zeigte keine positive Reaktion, sie blieb unterhalb des Threshold cycles (Ct-Wert). Die Schmelztemperatur lag hier bei $82^{\circ} \mathrm{C}$.

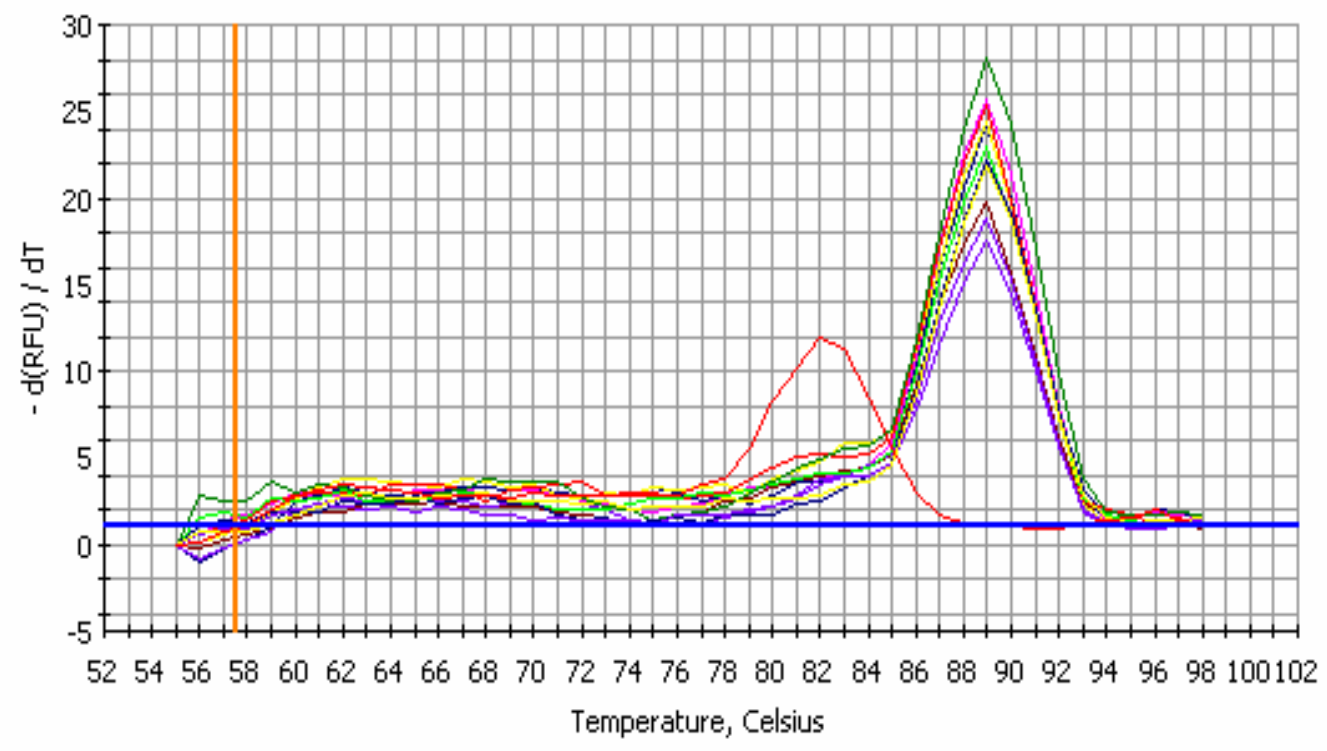

Abb. 22: Abgeleitete Schmelzkurvenprofile (-(dRFU) / dTemp $\left.{ }^{\circ} \mathrm{C}\right)$ von DNA von zehn verschiedenen Sclerotinia-Isolaten (Ss 1.1, Ss 1.2, Ss 1,3 Ss 1.5, Ss 1.6, Ss 2.4, Ss 4.5, Ss 5.5, Ss 6.11, Ss 11.4 und einer Wasserkontrolle (rot)), eingesetzt wurden 1ng DNA. 


\subsection{2 Überprüfung der Spezifität gegenüber anderen Pathogenen}

Vor einem routinemäßigen Einsatz der S. sclerotiorum Real-time PCR mit Feldproben musste überprüft werden, ob die Primer mit anderen Pilzarten kreuzreagieren. Dabei wurden verschiedene Pathogenarten ausgesucht die entweder direkt auf Raps vorkommen oder deren Sporen sich auf den Blütenblättern niederlassen können. Getestet wurden verschiedene Isolate von Alternaria alternata, Botrytis cinerea, Phoma lingam, Verticillium longisporum und dahliae sowie Fusarium graminearum, F. culmorum und F. oxysporum. Eingesetzt wurde 1 ng DNA. Aus der Abbildung 23 geht hervor, dass außer Phoma und der Wasserkontrolle, alle Isolate eine positive Reaktion in der Real-time PCR zeigen. Die nichtspezifischen Amplifikate der anderen getesteten Arten wurden aber erst zum Ende des PCR-Programms gebildet (erst nach dem 30. Zyklus). Für die positive Kontrolle wurde das Sclerotinia-Isolat Ss 1.5 gewählt, der Ct -Wert lag bei 22.3 Zyklen.

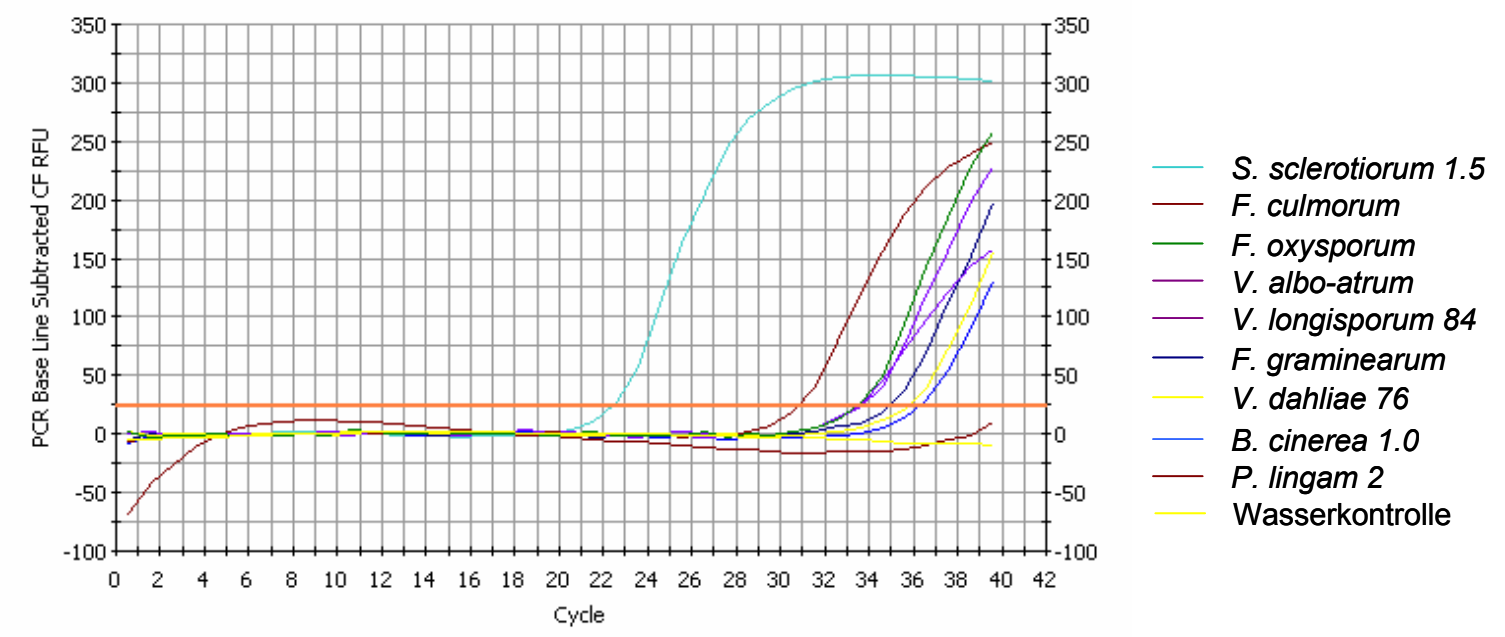

Abb. 23: Real-time PCR mit SYBR Green und dem Primerpaar SSFWD/SSREV für eine spezifische und quantitative Amplifikation von DNA von verschiedenen Pathogenen (Alternaria alternata, Botrytis cinerea, Phoma lingam, Verticillium dahliae, Verticillium longisporum, Fusarium culmorum, F. graminearum und F. oxysporum), einer positiv Kontrolle (Sclerotinia-Isolat Ss 1.5) und einer negativ Kontrolle (Wasserkontrolle). Eingesetzt wurden 1ng DNA.

Bei der Betrachtung der Schmelzkurven wird deutlich, dass sich bei keinem der getesteten Isolate ein spezifisches Amplifikationsprodukt ergab (Abb. 24). Bei allen Arten wiesen die Amplifikate eine geringere Schmelztemperatur auf als das spezifische Produkt des 
Sclerotinia-Isolates Ss 1.5. Bei der Wasserprobe konnte kein Schmelzpunkt ermittelt werden.

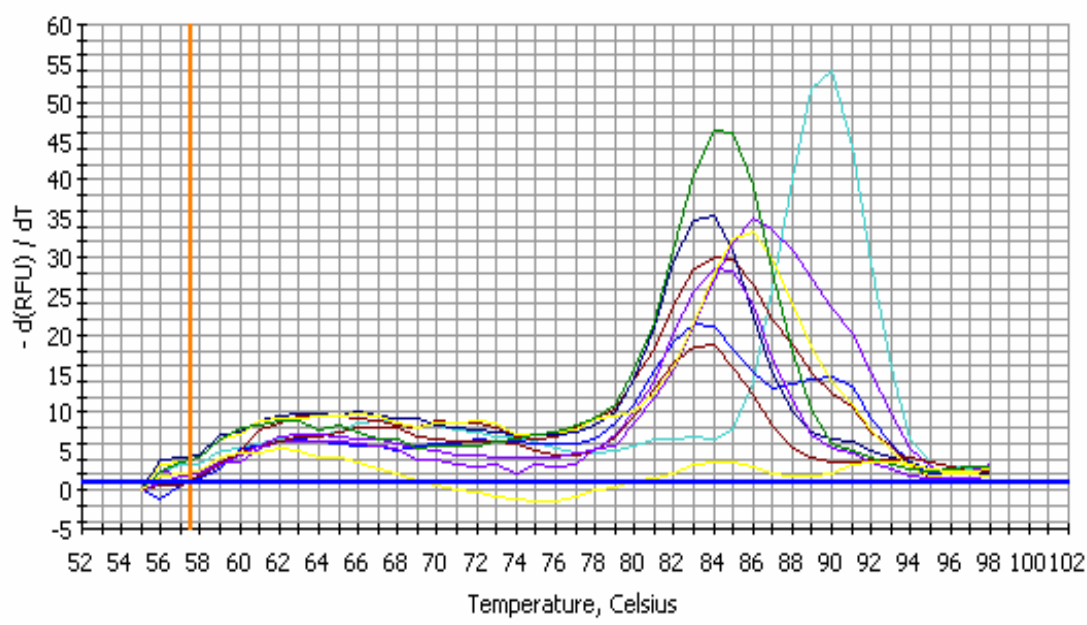

S. sclerotiorum 1.5

- F. culmorum

- F. oxysporum

- V. albo-atrum

V. longisporum 84

- F. graminearum V. dahliae 76

B. cinerea 1.0

- P. lingam 2 Wasserkontrolle

\begin{abstract}
Abb. 24: Abgeleitete Schmelzkurvenprofile (-(dRFU) / dTemp $\left.{ }^{\circ} \mathrm{C}\right)$ von DNA von verschiedenen anderen Pathogenen (Alternaria alternata, Botrytis cinerea, Phoma lingam, Verticillium dahliae, Verticillium longisporum, Fusarium culmorum, $F$. graminearum und $F$. oxysporum), einer positiv Kontrolle (Sclerotinia-Isolat Ss 1.5) und einer negativ Kontrolle (Wasserkontrolle). Eingesetzt wurden 1ng DNA.
\end{abstract}

\title{
3.6.3 Ermittlung der Nachweisgrenze
}

Eine hohe Empfindlichkeit des Tests ist insofern wichtig, da es sich gerade beim Nachweis von S. sclerotiorum auf Blütenblättern um sehr geringe DNA-Mengen handelt. Als Maß für die Empfindlichkeit dient die Nachweisgrenze, d.h. die gewonnene DNA-Menge aus Sporen oder Myzel, die unter den verwendeten Testbedingungen noch nachgewiesen werden kann.

Zur Überprüfung der Empfindlichkeit der S. sclerotiorum Real-time PCR wurde eine Verdünnungsreihe von 1000 ng, 100 pg, 10 pg und 1 pg aus Myzel DNA sowie eine weitere Verdünnungsreihe von DNA aus 1000, 100 und 5 Ascosporen hergestellt. Die Nachweisgrenze lag bei 5 Sporen (Abb. 26). 
a

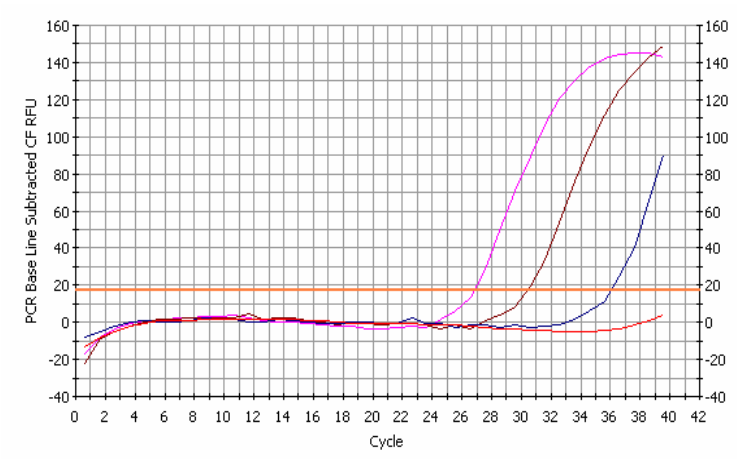

b
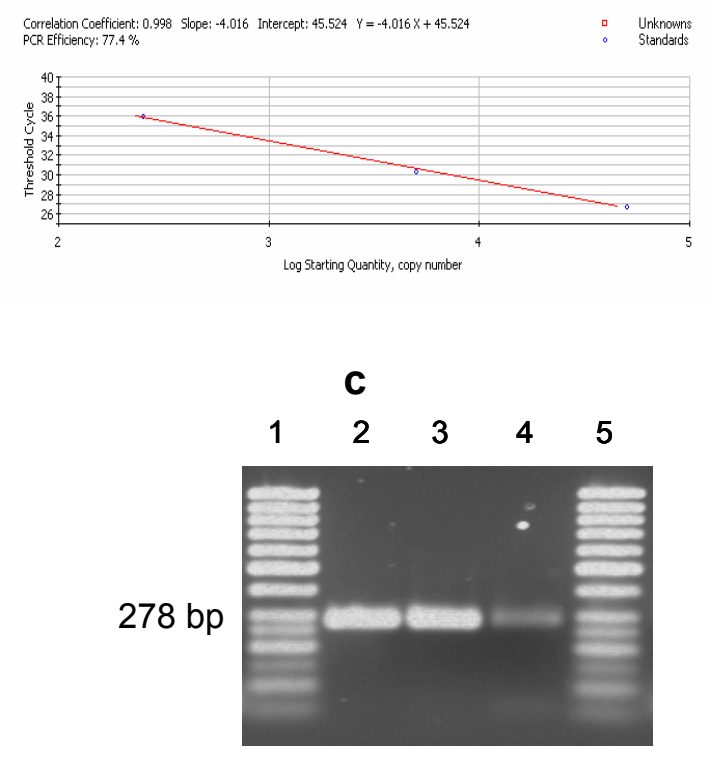

b

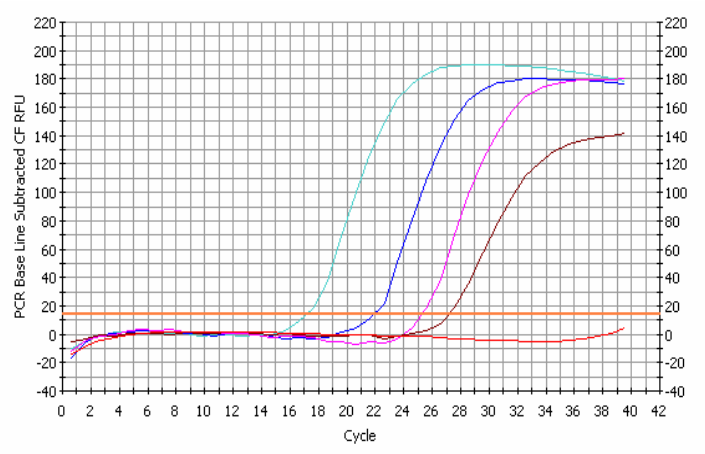

e
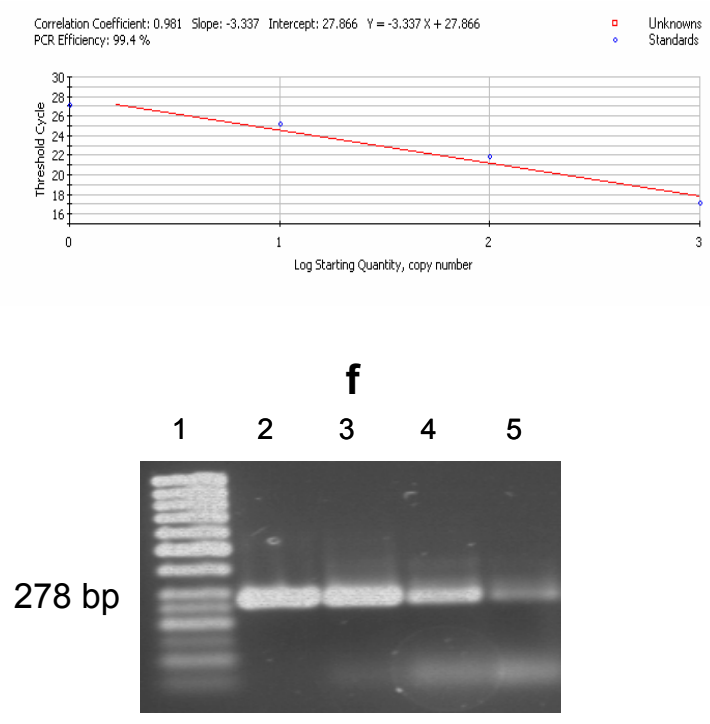

Abb. 25: a) Amplifikationskurve der Real-time PCR mit SYBR Green und dem spezifischen Primerpaar SSFWD/SSREV vom S. sclerotiorum DNA-Standard (von 1000, 100 und 5 Sporen) aus Ascosporen und einer Wasserkontrolle (rot). Aus dem Fluoreszenzschwellenwert (CF RFU) und der Zyklenanzahl ergeben sich die Ct-Werte der einzelnen Proben. Von jeder Standardprobe wurde $1 \mu 1$ eingesetzt.

b) Standardkurve des Sporenstandards (von 1000, 100 und 5 Sporen).

c) Agarosegel des Sporenstandards 1+5) Marker 2) 1000 Sporen 3) 100 Sporen 4) 5 Sporen.

d) Amplifikationskurve der Real-time PCR mit SYBR Green und dem Primerpaar SSFWD/SSREV vom S. sclerotiorum Myzelstandard (von $1 \mathrm{ng}, 100 \mathrm{pg}, 10 \mathrm{pg}$ und $1 \mathrm{pg}$ ) vom Sclerotinia-Isolat Ss 1.5 und einer Wasserkontrolle (rot). Aus dem Fluoreszenzschwellenwert (CF RFU) und der Zyklenanzahl ergeben sich die Ct-Werte der einzelnen Proben. Von jeder Standardprobe wurde $1 \mu 1$ eingesetzt.

e) Standardkurve des Myzelstandards (1 ng, 100 pg, 10 pg und $1 \mathrm{pg}$ ).

f) Agarosegel des Myzelstandards von dem Isolat Ss 1.5 1) Marker 2) 1ng 3) 100 pg 4) 10 pg

5) $1 \mathrm{pg}$. 
Aufgrund der geringen Amplifikationsmengen wurde der Ct-Wert bei 5 Sporen erst sehr spät im Reaktionslauf, beim 36. Zyklus, überschritten. Im Vergleich dazu lagen die CtWerte beim konventionellen Standard aus DNA von Pilzmyzel aufgrund der höheren DNA Mengen deutlich niedriger. Der kleinste Myzelstandard mit 1 pg DNA, erreichte den CtWert beim 27. Zyklus. Der Korrelationskoeffizient des Sporenstandards lag bei 0,998 und die Effizienz bei 77,4\%. Im Vergleich dazu lagen der Korrelationskoeffizient des Myzelstandards bei 0,98 und die Effizienz bei 99,4\%. Beim Einsatz der Real-time PCR mit Blütenblattproben vom Feld wurden immer beide Standards mitgetestet, da man sowohl von Ascosporen auf den Blütenblättern als auch von den ersten gebildeten Myzelkissen in den Blütenblättern ausgehen kann.

\subsubsection{Bestimmung des Befalls von $S$. sclerotiorum auf Blütenblättern und Vergleich mit dem Befall im Feld}

Um die Eignung der Real-time PCR für den sensitiven Nachweis von S. sclerotiorum in planta zu überprüfen, wurden Blütenblattproben von Versuchsstandorten mit unterschiedlich starken Befallshäufigkeiten untersucht. Wie unter Kapitel 3.3 beschrieben, wurden aus 15 Blütenblättern je Probeentnahmestelle ein Homogenat hergestellt und aus diesem die DNA extrahiert und direkt in der Real-time PCR eingesetzt. Es wurden nur fest an der Blüte haftende Blütenblätter zum BBCH-Stadium 65 untersucht. An jedem Versuchsstandort wurden an 3 (Praxisschlag) bzw. 4 Stellen (Exaktversuch mit vier Wiederholungen) Proben entnommen. In Tabelle 11 sind die Ergebnisse der Real-time PCR und des pH-Tests im Vergleich zum Befall im Feld an fünf verschiedenen Standorten dargestellt. Anhand der Ct-Werte der befallenen Proben wird deutlich, dass die zu amplifizierenden Produkte erst zu einem sehr späten Zeitpunkt, während des PCR-Laufs, den Schwellenwert überschreiten. Demnach kann davon ausgegangen werden, dass es sich sogar in stark befallenen Proben nur um geringe Mengen an nachzuweisender DNA handelt. Die Ct-Werte lagen bei allen befallenen Proben zwischen dem 30. und dem 37. Zyklus. Diese Werte sind vergleichbar mit einer Ascosporenkonzentration von 5 oder weniger Sporen (Ct-Wert beim 32. Zyklus). Einen Bezug zum Befall im Feld lässt sich aus den Ergebnissen der Real-time PCR nur schwer ableiten. Zwar konnten an den stark befallenen Standorten Goslar und Leinefelde auch mittels Real-time PCR ein Befall der 
Blütenblätter nachgewiesen werden, doch ist eine Quantifizierung des Befalls, aufgrund der geringen Nachweismengen nicht möglich.

Tab. 11: Nachweis von S. sclerotiorum in Blütenblättern mittels Real-time PCR (Ct-Wert) und Klassifikation nach dem pH-Test (Werte von 0-3) im Vergleich zum Befall im Feld (\%) an fünf verschiedenen Standorten aus den Jahren 2004 und 2005. N/A = kein Nachweis mittels Real-time PCR.

\begin{tabular}{|l|c|c|c|c|}
\hline $\begin{array}{c}\text { Versuchsstandort } \\
\text { und Jahr }\end{array}$ & Probe & $\begin{array}{c}\text { Real-time PCR } \\
\text { (Ct-Wert) }\end{array}$ & $\begin{array}{c}\text { Klassifikation } \\
\text { nach pH-Test } \\
\mathbf{( 0 - 3 )}\end{array}$ & $\begin{array}{c}\text { Befall } \\
\text { (\%) }\end{array}$ \\
\hline Sömmerda (2004) & 1 & N/A & 3 & \\
& 2 & N/A & 1 & $8 \%$ \\
\hline Leinefelde (2004) & 1 & 37.8 & 3 & \\
& 2 & 35.8 & 3 & $74 \%$ \\
& 3 & 34.9 & 3 & \\
\hline Goslar (2004) & 1 & N/A & 2 & \\
& 2 & 34.4 & 2 & $25 \%$ \\
& 3 & 36.8 & 2 & \\
\hline Braunschweig & 4 & 34.3 & 2 & \\
(2005) & 1 & N/A & 0 & \\
& 2 & 34.7 & 1 & \\
& 3 & 33.3 & 0 & \\
\hline Kiel (2005) & 4 & N/A & 0 & \\
& 1 & N/A & 2 & \\
& 2 & N/A & 1 & \\
& 3 & 30.9 & 2 & \\
& 4 & N/A & 1 & \\
\hline
\end{tabular}

Anhand des Befalls der einzelnen untersuchten Proben je Versuchsstandort lässt sich aber ähnlich dem pH-Test folgern, wie hoch der zu erwartende Befall im Feld sein kann. So konnte in keiner Probe am Versuchsstandort Sömmerda S. sclerotiorum nachgewiesen werden, der anschließende Befall im Feld blieb dementsprechend auf einem sehr geringen Niveau. Ein ähnliches Ergebnis konnte auch am Versuchsstandort Kiel festgestellt werden. Bei den Versuchsstandorten Leinefelde und Goslar konnte mittels Real-time PCR in fast jeder Probe S. sclerotiorum nachgewiesen werden, infolgedessen konnte im Feld ein hoher Befall der Pflanzen beobachtet werden. Die amplifizierten DNA-Mengen von $S$. sclerotiorum am Standort Braunschweig geben jedoch keine Erklärung des geringen 
Befalls im Feld zum Zeitpunkt der Ernte. Zusammenfassend ist zu berücksichtigen, dass es sich um Befallserhebungen des gesamten unbehandelten Schlages bzw. der Kontrollvariante handelt. Dagegen werden bei den Blütenblattproben nur Stichproben eines Schlages bzw. einer Variante untersucht.

Ein Vergleich der Real-time PCR und des pH-Tests ist nicht durchführbar, da zum Nachweis von S. sclerotiorum eine unterschiedliche Anzahl von Blütenblättern untersucht wurde. Bei der Real-time PCR wurde ein Homogenat aus fünfzehn Blütenblättern verwendet, während beim $\mathrm{pH}$-Test nur drei Blütenblätter pro Probeentnahmepunkt untersucht wurden.

\subsection{Boxentest}

\subsubsection{Ermittlung der Minimumtemperatur für eine Ascosporeninfektion}

Mit Hilfe des Boxentests konnte gezeigt werden, dass die Infektionen von S. sclerotiorum durch Ascosporen besonders temperaturabhängig sind. So konnten unter $6^{\circ} \mathrm{C}$ keine Infektionen von Ascosporen auf den Blattachseln beobachtet werden. Die Ausbreitung der Krankheit verlief bei niedrigen Temperaturen wesentlich langsamer. Bei einer Temperatur von $8-10^{\circ} \mathrm{C}$ konnte nach 14 Tagen konnten lediglich Läsionen am Stängel um die Infektionsstelle beobachtet werden. Bei Temperaturen von über $18^{\circ} \mathrm{C}$ war innerhalb des Untersuchungszeitraums der gesamte Stängel mit Myzel bewachsen (Abb. 26). In dem Bereich von $16^{\circ} \mathrm{C}$ bis $20^{\circ} \mathrm{C}$ konnte nach 14 Tagen eine starke Luftmyzelbildung beobachtet werden. $\mathrm{Ab} 26^{\circ} \mathrm{C}$ konnte keine Infektion mit $S$. sclerotiorum durch Ascosporen beobachtet werden.
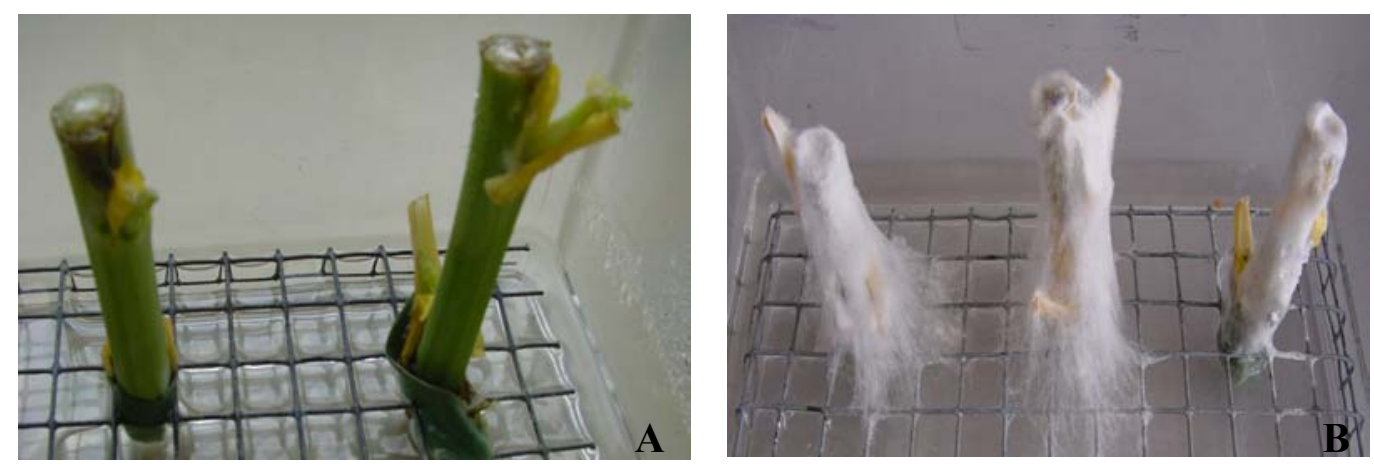

Abb. 26: Myzelwachstum nach Ascosporeninokulation eines Blütenblattes in der Blattachsel bei $8^{\circ} \mathrm{C}(\mathbf{A})$ und $18^{\circ} \mathrm{C}(\mathbf{B})$ und einer rel. Luftfeuchte von $99 \%, 14$ dpi. 
Weiterhin konnte festgestellt werden, dass die Blütenblätter eine wesentliche Rolle bei der Infektion mit Ascosporen von S. sclerotiorum spielen. Ab der Mindesttemperatur konnte bei allen Rapsstängeln eine Infektion beobachtet werden, bei denen die Sporensuspension auf ein Blütenblatt in der Blattachsel pipettiert wurde. Demgegenüber zeigten nur 23\% der Stängel einen Befall, bei denen die Sporensuspension direkt auf die Blattachsel getan wurde.

In Abbildung 27 ist das Temperaturoptimum für eine Ascosporeninfektion dargestellt. Erst $\mathrm{ab}$ einer Temperatur von $7^{\circ} \mathrm{C}$ finden erste Infektionen an der Pflanze statt mit zunehmendem Anstieg der Temperatur nehmen auch die Infektionen an der Pflanze zu. Das Temperaturoptimum ist in einem Bereich von $16-22^{\circ} \mathrm{C}$ erreicht, bei weiter zunehmender Temperatur kann ein Rückgang der Ascosporeninfektionen beobachtet werden. Oberhalb von $26^{\circ} \mathrm{C}$ findet keine Infektion statt.

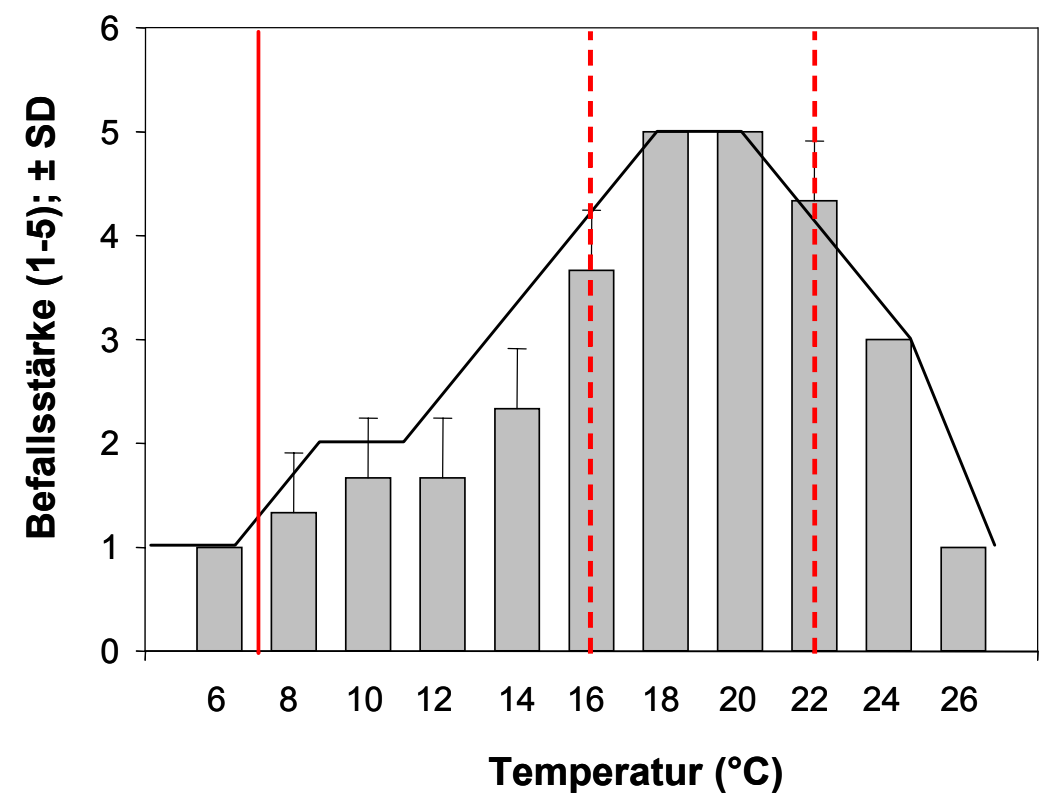

Abb. 27: Befallsstärke der Rapsstängel bei unterschiedlichen Temperaturen nach Ascosporeninfektion von S. sclerotiorum. Temperaturminimum und -optimum durch die rote Linie dargestellt. Befallsstärke: $1=$ kein Befall; $2=$ Läsionen um die Infektionsstelle in der Blattachsel; $3=$ Myzelbildung am Stängel um die Infektionsstelle; 4 = Myzelbildung umfasst die Hälfte des Stängelsegments; 5 = Luftmyzelbildung um den ganzen Stängel. SD = Standardabweichung. 


\title{
3.8 Einfluss von Standortfaktoren und pflanzenbaulichen Maßnahmen auf den Befall
} mit S. sclerotiorum

\subsubsection{Analyse der schlagspezifischen Daten aus dem gesamten Datensatz}

Bei der Analyse des gesamten Datensatzes wurde anhand von 650 Versuchsstandorten der Pflanzenschutzdienste der Länder aus den Jahren 1994-2004 der Einfluss verschiedener schlagspezifischer Faktoren wie Aussaattermin, Vorfrucht, Sorte und Jahr auf den Befall mit S. sclerotiorum untersucht.

Für die statistische Analyse wurden die Aussaattermine in drei Klassen, in früher $(<18$. August), mittlerer (18.-26. August) und später Aussaattermin ( $>26$. August) eingeteilt. Die Ergebnisse der varianzanalytischen Berechnung zeigen, dass über die einzelnen Bundesländer hinweg der Befall mit S. sclerotiorum in den Spätsaaten zunimmt (Abb. 28). So konnte in den Rapsbeständen, die vor dem 18. August ausgesät wurden, eine signifikant geringere Befallshäufigkeit ermittelt werden, als bei dem späteren Aussaattermin. Keine signifikanten Unterschiede konnten zwischen dem frühen und dem mittleren Termin festgestellt werden.

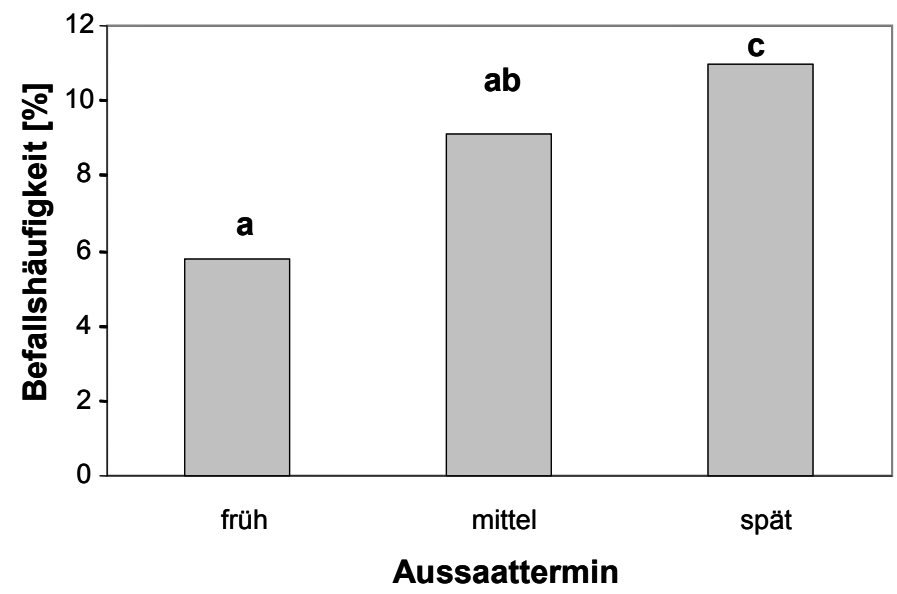

\begin{abstract}
Abb. 28: Einfluss des Aussaattermins auf die Befallshäufigkeit von $S$. sclerotiorum (650 unbehandelte Kontrollen aus Feldversuchen der Pflanzenschutzdienste der Länder 1994-2004). Unterschiedliche Buchstaben kennzeichnen signifikante Unterschiede, $\mathrm{p} \leq$ 0,05 (Tukey-Test).
\end{abstract}

Bei der Einteilung der Vorfrucht konnte Raps als Vorfrucht ausgeschlossen werden. Die Vorfrüchte wurden in die Gruppen Gerste, Weizen und weitere Vorfrüchte (alle weiteren 
Feldfrüchte, Brache und Wiesen) eingeteilt. Aus Abbildung 29 geht hervor, dass in Raps nach Weizen, ein höheres Befallsrisiko zu erwarten ist, als in Raps nach Gerste. Ein signifikanter Einfluss der Vorfrucht auf die Befallshäufigkeit konnte aber nicht festgestellt werden.

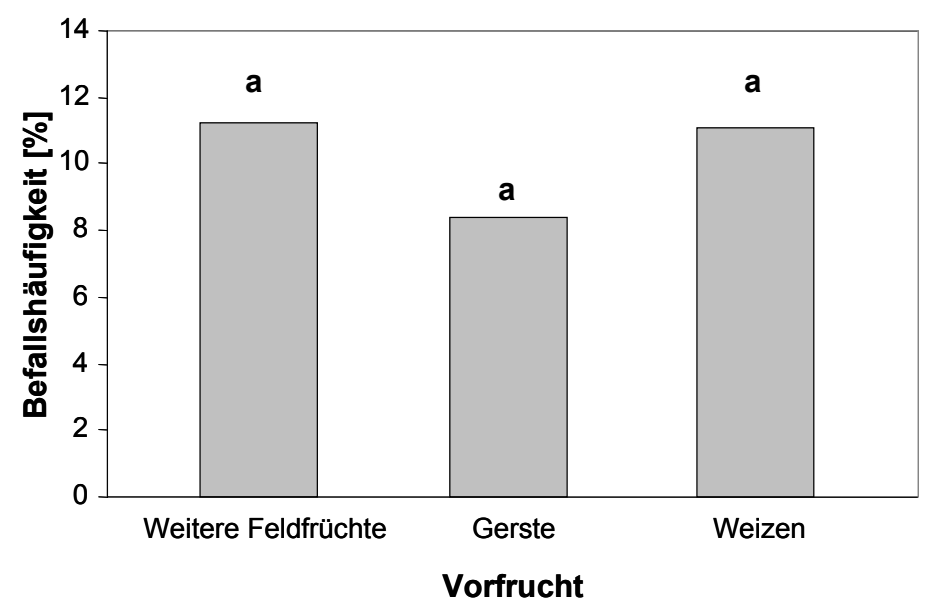

\begin{abstract}
Abb. 29: Einfluss der Vorfrucht auf die Befallshäufigkeit von S. sclerotiorum (650 unbehandelte Kontrollen aus Feldversuchen der Pflanzenschutzdienste der Länder 1994-2004), Unterschiedliche Buchstaben kennzeichnen signifikante Unterschiede, $\mathrm{p} \leq 0,05$ (Tukey-Test).
\end{abstract}

Bei der statistischen Auswertung von 13 Sorten konnte ein signifikanter Einfluss auf den Befall festgestellt werden (Abb. 30). Die Untersuchung zeigte, dass die beiden Sorten Panther und Pronto einen signifikant höheren Befall in den letzten zehn Jahren aufwiesen, als die übrigen Sorten. Demgegenüber wurden bei der Sorte Bristol signifikant geringere Befallshäufigkeiten erreicht. Eine ähnliche Einstufung der Sorten ist auch in der Bundessortenliste aufgeführt. So wurden die Sorten Panther und Pronto mit der Note 7 eingestuft (ANONYM, 2004). Zwischen den übrigen Sorten konnten keine Unterschiede hinsichtlich der Anfälligkeit für S. sclerotiorum festgestellt werden. 


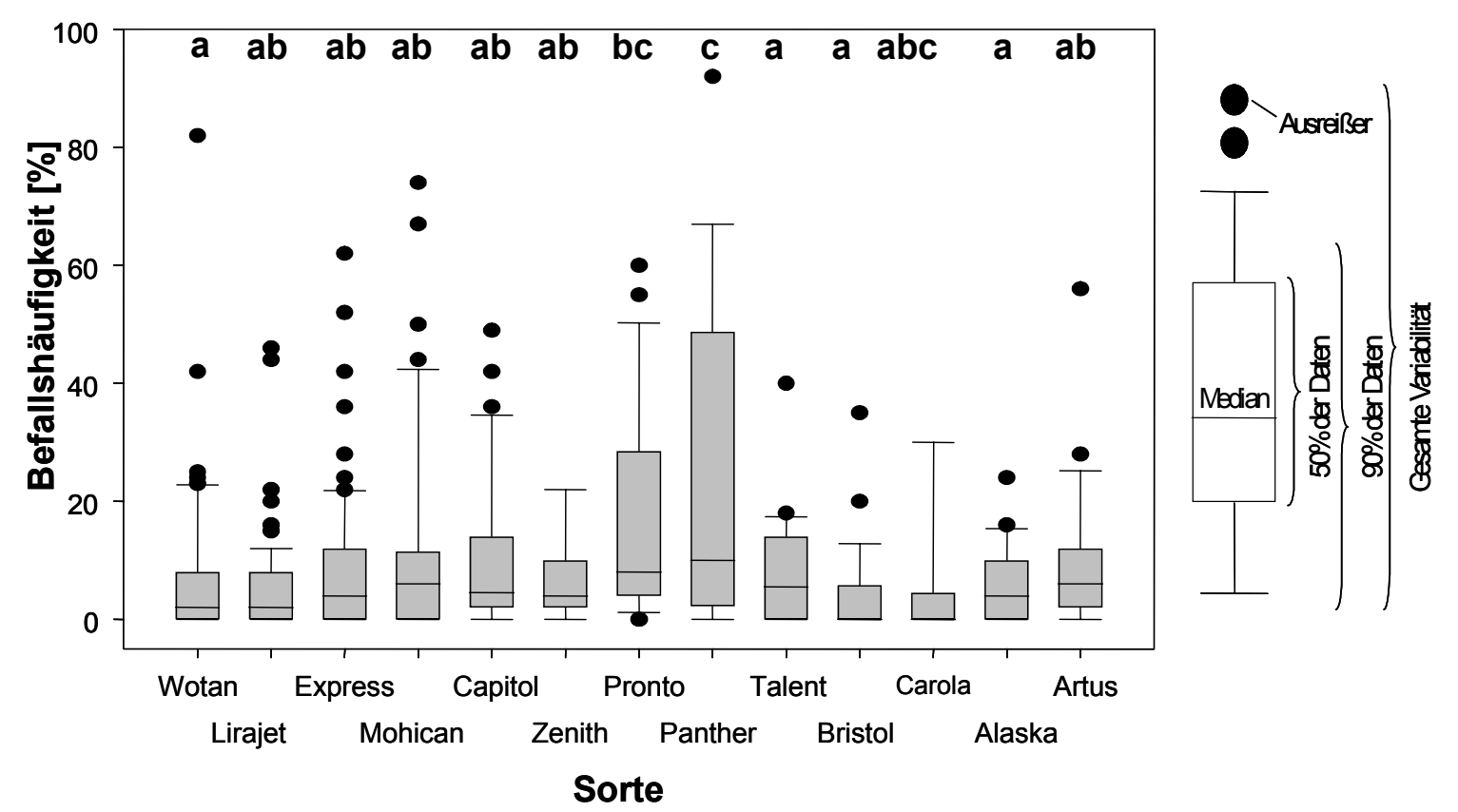

Abb. 30: Einfluss der Sorte auf den Befall mit S. sclerotiorum anhand von 650 unbehandelte Kontrollen aus Feldversuchen der Pflanzenschutzdienste der Länder 1994-2004. Unterschiedliche Buchstaben kennzeichnen signifikante Unterschiede, $\mathrm{p} \leq$ 0,05 (Tukey-Test).

Für die Befallsentwicklung von S. sclerotiorum im Winterraps ist die Witterung von entscheidender Bedeutung. Besonders die Witterungsfaktoren Niederschlag, relative Luftfeuchte und Temperatur spielen eine wichtige Rolle bei der Infektion und Ausbreitung der Weißstängeligkeit. In Abbildung 31 ist der Jahres- bzw. Witterungseinfluss aus den Jahren (1994-2004) über alle Regionen dargestellt. Dabei ist zu erkennen, dass die Krankheit in Deutschland in den letzten Jahren in der Tendenz stetig zugenommen hat. In einigen Jahren kann aufgrund extremer Witterung ein Befallsanstieg (Jahr 1997), beziehungsweise ein starker Rückgang der Krankheit (Jahr 2003) verzeichnet werden. Die Jahre 1997, 2002 und 2004 zeichneten sich durch signifikant höhere Befallshäufigkeiten gegenüber den anderen Jahren aus. Die übrigen Jahre erreichten mittlere Befallshäufigkeiten, die sich nicht signifikant voneinander unterschieden. Jahre mit einem besonders niedrigen Befallsauftreten waren 1994 und 2003. 


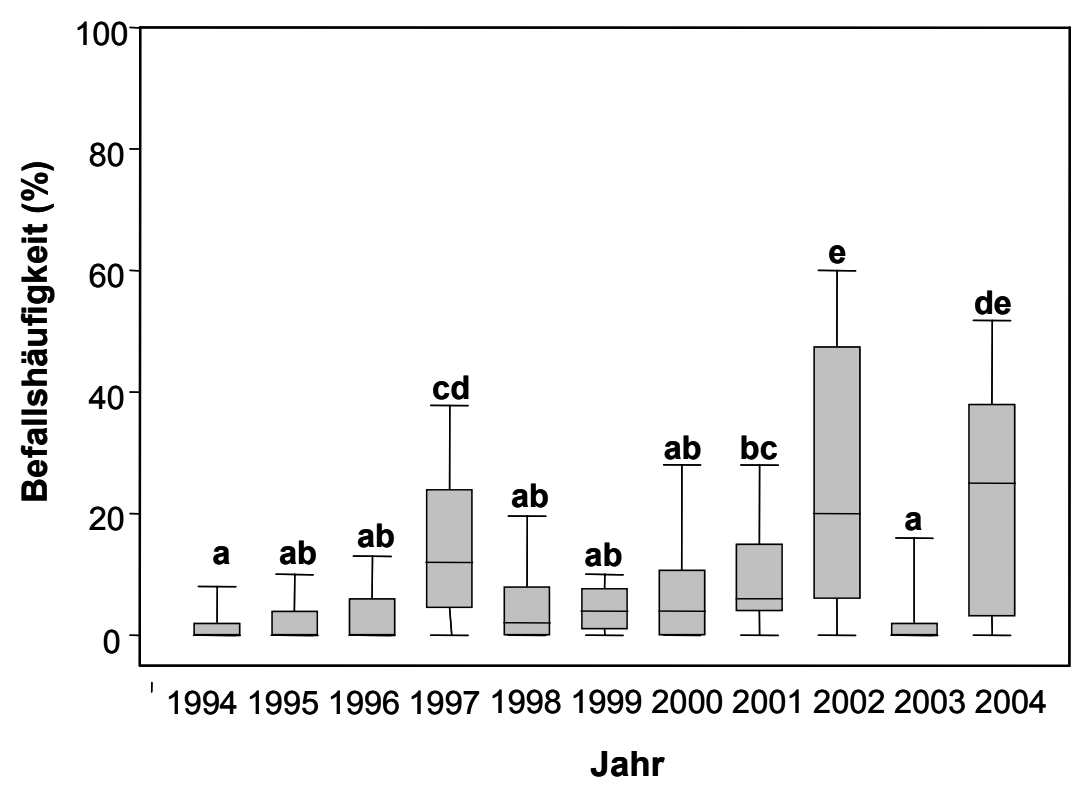

\begin{abstract}
Abb. 31: Einfluss des Jahres auf die Befallshäufigkeit von S. sclerotiorum (650 unbehandelte Kontrollen aus Feldversuchen der Pflanzenschutzdienste der Länder 1994-2004). Unterschiedliche Buchstaben kennzeichnen signifikante Unterschiede, $\mathrm{p} \leq$ 0,05 (Tukey-Test).
\end{abstract}

\title{
3.8.2 Analyse der schlagspezifischen Daten aus einzelnen Datensätzen der Pflanzenschutzdienste der Länder
}

Der Rapsanbau konzentriert sich fast ausschließlich auf Standorte mit tiefgründigen guten Böden. Aufgrund der starken Durchwurzelung des Bodens sind schwere und stark tonige Böden ungeeignet für den Anbau von Raps. In die varianzanalytische Berechnung wurde nur der Datensatz von Sachsen-Anhalt mit einbezogen, da in der übrigen Datensammlung der Faktor Bodenart nicht mit berücksichtigt wurde. Vor der Analyse wurde die Bodenart in die vier Gruppen Lößböden, lehmige Sandböden (D3/4), sandige Lehmböden (D5/6) und in Überschwemmungsböden (Alluvial), eingeteilt. Die Ergebnisse zeigen, dass die Befallshäufigkeit von den alluvialen Böden bis hin zu den Lößböden ansteigt (Tab. 12).

Aufgrund der immer größer werdenden Bedeutung der Kulturpflanze Raps als Öllieferant, dehnt sich auch die Anbaufläche von Raps immer weiter aus. Zudem wird die Fruchtfolgegestaltung bezüglich des Winterrapses besonders in den traditionellen Anbaugebieten immer enger. Für die statistische Auswertung des Einflusses der 
Fruchtfolge auf den Befall mit S. sclerotiorum wurde der Anteil Raps in zweijährige, dreijährige und mehrjährige Fruchtfolgen eingeteilt. Die Analyse zeigte, dass die Fruchtfolge einen signifikanten Einfluss auf den Befall ausübt. Dabei lag der Befall in den engen Fruchtfolgen deutlich höher, als bei einer dreijährigen oder mehrjährigen Fruchtfolge.

Tab. 12: Einfluss verschiedener schlagspezifischer Parameter auf den Befall mit $S$. sclerotiorum ermittelt anhand von Datensätzen der Pflanzenschutzdienste der Länder (PSA Jena für die Region Thüringen, SLL Dresden für den Bereich Sachsen, LPP Mainz für Rheinland-Pfalz, LWK Hannover, Bezirksstelle Northeim, LBP Freising Weihenstephan für Bayern, PSA Mecklenburg-Vorpommern, Amt für ländliche Räume Kiel, Landesanstalt für Verbraucherschutz und Landwirtschaft Brandenburg, Landesanstalt für Landwirtschaft und Gartenbau Sachsen-Anhalt).

\begin{tabular}{|c|c|c|c|c|}
\hline Faktor & Einstufung & $\mathbf{n}$ & $\%$ Befall & F-Wert \\
\hline \multirow[t]{4}{*}{ Bodenart } & Lößboden & 161 & 9,7 & $8,7 * * *$ \\
\hline & Sandiger Boden & 79 & 6,5 & \\
\hline & Sandiger Lehmboden & 37 & 7 & \\
\hline & Alluvial & 34 & 5,7 & \\
\hline \multirow[t]{3}{*}{ Fruchtfolge } & mehr als 3 jährig & 81 & 9,7 & $4,9^{*}$ \\
\hline & 3 jährig & 13 & 12 & \\
\hline & 2 jährig & 5 & 25 & \\
\hline \multirow[t]{3}{*}{ Bestandesdichte } & Gering $\left(<30 \mathrm{Pfl} / \mathrm{m}^{2}\right)$ & 24 & 6,5 & 2,8 n.s. \\
\hline & Mittel (30-50 Pfl/ $\left./ \mathrm{m}^{2}\right)$ & 37 & 9 & \\
\hline & $\operatorname{Hoch}\left(>60 \mathrm{Pfl} / \mathrm{m}^{2}\right)$ & 22 & 14 & \\
\hline \multirow[t]{3}{*}{ N-Düngung } & Gering $(<175 \mathrm{~kg} / \mathrm{ha})$ & 15 & 14,3 & 0,7 n.s. \\
\hline & Mittel (175-220 kg/ha) & 19 & 24,4 & \\
\hline & $\operatorname{Hoch}(>220$ kg/ha) & 11 & 21,5 & \\
\hline \multirow[t]{2}{*}{ Bodenbearbeitung } & Pflug & 67 & 10,1 & 0,3 n.s. \\
\hline & Pfluglos & 32 & 12 & \\
\hline
\end{tabular}

Die Bestandesdichte spielt eine wichtige Rolle in der Bestandesführung des Rapses. Ziel ist es, eine optimale Bestandesdichte für den jeweiligen Standort zu erreichen. Eine Reihe von Faktoren, wie zum Beispiel der Aussaattermin, Aussaatstärke, Sorte, Düngung und Bodenbearbeitung bestimmen die Höhe der Bestandesdichte. Bei der statistischen Analyse 
konnte kein signifikanter Einfluss der Bestandesdichte auf den Befall festgestellt werden. Es zeigte sich dennoch, dass mit steigender Bestandesdichte die Befallshäufigkeit zunimmt.

Die N-Düngung beeinflusst im Wesentlichen das Wachstum der Pflanze und somit auch indirekt die Bestandesdichte. Für die statistische Auswertung des Datensatzes wurde die NDüngung in drei Gruppen, geringe, mittlere und hohe N-Düngung eingeteilt. Über diese Düngungsstufen konnte kein signifikanter Unterschied bezüglich des Befalls festgestellt werden. Der höchste Befall konnte bei der mittleren N-Düngungsstufe beobachtet werden.

Bei der Beurteilung der Bodenbearbeitung wurde diese zuvor in die Gruppen wendende Bodenbearbeitung mit dem Pflug und nichtwendende Bodenbearbeitung mit dem Grubber eingeteilt. Bei der Bodenbearbeitung konnte kein statistischer Einfluss auf den Befall mit S. sclerotiorum festgestellt werden. Jedoch konnte die Tendenz beobachtet werden, dass bei pflugloser Bodenbearbeitung die Befallshäufigkeit zunimmt.

\subsection{Multiple Varianzanalysen zur Berechnung des Varianzanteils der Einflussgrößen nach Bundesländern}

Ziel ist es, mit der multiplen Varianzanalyse die Relevanz der einzelnen Faktoren für den Befall durch S. sclerotiorum an Winterraps herauszuarbeiten und damit den Anteil der Faktoren an der Merkmalsvariabilität zu bestimmen. Für die Auswertung wurden die Bundesländer (Mecklenburg-Vorpommern, Schleswig-Holstein, Sachsen-Anhalt und die übrigen Länder) zuerst getrennt bewertet und anschließend erfolgte eine Bewertung aller Regionen zusammen.

Folgende Faktoren und Wechselwirkungen wurden in die Berechnung mit einbezogen:

- Jahr (unterschiedliche Befallsniveaus der einzelnen Jahre)

- Aussaattermin

- Fruchtfolge (Vorfrucht)

- Aussaatstärke

- Sorte

- Bodenart 
Wechselwirkungen:

- Jahr x Vorfrucht

- Jahr x Sorte

- Jahr x Aussaattermin

- Vorfrucht x Sorte

- Vorfrucht x Aussaattermin

- Sorte x Aussaattermin

- Jahr x Vorfrucht x Sorte

- Jahr x Vorfrucht x Aussaattermin

- Jahr x Sorte x Aussaattermin

- Jahr x Vorfrucht x Sorte x Aussaattermin

Der Anteil der Faktoren an der Gesamtvarianz ist in Abbildung 32 aufgeführt. In allen vier Gebieten ist erkennbar, dass sich der in die Berechnung miteinbezogene Einfluss der Wechselwirkungen zu einem sehr großen Anteil auf den Befall auswirkt. Ebenso zeigt sich auch, dass der Jahresfaktor eine größere Rolle für die Höhe des Befallsgrades spielt. Signifikante Varianzanteile, die auf den Einfluss der Vorfrucht zurückzuführen sind, ergeben die Berechnungen der sonstigen Länder, Mecklenburg-Vorpommern und Schleswig-Holstein. Der Aussaattermin hat gegenüber dem Faktor Vorfrucht nur einen geringen Anteil an der Variabilität des Befallsmerkmals. Nur in den sonstigen Ländern, Mecklenburg-Vorpommern und Sachsen-Anhalt zeigt sich ein mäßiger bis starker Einfluss des Aussaattermins auf den Befall. Die Sorte hat bei dieser Berechnung den geringsten Anteil auf die Gesamtvarianz. 


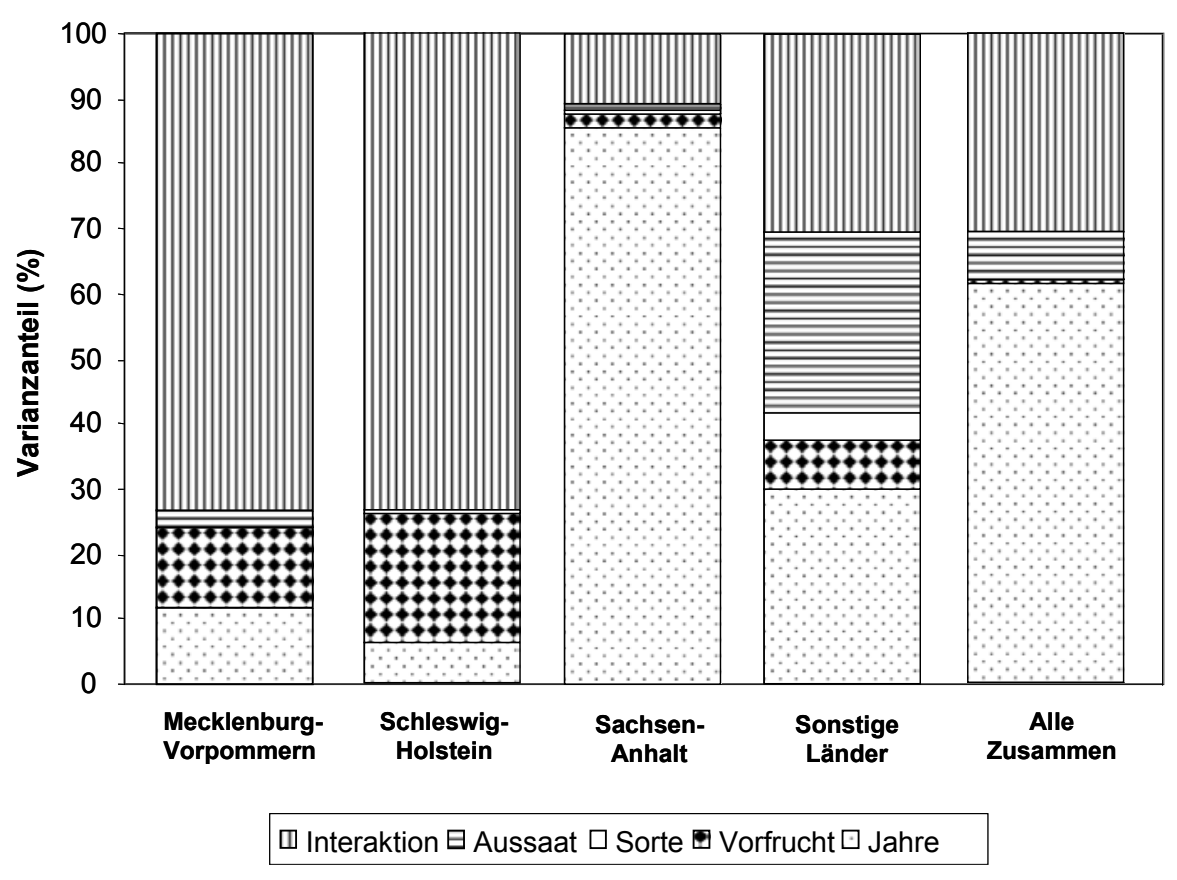

Abb. 32: Varianzanteile der einbezogenen Variablen (Aussaat, Sorte, Vorfrucht und Jahr) und deren Wechselwirkungen am Gesamteinfluss auf den Befall mit $S$. sclerotiorum von 811 Standorten aus den Jahren 1994-2004.

\subsection{Validierung von SKLERO anhand vorhandener Versuchsdaten}

\subsubsection{Vorhersagegenauigkeit des Erscheinens der Apothezien}

Für die Überprüfung von SKLERO wurden die Versuchsergebnisse der SclerotiniaBekämpfungsflächen aus den Jahren 2002-2004 der einzelnen Pflanzenschutzämter ausgewertet. Für die Überprüfung des Erscheinens der Apothezien wurden die in den Versuchen angelegten Depots mit der Vorhersage des Modells SKLERO verglichen. Es konnte beobachtet werden, dass das tatsächliche Auftreten der Apothezien nicht immer mit dem von SKLERO prognostiziertem Auftreten übereinstimmt. In allen Ländern wurde im Jahr 2003 das tatsächliche Erscheinen der Fruchtkörper früher beobachtet, als der Termin des Erstauftretens der durch SKLERO errechnet wurde. Die Differenz zwischen Bonitur und Modell lag zwischen 1 und 23 Tagen. An drei Standorten konnte kein Auftreten beobachtet werden, obwohl das Prognosemodell auch hier ein Erscheinen prognostizierte. Bei der Auswertung aller Versuche von 2000-2004 konnte festgestellt werden, dass das 
Erscheinen der Apothezien zu 32\% genau prognostiziert wurde, 58\% wurden zu früh und 10\% zu spät vorhergesagt (Abbildung 33). In allen Jahren wurde auf den Versuchsflächen ein Apothezienwachstum vom Modell vorhergesagt. Durch die ungenaue und zum Teil zu späte Vorhersage des Modells werden Infektionen, die vor dem prognostizierten Erscheinen der Apothezien stattgefunden hätten, nicht berücksichtigt.

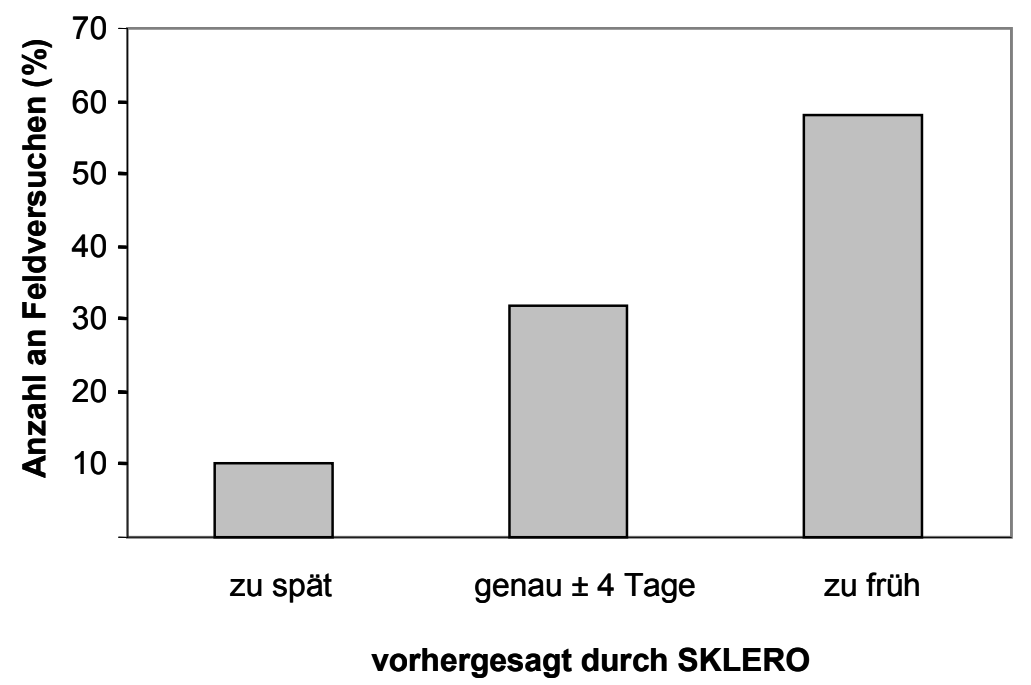

\begin{abstract}
Abb. 33: Vorhersage des Erscheinens der Apothezien nach dem Modell SKLERO anhand von 28 Versuchsstandorten der Pflanzenschutzdienste der Länder in den Jahren 2002-2004. Zu spät $=5-25$ Tage; genau $= \pm 4$ Tage; zu früh $=5$ - 20 Tage .
\end{abstract}

\title{
3.10.2 Vorhersagegenauigkeit der Befallshäufigkeit
}

In Abbildung 34 wurden die infektionsgünstigen Stunden nach SKLERO zum Zeitpunkt der Blüte mit dem Sclerotinia-Befall zur Ernte in Beziehung gesetzt. In der Auswertung wurden unbehandelte Schläge von 75 Standorten verschiedener Jahre mit den dazugehörigen Wetterdaten berücksichtigt. Bei SKLERO werden nur die infektionsgünstigen Stunden in die Auswertung mit einbezogen, die zu einer gelungenen Infektion geführt haben, dass heißt nur die Stunden, die mindestens 22 ununterbrochene Infektionsstunden überschritten haben und bei denen der Infektionsdruck einen Wert von 5 und höher erreicht hat. Anhand des Ergebnisses zeigt sich, dass selbst beim Erreichen von sehr vielen infektionsgünstigen Stunden (bis zu 140 Stunden) und damit einer Vielzahl von prognostizierten Infektionen kein Befall oder nur sehr geringe Befallshäufigkeiten im Feld aufgetreten sind. Ebenso konnte man beobachten, dass bei keiner prognostizierten 
gelungenen Infektion sehr hoher Befall (über 50\% befallener Pfl. $/ \mathrm{m}^{2}$ ) im Feld auftrat. Die regressionsanalytische Berechnung weist zudem darauf hin, dass die infektionsgünstigen Stunden, die durch das Modell SKLERO berechnet werden den Befall nur zu 16\% erklären. Anhand der infektionsgünstigen Stunden bzw. der gelungenen Infektionen in SKLERO ist es somit nicht möglich, den zu erwartenden Befall im Feld vorherzusagen.

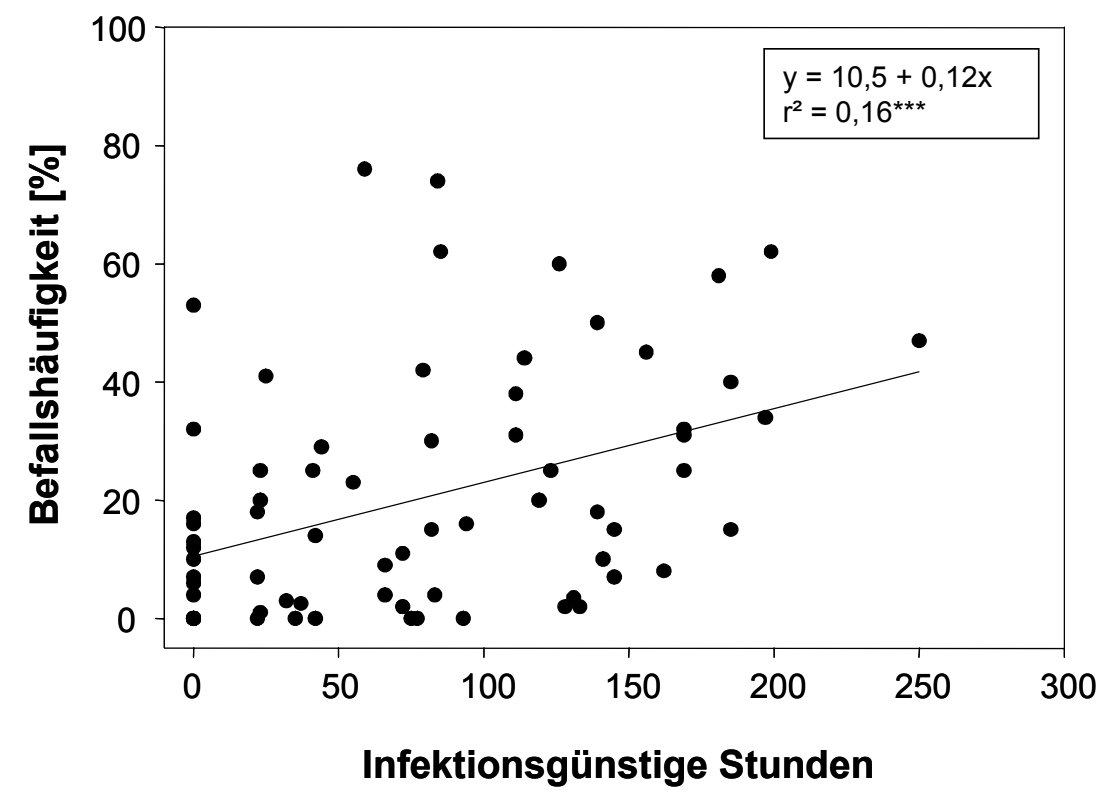

Abb. 34: Lineare Regression der Befallshäufigkeit (\%) und der Summe der infektionsgünstigen Stunden $\left(3^{\circ} \mathrm{C}\right.$ Minimumtemperatur, $84 \%$ Minimum der rel. Luftfeuchtigkeit) bei SKLERO anhand von 72 Feldversuchen aus den Jahren 2000-2004.

\subsubsection{Vorhersagegenauigkeit der Rapsentwicklung während der Blüte}

Im Weiteren wurde die Vorhersage der Rapsentwicklung durch SKLERO mit der aktuell ermittelten Entwicklung im Feld verglichen. Die Validierung von SKLERO an verschiedenen Standorten und Jahren ergab, dass die Vorhersage der Rapsentwicklung ab Beginn der Blüte langsamer verlief, als die aktuelle Rapsentwicklung im Feld. Besonders $\mathrm{ab}$ der Vollblüte (BBCH 65) konnten Unterschiede von bis zu 14 Tagen zwischen Prognose und tatsächlichem Entwicklungsstand beobachtet werden. Insgesamt wurde auf allen untersuchten Standorten die Rapsblüte über einen längeren Zeitraum prognostiziert, als sie aktuell beobachtet werden konnte. Vorhergesagte Spritztermine zum Zeitpunkt der Vollblüte wären demnach zum Ende der Blüte appliziert worden. In Abbildung 35 ist am Beispiel des Versuchsstandortes Birkenmoor bei Kiel im Jahr 2003 die 
Entwicklungsprognose von SKLERO im Vergleich zur aktuellen bonitierten Entwicklung im Feld dargestellt.

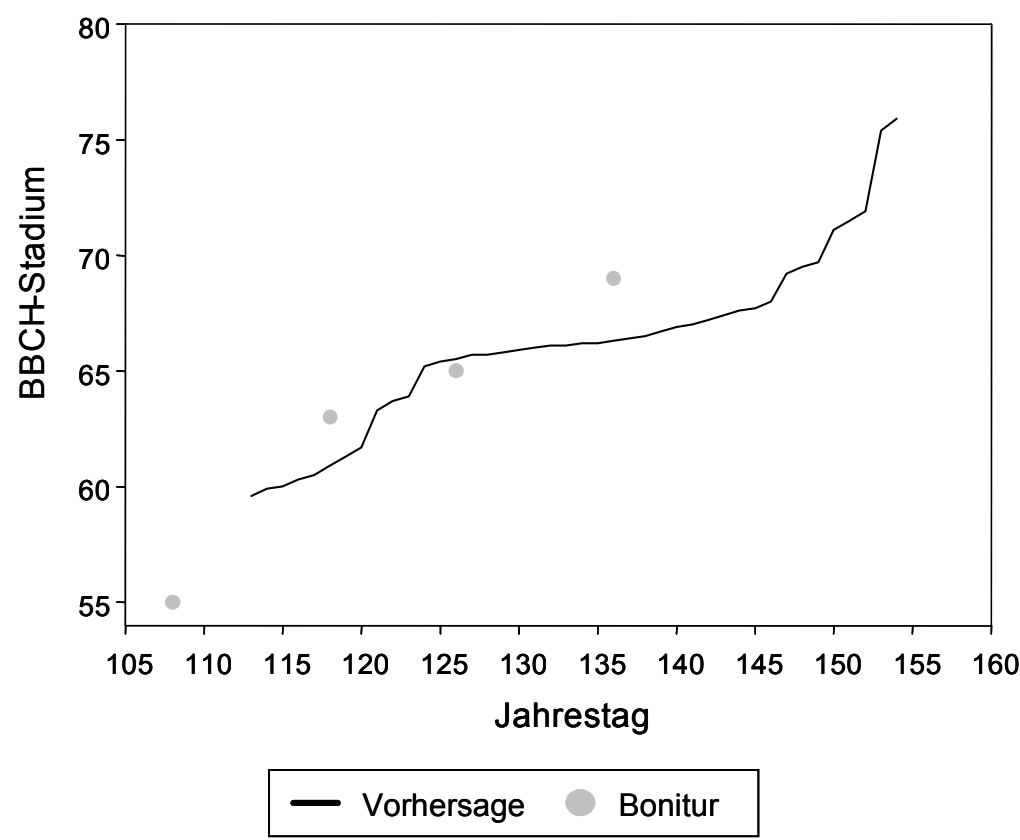

\begin{abstract}
Abb. 35: Vergleich der Vorhersage der Rapsphänologie (BBCH-Stadium) mit der visuell erfassten Rapsentwicklung im Feld am Beispiel des Versuchsstandortes in Kiel im Jahr 2003. Die Vorhersage erfolgte mit den Wetterdaten der Wetterstation Kiel-Holtenau des DWD.
\end{abstract}

\title{
3. 11 Beschreibung des Modells SkleroPro
}

Als Grundlage für die Modellierung von SkleroPro diente das Modell SKLERO (FrIESLAND, 1999) vom DWD. In Abbildung 36 sind der Aufbau und die einzelnen Komponenten von SkleroPro dargestellt. Das Grundgerüst eines jeden Modells bilden die Eingabedaten, danach erfolgt programmintern die Berechnung einzelner Parameter, die am Ende eines jeden Programmlaufs in der Ausgabemaske erscheinen. In SkleroPro sind zwei Vorhersagen möglich, zum einen kann eine regionale Vorhersage abgefragt werden, bei der die Notwendigkeit einer individuellen Behandlungsentscheidung prognostiziert wird und zum anderen eine schlagspezifische Vorhersage, die den genauen Behandlungstermin berechnet. Auf der Basis von Wetterdaten, schlagspezifischen Daten und der Einbindung einer flexiblen Schadensschwelle werden die infektionsgünstigen Stunden berechnet und 
daraus der optimale Termin der Behandlungsentscheidung während der Blüte abgeleitet. Voraussetzung für den Einsatz des Prognosemodells sind lückenlose Wetterdaten ab dem Knospenstadium (BBCH 55) des Rapses. Mit Hilfe der stündlich gemessenen rel. Luftfeuchte (in \% in $2 \mathrm{~m}$ Höhe), Temperatur (in ${ }^{\circ} \mathrm{C}$ in $2 \mathrm{~m}$ Höhe) und Niederschlag (mm) wird ab der Eingabe des Knospenstadiums das Mikroklima im Bestand berechnet. Die Bestandesklimadaten, welche aus der berechneten rel. Luftfeuchte und Temperatur im Bestand bestehen, sind sowohl Voraussetzung für die Berechnung der weiteren Entwicklung des Rapses bis zum Ende der Blüte, als auch für die Berechnung der infektionsgünstigen Stunden. Die infektionsgefährdeten Stadien des Rapses liegen in einem sehr engen Zeitfenster von Beginn bis zum Ende der Blüte. Aufgrund der Simulation der Rapsentwicklung ab dem Knospenstadium bleibt dem Anwender eine aufwändige Beobachtung seiner Rapsschläge erspart. Durch die genaue Vorhersage des täglich aktuellen Entwicklungsstadiums werden ab dem Blühbeginn die infektionsgünstigen Stunden berechnet. Diese sind eine Kombination aus relativer Luftfeuchte und Temperatur. Eine infektionsgünstige Stunde ist erreicht bei Überschreiten einer Minimumtemperatur von $7^{\circ} \mathrm{C}$ bei gleichzeitig anhaltender rel. Luftfeuchte von $>86 \%$. Unterhalb $80 \%$ rel. Luftfeuchte findet keine Infektion durch Ascosporen statt. Als Bedingung für eine gelungene Infektion im Feld müssen mindestens 23 ununterbrochen günstige Infektionsstunden vorherrschen.

Die Wirkung der Fruchtfolge wird durch die Veränderung der Schwelle der infektionsgünstigen Stunden berücksichtigt. Je enger die Fruchtfolge von Raps ist, desto niedriger liegt die Schwelle der infektionsgünstigen Stunden. Ein Infektionsereignis reicht aber häufig nicht aus, um einen ertragsrelevanten Befall im Feld zu verursachen. In einem weiteren Projekt am Institut für Pflanzenpathologie in Göttingen wurden Befalls/Verlustanalysen von S. sclerotiorum an Raps erarbeitet (DUNKER \& V. TIEDEMANN, 2004). Die Ergebnisse dieser Arbeit wurden in Form einer flexiblen Schadensschwelle in das Prognosemodell integriert. Anhand verschiedener schlagspezifischer Eingabedaten durch den Anwender wie erwartetes Ertragsniveau, Rapspreis, Überfahrtverluste und Fungizidkosten, wird ein schadschwellenbezogener Wert der infektionsgünstigen Stunden berechnet und erst, wenn dieser durch die aktuell gemessenen infektionsgünstigen Stunden überschritten wird, wird eine individuelle schlagspezifische Bekämpfung gegen $S$. sclerotiorum empfohlen. 
Die Behandlungsentscheidung der Prognose wird dem Anwender in Form einer Tabelle in der Ausgabemaske angezeigt. In dieser Tabelle sind noch einmal die Eingabedaten und Ausgabedaten aufgelistet, hierzu zählen:

- $\quad$ ausgewählte Wetterstation

- $\quad$ Termin des Knospenstadiums

- Rapsanteil in der Fruchtfolge

- $\quad$ kostendeckender Mehrertrag

- $\quad$ aktuell berechnetes Entwicklungsstadium des Rapses

- $\quad$ aktuell akkumulierte infektionsgünstige Stunden

- $\quad$ errechneter Schwellenwert der infektionsgünstigen Stunden

- Behandlungsempfehlung.

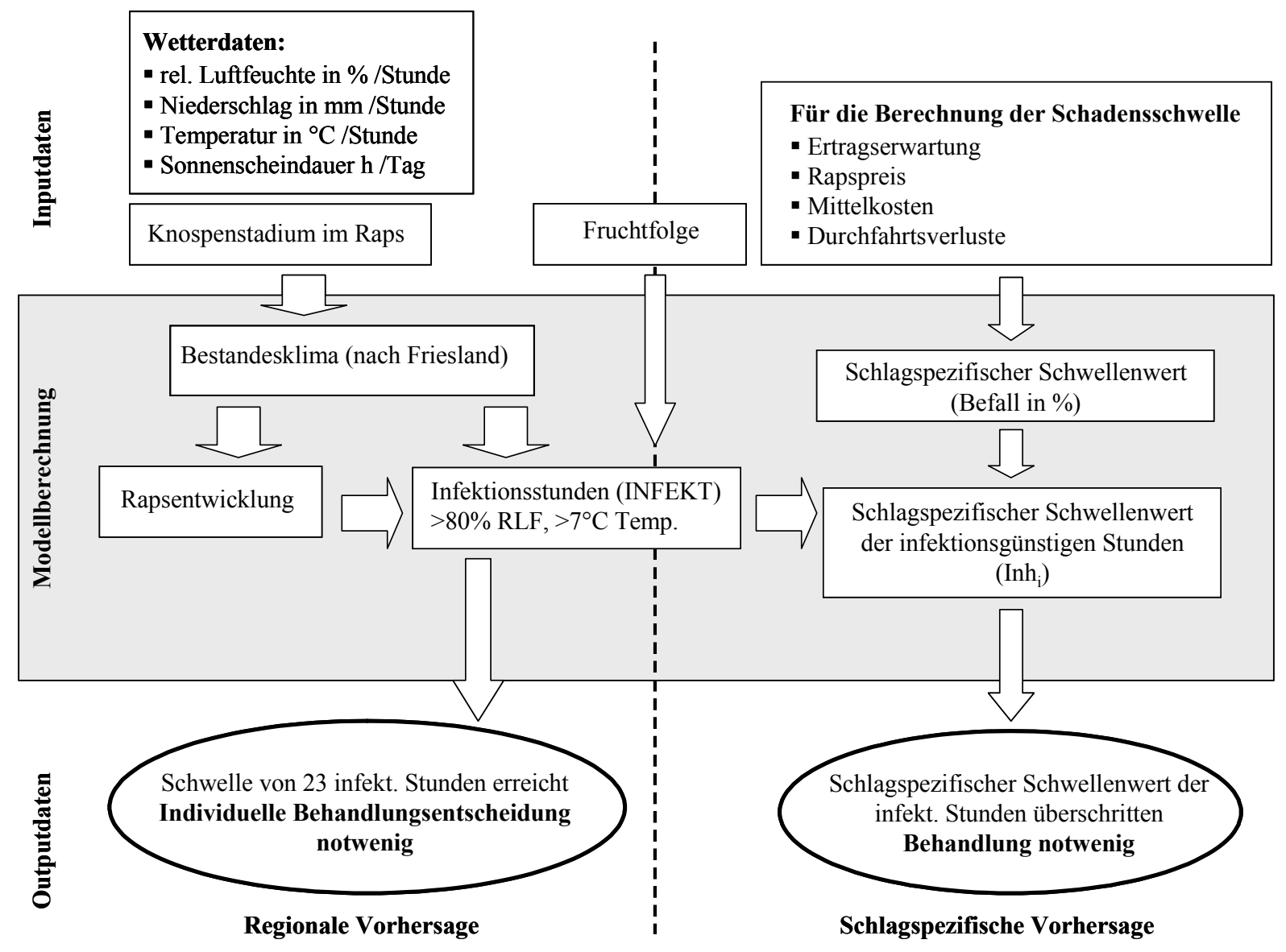

Abb. 36: Aufbau von SkleroPro mit Inputdaten, internen Berechnungskomponenten und Ausgabedaten. 


\subsection{Erstellung des Modells SkleroPro und Veränderungen zu SKLERO}

Durch die Validierung des Modells SKLERO und der daraus resultierenden Bewertung einiger Funktionen und Gleichungen konnte eine grundsätzliche Modifikation des Modells SkleroPro durch die Entfernung überflüssiger Gleichungen vorgenommen werden. Eine erste Veränderung und Modifizierung des Modells SkleroPro erfolgte durch die Eliminierung der komplexen Berechnung des Erscheinens der Apothezien, in der sowohl die Berechnung des Absterbens der Apothezien durch Trockenheit oder Frost sowie das Aufwachsen alter bzw. neuer Apothezien integriert war. Anhand der Validierung von SKLERO (Kapitel 3.10.1) konnte gezeigt werden, dass das Modell in jedem Jahr das Erscheinen der Apothezien prognostizierte, obwohl besonders im extrem trockenen Jahr 2003 an drei Versuchsstandorten kein Aufwachsen beobachtet werden konnte. Des Weiteren führte die zum Teil verspätet prognostizierte Vorhersage dazu, dass die infektionsgünstigen Stunden, die vor dem prognostizierten Erscheinen berechnet worden wären, nicht mit berücksichtigt wurden.

Eine weitere Modifikation lag in der Entfernung der mathematischen Gleichungen zur Berechnung des Sporenfluges bzw. des Absterbens vorhandener Sporen. Bei der Auswertung des Modells SKLERO konnte kein Einfluss der Berechnung des Sporenfluges auf das Infektionsereignis beobachtet werden. Nach dem Erscheinen der Apothezien und mit Beginn der Blüte berechnet das Modell SKLERO die Infektionswahrscheinlichkeiten, egal ob ein Sporenflug stattgefunden hat oder die Sporen nach Trockenheit bereits abgestorben sind. Der Sporenflug in SKLERO spielt somit bei der Berechnung von Infektionsstunden und Infektionsdruck keine Rolle. Aus diesem Grund wurde der Sporenflug bei der Erstellung des neuen Modells nicht berücksichtigt. Ferner kann davon ausgegangen werden, dass das Ausgangsinokulum auf den meisten Rapsanbauflächen vorhanden ist. Eine Erfassung bzw. Überprüfung des Sporenfluges sollte zudem in dem neuen Modell SkleroPro mit geeigneten Nachweismethoden erfolgen.

Ein weiterer Parameter, der in SkleroPro nicht mit einbezogen wurde, ist der Infektionsdruck. Der Infektionsdruck gilt als zusätzliche Bedingung für eine gelungene Infektion. Die Validierung von SKLERO zeigte, dass an Tagen, an denen zwar die Schwelle von 22 ununterbrochenen infektionsgünstigen Stunden erreicht war, der Infektionsdruck jedoch noch nicht den Schwellenwert von 5 überschritten hat, keine gelungene Infektion vom Modell prognostiziert wurde. Um diese infektionsgünstigen 
Stunden zu berücksichtigen, wurde die Berechnung des Infektionsdrucks in SkleroPro nicht übernommen.

\subsubsection{Berechnung der Rapsentwicklung}

Aus den Bestandesklimadaten wird mit Hilfe verschiedener Gleichungen das phänologische Stadium des Rapses vom Knospenstadium bis zum Ende der Blüte berechnet. Dabei wird das aktuelle Entwicklungsstadium des Rapses durch Eingabe des Datums des Knospenstadiums berücksichtigt. Ab dem Tag des Knospenstadiums wird mit der Berechnung der weiteren Entwicklung des Rapses begonnen. Der tägliche Faktor für die Berechnung des Entwicklungsfortschritts ist abhängig vom errechneten Stadium des Rapses (GS). Je weiter der Raps in seiner Entwicklung ist, desto geringer ist der tägliche Faktor für den Entwicklungsfortschritt. Bei einem BBCH-Stadium (GS-Stadium) bis 61 ist der täglich berechnete Faktor höher als nach Erreichen des BBCH-Stadiums 61 (Abb. 37a).

Eine Veränderung zum Modell SKLERO war, dass die Berechnung der Rapsphänologie durch die Integration einer zusätzlichen Gleichung schon ab dem BBCH-Stadium 55 (Knospenstadium) beginnt. Insgesamt wurden für die Berechnung des Faktors für den Entwicklungsverlauf drei Gleichungen aufgestellt. Die erste Gleichung bezieht sich auf den Zeitraum vom Knospenstadium bis zum Anfang der Blüte. Die zweite Gleichung betrifft die Stadien Anfang Blüte bis Mitte Blüte und die dritte Gleichung berechnet den Faktor ab Mitte Blüte bis Ende Blüte.

$$
E S F=\left\{\begin{array}{llc}
\frac{0.6}{0.02 \cdot \mathrm{e}^{(G S-55)^{2}}} & \text { if } & 55 \leq G S<61 \\
\frac{0.15}{0.05 \cdot \mathrm{e}^{(G S-61)^{2}}} & \text { if } & 61 \leq G S<65 \\
\frac{0.15}{0.05 \cdot \mathrm{e}^{(G S-65)^{2}}} & \text { if } & 65 \leq G S<75
\end{array}\right.
$$


$\mathbf{a}$

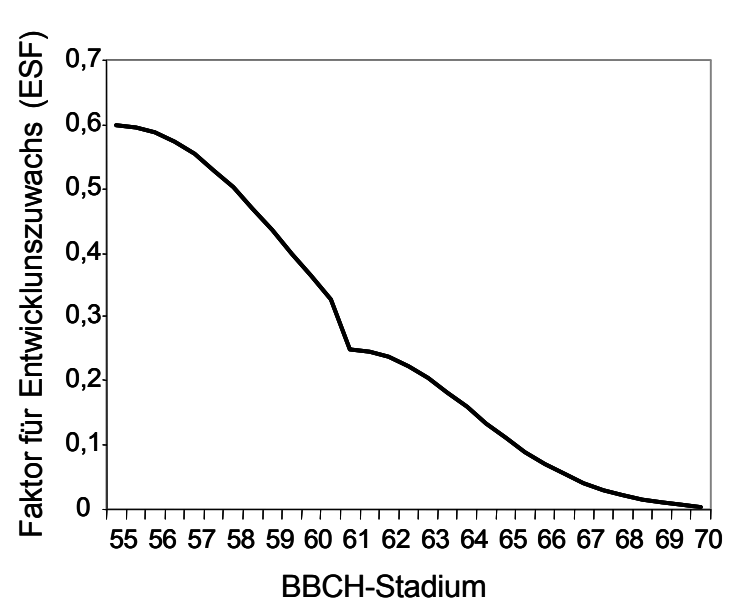

b

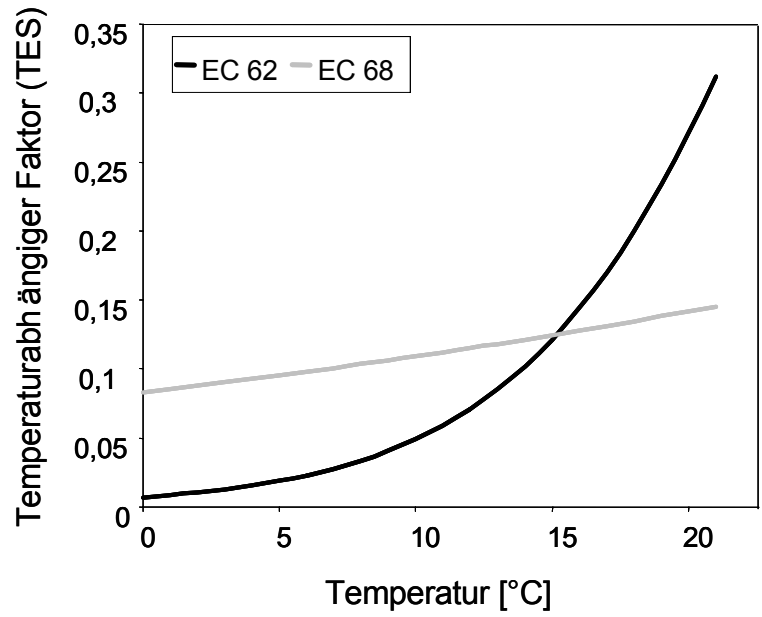

Abb. 37: a) Berechnung des Faktors für den Entwicklungszuwachses in Abhängigkeit vom BBCH-Stadium des Rapses.

b) Berechnung des temperaturabhängigen Faktors in Abhängigkeit von der Temperatur und vom BBCH-Stadium nach FRIESLAND.

Jedes Pflanzenwachstum ist temperaturabhängig. Zahlreiche Wachstumsmodelle in der Pflanzenpathologie basieren auf Temperatursummenfunktionen (KRANZ, 1996). Für die Vorhersage der Rapsentwicklung ist es daher wichtig die Temperatur in die Berechnungen mit einzubeziehen. Die mathematischen Gleichungen zur Berechnung des temperaturabhängigen Faktors (TES) wurden direkt von dem Modell SKLERO übernommen. In einem ersten Schritt erfolgt die Berechung der Temperatur im Rapsbestand über eine Regressionsgleichung. Dabei wird die aktuell gemessene Temperatur in $2 \mathrm{~m}$ Höhe berücksichtigt. Mit Hilfe der berechneten Bestandestemperatur kann in einem weiteren Schritt der temperaturabhängige Faktor berechnet werden.

Bei einem frühen Entwicklungsstadium des Rapses vom Knospenstadium (BBCH 55) bis zur Vollblüte (BBCH 66) nimmt der temperaturabhängige Faktor mit steigender Temperatur exponentiell ab. Ab der Vollblüte (BBCH-Stadium 66) ist der Zuwachs des Faktors mit steigender Temperatur nur noch gering (Abb. 37b).

$T E S=\left\{\begin{array}{lll}\frac{1}{1+\mathrm{e}^{0.198 \cdot(25-T R)}} & \text { if } & 55 \leq G S \leq 66 \\ \frac{1}{1+\mathrm{e}^{0.03 \cdot(80-T R)}} & \text { if } & 66<G S<75\end{array}\right.$ 
$D G R=E S F \cdot T E S$

$D G R=$ tägliche Zuwachsrate

Durch die Multiplikation der Ergebnisse der beiden Faktoren erhält man die tägliche Zuwachsrate (DGR) des Entwicklungsstadiums. Anhand der Abbildung 38 wird deutlich, dass sich durch die Veränderung der Formeln bzw. Erstellung neuer Gleichungen für die Entwicklung des Rapses ganz neue tägliche Zuwachsraten ergeben. Der tägliche Zuwachs bei SkleroPro ist in den BBCH-Stadien 55-68 höher als bei SKLERO. Dies führt dazu, dass die Rapsentwicklung bei SkleroPro während der Blüte wesentlich schneller verläuft. Im Gegenzug verläuft die Entwicklung ab dem BBCH-Stadium 68 wesentlich verzögerter ab.
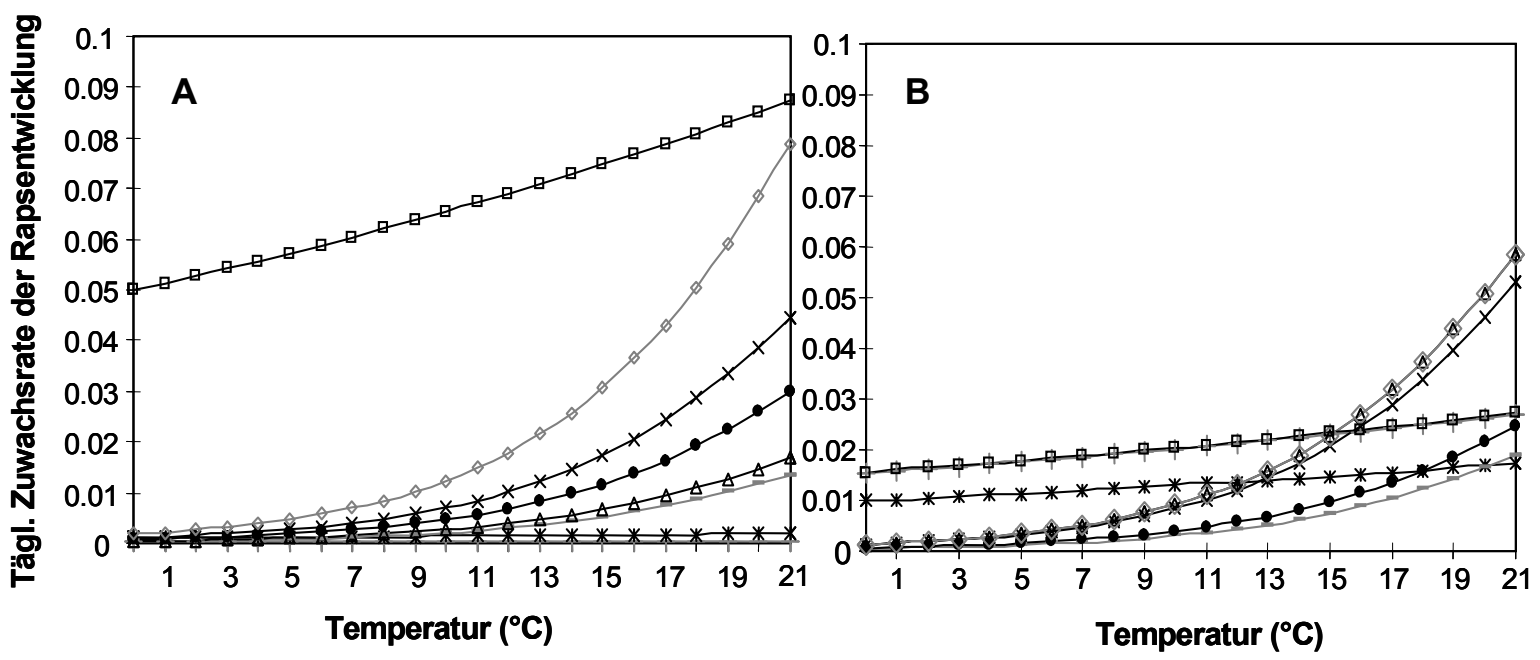

$$
\begin{aligned}
& +\mathrm{BBCH} 70 \rightarrow \mathrm{BBCH} 68-\mathrm{BBCH} 66-\mathrm{BBCH} 64 \\
& \leftarrow \text { BBCH } 62 \triangle \mathrm{BBCH}_{60} \diamond \mathrm{BBCH} 58 \rightarrow \mathrm{BBCH} 55
\end{aligned}
$$

Abb. 38: Tägliche Zuwachsraten der Rapsentwicklung in Abhängigkeit von der Temperatur und den Entwicklungsstadien $(\mathrm{BBCH})$ bei den Modellen SkleroPro (A) und SKLERO (B). 


\subsubsection{Berechnung der infektionsgünstigen Stunden}

Parallel zur Errechnung der Rapsentwicklung werden direkt aus den stündlichen Wetterdaten bzw. den Bestandesklimadaten die infektionsgünstigen Stunden berechnet. Die infektionsgünstigen Stunden sind abhängig von der Temperatur (TTRA) und der rel. Luftfeuchte (RLF) im Rapsbestand. Der Kurvenverlauf für die Berechnung der infektionsgünstigen Stunden wurde nach Friesland übernommen und folgt wie viele biologische Prozesse einer Optimumfunktion. Die einzelnen Parameter in den Gleichungen wurden aber, nach den im Boxentest erarbeiteten Infektionsbedingungen, verändert. So konnte aus dem Ergebnis des Boxentests eine Minimumtemperatur von $7^{\circ} \mathrm{C}$ abgeleitet werden und eine optimale Temperatur für die Infektion mit Ascosporen im Bereich von 16-22 ${ }^{\circ} \mathrm{C}$. Diese Erhebungen stehen im Widerspruch zu den Infektionsbedingungen im Modell SKLERO, in dem die optimale Temperatur bei $15^{\circ} \mathrm{C}$ und die Mindesttemperatur bei $3^{\circ} \mathrm{C}$ liegen. Eine infektionsgünstige Stunde spiegelt immer das Verhältnis von Temperatur und rel. Luftfeuchte wieder. Infektionen können somit zum Beispiel in SkleroPro bei einer Minimumtemperatur von $7^{\circ} \mathrm{C}$ in Verbindung mit einer rel. Luftfeuchte von $86 \%$ stattfinden. Umgekehrt beträgt die rel. Luftfeuchte, die mindestens für eine Infektion vorhanden sein muss, $80 \%$ verbunden mit einer Temperatur von $11^{\circ} \mathrm{C}$. Die optimalen Bedingungen für eine Infektion mit S. sclerotiorum, liegen bei $18^{\circ} \mathrm{C}$ und $94 \%$ rel. Luftfeuchte (Abb. 39).

$I N F E K T=\left\{\begin{array}{lll}\frac{1}{\mathrm{e}^{0.01 \cdot(18-T R)^{2.5}+0.04 \cdot(94-R L F)^{2}}} & \text { if } & T R \leq 18^{\circ} \mathrm{C} \\ \frac{1}{\mathrm{e}^{0.003 \cdot(T R-18)^{2.5}+0.04 \cdot(94-R L F)^{2}}} & \text { if } & T R>18^{\circ} \mathrm{C}\end{array}\right.$

Der Index für die Berechnung der infektionsgünstigen Stunden (INFEKT) kann Werte zwischen 0 und 1 annehmen. Erst wenn der Index den Wert größer oder gleich 0.005 erreicht hat, wird eine infektionsgünstige Stunde herausgegeben. Sobald die Bedingungen für eine infektionsgünstige Stunde erreicht sind (z.B. $7^{\circ} \mathrm{C}$ und $86 \%$ ), wird der Schwellenwert von 0.005 erreicht bzw. überschritten. In der Abbildung 40 sind die Kombinationen von rel. Luftfeuchte und Temperatur im Raps dargestellt, die für die Berechnung einer infektionsgünstigen Stunde notwendig sind. 
In Untersuchungen von JAMAUX et al. (1995) konnte gezeigt werden, dass die Infektion der Blütenblätter durch Ascosporen mindestens 20-30 Stunden bei optimalen Temperaturen und Luftfeuchten dauert. In Anlehnung an diese Ergebnisse wurde in dem Modell SkleroPro eine Mindestdauer von 23 ununterbrochenen infektionsgünstigen Stunden festgesetzt. Eine Infektion ist laut dem Modell erst nach 23 ununterbrochenen Stunden, die den Infektionsindex von 0.005 überschritten haben, erreicht.

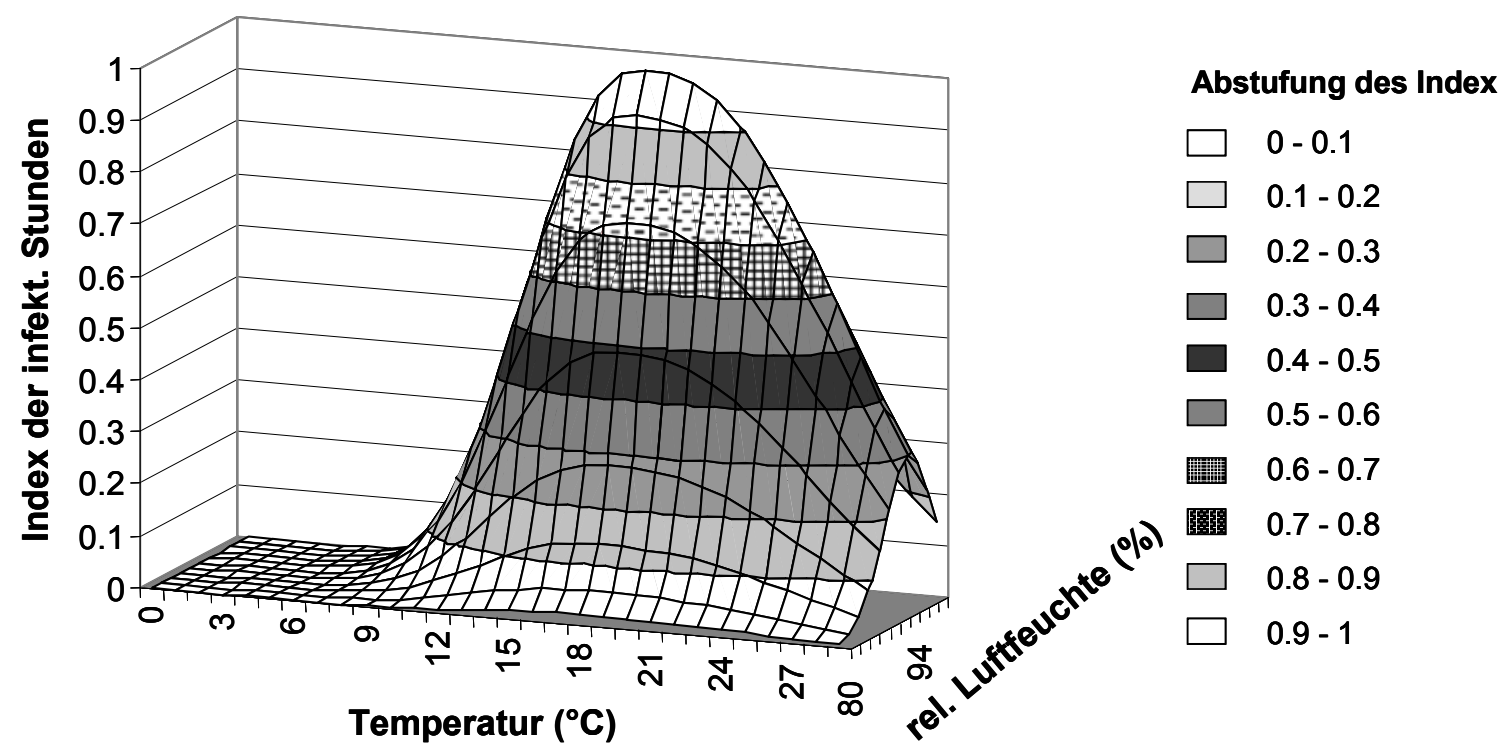

Abb. 39: Abhängigkeit der infektionsgünstigen Stunden von Temperatur $\left({ }^{\circ} \mathrm{C}\right)$ und rel. Luftfeuchte (\%) in SkleroPro. Beim Überschreiten des Infektionsindex (INFEKT) von 0.005 ist eine infektionsgünstige Stunde erreicht.

Von den ermittelten infektionsgünstigen Stunden kann direkt der Befall im Feld abgeleitet werden. In Abbildung 40 ist die Beziehung zwischen infektionsgünstigen Stunden und der Befallshäufigkeit der unbehandelten Schläge zum Zeitpunkt der Ernte am Beispiel von 107 Feldversuchen aus den Jahren 2000-2005 dargestellt. Anhand der Regressionsanalyse wird deutlich, dass eine signifikante Beziehung zwischen dem Befall und den infektionsgünstigen Stunden besteht. Der errechnete Korrelationskoeffizient zwischen infektionsgünstigen Stunden und Befallshäufigkeit beträgt 0.56 . 


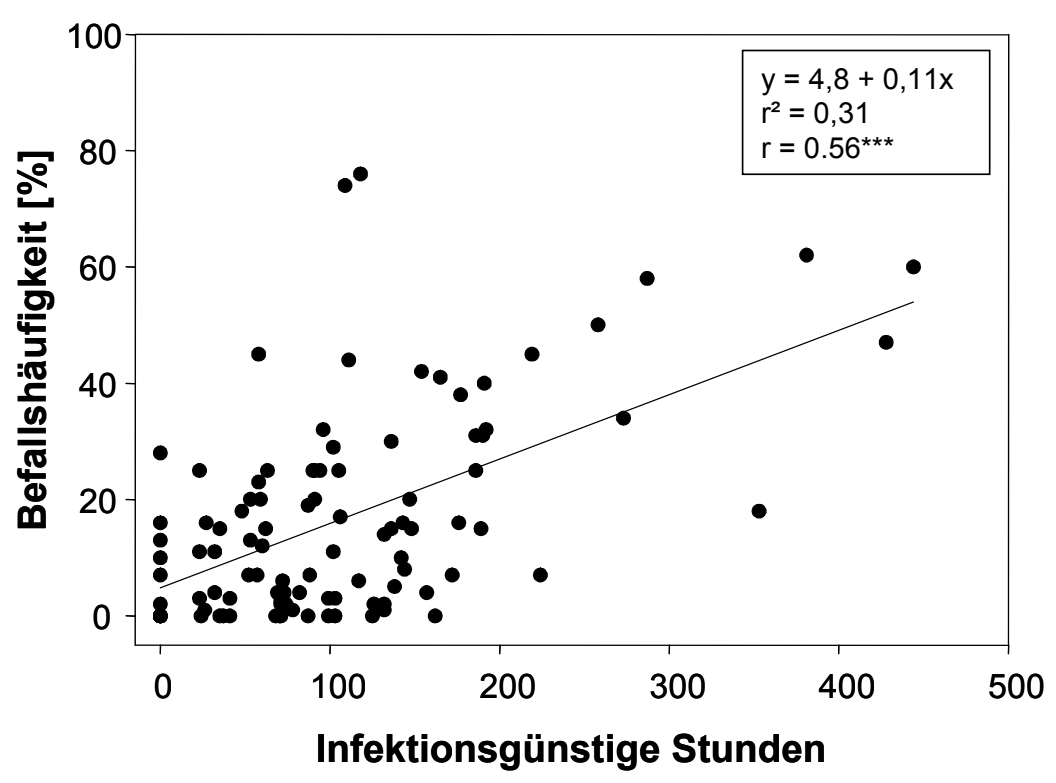

Abb. 40: Lineare Regression zwischen der Befallshäufigkeit (\%) und der Summe der infektionsgünstigen Stunden $\left(7^{\circ} \mathrm{C}\right.$ Temperatur, $80 \%$ rel. Luftfeuchte) bei SkleroPro anhand von 107 Feldversuchen aus den Jahren 2000-2005. Die Schwelle für eine erfolgreiche Infektion im Feld liegt bei einer Abfolge von 23 ununterbrochenen infektionsgünstigen Stunden. $\mathrm{r}^{2}=$ Bestimmtheitsmaß; $r=$ Korrelationskoeffizient.

\subsubsection{Integration der Fruchtfolge als schlagspezifischer Faktor}

Anhand der Überprüfung des Einflusses schlagspezifischer Faktoren auf das Auftreten von S. sclerotiorum (Kapitel 3.12.3) konnte gezeigt werden, dass unter anderem der Faktor Fruchtfolge einen signifikanten Einfluss auf das Infektionsgeschehen ausübt. Die Integration der Fruchtfolge erfolgte durch eine Klassifizierung in drei Gruppen und anschließender Bewertung der einzelnen Gruppen. Ähnlich wie bei der statistischen Auswertung wurde die Fruchtfolge in die Kategorien, zweijährig, dreijährig und mehrjährig eingeteilt. Die Bewertung der Kategorien erfolgte in Anlehnung an das Modell SIMCERC (KRAATZ, 1994; WEINERT, 2005) nach sachlogischen Kriterien. So weist eine engere Fruchtfolge meist höhere Befallshäufigkeiten auf, als eine mehrjährige Fruchtfolge. Eine zweijährige Fruchtfolge wurde demnach mit einem höheren Faktor (Faktor 1.3) bewertet, als eine mehrjährige Fruchtfolge (Faktor 0.8). Da auf den meisten Betrieben eine dreijährige Fruchtfolge vorherrscht, wurde diese Kategorie mit dem Faktor 1 bewertet, so dass von dieser Fruchtfolge keine Veränderungen der infektionsgünstigen Stunden zu erwarten sind. Der Fruchtfolgefaktor wurde in dem Modell direkt an die Berechnung der 
infektionsgünstigen Stunden gekoppelt. Durch die Integration werden die aktuell gemessenen infektionsgünstigen Stunden anschließend bei einer zweijährigen Fruchtfolge erhöht oder sie bleiben bei einer dreijährigen Fruchtfolge gleich oder die Stunden werden bei einer weiten Fruchtfolge von mehr als drei Jahren gemindert. Es müssen mindestens 23 ununterbrochen infektionsgünstige Stunden vorliegen, um eine Infektion als gelungen aus dem Modell herausschreiben zu können. Über die Berechnung der infektionsgünstigen Stunden erfolgt programmintern die Berechnung der Befallshäufigkeit.

\subsubsection{Integration der Berechnung einer Schadensschwelle für $S$. sclerotiorum}

Durch die Befallsvorhersage und durch die Integration einer Schadschwellenfunktion in das Modell kann eine schlagspezifische Behandlungsentscheidung berechnet werden. Die Schadensschwellen von S. sclerotiorum wurden in einem dreijährigen Parallelprojekt mit Hilfe künstlicher Infektionen in Feldversuchen erarbeitet (DUNKER, 2005). Die aus dieser Arbeit und für die Eingliederung in das Modell abgeleitete Schadensschwelle, basiert auf künstlichen Infektionen der Hybridsorte Talent/Maja zum BBCH-Stadium 61-65. Je nach Ertragserwartung (30-50 dt/ha) liegen die Schadensschwellen in einem Bereich zwischen $25 \%$ und $13 \%$ befallener Pflanzen.

Für die Berechnung einer wirtschaftlichen Schadensschwelle müssen vom Modellanwender verschiedene schlagspezifische Inputs in das Modell eingegeben werden, wie Fungizidkosten (M), Überfahrtskosten (U), Rapspreis (P) und Ertragserwartung (E). Anhand dieser Eingabedaten werden verschiedene Parameter nach folgenden Formeln berechnet:

Regression infektionsgünstiger Stunden-Befallshäufigkeit:

$\mathrm{BH}[\%]$ $=4,76+0,21 *$ infekt. Stunden $[\mathrm{h}]$

Regression Befallshäufigkeit [BH] - Ertrag [\%]:

Ertrag [\%]

$$
=97,837-0,352659 * \mathrm{BH}[\%]
$$

Ertragserwartung E [dt/ha] $\quad \Rightarrow$ Eingabe durch den Modellanwender

Mittelkosten M $[€ /$ ha $] \quad \Rightarrow \quad$ Eingabe durch den Modellanwender

Überfahrtkosten $U[€ /$ ha $] \quad \Rightarrow \quad$ Eingabe durch den Modellanwender 


$\begin{array}{ll}\text { Rapspreis } \mathrm{P}[€ / \mathrm{dt}] & =>\text { Eingabe durch den Modellanwender } \\ \text { Durchfahrtsverluste D }[€ / \mathrm{ha}] & =\left(\mathrm{E}^{*} 2,6 / 100\right)^{* \mathrm{P}} \\ \text { Gesamtkosten } \mathrm{K}[€ / \mathrm{ha}] & =\mathrm{M}+\mathrm{U}+\mathrm{D}\end{array}$

kostendeckender Mehrertrag CCSY [dt/ha]:

$\operatorname{CCSY}[\mathrm{dt} / \mathrm{ha}]=\frac{(M+U+0.026 \cdot E \cdot P)}{P}$

kostendeckender Mehrertrag (kM) [\%]:

$\mathrm{kM}[\%]=\frac{\left(\frac{K}{P}\right) \cdot 100}{E}$

wirtschaftliche Schadensschwelle (S) [\%]:

$\mathrm{S}[\%]=\frac{2 \cdot((100-k M)-97,837)}{-0,352659}$

Nach der Berechnung der wirtschaftlichen Schadensschwelle erfolgt die Berechnung der Bekämpfungsentscheidung. Diese setzt sich aus der Regression zwischen Ertrag und Befallshäufigkeit sowie der Regression zwischen Befallshäufigkeit und infektionsgünstigen Stunden zusammen. Anhand des berechneten Schwellenwertes der infektionsgünstigen Stunden $\left(\operatorname{Inh}_{\mathrm{i}}[\mathrm{h}]\right)$ kann direkt über die aktuell gemessenen infektionsgünstigen Stunden die Behandlungsentscheidung von dem Modell gegeben werden.

Schwellenwert der infektionsgünstigen Stunden $\left(\operatorname{Inh}_{\mathrm{i}}[\mathrm{h}]\right)$ nach Einbeziehung der Schadensschwelle:

$\operatorname{Inh}_{\mathrm{i}}[\mathrm{h}]=(\mathrm{S}-4,76) / 0,21 \Rightarrow$

$\operatorname{Inh}_{i}=\frac{\frac{2.2-C C S Y \cdot \frac{100}{E}}{-0.35}-4.76}{0.21}$ 
Überschreiten die aktuell vom Modell berechneten infektionsgünstigen Stunden über dem Schwellenwert der infektionsgünstigen Stunden $\left(\mathrm{Inh}_{\mathrm{i}}\right)$ wird eine Behandlungsentscheidung bzw. der Tag der Behandlung vom Modell herausgegeben.

\subsection{Validierung von SkleroPro in Feldversuchen der Pflanzenschutzdienste der Länder}

\subsubsection{Vorhersagegenauigkeit der Befallshäufigkeit}

Für die Überprüfung der Vorhersagegenauigkeit von SkleroPro in Bezug zur Befallshäufigkeit wurden die unbehandelten Schläge von 79 Versuchsstandorten der Pflanzenschutzdienste der Länder aus verschiedenen Jahren mit den dazugehörigen Wetterdaten bewertet. In der Abbildung 41 in Kapitel 3.12 wurden die infektionsgünstigen Stunden zum Zeitpunkt der Blüte mit der Befallshäufigkeit von S. sclerotiorum zur Ernte in Beziehung gesetzt. Eine einfache Regression ergab die Regressionsfunktion y $=4,8+$ $0,11 \mathrm{x}$ bei einem Korrelationskoeffizient von $\mathrm{r}=0,6$ und einem Bestimmtheitsmaß von $31 \%$. Als Witterungskriterien gingen in diese Berechnung Temperaturen von über $7^{\circ} \mathrm{C}$ und Luftfeuchten von über $80 \%$ mit ein. In der Auswertung wurden nur die infektionsgünstigen Stunden berücksichtigt, die zu einer gelungenen Infektion geführt haben, dass heißt, die mindestens 23 ununterbrochene infektionsgünstige Stunden erreicht oder überschritten haben. Anhand der einzelnen Ergebnisse wird deutlich, dass bei keinen infektionsgünstigen Stunden dennoch Befallshäufigkeiten von bis zu 30\% erreicht wurden. Umgekehrt konnte in einigen Fällen bei steigender Anzahl gelungener Infektionen bzw. infektionsgünstiger Stunden kein oder nur ein sehr geringer Befall im Feld festgestellt werden.

\subsubsection{Vorhersagegenauigkeit der Rapsentwicklung}

Eine Veränderung des Modells SkleroPro lag in der Umgestaltung der Berechnung der Rapsentwicklung. In Abbildung 41 sind an verschiedenen Standorten und Jahren in Deutschland die Entwicklungsprognosen beider Modelle im Vergleich zur aktuell bonitierten Entwicklung im Feld dargestellt. 
SKLERO
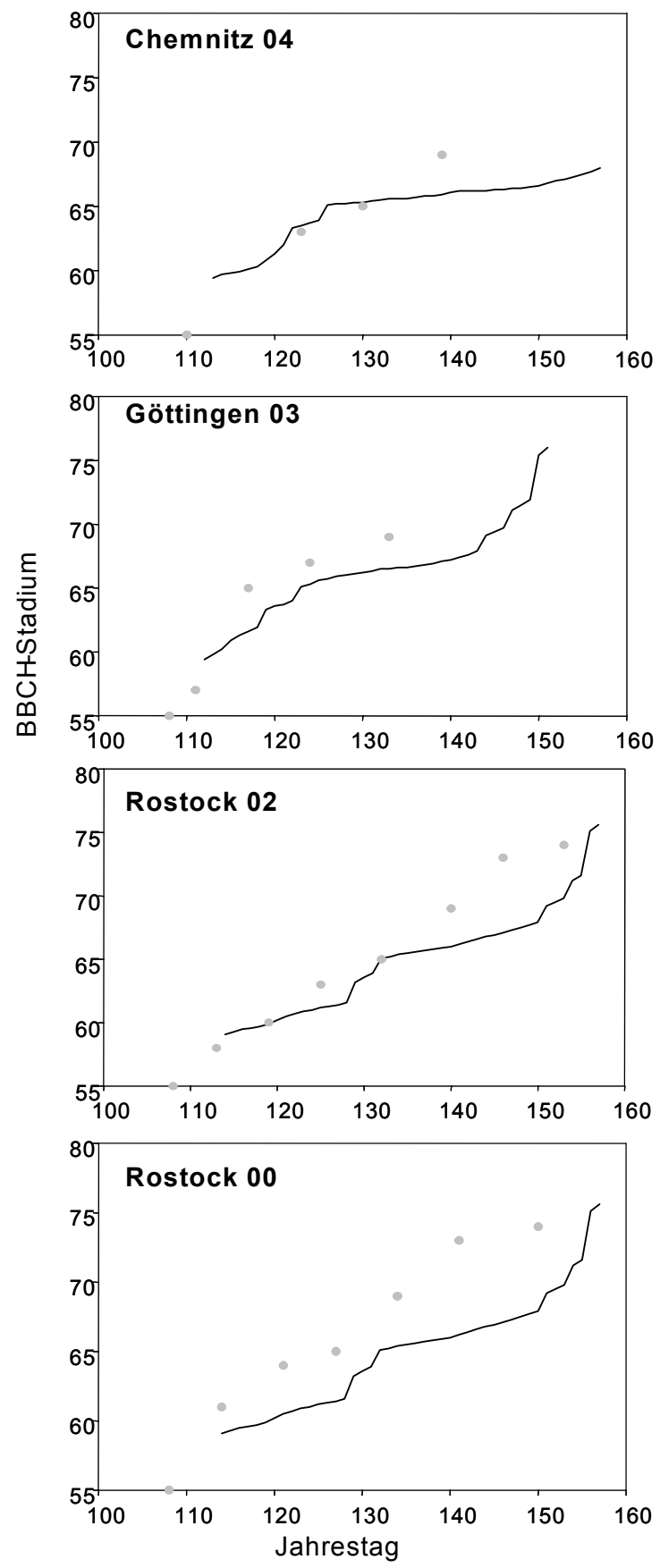

SkleroPro
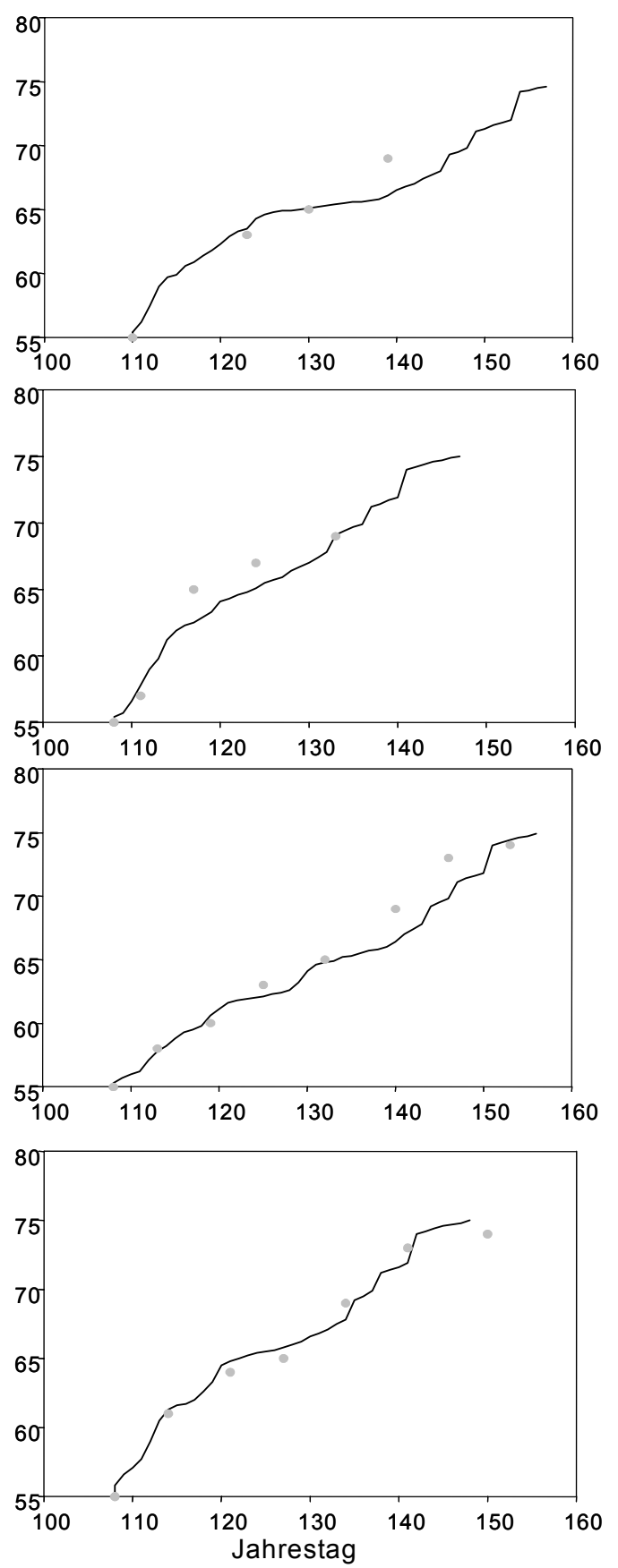

Vorhersage Bonitur

Abb. 41: Vergleich der Vorhersage der Rapsphänologie durch SkleroPro und SKLERO mit der Bonitur der Rapsentwicklung im Feld an verschiedenen Versuchsstandorten und Jahren, die Vorhersage erfolgte mit den Wetterdaten der jeweiligen Wetterstationen des DWD. 
Die Validierung des Modells SKLERO an verschiedenen Standorten und Jahren ergab, dass die Vorhersage der Rapsentwicklung ab Beginn der Blüte langsamer verlief als die aktuelle Rapsentwicklung im Feld. Durch die Veränderung der Funktionen für die Berechnung des Entwicklungsverlaufs in dem Modell SkleroPro, konnte eine verbesserte Anpassung der Vorhersage zur aktuellen Entwicklung erzielt werden.

\subsection{Vorhersage des optimalen Applikationstermins für die Blütenbehandlung anhand von Wetterdaten}

In Abbildung 42 ist ein Vergleich der Witterungsbedingungen für eine Infektion mit Ascosporen während der Blüte (25. April - 25. Mai) am Beispiel einer Wetterstation in der Nähe eines Versuchsstandortes in Thüringen mit der Behandlungsentscheidung nach SkleroPro und dem aktuellen Befall im Feld dargestellt. Im Jahr 2000 wurden nur über einen kurzen Zeitraum von Ende April bis Anfang Mai infektionsgünstige Stunden berechnet. Dieser Zeitraum reichte jedoch aus, um eine wirtschaftliche Behandlung vorherzusagen. Zum Zeitpunkt der Ernte wurden im Feld mittlere Befallshäufigkeiten von $25 \%$ erreicht.

Durch die wechselnden Niederschläge während der Blüte im Jahr 2001 wurden an einigen Tagen Luftfeuchten von über 95\% und milde Temperaturen gemessen. Dies führte zu mehr als 100 ununterbrochenen günstigen Infektionsstunden und einer Behandlungsentscheidung am 8. Mai. Im Vergleich dazu wurde in diesem Jahr eine Befallshäufigkeit von 53\% am Standort Gera gemessen.

Das Frühjahr 2002 war durch häufige starke Niederschläge und Temperaturen um $10^{\circ} \mathrm{C}$ gekennzeichnet. Zur Vollblüte konnte eine lange Periode mit relativen Luftfeuchten von über 90\% ermittelt werden. Sowohl in dieser Zeit als auch schon vor dem 16. April und zum Ende der Blüte konnten Tage mit über 23 infektionsgünstigen Stunden gemessen werden. Die Behandlungsentscheidung wurde zu Beginn der Vollblüte herausgegeben. Die Witterungsbedingungen im Jahr 2002 führten zu Befallshäufigkeiten von 62\% zum Zeitpunkt der Ernte. 


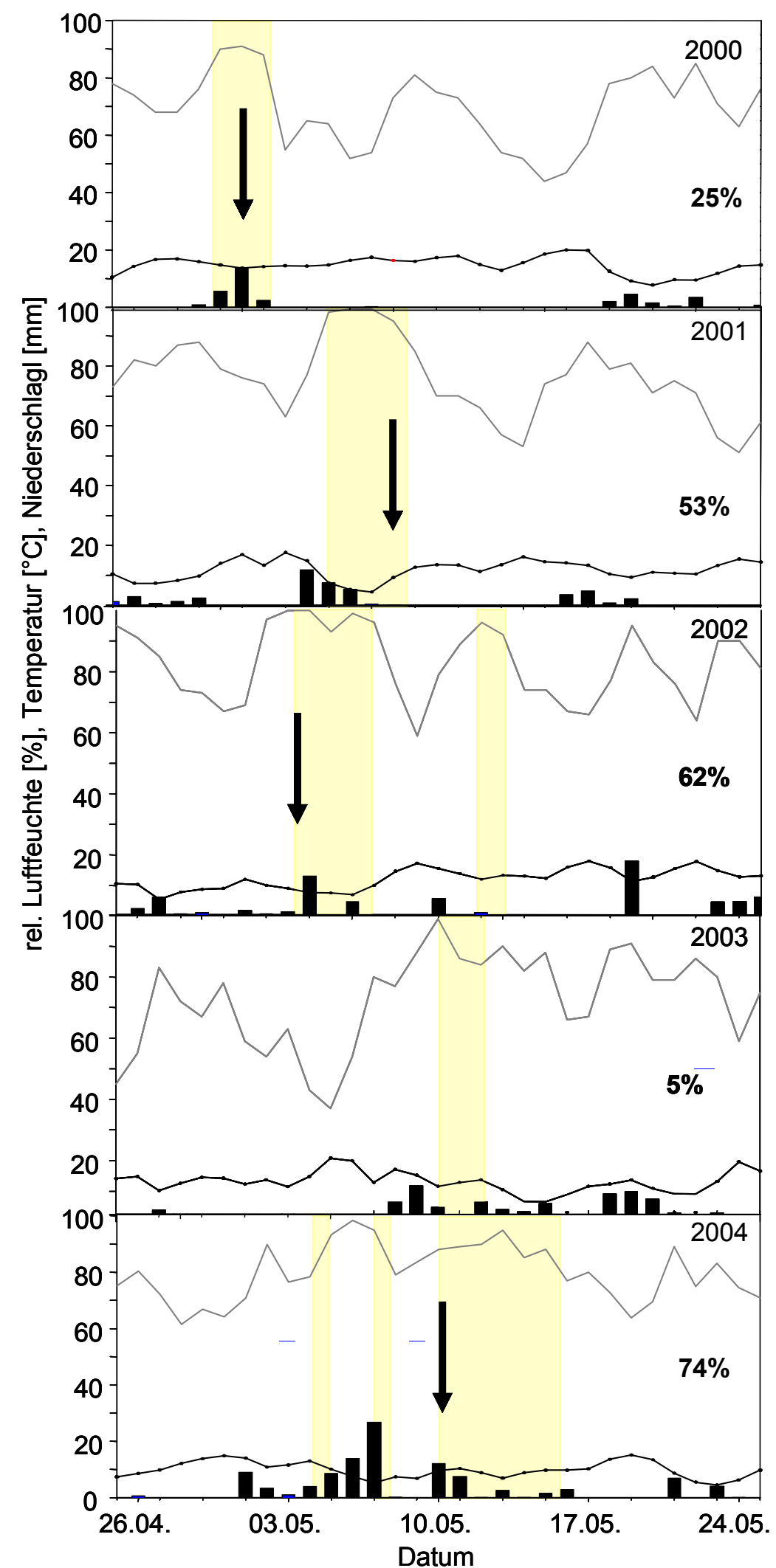

Abb. 42: Niederschläge (mm), Luftfeuchten (\%) und Temperaturverlauf $\left({ }^{\circ} \mathrm{C}\right)$ während der Blüte (25. April - 25. Mai), die Befallshäufigkeit zur Ernte und die Behandlungsentscheidungen von SkleroPro am Beispiel der Wetterstation Gera des DWD von 2000 bis 2004. 
Extrem warme und trockene Witterung herrschte im Frühjahr 2003. Die Temperaturen lagen über dem durchschnittlichen Mittel und die geringen Niederschläge führten zu Luftfeuchten, die meist unter 90\% lagen. Während der Blüte konnten maximal 23 infektionsgünstige Stunden erreicht werden, da ein einzelnes Infektionsereignis häufig nicht $\mathrm{zu}$ einem wirtschaftlichen Schaden führt, wurde in dem Jahr keine Behandlungsentscheidung prognostiziert. Dementsprechend wurde eine Befallshäufigkeit von $5 \%$ bonitiert.

Die Rapsblüte 2004 war durch häufige Niederschläge und geringe Temperaturen gekennzeichnet. Dies führte zu Beginn der Blüte, zur Vollblüte und zum Ende der Blüte zu insgesamt 108 infektionsgünstigen Stunden. Aufgrund der kühlen Witterung verzögerte sich die Befallsentwicklung nach der Blüte erheblich. Zum abschließenden Boniturtermin (BBCH 75-78) wurden dennoch Befallshäufigkeiten von 74\% beobachtet.

\subsection{Erste Überprüfung des Modellprototyps SkleroPro in Feldversuchen im Jahr 2004}

\subsubsection{Vorhersagegenauigkeit der Behandlungsentscheidung}

Die Überprüfung des Prototyps SkleroPro mit einer festgesetzten Schadensschwelle von 15\% erfolgte an 21 Feldversuchen der Pflanzenschutzdienste der Länder und der Biologischen Bundesanstalt im Jahr 2004. In der Abbildung 43 ist die Vorhersagegenauigkeit des Modellprototyps im Vergleich zu SKLERO dargestellt. Die exakten Behandlungsvorhersagen betrugen bei Anwendung des Prototyps von SkleroPro $57 \%$. Auf $43 \%$ der Flächen wurde der Befall überschätzt, das heißt, dass auf diesen Flächen eine Behandlung von dem Modell empfohlen wurde, diese aber nicht wirtschaftlich gewesen ist. Eine Unterschätzung des Befalls erfolgte im Jahr 2004 nicht.

Das Prognosemodell SKLERO schnitt bei der Vorhersagegenauigkeit etwas schlechter ab, die exakten Vorhersagen betrugen insgesamt 48\%, auf $43 \%$ der Flächen wurde die Behandlung überschätzt und auf $9 \%$ der Flächen unterschätzt. Bei einer Unterschätzung des Befalls bzw. der Behandlungsentscheidung wird keine Behandlung vom Modell 
empfohlen, der wirtschaftliche Schaden durch Ertragsverluste verursacht durch den Befall von S. sclerotiorum ist jedoch höher, als die Bekämpfungskosten gewesen wären.

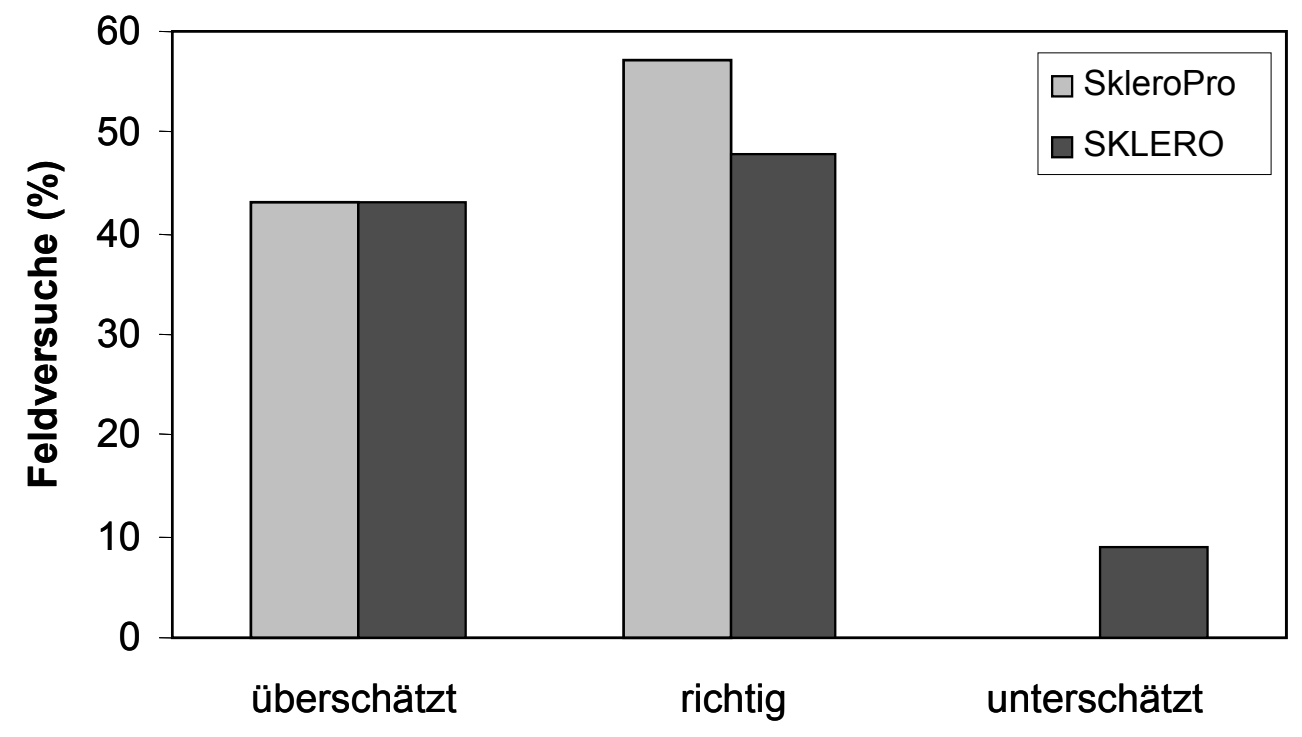

Vorhersage von SkleroPro und SKLERO

Abb. 43: Vorhersagegenauigkeit (\%) des Prototyps SkleroPro und SKLERO anhand von 21 Versuchsstandorten der Pflanzenschutzdienste der Länder aus dem Jahr 2004. Überschätzt $=$ Behandlungsentscheidung von SkleroPro wurde überschätzt, demzufolge war die Behandlung unwirtschaftlich; richtig = wirtschaftliche Behandlungsempfehlung durch SkleroPro; unterschätzt $=$ Behandlungsentscheidung von SkleroPro wurde unterschätzt, demzufolge war die Behandlung unwirtschaftlich.

\subsection{Implementierung von SkleroPro in ISIP und erste Überprüfung im Feld im} Versuchsjahr 2005

Die Praxiseinführung von SkleroPro in ISIP fand im Versuchsjahr 2004/2005 an insgesamt 32 Standorten in Feldversuchen der Pflanzenschutzdienste der Länder und der Biologischen Bundesanstalt statt. Bei der Überprüfung des Modells wurden insbesondere die Vorhersagegenauigkeit, die Effizienz und die Einsparungsmöglichkeiten durch SkleroPro im Vergleich zu Routinebehandlungen genauer untersucht. 


\title{
3.16.1 Vorhersagegenauigkeit der Behandlungsentscheidung
}

Anhand der Modellergebnisse der 32 Feldversuche aus dem Jahr 2005 konnte eine Vorhersagegenauigkeit der Behandlungsentscheidung von $81 \%$ erreicht werden. Eine Überschätzung der Behandlungsentscheidung erfolgte bei 19\% der Feldversuche. Eine Unterschätzung der Prognose konnte in 2005 auf keinem Versuchsstandort festgestellt werden (Abb. 44).

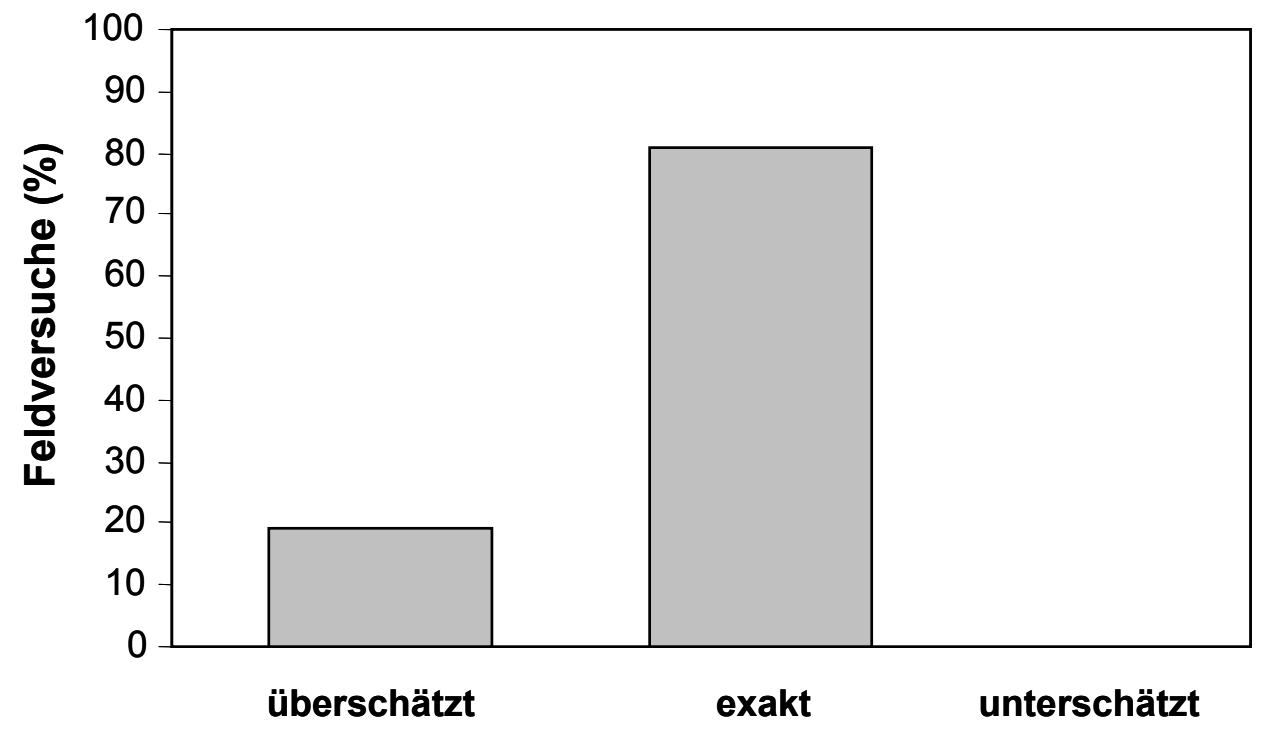

\begin{abstract}
Abb. 44: Vorhersagegenauigkeit (\%) des Modells SkleroPro anhand von 32 Versuchsstandorten der Pflanzenschutzdienste der Länder aus dem Jahr 2005. Überschätzt $=$ Behandlungsentscheidung von SkleroPro wurde überschätzt, demzufolge war die Behandlung unwirtschaftlich; richtig = wirtschaftliche Behandlungsempfehlung durch SkleroPro; unterschätzt $=$ Behandlungsentscheidung von SkleroPro wurde unterschätzt, demzufolge war die Behandlung unwirtschaftlich.
\end{abstract}

Im Versuchsjahr 2005 blieben die Befallshäufigkeiten in allen Regionen Deutschlands auf einem sehr geringen Niveau. Der durchschnittliche Befall lag bei 11\% befallener Pflanzen. Betrachtet man im Jahr 2005 die Routinebehandlungen, so lässt sich erkennen, dass nur 9\% aller Routinebehandlungen zur Vollblüte wirtschaftlich waren. Das heißt, dass 91\% aller Blütenbehandlungen unwirtschaftlich waren und infolgedessen hätten eingespart werden können (Abb. 45). Im Vergleich dazu wurde in dem gleichen Jahr durch die Anwendung von SkleroPro nur auf 25\% der Flächen eine Behandlung empfohlen (Abb. 46), folglich konnte durch die Anwendung von SkleroPro eine Reduzierung des Fungizideinsatzes von $82 \%$ im Vergleich zur Routinebehandlung erzielt werden. 

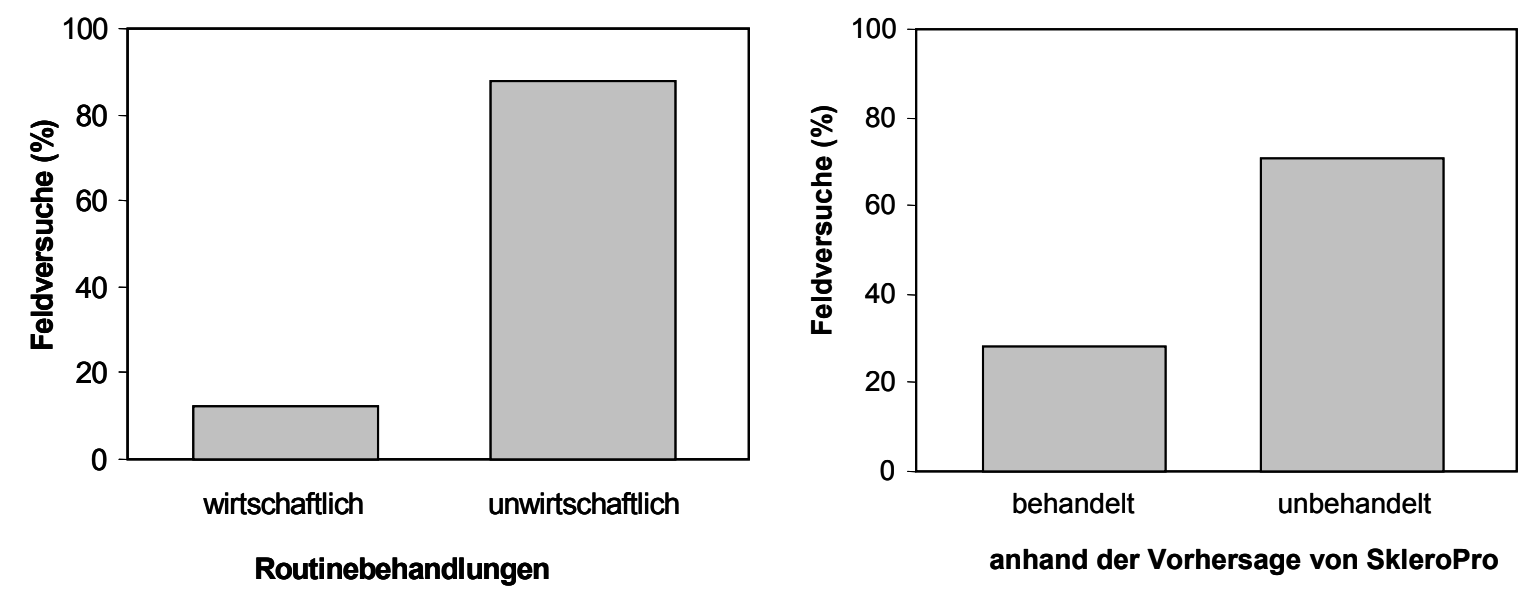

Abb. 45: Wirtschaftlicher und unwirtschaftlicher Anteil (\%) der Routinebehandlungen an 32 Versuchsstandorten der Pflanzenschutzdienste der Länder aus dem Jahr 2005.

Abb. 46: Anteil behandelter und unbehandelter Flächen (\%) durch die Vorhersage von SkleroPro an 32 Versuchsstandorten der Pflanzenschutzdienste und Bundesanstalten der Länder im Jahr 2005.

\subsubsection{Wirtschaftlichkeit}

Um die Wirtschaftlichkeit der Prognosen von SkleroPro zu überprüfen, wurden die durchschnittlichen Erlöse und Erträge der SkleroPro-Varianten mit denen der Routinebzw. Praxisvarianten der Versuchsstandorte aus dem Jahr 2005 ermittelt und miteinander verglichen. Aus Tabelle 12 ist ersichtlich, dass bei Anwendung von SkleroPro ein durchschnittlicher Erlös von 957 Euro/ha erwirtschaftet werden konnte, dagegen wurde bei der Routinebehandlung nur ein durchschnittlicher Erlös von 913 Euro/ha erzielt. Die durchschnittlichen Erträge betrugen bei SkleroPro 48,9 dt/ha und bei der Routine 49,5 dt/ha. Zusammenfassend kann in Hinblick auf die Wirtschaftlichkeit von SkleroPro in 2005 festgehalten werden, dass durch SkleroPro ein durchschnittlicher Mehrerlös von 44,2 Euro/ha bei einer Ertragsminderung von $0,5 \mathrm{dt} / \mathrm{ha} \mathrm{im}$ Vergleich $\mathrm{zu}$ einer Routinebehandlung erzielt werden konnte. Diese Ergebnisse ließen sich statistisch nicht absichern. 
Tab. 13: Durchschnittlicher Ertrag (dt/ha) und Erlös (Euro/ha) von 33 Versuchsstandorten der Pflanzenschutzdienste der Länder und der Bundesanstalt aus dem Jahr 2005 bei Anwendung von SkleroPro im Vergleich einer Routinebehandlung. ( $p \leq 0,05$ nach Tukey)

\begin{tabular}{|l|l|l|c|}
\hline & SkleroPro & Routine & $\begin{array}{c}\text { Durchschn. Mehrerlös (Euro/ha) } \\
\text { und Mehrertrag (dt/ha) durch } \\
\text { Anwendung von SkleroPro } \\
\text { (n= 32; 2005) }\end{array}$ \\
\hline $\begin{array}{l}\text { durchschn. Erlös (Euro/ha) } \\
\text { (n= 32; 2005) }\end{array}$ & 957,1 n.s & 912,9 n.s. & 44,2 \\
\hline $\begin{array}{l}\text { durchschn. Ertrag (dt/ha) } \\
\text { (n= 32; 2005) }\end{array}$ & 48,9 n.s. & 49,5 n.s. & $-0,5$ \\
\hline
\end{tabular}

\subsection{Wirtschaftlichkeit durch exakte Terminierung der Blütenbehandlung}

Im Modell SkleroPro werden nicht nur die infektionsgünstigen Stunden, sondern auch der genaue Tag einer wirtschaftlichen Behandlung prognostiziert. Um zu testen, ob ein exakter Termin einer Behandlungsentscheidung überhaupt notwendig ist, wurden an 9 Feldversuchen der Pflanzenschutzdienste der Länder im Jahr 2005 die behandelten Flächen nach Anwendung des Modells SkleroPro und die Routinebehandlungen miteinander verglichen (Tab. 14). Die Flächen unterschieden sich nur in der prognostizierten Terminierung der Fungizidapplikation durch das Modell. Die Routinebehandlung wurde dagegen immer zum BBCH-Stadium 65 durchgeführt. Bei allen Versuchen wurde das Fungizid Cantus (BASF; Aufwandmenge $=0,5$ 1/ha) eingesetzt. Im Vergleich zur Routinebehandlung konnte durch das neue Prognosemodell SkleroPro ein Mehrertrag von 1,5 dt/ha erzielt werden, womit ein Mehrerlös von 18 Euro/ha erbracht wurde. Diese Ergebnisse ließen sich nicht statistisch absichern. Zusammenfassend lässt sich sagen, dass allein durch die exakte Terminierung der Blütenbehandlung ein höherer Ertrag und ein höherer Erlös erzielt werden können. 
Tab. 14: Effekt der exakten Terminierung der Blütenbehandlung durch die Vorhersage von SkleroPro gegenüber einer Routinebehandlung zu BBCH 65 auf Ertrag und Erlös anhand von 9 Feldversuchen im Jahr 2005. ( $\mathrm{p} \leq 0,05$ nach Tukey; n.s. = nicht signifikant).

\begin{tabular}{|l|c|c|c|}
\hline & SkleroPro & Routine & $\begin{array}{c}\text { durchschn. Mehrerlös (Euro/ha) } \\
\text { und Mehrertrag (dt/ha) durch } \\
\text { Anwendung von SkleroPro } \\
\text { (n= 9; 2005) }\end{array}$ \\
\hline $\begin{array}{l}\text { durchschn. Erlös (Euro/ha) } \\
\text { (n= 9; 2005) }\end{array}$ & 1001 n.s. & 983 n.s. & 18 \\
\hline $\begin{array}{l}\text { durchschn. Ertrag (dt/ha) } \\
(\mathbf{n}=\mathbf{9 ;} \text { 2005) }\end{array}$ & 54,8 n.s. & 53,3 n.s. & 1,5 \\
\hline
\end{tabular}

\subsection{Retrospektive Wirtschaftlichkeitsuntersuchungen von SkleroPro aus den Jahren 1994-2005}

Für die retrospektive Anwendung des Modells SkleroPro wurden die Fungizidversuche im Winterraps der Pflanzenschutzdienste der Länder und die dazugehörigen Wetterdaten aus den Jahren 1994-2004 herangezogen. Die Überprüfung des Modells erfolgte in Bezug auf die Vorhersagegenauigkeit und die Reduktion des Fungizideinsatzes durch die Behandlungsentscheidung von SkleroPro. Bei der rückwirkenden Anwendung des Modells wurden die Behandlungsempfehlungen mit den Blütenbehandlungen aus den Fungizidversuchen im Winterraps der einzelnen Pflanzenschutzdienste der Länder verglichen. Der exakte Applikationstermin der Behandlungsempfehlung von SkleroPro konnte dabei nicht berücksichtigt werden.

\subsubsection{Vorhersagegenauigkeit der Behandlungsentscheidung}

Eine rückwirkende Betrachtung der Wirtschaftlichkeit der Fungizidapplikationen zur Blüte auf der Basis von 108 Versuchsstandorten der Pflanzenschutzdienste der Länder aus den Jahren 1994-2005 und den dazugehörigen Wetterdaten nach den Modellen SkleroPro und SKLERO zeigte, dass durch die Behandlungsentscheidungen von SkleroPro insgesamt 
73\% aller Blütenbehandlungen richtig vorhergesagt wurden und demnach auch wirtschaftlich waren (Abb. 47). In 22\% der Flächen wurde eine Behandlung überschätzt und in 5\% der untersuchten Flächen wurde eine Behandlung unterschätzt. Im Vergleich dazu konnten mit Hilfe des Modells SKLERO 60\% der Flächen richtig bzw. wirtschaftlich behandelt werden. An insgesamt 37\% der Flächen wurde eine Behandlung überschätzt und in 3\% der Fälle wurde eine Behandlung unterschätzt.

Eine nähere Betrachtung der Routinebehandlungen auf diesen Flächen zeigte, dass nur $35 \%$ der Flächen wirtschaftlich behandelt wurden, das heißt, dass 65\% der Behandlungen gegen $S$. sclerotiorum nicht notwendig gewesen wären und somit hätten eingespart werden können.

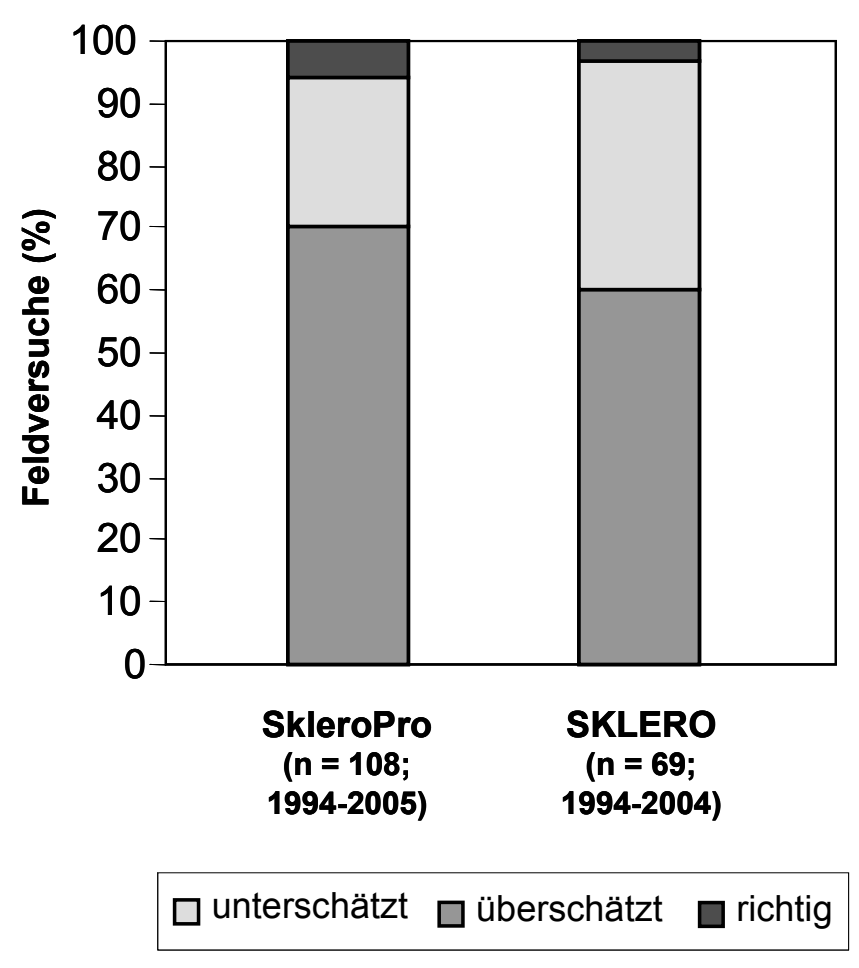

\begin{abstract}
Abb. 47: Vorhersagegenauigkeit der Modelle SkleroPro und SKLERO in Bezug zur Behandlungsentscheidung anhand von 108 bzw. 69 Feldversuchen der Pflanzenschutzdienste der Länder aus den Jahren 1994-2005. Überschätzt = Behandlungsentscheidung von SkleroPro wurde überschätzt, demzufolge war die Behandlung unwirtschaftlich; richtig = wirtschaftliche Behandlungsempfehlung durch SkleroPro; unterschätzt = Behandlungsentscheidung von SkleroPro wurde unterschätzt, demzufolge war die Behandlung unwirtschaftlich.
\end{abstract}




\subsubsection{Reduktion des Fungizideinsatzes durch SkleroPro im Vergleich zur Routinebehandlung}

Im Vergleich zur Routinebehandlung, bei der auf allen untersuchten Flächen $(\mathrm{n}=108)$ aus den Jahren 1994-2005 zur Vollblüte eine Behandlung gegen Sclerotinia appliziert wurde, wurde durch die Vorhersage von SkleroPro nur auf 54\% der Felder eine Blütenbehandlung durchgeführt (Abb. 48). Die Ergebnisse beim Einsatz von SKLERO auf nur 69 Standorten in den Jahren 1994-2004 zeigen, dass für insgesamt 71\% der Flächen eine Behandlung vorhergesagt wurde. Die wirtschaftliche Untersuchung Blütenbehandlungen in diesem Zeitraum zeigte, dass nur 35\% der Routinebehandlung wirtschaftlich waren.

Durch die Vorhersage von SkleroPro konnten damit im Vergleich zur Routinebehandlung Einsparungen im Fungizideinsatz von $72 \%$ erzielt werden. Im Vergleich dazu hätten bei der Anwendung von SKLERO Einsparungen auf 45\% der Versuchsstandorte erzielt werden können.

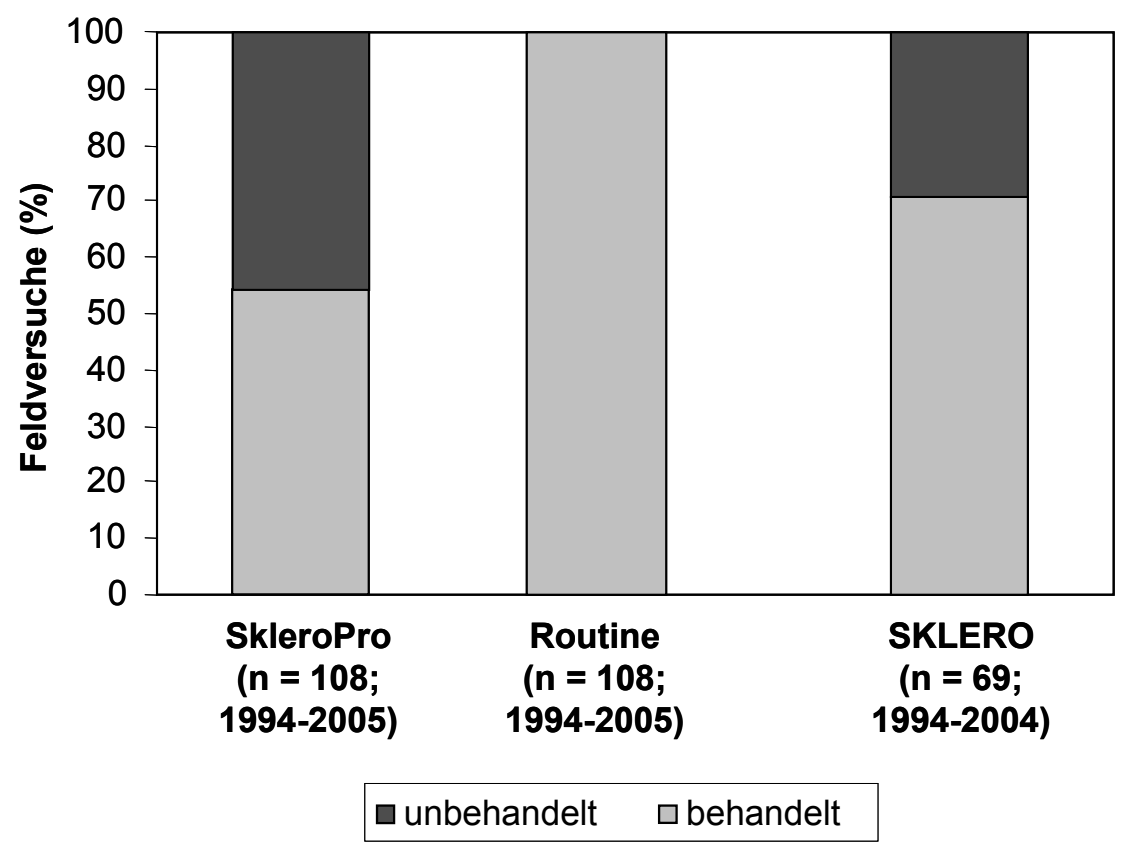

\footnotetext{
Abb. 48: Einsparungen im Fungizideinsatz durch die Modelle SkleroPro und SKLERO im Vergleich zur Routinebehandlung auf Basis von 108 bzw. 69 Versuchen der Pflanzenschutzdienste der Länder aus den Jahren 1994-2005.
} 
Eine nähere Betrachtung der Vorhersage von SkleroPro auf 75 Versuchen der Pflanzenschutzdienste der Länder aus den Jahren 1994-2004 ergab, dass durch die Behandlungsempfehlung ein Mehrertrag von durchschnittlich $5 \mathrm{dt} /$ ha auf den behandelten Flächen erzielt werden konnte (Abb. 49). Das entspricht einem Mehrerlös von 29 Euro/ha. Der kostendeckende Mehrertrag für den betrachteten Zeitraum, der erzielt werden muss, damit sich eine Blütenbehandlung lohnt, liegt bei 4,6 dt/ha. Auf den Flächen, auf denen das Modell keine Behandlungsentscheidung vorhergesagt hat, aber trotzdem eine Blütenblattbehandlung durchgeführt wurde, konnte nur ein Mehrertrag von 1,5 dt/ha erreicht werden. Dies führte dazu, dass Kosten von 50 Euro/ha verursacht wurden. Anhand dieser Ergebnisse wird deutlich, dass durch das Prognosemodell SkleroPro im Vergleich mit einer ortsüblichen bzw. routinemäßigen Fungizidapplikation gegen Sclerotinia deutlich bessere Bekämpfungserfolge bei gleichzeitig reduziertem Pflanzenschutzmittelaufwand erzielt werden konnten. Zusammenfassend lässt sich sagen, dass sich beim Unterlassen einer Behandlung Kosten von bis zu 50 Euro/ha einsparen lassen.

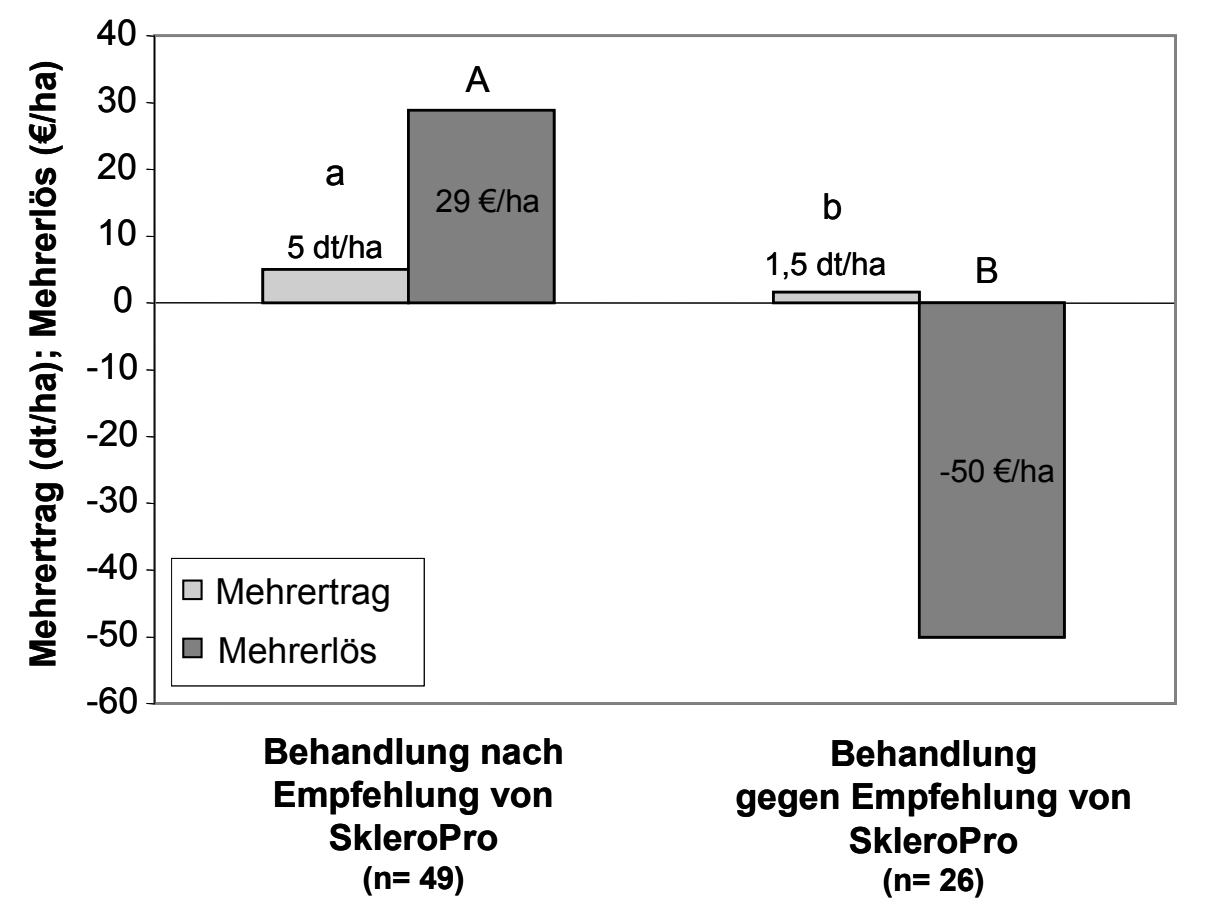

\footnotetext{
Abb. 49: Wirtschaftlichkeit der Sclerotinia-Bekämpfung auf Basis von 75 behandelten Feldversuchen der Pflanzenschutzdienste der Länder aus den Jahren 1994-2004; Vergleichsbasis (Nulllinie): unbehandelte Kontrolle, Unterschiedliche Buchstaben kennzeichnen signifikante Unterschiede, $\mathrm{p} \leq 0,05$ (Tukey-Test). Signifikante Unterschiede sind beim Mehrerlös mit A-B, beim Mehrertrag mit a-b gekennzeichnet.
} 
Bei der Betrachtung der Wirtschaftlichkeit bei Anwendung von SkleroPro im Vergleich zur Routinebehandlung von insgesamt 108 Versuchen der Pflanzenschutzdienste der Länder aus den Jahren 1994-2005 konnte festgestellt werden, dass mit Hilfe von SkleroPro ein Mehrerlös von durchschnittlich 23 Euro/ha erzielt werden konnte (Tab. 13).

Tab. 15: Durchschnittlicher Erlös und Ertrag bei Anwendung von SkleroPro und einer Routinebehandlung zur Vollblüte auf der Basis von insgesamt 108 Versuchsstandorten der Pflanzenschutzdienste der Länder aus den Jahren 1994-2005. ( $\mathrm{p} \leq 0,05$ nach Tukey, n.s. $=$ nicht signifikant).

\begin{tabular}{|l|c|c|c|}
\hline & SkleroPro & Routine & $\begin{array}{c}\text { Durchschn. Mehrerlös (Euro/ha) } \\
\text { und Mehrertrag (dt/ha) durch } \\
\text { Anwendung von SkleroPro } \\
\text { (n= 108; 1994-2005) }\end{array}$ \\
\hline $\begin{array}{l}\text { Durchschn. Erlös (Euro/ha) } \\
\text { (n= 108; 1994-2005) }\end{array}$ & 953 n.s. & 930 n.s. & 23 \\
\hline $\begin{array}{l}\text { Durchschn. Ertrag (dt/ha) } \\
\text { (n= 108; 1994-2005) }\end{array}$ & 47,5 n.s. & 47,4 n.s. & 0,1 \\
\hline
\end{tabular}

\subsection{SkleroPro als Entscheidungsmodell auf der Internet Plattform des Informationssystems integrierte Pflanzenproduktion (ISIP)}

Hauptziel dieser Arbeit war es, ein Prognosemodell zu erarbeiteten, welches über die Internet Plattform ISIP für die landwirtschaftliche Praxis nutzbar gemacht wird. Nach einer ausführlichen Beschreibung des Modells SkleroPro in den vorherigen Kapiteln (3.8 und 3.9), wird in diesem Kapitel näher auf die Darstellung und die Anwendung des Modells in „ISIP“ eingegangen.

Nach der Auswahl der Sclerotinia-Prognose im Winterraps auf der Startseite von ISIP, gelangt man auf eine Deutschlandkarte. Auf dieser Karte kann das gewünschte Gebiet ausgewählt werden, für welches man eine Prognose berechnen lassen möchte. Die Wetterstationen des jeweiligen Gebietes sind als farbige Wolken gekennzeichnet (Abb. $50)$. 


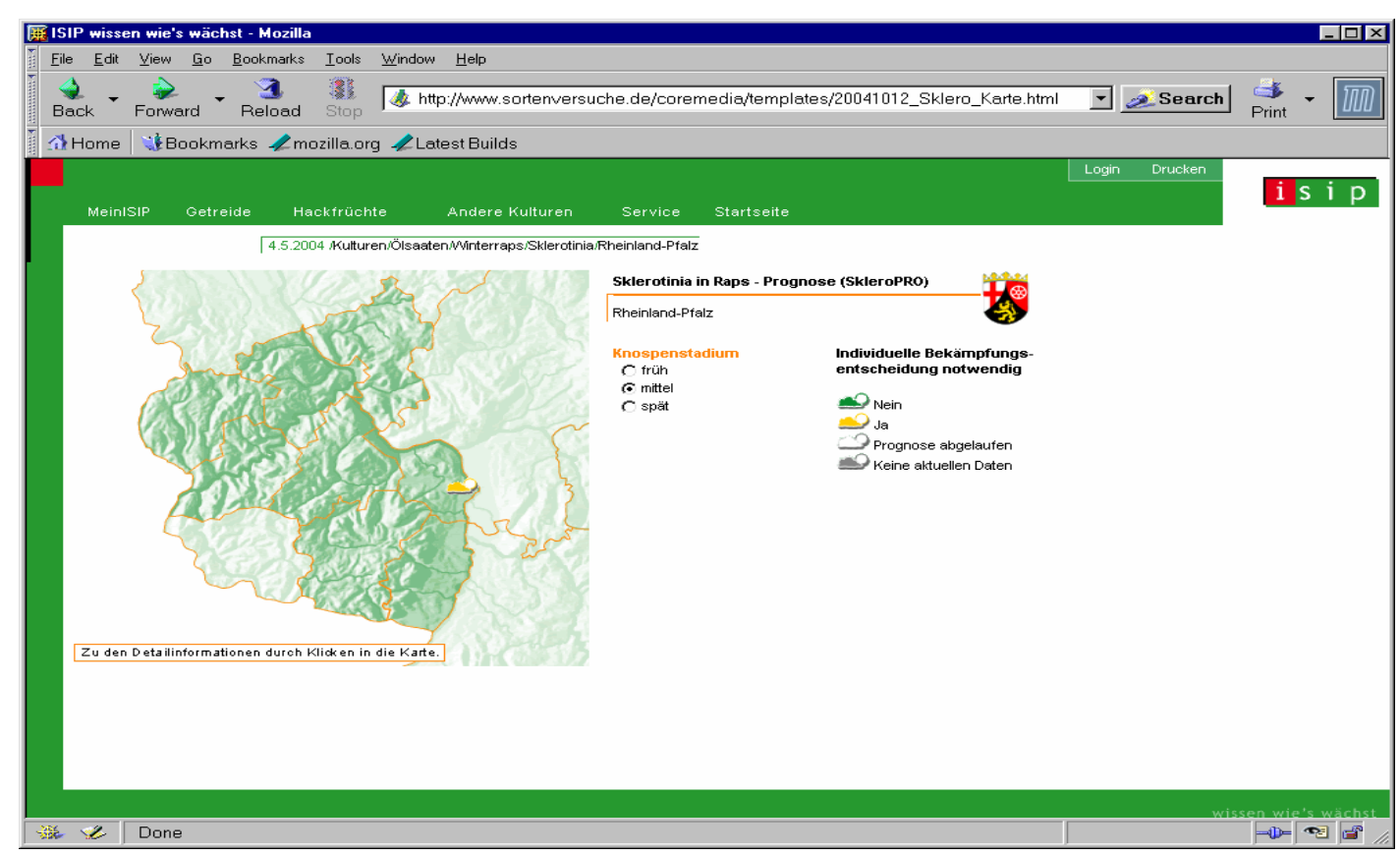

Abb. 50: Anzeige der Wetterstationen im Bundesgebiet mit einer Entscheidung für eine Individualprognose abhängig vom Knospenstadium.

Eine grüne Wolke bedeutet, dass noch keine Individualprognose bzw. schlagspezifische Prognose notwendig ist, da die aktuell gemessenen infektionsgünstigen Stunden noch unter 23 liegen. Eine gelbe Wolke bedeutet, dass die Schwelle der 23 ununterbrochenen Infektionsstunden überschritten ist und eine Individualprognose notwendig ist. Bei einer weißen Wolke ist die Rapsblüte im Umkreis dieser Wetterstation bereits abgelaufen und es ist keine Prognose mehr notwendig. Eine graue Wolke steht dafür, dass derzeit keine aktuellen Wetterdaten für diese Wetterstation verfügbar sind.

Des Weiteren kann der Anwender in diesem Fenster das Knospenstadium im Raps auswählen. Es besteht die Möglichkeit zwischen frühem (<10. April), mittlerem (10.-20. April) und spätem (>20. April) Knospenstadium zu wählen.

Nach Auswahl der nächstgelegenen Wetterstation des Rapsschlages, für welche eine Prognose berechnet werden soll und der Angabe des Knospenstadiums wird dann eine regionale Prognose berechnet (Abb. 51). In der tabellarischen Übersicht wird das Ergebnis der Prognose der gewählten Wetterstation angezeigt. Neben dem Namen der Wetterstation werden das Prognosedatum, das Knospenstadium, das prognostizierte Entwicklungsstadium des Rapses und die Prognoseergebnisse für drei Rapsfruchtfolgen dargestellt. Zusätzlich wird ein Link auf die Individualprognose mittels Anklicken des Taschenrechnersymbols angeboten. Eine schlagspezifische Prognose wird bei einer gelben Wolke empfohlen. 


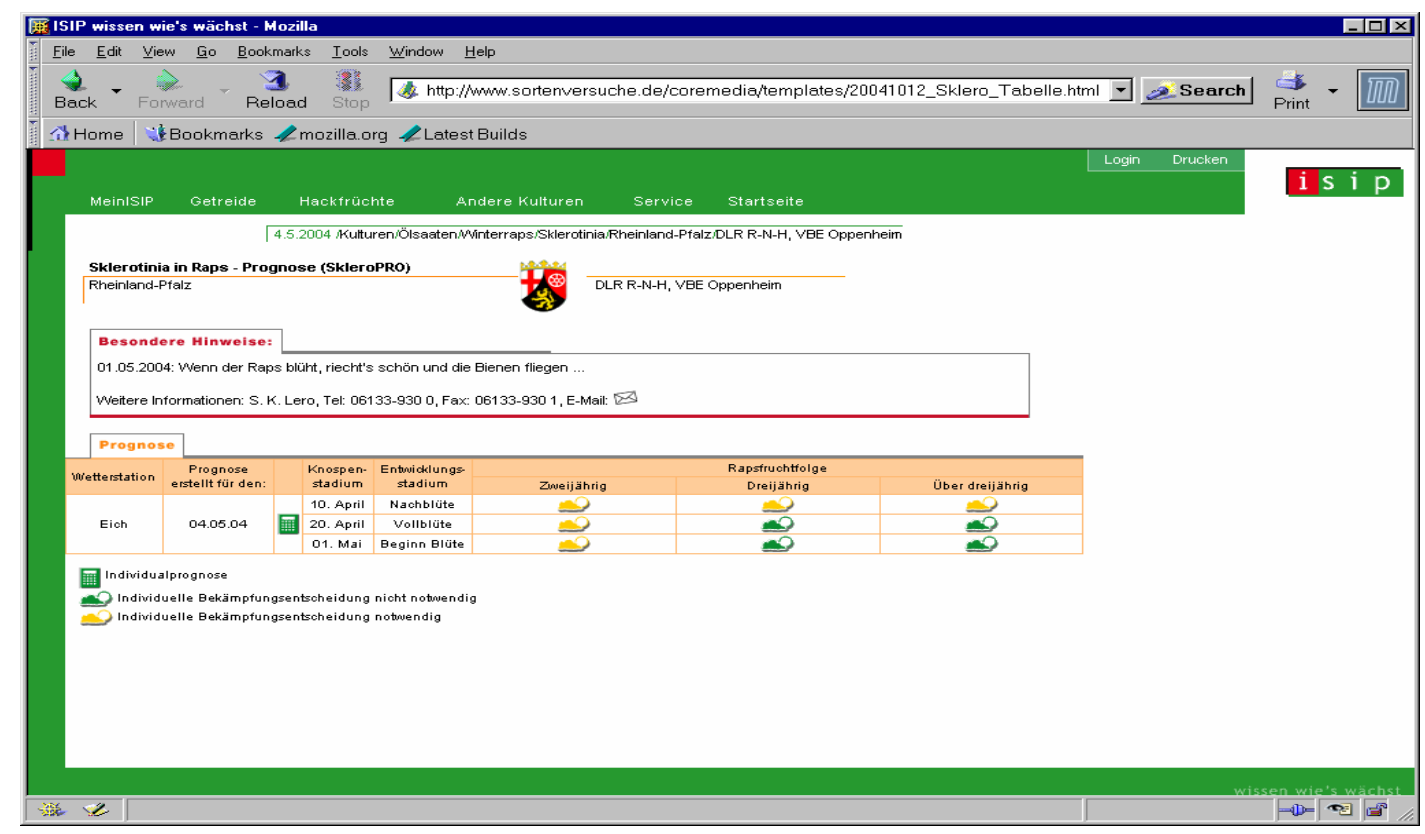

Abb. 51: Regionalprognose für eine Wetterstation mit der Entscheidung für eine Individualprognose abhängig von Knospenstadium und Fruchtfolge.

Nach anklicken des Taschenrechnersymbols kommt man zur Individualprognose bzw. schlagspezifischen Prognose. Für die Berechnung einer Individualprognose müssen folgende Daten in die Tabelle eingetragen werden: Die Wetterstation, das genaue Datum des Knospenstadiums, die Fruchtfolge, der zu erwartende Rapspreis, die Ertragserwartung, die Fungizidkosten und die Überfahrtskosten (Abb. 52).

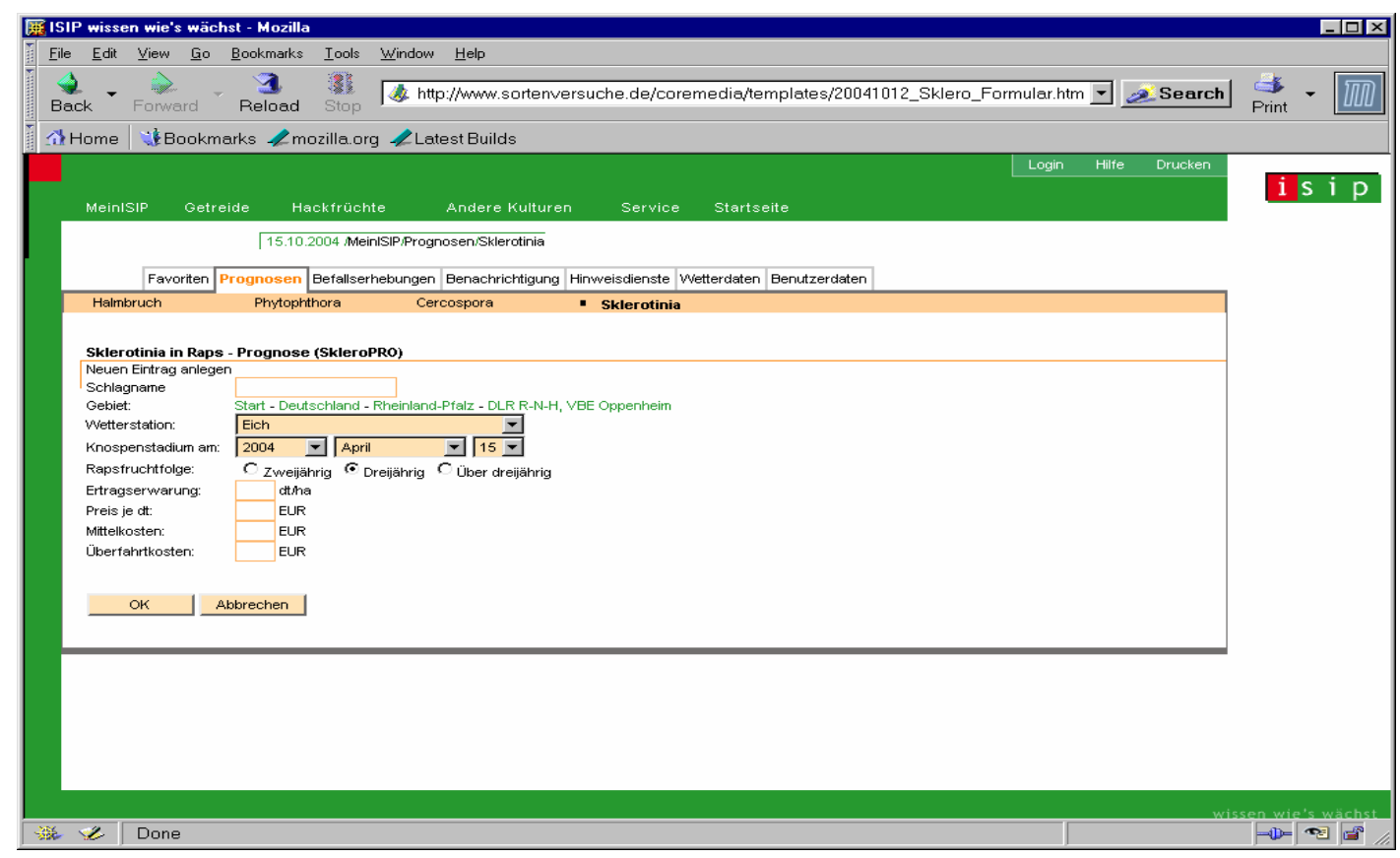

Abb. 52: Individualprognose mit Hilfe der Eingabemaske in ISIP für verschiedene schlagspezifische Eingabeparameter und Berechnung einer schlagspezifischen Behandlungsentscheidung. 
Das Ergebnis einer schlagspezifischen Prognose wird in einer tabellarischen Form ausgegeben (Abb. 53).

In dieser Tabelle sind noch einmal alle individuellen Einstellungen des Anwenders sowie die berechneten Ergebnisse des Modells dargestellt, wie:

- das prognostizierte Entwicklungsstadium

- die Fruchtfolge

- der kostendeckende Mehrertrag

- die ausgewählte Wetterstation

- der Tag für den die Prognose erstellt wurde

- die aktuell berechnete Summe der infektionsgünstigen Stunden

- der zu erreichende Schwellenwert der infektionsgünstigen Stunden

- die Behandlungsempfehlung

Erst wenn die aktuell berechneten infektionsgünstigen Stunden den schlagspezifischen Schwellenwert überschreiten, wird eine Behandlungsempfehlung herausgegeben.

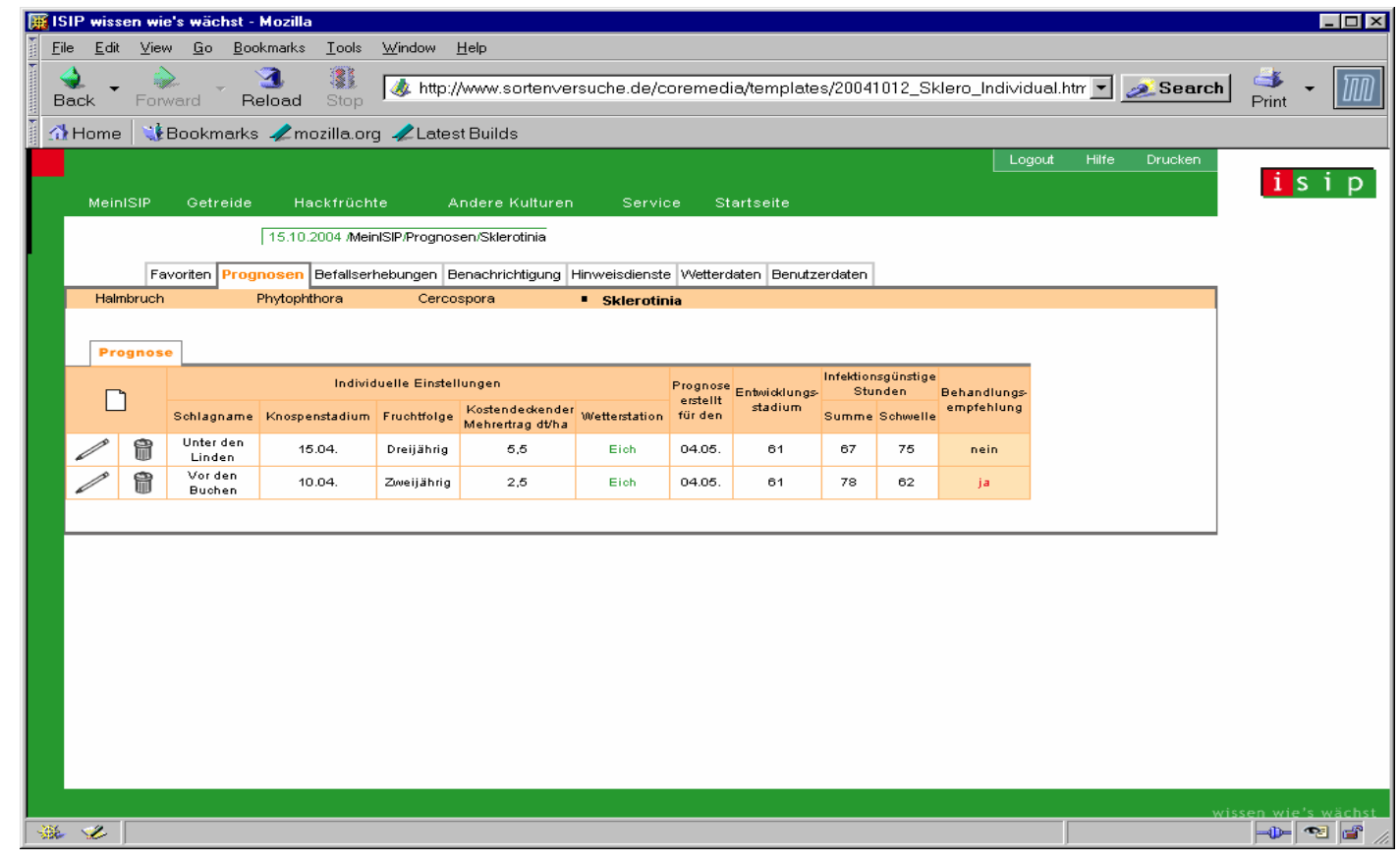

Abb. 53: Beispielhaftes Ergebnis einer schlagspezifischen Individualprognose bei einer dreijährigen bzw. zweijährigen Fruchtfolge in ISIP. 


\section{Diskussion}

Im Mittelpunkt der Untersuchung stand das Ziel, das von FRIESLAND (1999) entwickelte Prognosemodell $\mathrm{zu}$ validieren und basierend auf diesem Modell ein regionales und schlagspezifisches sowie schadensbezogenes Prognosemodell zu entwickeln. Für die Erarbeitung eines verbesserten Modells wurde zunächst das vorhandene Modell SKLERO in Bezug auf die Vorhersagegenauigkeit verschiedener Berechnungen und Simulationen genau untersucht. Zusätzlich konnte durch umfassende statistische Auswertungen von Erhebungsdaten der einzelnen Pflanzenschutzdienste der Länder der Einfluss verschiedener schlagspezifischer Faktoren sowie deren Wechselbeziehungen zueinander auf den Befall mit S. sclerotiorum festgestellt und bewertet werden. Die einflussreichsten Faktoren wurden anschließend in das Modell integriert. Mit der Weiterentwicklung des Modells erfolgten im dritten Versuchsjahr die Überprüfung der Praxistauglichkeit des ersten Prototyps im Feld und schließlich die Einführung in die Praxis über die Internetplattform „ISIP“.

Begleitend zur Entwicklung und Optimierung des Modells wurden verschiedene Verfahren zum Nachweis von S. sclerotiorum auf Blütenblättern getestet. Ziel war es, eine möglichst schnelle und sichere Methode zur frühen Erfassung des zu erwartenden Befalls zu entwickeln, um diese eventuell für eine Überprüfung der Behandlungsentscheidung nutzen zu können. Als mögliche Verfahren wurden der pH-Indikator-Test nach GERMEIER et al. (1999), ein ELISA und eine Real-time PCR entwickelt bzw. optimiert und getestet.

\subsection{Nachweisverfahren für $S$. sclerotiorum auf Blütenblättern}

Eine visuelle Symptombonitur als Entscheidungshilfe für eine Behandlungsmaßnahme gegen $S$. sclerotiorum ist nicht möglich, da die ersten sichtbaren Symptome je nach Witterung an der Pflanze erst 10 - 20 Tage nach dem Infektionsereignis auftreten. Zu diesem Zeitpunkt ist eine Behandlungsmaßnahme im Bestand oft nicht mehr durchführbar, da zum einen die Fungizide nur eine geringe kurative Wirkung haben (PAUL et al., 2000; PAUL, 2005) und zum anderen die Durchfahrtsverluste während der Fungizidapplikation mit zunehmender Abreife des Rapses stark ansteigen. Für eine frühzeitige Diagnose der Krankheit muss daher schon sehr früh, bevor der Stängel infiziert wird, in das 
Infektionsgeschehen eingegriffen werden. Aus diesem Grund wurden verschiedene Verfahren zum Nachweis von Ascosporen von S. sclerotiorum auf Blütenblättern entwickelt (TURKINGTON \& MORALL, 1993; JAMAUX et al., 1994; GERMEIER et al., 1994; FrEEMAN et al., 2002).

\subsubsection{Nachweis von $S$. sclerotiorum mittels pH-Indikator-Test}

Bei der Ausbreitung des Myzels von S. sclerotiorum in der Pflanze sind vor allem Oxalsäure und Polygalacturonsäure sowie Proteasen für den Abbau der Zellwände und die Zerstörung der Zellen verantwortlich, wodurch eine pH-Wert-Absenkung und Permeabilitätsveränderungen stattfinden und Nährstoffe für den Pilz erschlossen werden (Lumsden, 1979; Rollins \& Dickman, 2001; Hegedus et al., 2005). Aufgrund der Bildung und Freisetzung von Oxalsäure kann der Erreger eindeutig durch den Farbumschlag eines pH-Indikatormediums diagnostiziert werden. Der pH-Indikator-Test bietet als Nachweismethode eine einfache und schnelle Methode, um S. sclerotiorum auf Blütenblättern nachzuweisen. Für ein schnelles und sicheres Ergebnis bei der Untersuchung von Feldmaterial mussten vor einem großflächigen praktischen Einsatz die Calciumcarbonat-Mengen optimiert werden. Ein zu hoher Gehalt an Calciumcarbonat puffert die Säurebildung sehr stark ab und es kommt nur zu sehr geringen Verfärbungen. Bei einem zu geringen Calciumcarbonat-Gehalt kann es dazu kommen, dass auch schwach säurebildende Pathogene nachgewiesen werden und somit eine eindeutige Diagnostizierung von S. sclerotiorum nicht mehr möglich ist. Anhand der Ergebnisse erwies sich ein Gehalt von 3g/l Calciumcarbonat als optimal. Nach insgesamt vier Tagen unter NUV-Licht konnte der Befall auf den Blütenblättern festgestellt werden, nach weiteren vier Tagen waren die ersten Sklerotien sichtbar.

HEDKE (1992) nutzte den pH-Indikator-Test bereits zum Nachweis der myzeliogenen Keimung von Sklerotien von S. sclerotiorum. In Untersuchungen von GERMEIER et al. (1994) wurde der pH-Indikator-Test erfolgreich zur Diagnose von Sclerotinia rolfsii an Weizenpflanzen eingesetzt. Als eine weitere Möglichkeit zur Erfassung des Befalls von $S$. sclerotiorum auf Blütenblättern nutzten TURKINGTON \& MORALL (1993) den so genannten Petaltest zur frühzeitigen Diagnose des zu erwartenden Befalls im Feld. In den Untersuchungen wurde der Befall der Blütenblätter zu drei verschiedenen Terminen der Blüte (früher, mittlerer und später Blüte) mittels Agar-Test festgestellt. Anhand der 
Ergebnisse des Petaltests, des Blattflächenindex, der Lichtdurchlässigkeit des Bestandes und der Pflanzenhöhe des Rapses wurde mittels Regressionsanalysen das Befallsauftreten berechnet. Die Erfolgsrate bezüglich des vorhergesagten Befalls wurde mit 73\% angegeben. Auch BOM \& BOLAND (2000) setzten den Petaltest bei der Erfassung des Blütenblattbefalls in Kombination mit der Bodenfeuchte zur Vorhersage des Befalls von $S$. sclerotiorum im Feld ein. Nach Meinung von MCCARTNEY et al. (1999) kann durch den Nachweis von S. sclerotiorum auf Blütenblättern eine gute Vorhersage auf den zu erwartenden Befall im Feld gegeben werden. In den eigenen Untersuchungen aus dem Jahr 2004 konnten ebenfalls eine gute Übereinstimmung zwischen pH-Indikator-Test und Befall im Feld festgestellt werden.

Die geringen Abweichungen zwischen der Klassifizierung des Befalls der Blütenblätter nach pH-Indikator-Test und dem zum BBCH 75 festgestellten Befall im Feld können im wesentlichen dadurch erklärt werden, dass bei dem $\mathrm{pH}$-Indikator-Test die erste Infektionsstufe über Ascosporen nachgewiesen wird, während bei der Erhebung des Befalls der infizierte Stängel bonitiert wird. Eine Infektion der Blütenblätter mit Ascosporen ist jedoch nicht immer gleichzusetzen mit einer Infektion der Stängel. Nur bei optimalen Witterungsbedingungen können die Sporen auskeimen und in das Pflanzengewebe eindringen (AHLERS, 1987; YOUNG et al., 2004). So konnten JAMAUX et al. (1994) in elektronenmikroskopischen Untersuchungen feststellen, dass der Pilz erst nach 70 Stunden bei 99\% Lufteuchte und Raumtemperatur in das Pflanzengewebe eingedrungen ist. In eigenen Untersuchungen wurde unter $7^{\circ} \mathrm{C}$ keine Ascosporenkeimung beobachtet. Aus diesem Grund können die erzielten Ergebnisse mittels pH-Indikator-Test nicht allein für eine Behandlungsentscheidung herangezogen werden, sie können lediglich einen Hinweis auf den zu erwartenden Befall im Feld geben.

Im Hinblick auf die erwähnten Unterschiede zwischen pH-Test und Befall ist auch die untersuchte Probenanzahl zu hinterfragen. Aufgrund der großen Anzahl an Versuchsstandorten und der dreimaligen Beprobung der Flächen während der Blüte konnte nur eine geringe Stichprobe der genommenen Blütenblattproben pro Versuchsfeld untersucht werden. Insgesamt wurden jeweils 36 feste und abgefallene Blütenblätter pro Versuchsfeld untersucht. In Anlehnung daran wurden in dreijährigen Untersuchungen von KRUSE (2004) zur Vorhersage des Befalls von S. sclerotiorum insgesamt 40 Blütenblätter je Probeentnahmeparzelle auf ein Agarmedium ausgelegt, dabei wurden ausschließlich Blütenblätter von ganzen Blüten entnommen. Ergebnisse aus dieser Arbeit zeigten, dass 
nur in einem Untersuchungsjahr eine adäquate Vorhersage durch den Befall der Blütenblätter möglich war. In den anderen Jahren konnte trotz nachgewiesener erhöhter Blütenblattkontamination kein Stängelbefall festgestellt werden. Eventuell müssten daher für ein repräsentatives Ergebnis mehr Blütenblätter pro Versuchsstandort mittels pH-Test untersucht werden.

Die Ergebnisse der Blütenblattuntersuchungen von abgefallen Blütenblättern zeigten eine gute Korrelation zu den Ergebnissen der festen Blütenblätter aus den Versuchsjahren 20022004. Es fiel jedoch auf, dass die abgefallenen Blütenblätter sehr oft einen geringeren Befall aufzeigten, als die festen Blütenblätter. Aufgrund der Tatsache, dass die Apothezien am Boden aufwachsen und von dort die Ascosporen ausschleudern, liegt die Vermutung nahe, dass der Befall von Ascosporen bei abgefallen Blütenblättern in Bodennähe stärker sein müsste, als an noch fest an der Blüte haftenden Blütenblättern. Eine mögliche Erklärung hierfür könnte sein, dass zum einen ein großer Teil der ausgeschleuderten Sporen durch den Wind verbreitet werden und somit auf die oberen Teile der Pflanze gelangen oder ein Teil der Sporen von Nachbarschlägen einfliegen. WILLIAMS \& STELLFOX (1979) stellten in ihren Untersuchungen fest, dass Ascosporen bis zu $150 \mathrm{~m}$ weit mit Hilfe des Windes transportiert werden können. Demnach geht von Nachbarschlägen nur ein mäßiger Infektionsdruck aus, der sich auf die Randflächen eines Feldes beschränkt. Eine mögliche weitere Erklärung, weshalb in den eigenen Untersuchungen die festen Blütenblätter einen höheren Befall zeigten als die abgefallenen, kann vermutlich auch an der starken Seneszenz der abgefallenen Blütenblätter gelegen haben, zudem waren diese verstärkt mit saprophytischen Pathogenen versetzt, so dass die Sporenkeimung bzw. das Myzelwachstum von $S$. sclerotiorum auf dem Indikatormedium durch andere Pilze gehemmt wurde.

Insgesamt kann festgehalten werden, dass durch die mittels $\mathrm{pH}$-Test erfasste Blütenblattkontamination ein Aufschluss über die bis zum Zeitpunkt der Probenahme herrschenden Bedingungen für das Heranreifen der Apothezien und den aktuellen Sporenflug gegeben werden kann. Darüber hinaus bietet der Test eine einfache und kostengünstige Möglichkeit den zu erwartenden Befall im Feld einzuschätzen, wobei es häufig zu einer Überschätzung des Befalls kommen kann (KRUSE, 2004). 


\subsubsection{Nachweis von $S$. sclerotiorum mittels ELISA}

Die ersten serologischen Methoden wurden ursprünglich in der Humanmedizin für die klinische Mikrobiologie entwickelt. In den 70er Jahren wurden von CLARK und ADAMS

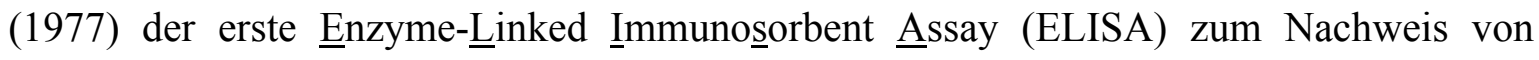
Pflanzenviren entwickelt. Daraufhin folgten weitere ELISA Tests zum Nachweis von phytopathologischen Pilzen an der Pflanze und im Boden (NACHMIAS et al., 1979; CASPER \& Mendgen, 1979; Unger, 1989; Cernusko, 1995; HepPner, 1995). Die ersten Ansätze zum quantitativen Nachweis von S. sclerotiorum auf Blütenblättern mittels ELISA wurden von JAMAUX \& SPIRE (1994) durchgeführt. In diesen ersten Untersuchungen wurden von zwei verschiedenen polyklonalen Antiseren, welche aus Antikörpern, die aus Myzelproteinen und Ascosporenproteinen gewonnen wurden, die Spezifität und die Sensitivität überprüft. In diesen Untersuchungen wurde keine Überprüfung der Antiseren anhand von Feldmaterial durchgeführt.

Die Art der verwendeten Antigene ist entscheidend für die Qualität des Antiserums. Für die Herstellung von $S$. sclerotiorum spezifischen Antikörpern wurden zwei Antigenfraktionen verwendet, die zum einen aus Myzelhomogenat und zum anderen aus Kulturfiltrat durch unterschiedliche Aufarbeitung hergestellt wurden. Die Anzucht des in den eigenen Untersuchungen verwendeten Myzels und Kulturfiltrates erfolgte jeweils auf Czapek-Dox-Medium mit Pepton (CPDP) (WOLF, 2003). In der vorliegenden Arbeit erwies sich das gewonnene Antiserum, welches gegen lösliche Myzelkomponenten hergestellt wurden, als weniger spezifisch im Hinblick auf andere Pathogene und wurde daher nicht weiter in die Untersuchungen mit aufgenommen.

Auch UNGER (1989) setzte in seinen Untersuchungen Kulturfiltrate zur Herstellung von Fusarium spezifischen Antikörpern ein. VON SCHWARZENBERG (1984) berichtet über Verwendung von Antigenen aus Myzelhomogenaten. Im ELISA können sowohl monoklonale, polyklonale und monospezifische Antikörper verwendet werden. Monoklonale Antikörper entstehen durch Klonung einer Zelllinie. Alle von einem solchen einzelnen „Zellklon“ gebildeten Antikörper sind demnach baugleich und auf die Erkennung nur einer bestimmten Struktur oder eines bestimmten Merkmals spezialisiert (Peters \& Baumgarten, 1990) Der Vorteil der monoklonalen Antikörper liegt in der höheren Spezifität gegenüber verwandten Arten. Als nachteilig erweisen sich jedoch die höheren Kosten bei der Herstellung der Antikörper. Zudem kann die hohe Empfindlichkeit 
dazu führen, dass verschiedene Isolate des nachzuweisenden Pathogens immunologisch nicht mehr erkannt werden können. Ebenso zeichnen sich auch die monospezifischen Antikörper durch ihre hohe Spezifität aus. Bei der Anwendung für pilzliche Erreger wurde nur eine geringe Abnahme der Kreuzreaktionen beobachtet, zudem nahm aber die Empfindlichkeit gegenüber dem zu untersuchenden Pathogen ab (FoRTNAGEL, 1994). Durch die Immunisierung von Myzel oder Kulturfiltrat werden viele Antigene bereitgestellt, so dass die Antikörper gegen viele Antigene gebildet werden können. Polyklonale Antikörper zeichnen sich zwar durch eine hohe Empfindlichkeit aus, es kann aber, verursacht durch die höhere Vielfalt von Antikörpern im Serum, zu einer Verringerung der Spezifität kommen (ForTNAGEL, 1994). Bei den eigenen Untersuchungen wurde ein polyklonales Antiserum, welches aus Kulturfiltrat gewonnen wurde, verwendet.

Neben dem indirekten ELISA (UNGER, 1989) werden für die Untersuchung pilzlicher Schaderreger in den meisten Fällen auch der direkte oder Double-Anntibody-Sandwich (DAS)-ELISA oder der Biotin-Avidin (BA)-ELISA eingesetzt (JAMAUX \& SPIRE, 1994; Cernusko, 1995; VolKe, 1999). Im Gegensatz zu dem direkten ELISA werden bei dem indirekten ELISA die Mikrotiterplatten zuerst mit der Probe beschichtet. Dabei konkurrieren die Antigene mit anderen in der Probe enthaltenen Substanzen um die Bindungsplätze und es können unspezifische Reaktionen auftreten. Die Nachweisempfindlichkeit kann somit geringer sein als bei dem direkten ELISA (CERNUSKO, 1995). In den eigenen Untersuchungen wurde der DAS-ELISA mit biotinylierten Antikörpern eingesetzt, da wir davon ausgehen mussten, dass die nachzuweisenden Proteine von Ascosporen von $S$. sclerotiorum bei befallenen Blütenblättern nur in einer sehr geringen Konzentration vorliegen.

In einem ersten Schritt mussten einige Parameter für den ELISA überprüft und optimiert werden. Dabei wurde zunächst nach der optimalen Verdünnung der Antikörper und der biotinylierten Antikörper gesucht. Berücksichtigung fanden hier die Extinktionen der Standardreihe. Es stellte sich heraus, dass die optimalen Konzentrationen sowohl bei einem Verdünnungsgrad der IgG von 1:500 und der bio. IgG von 1:1000 als auch bei einem Verdünnungsgrad von 1:1000 IgG und 1:500 bio. IgG erreicht wurde. Für einen praktischen Einsatz und um die Kosten des ELISA gering zu halten, reichte aber auch eine Konzentration sowohl bei dem Beschichtungs-IgG als auch bei den biotinylierten IgG von $1 \mu 1 / \mathrm{ml}$ (= verd. $1: 1000)$ aus. 
Für den Einsatz des ELISA mit Freilandmaterial ist es von entscheidender Bedeutung, dass das gewonnene Antiserum nur auf das zu untersuchende Pathogen reagiert. Beim Auftreten von Kreuzreaktionen mit anderen am Raps vorkommenden Schaderregern wäre der Test nicht mehr brauchbar. Für die Untersuchung der Spezifität wurde zuerst die Reaktion auf verschiedene Sclerotinia-Isolate untersucht, da man davon ausgehen kann, dass im Freiland unterschiedliche Isolate von S. sclerotiorum in einer Region bzw. sogar auf einer Pflanze auftreten können. Hierfür wurden Myzelextrakte aus in vitro Kulturen von 12 verschiedenen Sclerotinia-Isolaten, die zum größten Teil von Rapspflanzen isoliert wurden, gewonnen. Die Ergebnisse zeigten, dass der ELISA auf alle Sclerotinia-Isolate reagierte. Zur Untersuchung von Kreuzreaktionen wurden Myzelextrakte in vitro von 13 verschiedenen Isolaten und 6 Pathogenarten (Fusarium, Alternaria, Phoma, Verticillium, Botrytis, Rhizoctonia) gewonnen. Bei allen getesteten Arten konnten keine positiven Reaktionen festgestellt werden, die gemessenen Extinktionen lagen alle unterhalb der Nachweisgrenze. Nichtbehandelte Kontrollblütenblätter zeigten in keinem Fall eine Reaktion. Bei der Untersuchung von $S$. sclerotiorum auf Blütenblättern ist die Nachweisgrenze von besonderer Bedeutung, da nur mit geringen Mengen von Ascosporen bzw. gebildeten Myzel in und auf den Blütenblättern zu rechnen ist. LEFOL \& MORRALL (1996) konnten mit Hilfe einer Immounofluoreszenz-Färbung von Ascosporen auf Blütenblättern beobachten, dass die Anzahl von Ascosporen auf Blütenblättern, welche vom Feld gesammelt wurden, von 0 bis über 100 Ascosporen pro Blütenblatt variieren kann.

Die Nachweisgrenze für den ELISA sollte daher bei einem sehr niedrigen Proteinbereich liegen. In der Literatur sind oft Nachweisgrenzen von 10-50 ng Protein/ml beschrieben (Unger, 1989; Fortnagel, 1994). Nach Clark \& AdAMS (1977) können Antigene Substanzen bis $\mathrm{zu}$ einer Konzentration von $1 \mathrm{ng} / \mathrm{ml}$ Protein im ELISA nachgewiesen werden. In den Untersuchungen von JAMAUX \& SPIRE (1994) lag die Nachweisgrenze für S. sclerotiorum bei $5 \mathrm{ng}$ Protein $/ \mathrm{ml}$. In der vorliegenden Arbeit wurde eine Nachweisgrenze von $2 \mathrm{ng} / \mathrm{ml}$ Pilzprotein erreicht.

Bei der Untersuchung von Blütenblattproben aus dem Feld wurde zwischen abgefallenen und noch fest an der Blüte haftenden Blütenblättern unterschieden. Im ersten Testjahr wurden vermehrt falsch-positive Signale von den abgefallenen Blütenblättern beobachtet. Eine mögliche Vermutung der erhöhten unspezifischen Reaktionen lag in den anhaftenden Bodenpartikeln an den abgefallenen Blütenblättern. Aus diesem Grund wurden in einer 
weiteren Testreihe verschiedene Bodenproben extrahiert und überprüft. Die Ergebnisse zeigten, dass der ELISA verstärkt auf verschiedene Bodenherkünfte reagierte. Auch HEPPNER (1995) berichtet über unspezifische Reaktionen beim Einsatz des direkten ELISA zum Nachweis von Verticillium dahliae bei unverseuchten Bodenproben. Diese konnten jedoch bei einem Zusatz von 1\% Casein, 0,1\% Triton X-100 und 20 nM EDTA zum Extraktionspuffer um 70\% reduziert werden. Diese Methode wurde auch in der vorliegenden Arbeit zur Verminderung der unspezifischen Reaktionen gewählt. Es zeigte sich aber, dass durch den Zusatz die Sensitivität des ELISA so stark vermindert wurde, dass auch in den gering befallenen Proben sowie in der Standardreihe keine Reaktion mehr gemessen werden konnte. Aus diesem Grund wurden in den weiteren Versuchsjahren nur noch die Blütenblätter zum Nachweis von S. sclerotiorum mittels ELISA herangezogen, die sich fest an der Blüte befanden.

Obwohl der ELISA mit in vitro Material sehr gute und sichere Ergebnisse lieferte, konnte keine Korrelation zwischen den untersuchten Feldproben aus den drei Versuchsjahren hinsichtlich der erhobenen Befallshäufigkeiten festgestellt werden. Vermutlich kann es auch bei den fest an der Blüte haftenden Blütenblättern zu unspezifischen Reaktionen gekommen sein, obgleich hier visuell keine Verunreinigungen festgestellt werden konnten.

Dies würde auch die höheren Extinktionen im befallsfreien Material erklären. Eine weitere mögliche Erklärung könnte darin liegen, dass die Grenze der nachzuweisenden Poteinmenge noch $\mathrm{zu}$ hoch ist und somit die geringen Sporen oder Myzelmengen auf den Blütenblättern nicht nachgewiesen werden konnten. Auch in den Untersuchungen von JAMAUX \& SPIRE (1994) wurden Probleme in der relativ hohen Nachweisgrenze von 5000 Sporen $/ \mathrm{ml}$ und $5 \mathrm{ng} / \mathrm{ml}$ Protein gesehen. Für eine Anwendung des ELISA mit Freilandmaterial müssten hier noch weitere Untersuchungen folgen.

\subsubsection{Nachweis von $S$. sclerotiorum mittels Real-time PCR}

Mit Hilfe der Polymerase-Kettenreaktion (PCR) ist es möglich, spezifische Sequenzbereiche aus geringsten Ausgangskonzentrationen von Nukleinsäuren in vitro und zudem schnell zu amplifizieren. Erstmals wurde die PCR Mitte der 80er Jahre durch Karl Mullis beschrieben (NICHOLL, 2002). Nach erfolgreichem Einsatz dieser Methode im humanmedizinischen Bereich zum Nachweis von Mutationen im Genom (wie zum Beispiel der Sichelzellanämie) findet sie ihre Anwendung heute auch zum Nachweis von 
Viren, Bakterien und Pilzen in der Pflanzenpathologie (HENSON \& FrenCH, 1993; KoOpMAnN, 1995; Nicholson et al., 1998; NABIZADEH-ARDEKANI, 1999; BENTE, 2003). Der Nachweis mittels PCR für phytopthogener Pilze in Raps wurden bereits für Verticillium longisporum (STEVENTON et al., 2002; DUNKER, 2005) und für S. sclerotiorum (FREEMAN et al., 2002) durchgeführt. Neben der konventionellen PCR wird seit den letzten Jahren auch vermehrt die quantitative Real-time PCR zum Nachweis von phytopathogenen Pilzen eingesetzt. Diese relativ neue Technik wurde zu Beginn der 90er Jahre entwickelt und ermöglicht eine Kombination der DNA-Amplifikation mit der Detektion des Produktes in einem einzigen Reaktionsansatz. Dadurch entfallen zeitaufwendige Auswertungen der Ergebnisse mittels Agarose-Gelelektrophorese. Bei der Real-time PCR erfolgt die Auswertung durch Messung der Fluoreszenz während der laufenden PCR. Dies kann zum einen mit Hilfe eines interkalierenden Farbstoffs oder mit fluoreszenzmarkierenden Sonden erfolgen (MÜlLER, 2001; JUNG et al., 2004; BÄUMLER, 2004). Bei beiden Methoden ist der Anstieg der Fluoreszenz proportional $\mathrm{zu}$ dem gebildeten Amplifikationsprodukt, wodurch ein quantitativer Nachweis der DNA-Konzentration des Ausgangsprodukts ermöglicht wird. SybrGreen ist ein interkalierender Farbstoff, der sich zwischen die doppelsträngigen Nukleinsäuren binden und daraufhin unter Anregung von kurzwelligem UV-Licht längerwelliges Licht emittieren kann. Die Stärke des Fluoreszenzsignals ist direkt mit der Menge neu synthetisierter DNA korreliert. Bei der TaqMan Sonde befindet sich am 5'Ende ein fluorogener Reporterfarbstoff, während sich an dem 3'Ende ein Quenchermolekül befindet. Nach der Denaturierung der DNA-Matritze und Anlagerung der sequenzspezifischen Oligonukleotide werden sowohl das 3'als auch das 5'Ende durch die Taq-DNA-Polymerase getrennt. Das Fluorophor wird somit vom Quencher getrennt und nach Anregung wird Licht in der erwarteten Wellenlänge emittiert (MÜLLER, 2001).

Aufgrund der Quantifizierung des nachzuweisenden Schaderregers hat sich diese Technik auch in der Pflanzenpathologie und Virologie für den quantitativen Nachweis von Pilzen durchgesetzt (JUNG et al., 2001; BATES et al., 2001; DELANOY et al., 2003; WAALWIJK et al., 2004; SALM \& GEIDER, 2004). In der vorliegenden Arbeit wurden die spezifischen $S$. sclerotiorum Primer SSFW und SSREV eingesetzt, die bereits von FREEMAN et al. (2002) etabliert wurden. Diese Primer basieren auf von WHITE et al. (1990) entwickelten ITS Primern. Die ITS3/ITS4 Primer amplifizieren ribosomale DNA vom 28S-Gen und 28SGen, dabei ist die Region des 5.8S-Gens eingeschlossen (WHITE et al., 1990). Das 
Primerpaar SSFW/SSREV amplifiziert eine Region, die in diesem Bereich der amplifizierten ITS-Primer liegt (FREEMAN et al., 2002). Die IST- (internal transcribed spacer) Regionen sind sehr variabel und werden häufig benutzt, um verschiedene Spezies voneinander zu unterscheiden (EDWARDS et al., 2002).

In einem ersten Schritt erfolgte die Validierung und anschließende Optimierung des Reaktionsansatzes in der konventionellen PCR. Zunächst wurden verschiedene Magnesiumkonzentrationen und Annealingtemperaturen in einem Reaktionsansatz überprüft. Im Gegensatz zum Reaktionsansatz von FrEEMAN et al. (2002), bei dem eine Annealingtemperatur von $65^{\circ} \mathrm{C}$ und eine Magnesiumkonzentration von $1 \mathrm{mM}$ angegeben wurde, stellte sich in der vorliegenden Arbeit heraus, dass die beste Amplifikationsrate bei einer Annealingtemperatur von $68^{\circ} \mathrm{C}$ und einer Magnesiumkonzentration von 2,5 mM erreicht wurde. Für die Sicherheit eines PCR-Nachweises, besonders bei der Untersuchung von Freilandmaterial, spielen mögliche Kreuzreaktionen mit anderen Pathogenen eine große Rolle. Aus diesem Grund wurde zunächst in der konventionellen PCR die Spezifität der Primer gegenüber DNA-Proben verschiedener Pathogenarten überprüft. Dabei wurden Schaderreger ausgewählt, die zum einen an der Rapspflanze vorkommen oder deren Sporen auf die Blütenblätter von Raps gelangen können. Kreuzreaktionen traten bei keinem der getesteten Arten auf. Diese Ergebnisse stehen in Einklang mit den Ergebnissen von FreEMAN et al. (2002). Neben der Empfindlichkeit der PCR und der Spezifität der Primer wird die Sicherheit des Nachweissystems besonders von der Breite der erfassbaren Sclerotinia-Isolate beeinflusst. Für die Untersuchung wurden insgesamt zehn SclerotiniaIsolate unterschiedlicher Herkunft gestestet. Alle Isolate zeigten in der PCR ein positives Signal. Auch FrEEMAN et al. (2002) testeten in ihren Untersuchungen 10 verschiedene Sclerotinia-Isolate und konnten bei allen untersuchten Isolaten eine positive Reaktion beobachten.

Die Ergebnisse des optimierten Reaktionsansatzes und der Spezifität der Primer waren in der konventionellen PCR positiv, so dass auf dieser Grundlage in einem zweiten Schritt die Real-time PCR aufgebaut werden konnte. Aufgrund der höheren Sensitivität der Real-time PCR musste auch hier noch einmal die Spezifität und die Empfindlichkeit der Primer untersucht werden. Im Folgenden wurden für die Spezifität und die Empfindlichkeit die gleichen Pathogene und Sclerotinia-Isolate wie bei der konventionellen PCR eingesetzt. Bei der Spezifitätsuntersuchung zeigte sich, dass außer bei dem Phoma-Isolat bei allen anderen Isolaten positive Reaktionen gemessen wurden. Diese positiven Signale traten 
aber erst sehr spät bei einem Ct-Wert von über 30 bzw. 33 auf. Die Schmelzkurvenanalyse zeigte jedoch, dass es sich bei den Signalen um unspezifisch amplifizierte Produkte handelte, deren Schmelzpunkte unterhalb des spezifischen Amplifikationsproduktes lagen.

Bei der Untersuchung der Empfindlichkeit der Real-time PCR auf der Grundlage von 10 verschiedenen Sclerotinia-Isolaten konnte bei allen Isolaten ein spezifisches Amplifikationsprodukt gemessen werden. Die Schmelztemperatur lag bei allen untersuchten Sclerotinia-Isolaten bei $89^{\circ} \mathrm{C}$.

Für den Nachweis von Sporen in oder an Pflanzenmaterial ist die Nachweisgrenze ein entscheidendes Kriterium für den erfolgreichen Einsatz der Real-time PCR. Zur Überprüfung der Sensitivität der Primer wurde zunächst die DNA aus verschiedenen Verdünnungsstufen der Sporensuspensionen isoliert. In Untersuchungen von FREEMAN et al. (2002) wurden die besten Detektionsergebnisse bei der Isolierung der DNA bei vorgeschalteter Aufspaltung der Sporen mittels Bellotini-Kugeln auf dem Schüttler erreicht. Der Nachweis von unbehandelten Sporensuspensionen und zuvor behandelter Sporen ohne DNA-Isolierung lieferten keine zufrieden stellenden Ergebnisse. Die in der vorliegenden Arbeit ermittelte Nachweisgrenze lag bei 5 Ascosporen. In Untersuchungen mit luftbürtigen Sporen von Penicillium roqueforti konnte mittels nestedPCR eine einzelne Spore nachgewiesen werden (WILLIAMS et al., 2001).

Mittels Real-time PCR konnte gezeigt werden, dass ein Nachweis von S. sclerotiorum auf Blütenblättern aus dem Feld möglich ist. Eine genaue Quantifizierung der DNA-Menge ist jedoch nicht durchführbar, da sich die zu amplifizierenden DNA-Mengen im Bereich der Nachweisgrenze von fünf Sporen oder sogar weniger befanden. Eine Aussage über den zu erwartenden Befall im Feld ist ebenso wie bei dem pH-Test anhand der Ergebnisse der Real-time PCR nicht zu treffen. Um deutlichere Angaben über die Vorhersagegenauigkeit des Befalls der Blütenblätter mittels Real-time PCR treffen zu können, sind weiterführende Untersuchungen mit Feldmaterial notwendig. 


\subsection{Einfluss schlagspezifischer Parameter auf den Befall mit $S$. sclerotiorum}

Die Analyse einzelner schlagspezifischer Faktoren in Bezug zum Befallsauftreten von phytopathogenen Krankheiten ist insofern schwierig, da sich die acker- und pflanzenbaulichen Maßnahmen oft nicht im Einzelnen auf die Krankheit auswirken, sondern nur im Zusammenwirken von mehreren Faktoren. So wird zum Beispiel die Bestandesdichte sowohl von der Aussaatstärke, der Stickstoffdüngung als auch von der Pflanzenentwicklung beeinflusst. Zusätzlich werden diese Faktoren mehr oder weniger von den jährlich schwankenden Witterungsbedingungen und dem technischen Fortschritt in der Pflanzenproduktion reguliert.

Um den Einfluss verschiedener schlagspezifischer Faktoren auf den Befall zu analysieren, wurde zuvor eine Einteilung der einzelnen Faktoren in verschiedene sachlogische Gruppen vorgenommen. Eine Einteilung der Rapsfruchtfolge kann zum Beispiel in der Differenzierung zweijährige, dreijährige und mehrjährige Rapsfruchtfolge bestehen. Die Einteilung der einzelnen Parameter hatte zur Folge, dass die Anzahl der Stichproben besonders in den äußeren Gruppen stark variierte. Zudem waren durch die starke Streuung der Befallshäufigkeiten in den einzelnen Gruppen die Voraussetzungen für eine Normalverteilung des Stichprobenumfangs nicht geben. Aus diesem Grund wurde eine verteilungsunabhängige, die so genannte nichtparametrische Varianzanalyse, für die Berechnung der einzelnen Parameter sowie deren Wechselbeziehungen zueinander ausgewählt. Bei dieser Methode werden nicht die einzelnen Messwerte verwendet, sondern den Werten werden Ränge zugewiesen. Der Nachteil dieses Verfahren ist jedoch, dass es nicht so sensitiv arbeitet wie die Methoden, die für eine Normalverteilung zugeschnitten sind (SACHS, 1992).

Die Erhebungen einzelner schlagspezifischer Faktoren schwankten in den einzelnen Bundesländern sehr stark, so dass bestimmte Faktoren nur in wenigen Bundesländern erhoben wurden. Der komplette Datensatz mit einer Anzahl von 811 Stichproben war somit nur für sehr wenige Faktoren zu verwenden. Für die anderen Parameter wurde der gesamte Datensatz nach Regionen bzw. Pflanzenschutzamt eingeteilt und einzeln ausgewertet. 
In der vorliegenden Arbeit konnte kein signifikanter Einfluss der beiden Bodenbearbeitungsvarianten, wendende Bodenbearbeitung mit dem Pflug und nichtwendende Bodenbearbeitung mit dem Grubber, festgestellt werden. Es zeigt sich jedoch die Tendenz, dass durch die tiefe wendende Bearbeitung der Befall mit $S$. sclerotiorum geringer ist als bei flacher Bodenbearbeitung.

Im Gegensatz dazu konnte WAHMHOFF (1999) in seinen Versuchen feststellen, dass nach flacher Bodenbearbeitung die Anzahl wieder gefundener Sklerotien im Folgejahr vermindert war. Dagegen war durch tiefes Eingraben nicht nur die Überlebensrate der Sklerotien höher, sondern auch die Anzahl karpogen keimfähiger Sklerotien war gegenüber der flachen Einarbeitung erhöht. Eine mögliche Erklärung für den schnellen Abbau bei flacher Bodenbearbeitung kann womöglich an der höheren biologischen Aktivität in den oberen Bodenschichten liegen. In biologisch aktiven Ackerböden konnte innerhalb von 6 Wochen durch den Mykoparasiten Coniothyrium minitans, der in den oberen Bodenschichten seine größte Wirkung entfaltet, eine Reduktion der Sklerotien von $40 \%$ beobachtet werden (VON TIEDEMANN et al., 2000). Des Weiteren werden die Sklerotien nahe der Bodenoberfläche stärker zum Keimen stimuliert als in tieferen Bodenschichten. So fanden SINGH \& SINGH (1983) heraus, dass die Sklerotien ab einer Tiefe von 4-6 cm in Abhängigkeit von verschiedenen Bodentypen nicht mehr auskeimen. KRÜGER (1975) stellte fest, dass bereits bei einer Tiefe von $3 \mathrm{~cm}$ die Sklerotienkeimung deutlich reduziert ist. Andere Autoren berichten ebenfalls, dass Sklerotien, die sich in tieferen Bodenschichten befinden, weniger auskeimen als an der Bodenoberfläche (Mitchell \& WheEler, 1990; FerRAZ et al., 1998). Diese Überlegungen führten dazu, dass eine tiefe Bodenbearbeitung und damit verbundene geringere Keimfähigkeit der Sklerotien in den tiefen Bodenschichten $\mathrm{zu}$ einer Reduzierung des Befalls führen (MERrimAn et al., 1982). Auch Mueller et al. (2002) beobachteten in Feldversuchen mit verschiedenen Bodenbearbeitungsvarianten, dass in den gepflügten Varianten die geringste Anzahl an Sklerotien pro Liter Boden im Vergleich zu der Grubber- und Direktsaatvariante gefunden werden konnte. Ebenso stellte sich heraus, dass die wendende Bodenbearbeitung den geringsten Befall mit $S$. sclerotiorum und den höchsten Ertrag aufwiesen, während in der Variante ohne Bodenbearbeitung der höchste Befall mit dem geringsten Ertrag festgestellt wurde.

In einem weiteren Feldversuch von WAHMHOFF et al. (1999) wurde die Bodenbearbeitung in Kombination mit der Fruchtfolge untersucht. Dabei wurde bei der dreijährigen 
Fruchtfolge zu jeder Kultur und bei der vierjährigen nur jeweils vor der Rapsaussaat eine wendende Bodenbearbeitung durchgeführt. Bei der vierjährigen Fruchtfolge wurde während der pfluglosen Bearbeitung die höchste Sklerotiendichte im Boden gefunden. Wobei nach der wendenden Bodenbearbeitung vor Raps fast keine Sklerotien mehr im Boden festgestellt werden konnten. In der dreijährigen Fruchtfolge mit jährlich wendender Bodenbearbeitung blieb die Sklerotiendichte konstant.

Die Bodenbearbeitung beeinflusst in gewissem Maß auch das Mikroklima im Boden. Durch die Bodenbedeckung mit Pflanzenresten bei der nichtwendenden Bodenbearbeitung wird zum einen die Bodenfeuchte, zum anderen aber auch die mikrobielle Aktivität gefördert (HAO et al., 2003). Nach SINGH \& SINGH (1983) fördert eine Bodenfeuchte von über 30\% den Abbau der Sklerotien.

Da sowohl in der vorliegenden Arbeit kein signifikanter Einfluss der Bodenbearbeitung festgestellt wurde und auch in der Literatur keine einheitlichen und konstanten Ergebnisse zum Einfluss der Bodenbearbeitung gefunden werden konnten, wurde dieser Faktor nicht im Modell berücksichtigt.

Zum Einfluss des Aussaattermins auf den Befall mit $S$. sclerotiorum ist wenig bekannt. In dieser Arbeit konnte gezeigt werden, dass eine späte Aussaat von Winterraps zu einer signifikant höheren Anfälligkeit gegenüber S. sclerotiorum führt. Im Gegensatz dazu berichtet MORALL et al. (1982) aus seinen Arbeiten in Kanada, dass es bei verschiedenen Aussaatterminen von Sommerraps zu einer unterschiedlichen Pflanzenentwicklung zum kritischen Stadium der Blüte kommen kann. So haben die spät ausgesäten Pflanzen die Vollblüte erst nach dem Ascosporenflug erreicht und somit geringere Befallshäufigkeiten als früh ausgesäte Pflanzen. Der Aussaattermin hat weiterhin auch einen Einfluss auf die Aussaatstärke und somit auf die Bestandesdichte. So werden häufig höhere Aussaatstärken bei einem späteren Aussaattermin gewählt, während eine geringe Anzahl Körner $/ \mathrm{m}^{2}$ in frühen Aussaaten genommen wird. Die erhöhten Aussaatstärken in Spätsaaten bedingen höhere Bestandesdichten, was wiederum zu verbesserten Mikroklimabedingungen für eine Infektion im Bestand führt.

Die Beurteilung und der Einfluss des Aussaattermins auf den Befall mit S. sclerotiorum kann nicht eindeutig erklärt werden, da mehrere pflanzenbauliche Faktoren, wie Bestandesdichte und Aussaatstärke, durch den Aussaattermin beeinflusst werden. Aus 
diesen Gründen wurde keine Integration dieses Faktors in das Prognosemodell vorgenommen.

Die Aussaatstärke korreliert eng mit der Bestandesdichte. In der vorliegenden Arbeit konnte kein signifikanter Einfluss der Bestandesdichte auf den Befall mit S. sclerotiorum festgestellt werden, es zeigte sich jedoch die Tendenz, dass mit zunehmender Bestandesdichte auch die Befallshäufigkeiten zunahmen. Ein Problem, welches oft bei der Analyse von Schlagdaten vorkommt ist, dass die Faktoren oft nicht einzeln betrachtet werden können, sondern von mehreren anderen Faktoren mehr oder weniger stark beeinflusst werden. So wirkt sich sowohl die Aussaatstärke, die Stickstoffdüngung aber auch die Witterung auf die Dichte des Rapsbestandes aus. Die Untersuchungen von TURKINGTON \& MORALL (1993) ergaben, dass durch die verbesserten Mikroklimabedingungen in dichteren Pflanzenbeständen das Krankheitsauftreten von $S$. sclerotiorum ansteigt. Ursachen sind die höheren Luftfeuchten und die längere Blattnässedauer. NORDIN et al. (1991) stellten fest, dass bei einer hohen Aussaatdichte die relative Befallshäufigkeit geringer war, die Befallsstärke jedoch wesentlich höher. Im Vergleich dazu war der Befall bei der geringen Aussaatdichte höher, wobei die Befallsstärke der Infektionsstellen wesentlich geringer war.

Sortenunterschiede hinsichtlich der Anfälligkeit von S. sclerotiorum sind derzeit nur in geringem Maß vorhanden (ANONYM, 2004). In der Bundessortenliste schwanken die Einstufungen zwischen der Note 5 und 7. In den Wertprüfungen ist bis heute noch keine Prüfung zur Anfälligkeit der Sorten auf S. sclerotiorum verfügbar. In der vorliegenden Arbeit konnten anhand von 650 Daten aus den Jahren 1994-2004 statistische Unterschiede zwischen 15 Sorten festgestellt werden. Der höchste Befall wurde bei den Hybridsorten Panther (NPZ) und Pronto (NPZ) beobachtet, demgegenüber zeigten die Liniensorten Bristol (LIPP) und die Sorte Karola (Semundo Saatzucht) die geringsten Befallshäufigkeiten im Mittel über die Jahre. Eine ähnliche Einstufung für die beiden hoch befallenen Sorten ist auch in der Bundessortenliste zu finden (Note 7). Im Gegensatz dazu konnte in der Bundessortenliste keine Übereinstimmung für die geringe Anfälligkeit der Sorten Bristol und Karola gefunden werden. Allein die starke Streuung und die hohe Variabilität der einzelnen Sorten über die Jahre lassen auf eine starke Interaktion zwischen Genotyp und Umweltbedingungen in den einzelnen Jahren schließen, so dass eine Einteilung der Sorten in verschiedene Anfälligkeiten nur schwer möglich ist. 
Sortenunterschiede bezüglich der Anfälligkeit gegenüber $S$. sclerotiorum wurden schon in mehreren Arbeiten untersucht. In einer Überprüfung von 21 Winterrapssorten auf die Anfälligkeit gegenüber S. sclerotiorum sowohl im Feld als auch im Gewächshaus konnte keine Übereinstimmung zwischen den erhobenen Ergebnissen und der Einstufung der Bundessortenliste gefunden werden (REWERTS, 2003). Im Gegensatz dazu berichtet AHLERS (1986), dass es in Jahren mit hohem Befallsdruck zu extremen Differenzierungen in der Anfälligkeit kommen kann. In einer weiteren Arbeit von DUNKER \& V. TIEDEMANN (2004) wurden in Feldversuchen in den Jahren 2002-2005 die Anfälligkeit von einer Hybridsorte und einer Liniensorte überprüft. Es zeigte sich, dass die Liniensorte in allen drei Feldversuchsjahren höhere Befallshäufigkeiten aufwies als die Hybridsorte.

Resistente Sorten sind bis heute noch nicht in Deutschland zugelassen. In China konnten aber die ersten resistenten Sommerrapssorten entwickelt werden (LI et al., 2003; HANZHONG et al., 2003; ZHAO et al., 2004). Am Institut für Pflanzenbau und Pflanzenzüchtung in Göttingen wurden Untersuchungen zur Anfälligkeit blütenblattloser Rapslinien gegenüber S. sclerotiorum durchgeführt (JIANG, 2001; ZHAO et al., 2002). Aus den Ergebnissen geht hervor, dass die blütenblattlosen Linien im Vergleich zu ihren normalen Geschwisterlinien einen geringeren Befall mit S. sclerotiorum aufzeigten (JIANG, 2001). Ausgehend von einer Reduktion der Lichteinstrahlung durch Blütenblättern in den oberen Blattetagen und dem daraus resultierenden geringeren Blattflächenindex, Verkürzung der Lebensdauer der Blätter und der Verringerung der Gesamttrockenmasse könnte neben der Befallsreduzierung auch mit höheren Kornerträgen bei blütenblattlosen Rapslinien gerechnet werden (JIANG, 2001; ZHAO et al., 2002).

Die hohe Variabilität der Krankheit in den einzelnen Sorten, Regionen und Jahren macht eine Gewichtung dieses Faktors in Bezug zur Anfälligkeit schwer. Aus diesem Grund wurde in der vorliegenden Arbeit der Faktor Sorte noch nicht in das Modell SkleroPro aufgenommen. Obwohl jedoch Hinweise auf Unterschiede in der Anfälligkeit von Sorten gegenüber S. sclerotiorum sowohl aus dieser Arbeit, als auch aus anderen Untersuchungen (AHLERs, 1986; REWERTS, 2003; DUNKER, 2004) zu erkennen sind, sind für die Einbindung der Sortenanfälligkeit in das Modell weiterführende Arbeiten auf diesem Gebiet notwendig.

Zum Einfluss der Stickstoffdüngung auf den Befall mit S. sclerotiorum liegen in der Literatur nur sehr wenige Ergebnisse vor. KRÜGER (1977) fand heraus, dass die Hauptnährstoffe Stickstoff, Phosphor und Kalium in normalen und in überhöhten Mengen 
keinen Einfluss ausüben. In Übereinstimmung dazu konnte auch in der vorliegenden Arbeit kein Einfluss der verschiedenen Einstufungen der Stickstoffdüngung auf den Befall festgestellt werden. Andere Autoren berichten, dass sich die N-Düngung sogar hemmend auf die Keimung von Apothezien auswirken kann (MitCHELL \& WHEELER, 1990).

Durch den vermehrten Anbau von Wirtspflanzen in der Fruchtfolge können besonders bodenbürtige Krankheiten in ihrem Auftreten stark gefördert werden. Eine enge Fruchtfolgegestaltung im Winterrapsanbau führt zu einer Anhäufung von Inokulum im Boden und kann nicht nur für den nächsten Raps, der auf dieser Fläche angebaut wird, eine Gefahr sein, sondern auch für die Nachbarschläge, die durch die Windverbreitung der Ascosporen befallen werden können. Übereinstimmend mit den Ergebnissen aus der Literatur (KURLE et al., 2001; GRACIA-GARZA et al., 2002) kann anhand der Auswertungen der schlagspezifischen Daten festgestellt werden, dass eine zweijährigen Fruchtfolge von Raps mit einer deutlichen Zunahme des Befalls verbunden ist. Je länger die Anbaupausen von Raps sind, desto geringer ist der Befall mit $S$. sclerotiorum. Die geringsten Befallshäufigkeiten konnten bei einer Rapsanbaupause von mehr als drei Jahren beobachtet werden. In dem Fruchtfolgeversuch von WAHMHOFF et al. (1999) wurde das Befallsauftreten in vier-, drei- und zweijährigen Fruchtfolgen und einer Monokultur von Raps miteinander verglichen. Es zeigte sich, dass in einer drei- und vierjährigen Fruchtfolge der Befall signifikant geringer ist, als in einer Rapsmonokultur. In den Versuchen von MUELLER et al. (2002) konnte durch die Fruchtfolge zwar kein signifikanter Effekt auf die Anzahl von Sklerotien im Boden beobachtet werden, doch auf die Anzahl von entwickelten Apothezien und auf den Ertrag. Im Hinblick auf den hier diskutierten starken Einfluss der Fruchtfolge, der stetig steigenden Rapsanbaufläche in Deutschland und der dadurch immer enger werdenden Rapsfruchtfolge, wurde die Integration dieses Faktors als ein wichtiger und unverzichtbarer Bestandteil im Modell angesehen. Die Gewichtung der Fruchtfolge wurde in die Stufen zweijährige, dreijährige und mehrjährige Rapsfruchtfolge vorgenommen. In Kapitel 3.12.3 wird ausführlicher auf die Integration der Fruchtfolge in SkleroPro eingegangen.

Bei der Analyse der schlagspezifischen Faktoren wurde neben der Fruchtfolge auch noch eine Einteilung der Vorfrucht vorgenommen. Der statistischen Berechnung zur Folge konnte kein signifikanter Einfluss der verschiedenen Vorfrüchte auf den Befall festgestellt werden. Lediglich in Raps nach Gerste trat im Vergleich $\mathrm{zu}$ Weizen und anderen Feldfrüchten als Vorfrucht, eine geringere Befallshäufigkeit auf. Aus der Literatur sind 
keine Untersuchungen zum Einfluss der Vorfrucht auf den Befall mit S. sclerotiorum bekannt.

Bei den Untersuchungen zur Auswirkung der Bodenart auf den Befall mit S. sclerotiorum konnte ein signifikanter Zusammenhang festgestellt werden. Ein Befallsanstieg war von den leichten bis zu den schweren Böden erkennbar, wobei die Überschwemmungsböden (Alluvialböden) den geringsten Befall zeigten. Die Bodenart übt einerseits einen direkten Effekt auf die Keimung von Sklerotien aus, andererseits wirkt sich die Bodenart auch auf das Wachstum der Pflanze aus. Auch KRÜGER (1977) konnte in seinen Arbeiten einen Einfluss der Bodenart auf die Entwicklung der Apothezien feststellen. Nach Untersuchungen von AHLERS (1986) verlief die Apothezienbildung in sandigen, trockenen Böden langsamer, während in Marschböden tendenziell mehr Apothezien gebildet wurden. Dagegen beobachteten SINGH \& SINGH (1983) die beste Keimung von Sklerotien in reinem Sandboden im Vergleich zu sandigem Lehm, Schlufflehm und verschiedenen Sand-TonGemischen. Die höhere Anzahl gekeimter Sklerotien in Sandböden kann durch die schnellere Erwärmung im Frühjahr in sandigen Böden im Vergleich zu tonhaltigen Böden begründet werden (BÄUMER, 1992). Mit zunehmendem Tonanteil im Boden verminderte sich die Reifung der Apothezien. Eine mögliche Erklärung für den höheren Befall in Lößböden als in Sandböden kann darin liegen, dass die sandigen Böden ein schlechteres Wasserhaltevermögen besitzen und somit schneller austrocknen. Für die Keimung der Sklerotien ist der Feuchtigkeitsgehalt im Boden aber von entscheidender Bedeutung (FERRISs et al., 1987; KRÜGER, 1976; FERRAZ et al., 1999).

Aufgrund der Tatsache, dass Raps durch seine starke Durchwurzelung des Bodens hauptsächlich auf tiefgründigen Lehmböden angebaut wird und weniger auf tonhaltigen Böden und dass die Bodenart innerhalb eines Feldes stark variieren kann, wurde die Aufnahme dieses schlagspezifischen Faktors im Modell vernachlässigt.

Die Witterung im Frühjahr stellt einen entscheidenden Faktor für die Befallsausprägung dar. Ein mäßig kühler und feuchter April und Mai fördern die Keimung von Sklerotien im Boden und das Auskeimen der Ascosporen auf den Blütenblättern (KRÜGER, 1977). In zahlreichen Untersuchungen zur Epidemiologie von S. sclerotiorum konnte belegt werden, dass neben der Bodentemperatur und der Bodenfeuchte auch die Luftemperatur und die Luftfeuchte einen Einfluss auf den Befall ausüben (WEISS et al., 1980; SINGH \& SINGH 2000; KORA et al., 2002; YOUNG et al., 2004; CLARKSON et al., 2004). 
Aufgrund der jährlich sehr unterschiedlichen Witterung, schwankt auch das Krankheitsauftreten von S. sclerotiorum in den einzelnen Jahren und Regionen. Die hohen Befallshäufigkeiten in den Jahren 1997, 2002 und 2004 sind durch die sehr milden, aber niederschlagsreichen Frühjahrsmonate gekennzeichnet. Ebenso kann der sehr geringe Befall im Jahr 2002 durch die extreme Trockenheit und damit verbundenen geringen Luftfeuchten erklärt werden. Um diesen Effekt der Jahreswitterung auf den Befall mit $S$. sclerotiorum bewerten zu können, wurde das Jahr als Parameter mit in die Auswertung der schlagspezifischen Faktoren aufgenommen. Anhand der Berechnungen wird deutlich, dass der Faktor Jahr einen hohen signifikanten Einfluss auf den Befall ausübt. Besonders bei der Betrachtung des Varianzanteils auf die Gesamtvarianz hat der Jahreseinfluss neben den Interaktionen zwischen den einzelnen Faktoren den höchsten Anteil an der Gesamtvarianz, ausgenommen Schleswig-Holstein. Dies erklärt auch, warum bei der Erstellung von Prognosemodellen zum einen die Infektionsbedingungen des Erregers genauesten bekannt sein müssen und zum anderen die Wetterprognose ein wichtiger Bestandteil eines Simulationsmodells ist.

\subsection{Prognosemodelle und Beratungssysteme im Pflanzenschutz}

Nach FeIER \& Rossberg (2001) ist ein Modell eine ideelle oder materielle Struktur, die einen bestimmten Bereich der objektiven Realität in schematischer oder idealisierter Form proportional oder ähnlich nachbildet. KRANZ (1996) unterscheidet dabei zwischen deskriptiven, prädiktiven und erklärenden Modellen. Wobei sich die einzelnen Modelle nicht gegenseitig ausschließen, sondern sich untereinander ergänzen können. Deskriptive Modelle beschreiben Hypothesen oder generalisieren experimentell erhaltene Ergebnisse, wie zum Beispiel Befallskurven und Wachstumsverläufe, ohne die dahinter stehenden Mechanismen erklären zu können. Prädiktive Modelle bestehen aus unterschiedlichen Variablen, deren Vorhersagen experimentell bestätigt worden sind. $\mathrm{Zu}$ den erklärenden Modellen gehören die analytischen Modelle und die Simulationsmodelle. Bei diesen Modellen wird versucht, die biologischen Prozesse verständlich darzustellen (KRANZ, 1996). Die Beschreibung analytischer Verfahren hat nach HAU (1990) zu unterschiedlichen Begriffsdefinitionen geführt. Analytische Modelle sind nach VAN DER PLANK (1982) komplexe Modelle, bei denen der Krankheitsverlauf mit Hilfe externer Variablen, wie z.B. 
Witterungsparametern, beschrieben wird. Synthetische Modelle (Simulationsmodelle) sind dagegen einfache Verfahren, die nur auf wenigen Gleichungen und einer geringen Anzahl an Parametern, ohne den Einfluss externer Variablen, beruhen. Im Widerspruch dazu verstehen JEGER (1986) und HAU (1990) unter analytischen Modellen eine einfache Beschreibung von Verläufen mit nur einer oder wenigen Differentialgleichungen ohne externe Faktoren und die Berechnung von komplexen Verläufen durch metrologische Parameter als Simulationsmodell. Obwohl diese Verfahren in der Vergangenheit streng getrennt voneinander betrachtet wurden, werden heute komplexe, auf verschiedenen Umweltfaktoren beruhende Simulationsmodelle mit analytischen Modellen, die auf theoretischen Untersuchungen beruhen, oft verknüpft (HAU, 1995). HAU (1990) sieht den Vorteil analytischer Modelle darin, dass diese aufgrund ihrer einfachen Struktur und der geringen Anzahl an Parametern präzisere Aussagen über das Infektionsgeschehen liefern können. Da dieses Verfahren konstanten Modellgleichungen unterliegt und demnach nur bei beständigen Umweltbedingungen genutzt werden kann, sind diese Modelle nur begrenzt nutzbar. Aufgrund der Tatsache, dass es sich bei S. sclerotiorum um einen monozyklischen Erreger handelt und darüber hinaus kein Befallsverlauf, sondern nur ein Behandlungstermin bestimmt werden sollte, konnte bei der Modellerstellung auf eine komplexe Berechnung eines Befallsverlaufs verzichtet werden. Dadurch konnten in dem vorliegenden Modell sowohl die Vorzüge des analytischen Modells, die vor allem in der einfachen Struktur liegen, als auch die Integration externer Variablen, wie verschiedene Umwelt- und schlagspezifische Faktoren, für eine überregionale Anwendbarkeit miteinander verknüpft werden.

$\mathrm{Zu}$ den Simulationsmodellen gehören auch die Prognosemodelle. Unter Prognose versteht man die Ableitung von Aussagen über jegliche Art von Sachverhalten, die nicht direkt untersucht werden. Sie ist nicht auf eine zeitliche Voraussage beschränkt, sondern kann die Befallssituation eines Augenblicks ohne direkte Messung des Befalls wiedergeben (GuTSCHE, 1992). Nach KRANZ (1996) sagen Prognosen Ereignisse oder Entwicklungen voraus und sollen eine optimale Kontrolle gewährleisten. Ziel der Prognose ist es, Routinebehandlungen durch gezielte Maßnahmen zu ersetzen, die wirtschaftlicher und umweltschonender sind. Das in dieser Arbeit vorgestellte und entwickelte Modell SkleroPro ist auf der einen Seite ein Prognosemodell, welches mittels Witterungsfaktoren den Befall zur Blüte vorhersagt. Zum anderen ist es aber auch ein Entscheidungsmodell, das unter Berücksichtigung einer Schadensschwelle eine Empfehlung für eine gezielte 
Fungizidmaßnahme berechnet. Das Modell dient somit dem Landwirt bzw. dem Anwender zur Unterstützung und als Entscheidungshilfe für eine wirtschaftliche Behandlungsmaßnahme gegen $S$. sclerotiorum.

Im Gegensatz dazu unterscheidet TISCHNER (1998) zwischen der Anwendung von Prognosesystem und Entscheidungssystem. Im Gegensatz zu einem Prognosesystem basiert das Entscheidungssystem immer auf einem Diagnosesystem und gibt dem Anwender anhand der Ergebnisse aus der Befallserhebung eine Empfehlung, ob eine Behandlung des Schaderregers erforderlich ist oder nicht. Ein Prognosemodell verzichtet dagegen auf aufwendige Befallserhebungen und berechnet die Entwicklung eines Schaderregers anhand aktueller Wetterdaten. Weiterhin können durch die Integration von Bekämpfungsschwellen, basierend auf Befalls-Verlust-Relationen, Bekämpfungsentscheidungen gegeben werden. Die Negativ-Prognose, bei der der befallsfreie Zeitraum berechnet wird, stellt die einfachste Form eines Prognosemodells dar.

$\mathrm{Zu}$ den ersten Simulationsmodellen zählt das von WagOONER \& HorsfalL (1969) entwickelte Modell EPIDEM, mit dem die Infektkette der Dürrfleckenkrankheit (Alternaria solani) an der Tomate simuliert wurde. Ausgehend vom Epidemieverlauf des Erregers wurden in diesem Modell biologische Vorgänge mit Hilfe mathematischer Formeln abgebildet. Mit der weiteren Forschung an epidemiologischen Wirt-ParasitZusammenhängen für die wichtigsten Schaderreger im Pflanzenbau und durch den rasanten Fortschritt in der Computerindustrie fand Mitte der 70er Jahren ein Aufschwung in der Entwicklung von Schaderregermodellen statt. Besonders in der ehemaligen DDR wurden auf der Grundlage von langjährigen Schaderregerüberwachungen und Erhebungen von Epidemieverläufen Prognosemodelle entwickelt, die zum Teil bis heute Anwendung in der Praxis finden (Herold \& SACHS, 1987 und Lutze et al., 1990). Derzeit sind mehr als 20 Modelle entwickelt und im praktischen Einsatz, sowohl aus Deutschland als auch aus dem englischsprachigen Raum (GuTSCHE, 1992). Zu den wohl bekanntesten und im Einsatz befindlichen Schaderregermodellen zählen die Phytophtora-Prognosen, Prognosen gegen Cercospora in Zuckerrüben und Septoria in Getreide, Apfelschorf und Apfelwickler im Obstbau und Falschen Mehltau der Rebe (GuTSCHE, 1992). Die Grundlage aller Modelle ist eine auf ausführliche biologische Systemanalyse. Der aufwendigste Prozess bei der Erstellung und Modellierung von Prognosemodellen ist die genaue Kenntnis über die epidemiologischen Verläufe des Schaderregers. 
Für die praktische Anwendung von Prognoseverfahren in der Beratung oder direkt für die Landwirte gibt es unterschiedliche Systemanbieter. Diese unterscheiden sich im Wesentlichen im Umfang der angebotenen Leistungen, in der Handhabbarkeit und in der Einbeziehung von Wetterdaten. Zu diesen bekanntesten Anbietern gehören unter anderem ProPlant (VOLK \& Herbert, 2002), IPS Modell Zuckerrübe und Weizen (Wolf et al., 1998), ZEPP (KLEINHENZ et al., 1998a), ISIP (RÖHRIG \& SANDER, 2004) und AMBER (FrIESLAND, 1998). Derzeit ist eine Prognose für die Bekämpfung der Weißstängeligkeit nur in dem Softwarepaket AMBER (Agrarmeteorologische Beratung) enthalten. Diese Beratung ist auf der Basis von agrarmeteorologischer Forschungs- und Entwicklungstätigkeit des Deutschen Wetterdienstes entstanden. Als Kernstück beinhaltet das Softwarepaket zwei Modelle zur Berechnung der boden- und bestandesklimatischen Bedingungen. Das Modell AMBAV (A aktuellen Verdunstung) simuliert auf der Grundlage verschiedener pflanzenbaulicher Parameter den Wasserversorgungsgrad von Kulturbeständen. Das Modell AMBETI (ㅁgrarmeteorologisches Modell zur Berechnung von Evaporation, Transpiration und Interzeption) berechnet neben dem Energie- und Wasserhaushalt der Bestände auch den Gefriervorgang im Boden (BRADEN, 1995). Diese beiden Modelle werden in dem Softwarepaket zu BEKLIMA zusammengefasst und bilden die Grundlage vieler weiterer Modelle (Deutscher Wetterdienst, 2004). Neben der Prognose von einigen pilzlichen und tierischen Schaderregern, wie Apfelschorf, Rapskrebs, Feuerbrand, Braun-/Gelbrost und Weizenmehltau werden auch umweltspezifische Problematiken wie N-min Bestimmung, Ammoniakverluste und der Bienenflug, aber auch Ernteparameter in AMBER angeboten. So wird in AMBER auch das von FRIESLAND (1991) entwickelte Prognosemodell von S. sclerotiorum an Winterraps angeboten, welches als Grundlage für die vorliegende Arbeit genutzt wurde. Anhand von Wetterdaten wird hier auf der Basis vom Bestandesklima die meteorologische Infektionswahrscheinlichkeit berechnet. Eine ausführliche Beschreibung des Modells wurde bereits in den Kapiteln 2.19 und 3.10 vorgenommen.

Ein weiteres Beratungssystem ist aus dem erfolgreichen Modellvorhaben „Praxiseinführung rechnergestützter Entscheidungshilfen in den Pflanzenschutz“ entstanden, welches vom Ministerium für Ernährung, Landwirtschaft und Forsten gefördert wurde und in den Jahren 1991-1997 von 13 Pflanzenschutzdiensten der Länder durchgeführt wurde (KLEINHENZ et al., 1998b). Um dieses Verfahren fortzusetzen und die 
Pflege und Weiterentwicklung von Prognosemodellen $\mathrm{zu}$ gewährleisten, wurde seit Oktober 1997 auf der Basis einer Verwaltungsvereinbarung der Länder, die Zentralstelle der Länder für EDV-gestützte Entscheidungshilfen und Programme im Pflanzenschutz (ZEPP) aufgebaut (KLEINHENZ et al., 1998b). Sitz der ZEPP ist das Dienstleistungszentrum ländlicher Raum Rheinhessen-Nahe-Hunsrück in Bad Kreuznach. Insgesamt beteiligen sich an diesem Projekt 12 Bundesländer und 14 Pflanzenschutzdienste (ZEPP, 2005). Ziel der ZEPP ist es, zum einen Prognose- und Simulationsmodelle von verschiedenen Modellerstellern (Universitäten im In- und Ausland, Biologische Bundesanstalt) für Schaderreger in der Landwirtschaft und im Gartenbau zu überprüfen, eventuell weiterzuentwickeln und für die Praxis nutzbar zu machen, zum anderen aber auch die Erarbeitung und Entwicklung neuer Modelle anzuregen und zu organisieren (KLEINHENZ, 1998a).

In den letzten Jahren wurden mehr als 16 wetterbasierte Prognose- und Simulationsmodelle bei der ZEPP getestet und überprüft, wobei fünf Modelle aus den neuen Bundesländern stammen. In Zusammenarbeit mit dem Deutschen Wetterdienst werden täglich aktuelle Wetterdaten aus mehr als 97 Wetterstationen herausgelesen und für die Berechnung der Prognosen genutzt. Zusätzlich werden 339 eigene agrarmeteorologische Wetterstationen von den Pflanzenschutzdiensten der Länder zur Berechnung von Schaderregerprognosen herangezogen (KLEINHENZ, 2005). Ziel der Einführung von Prognosemodellen in die Praxis ist es zum einen, den Einsatz prophylaktischer Behandlungen auf ein notwendiges $\mathrm{Maß} \mathrm{zu}$ reduzieren, zum anderen werden aber auch zeitaufwendige Felderhebungen und Bonituren vermieden. Unter der

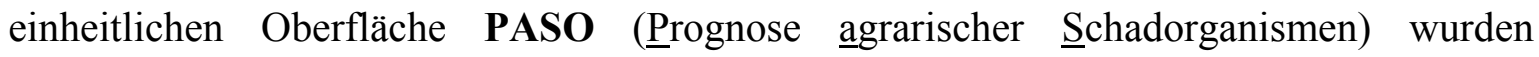
verschiedene Prognosemodelle zu einem Programmpaket zusammengefasst und den Beratern der Pflanzenschutzdienste als PC-Version zur Verfügung gestellt (KLEINHENZ, 1998a).

In Kooperation mit der ZEPP erfolgte auch die Modellierung von SkleroPro, besonders im Hinblick auf die Wetterdatenbereitstellung und bei der Mitwirkung einer großräumigen, deutschlandweiten Anlage von Feldversuchen. Des Weiteren wird SkleroPro ab 2006 für die Praxis auf der internetbasierten Plattform ISIP zur Verfügung stehen. Das Informationssystem für die Integrierte Pflanzenproduktion“ (ISIP) wird seit 2001 in Zusammenarbeit mit der ZEPP aufgebaut (RöHrig \& KLEINHENZ, 2002). Dieses System basiert auf dem Einsatz moderner Informationstechnologien, wie dem Internet. Es 
ermöglicht so, den Datenfluss verschiedener betrieblicher und schlagspezifischer Daten zusammen mit Wetterdaten sowie den Ergebnissen der Prognose und zusätzlichen Beratungshinweisen zu verknüpfen und aufbauend auf diesen dem Berater und Landwirt individuelle Behandlungsentscheidungen vorzuschlagen (ISIP, 2005). Neben der Prognose werden weiterhin alle notwendigen Informationen $\mathrm{zu}$ Befallserhebungen aus Versuchsstandorten, Hintergrundinformationen zu mehr als 150 Schaderregern in über 20 Kulturen, Bewertungen von Wirkungsgraden und Wirkungsspektren verschiedener Pflanzenschutzmittel sowie Anwendungshinweise für Pflanzenschutzmittel und eine regionale und zeitlich angepasste Beraterempfehlung herausgegeben (RÖHRIG \& SANDER, 2004). Hierfür sind eine fortlaufende Aktualisierung der Datenbanken sowie eine geprüfte Datenqualität unverzichtbar. Im Jahr 2002 wurde erstmals ein aktuelles Internetangebot in ISIP präsentiert. Schwerpunkte sind Prognosemodelle und Entscheidungshilfen für Schaderreger in Getreide, Zuckerrüben und Kartoffeln (Tab. 15) (KLEINHENZ \& RÖHRIG, 2003). Die aktuell verfügbaren Entscheidungshilfen in ISIP sind in Tabelle 12 aufgeführt, zusätzlich zu den Entscheidungshilfen werden für Blattkrankheiten in Getreide und Zuckerrübe aktuelle Felderhebungen aus verschiedenen Regionen angeboten. Weitere Modelle sind in der Entwicklung. Ab 2006 wird zusätzlich das Modell SkleroPro für die Bekämpfung der Weißstängeligkeit im Raps für die Praxis in ISIP nutzbar sein (KoCH \& von TIEDEMAnN, 2004, 2005). Der Zugriff auf das Internetangebot von ISIP ist in das Beratungsangebot der Landwirtschaftskammern und Länder eingebettet, zudem besteht auch die Möglichkeit, einen situationsbezogenen Benachrichtigungsservice per Fax, Mail oder SMS zu aktivieren (RÖHRIG \& SANDER, 2004).

Tab. 16: Aktuell verfügbare Entscheidungshilfen auf der Internetplattform ISIP

\begin{tabular}{|l|l|l|l|}
\hline \multicolumn{1}{|c|}{ Kultur } & \multicolumn{1}{|c|}{ Schaderreger } & \multicolumn{1}{c|}{ Modell } & \multicolumn{1}{c|}{$\begin{array}{c}\text { Individuelle } \\
\text { Einstellungen }\end{array}$} \\
\hline \multirow{2}{*}{ Getreide } & Halmbruch in Weizen & SIMCERC 3 & möglich \\
\cline { 2 - 5 } & $\begin{array}{l}\text { Entwicklungsverlauf von } \\
\text { Wintergetreide }\end{array}$ & SIMONTO & möglich \\
\hline \multirow{2}{*}{ Kartoffeln } & Kartoffelkäfer & SIMLEP & erforderlich \\
\cline { 2 - 5 } & Kraut- und Knollenfäule & SIMPHYT & möglich \\
\hline Zuckerrübe & Cercospora-Blattflecken & CERCBET 1 und 3 & erforderlich \\
\hline $\begin{array}{l}\text { ab 2006 } \\
\text { Raps }\end{array}$ & $\begin{array}{l}\text { Weißstängeligkeit } \\
\text { Sclerotinia sclerotiorum }\end{array}$ & SkleroPro & erforderlich \\
\hline
\end{tabular}




\subsection{Erstellung des Modells SkleroPro}

Bei der Erstellung eines neuen Prognosemodells ist es besonders wichtig, genaue Kenntnisse über das Infektionsgeschehen und über die Epidemiologie des Schaderregers zu bekommen (VAN MAANEN \& XU, 2003). Aus diesem Grund wurden zunächst die Infektionsbedingungen für eine Infektion mit Ascosporen überprüft. In der Klimakammer wurden mit Hilfe eines Boxentests der Schwellenwert der Minimumtemperatur und die optimalen Bedingungen für eine Infektion überprüft. Die optimale Temperatur lag demnach in einem Bereich von $16-22^{\circ} \mathrm{C}$ und die Mindestbedingungen für eine Infektion bei $7^{\circ} \mathrm{C}$. Über $25^{\circ} \mathrm{C}$ und unter $6^{\circ} \mathrm{C}$ kam es zu keiner Infektion durch Ascosporen. Diese Ergebnisse stehen im Einklang mit anderen Untersuchungen zu S. sclerotiorum an Bohnen, auch hier konnte die schnellste Keimung bzw. das beste Wachstum von Ascosporen und Myzel in diesem Temperaturoptimum beobachtet werden (PHILLIPS, 1994). Auch CAESAR \& PEARSON (1983) beobachteten, dass sich Temperaturen von über $25^{\circ} \mathrm{C}$ schädlich auf das Überleben der Ascosporen auswirken. Nach AHLERS (1987) und YounG et al. (2004) liegen die Temperaturen für eine Infektion durch Ascosporen im Bereich von $8-27^{\circ} \mathrm{C}$, wobei die optimalen Temperaturen bei $16-20^{\circ} \mathrm{C}$ erreicht sind (ABAWI \& GROGAN, 1979). Basierend auf den Untersuchungen von AHLERS (1987) und KRÜGER (1979) lag in dem Modell SKLERO die Optimumtemperatur für die Berechnung der infektionsgünstigen Stunden bei $15^{\circ} \mathrm{C}$ und die Minimumtemperatur bei $3^{\circ} \mathrm{C}$. Aufgrund der sehr niedrigen Minimum- und Optimumtemperaturen bei SKLERO wurden in einem ersten Schritt die Infektionsbedingungen in dem neuen Modell verändert. Die optimale Temperatur für eine Infektion wurde somit auf $18^{\circ} \mathrm{C}$ und die Minimumtemperatur auf $7^{\circ} \mathrm{C}$ erhöht.

Laut AHLERS (1987) konnte keine Keimung der Ascosporen bei 70\% rel. Luftfeuchte beobachtet werden. In Untersuchungen wurde die unterste Grenze der rel. Luftfeuchte bei $83 \%$ erreicht. Die optimalen Luftfeuchten für eine Infektion liegen in einem Bereich von 84-92\% (KRÜGER, 1979). Aufbauend auf den Aussagen von KRÜGER (1979) lag die Mindestbedingung der rel. Luftfeuchte für eine Infektion mit Ascosporen in dem Modell SKLERO bei $84 \%$. Einige Autoren berichten, dass die Symptomausprägung von $S$. sclerotiorum durch das Zusammenspiel von Temperatur und Luftfeuchte beeinflusst wird (Ahlers \& Hindorf, 1987; ClARKSON et al., 2004). Aufgrund der Erhöhung der Minimumtemperatur für eine Infektion wurde in dem Modell SkleroPro die unterste Grenze der Luftfeuchte bei $80 \%$ angesetzt. 
Neben der Überprüfung der Klimabedingungen für eine Infektion mit Ascosporen erfolgte die Validierung des Modells SKLERO im Feld. Anhand von Feldversuchen aus den Jahren 1994-2004 konnte SKLERO ausführlich validiert und die Genauigkeit einzelner Berechnungen überprüft werden, um dann aufbauend auf den Ergebnissen das neue Modell SkleroPro zu erstellen. Der erste Modellierungsaspekt war die Berechnung der Keimung der Sklerotien sowie das Erscheinen der ersten Apothezien. Der Einfluss dieser beiden Faktoren auf den Befall mit S. sclerotiorum wurde schon in vielen Arbeiten untersucht (HAO et al., 2003; Ahlers, 1986; Sun \& YANG, 2004; KorA et al., 2005), wobei auch die optimalen Witterungsbedingungen für das Keimen der Sklerotien und das Aufwachsen der Apothezien ausführlich beschrieben worden sind (WEISS et al., 1980; SINGH \& SINGH 2000; Clarkson et al., 2004). BolAND \& HALL (1988b) stellten in ihren Untersuchungen fest, dass eine Beziehung zwischen dem räumlichen Auftreten der Apothezien und dem späteren Befall im Feld besteht. So basieren einige Vorhersagemodelle für einen Befall mit S. sclerotiorum einzig oder zum großen Teil auf den Berechnungen der Sklerotienkeimung (Clarkson et al., 2004; FriEsLAND 2000; Nordin, 1992). Neben der direkten Berechnung der Sklerotienkeimung wird in einigen Modellen auch indirekt über die Erfassung der Bodenfeuchte in Kombination mit dem Blütenblattbefall das Auftreten von S. sclerotiorum vorhergesagt.

Der Vergleich der Vorhersagegenauigkeit des Modells SKLERO mit den Beobachtungen auf dem Feld in Bezug auf das Erscheinen der Apothezien zeigte, dass das Modell in sehr vielen Fällen das Erscheinen zu früh berechnet hat. Des Weiteren konnte festgestellt werden, dass besonders im Jahr 2003 das Erscheinen erst sehr spät zum Ende der Blüte des Rapses vorhergesagt wurde und somit Infektionen, die vor diesem Zeitpunkt stattgefunden haben, nicht erfasst wurden. Auch WoHLLEBEN (2001) konnte bei der Überprüfung der Vorhersagegenauigkeit von SKLERO in Bezug auf das Auftreten der Apothezien eine maximale Abweichung von fünf Tagen zwischen dem Untersuchungsergebnis zur Apothezienbildung und den Angaben des Prognosemodells feststellen. In einer weiterführenden Arbeit (KRUSE, 2004) zur Überprüfung der Vorhersagegenauigkeit des Apothezienaufwuchses von SKLERO in Feldversuchen aus den Jahren 2001-2004 zeigte sich eine Differenz von 5-8 Tagen, wobei an einigen Standorten sogar ein Unterschied von mehr als zwei bis drei Wochen beobachtet werden konnte. Ferner konnte in den eigenen Untersuchungen bei der rückwirkenden Anwendung des Modells SKLERO festgestellt werden, dass in allen untersuchten Jahren ein Erscheinen der Apothezien vorhergesagt 
wurde. Dies lässt sich dadurch erklären, dass die Witterungsbedingungen für die Sklerotienkeimung, die in das Modell eingehen, eine sehr breite Spanne haben. Sowohl in dem Modell von FrIESLAND (2000), als auch bei CLARKSON et al. (2004) lag die Spanne der Bodentemperatur für das Keimen der Sklerotien bei $5-20^{\circ} \mathrm{C}$. Diese Temperaturen werden jedoch in den Monaten April und Mai fast immer erreicht.

Des Weiteren kann man in den meisten Regionen in Deutschland davon ausgehen, dass aufgrund des sehr weiten Wirtpflanzenkreises, der langen Überlebenszeit der Sklerotien im Boden und der Verbreitung der Sporen durch den Wind, eine Verseuchung der Böden durch Sklerotien oder ein Sporenflug aus nahe gelegenen Feldern auf fast allen Rapsanbauflächen vorherrscht (AHLERS, 1986; STEADMAN, 1983). Dies zeigt, dass das Erscheinen der Apothezien auf den Rapsanbauflächen in Deutschland kein limitierender Faktor in dem Auftreten von S. sclerotiorum sein kann. Aus diesen Gründen wurde die Berechnung der Keimung der Sklerotien und des Erscheinens der Apothezien aus dem Modell herausgenommen.

Eine weitere Verbesserung des neuen Modells SkleroPro konnte durch die Entfernung des Sporenfluges und des Infektionsdruckes erreicht werden. Anhand der Ergebnisse aus der vorliegenden Arbeit konnte gezeigt werden, dass der Sporenflug keinerlei Einfluss auf die berechneten Infektionsstunden und somit auf das Infektionsgeschehen nimmt. Die Berechnung des Infektionsdrucks ist eine zusätzliche Funktion, die maßgeblich an der Höhe der Infektion beteiligt ist, die aber durch keine epidemiologischen Prozesse erklärt werden kann und zudem zu Fehlentscheidungen geführt hat. Übereinstimmend mit den Ergebnissen von WOHLLEBEN (2001) neigt das Modell SKLERO dazu, die Infektionen in vielen Fällen zu überschätzen. Es hat sich gezeigt, dass durch die Veränderung der Infektionsbedingungen anhand der Laborergebnisse eine verbesserte Vorhersage der Infektionsgenauigkeit in Bezug zur Befallshäufigkeit erzielt werden konnte. Die Klimabedingungen für eine Infektionsstunde wurden von einer Minimumtemperatur von $3^{\circ} \mathrm{C}$ auf $7^{\circ} \mathrm{C}$ erhöht und die Minimumbedingung der rel. Luftfeuchten wurden von $84 \%$ bei SKLERO auf $80 \%$ bei SkleroPro gesenkt. Diese geringen Temperaturen wurden auch schon in früheren Arbeiten beschrieben. Bei Temperaturen von $8-11^{\circ} \mathrm{C}$ konnten die ersten Symptome von Sclerotinia an Salat 20-26 Tage nach Inokulation festgestellt werden (Young et al., 2004).

Bei der Validierung von SKLERO konnte weiterhin festgestellt werden, dass die Vorhersage der Rapsentwicklung während der Blüte nicht mit der aktuellen Entwicklung 
des Rapses im Feld übereinstimmt. Die Rapsentwicklung ist in dem Modell aber eng mit der Berechnung der infektionsgünstigen Stunden gekoppelt, denn erst zu Beginn der Vollblüte wird mit der Berechnung der infektionsgünstigen Stunden begonnen. Sind zu diesem Zeitpunkt schon erste Fehler in der Berechnung der Rapsentwicklung vorhanden, können sich diese auf die gesamte Berechnung des Infektionsgeschehens auswirken. Die Ergebnisse der Validierung von SKLERO in Bezug zur Rapsentwicklung zeigten, dass die Rapsentwicklung während der Blüte mit einer Verspätung von bis zu 12 Tagen im Vergleich zur aktuellen Entwicklung berechnet wurde. Aus diesem Grund wurden mit Hilfe der Parameterschätzung in ModelMaker die Parameter für den Entwicklungszuwachs neu errechnet und ein anderer Funktionsverlauf für den Entwicklungszuwachs im Raps gewählt. Durch diese Veränderung konnte eine genauere Vorhersage des aktuellen Blühverlaufs berechnet werden. Eine weitere Veränderung in SkleroPro erfolgte mit der Vorverlegung des Starts der Berechnung der infektionsgünstigen Stunden. Statt erst zum BBCH-Stadium 62 anzufangen, wie dies bei SKLERO der Fall war, wurde in SkleroPro das BBCH-Stadium 58 ausgewählt. Aufgrund der Tatsache, dass die Ascosporen von $S$. sclerotiorum, die noch fest an der Blüte haftenden Blütenblätter infizieren (Kapitel 3.3.2), besteht die Möglichkeit, dass schon mit Beginn der Blüte und sogar wenn die Blüten noch geschlossen sind, die jungen Blütenblätter infiziert werden können. Laut WEBER \& BLEIHOLDER (1990) endet zum BBCH-Stadium 59 die Knospenbildung und bei den noch geschlossenen Einzelblüten werden die ersten Blütenblätter sichtbar.

In diesem Zusammenhang ist die Vorhersage der Ontogenese der jeweiligen Kulturart eine wichtige Voraussetzung für die Erstellung und die spätere Anwendung von Prognosemodellen. Ein Ontogenesemodell sollte bestimmte praxisrelevante Entwicklungsstadien einer landwirtschaftlichen Kultur sehr präzise d.h. mit möglichst geringen Abweichungen zwischen simulierten und tatsächlich festgestellten BBCHStadien, vorhersagen (ROSSBERG et al., 2004). Derzeit gibt es praxistaugliche Ontogenesemodelle für die Kulturen Weizen, Roggen und Gerste. Ein Ontogenesemodell für die gesamte Entwicklung ab der Aussaat bis zur Ernte des Winterrapses ist noch in der Entwicklung (ROSSBERG, 2005).

Ein weiteres Ziel dieser Arbeit war es, nicht nur ein befallsbezogenes, sondern auch ein schlagspezifisches Prognosemodell zu entwickeln. Für die Abschätzung einer regionalen Vorhersage von S. sclerotiorum wurden bereits an der Universität von Iowa verschiedene schlagspezifische Einflussfaktoren auf den Befall mit S. sclerotiorum untersucht und in ein 
Prognosemodell eingebaut (MILA et al., 2004). In der vorliegenden Arbeit wurden ausführliche statistische Analysen von verschiedenen schlagspezifischen Faktoren vorgenommen (siehe Kapitel 3.8). Es stellte sich heraus, dass unter anderem der Fruchtfolgefaktor einen großen Einfluss auf den Befall mit S. sclerotiorum ausübt. Zahlreiche andere Arbeiten bestätigen dieses Ergebnis (GARBE, 2000; KURLE et al., 2001; Gracia-GarZA et al., 2002; MÜller et al., 2002; MilA et al., 2004). Um die Fruchtfolge in das Modell SkleroPro integrieren zu können, erfolgte eine empirische Einteilung dieses Faktors nach seinem Gefährdungsgrad. Die Multiplikatoren bewegen sich in einem engen Wertebereich um 1.0, der annährend der durch den Fruchtfolgeeinfluss bedingten Variation der Befallshäufigkeit entspricht. So wurde eine zweijährige Rapsfruchtfolge mit dem Faktor 1.3, eine dreijährige mit 1 und eine mehr als dreijährige Rapsfruchtfolge mit dem Faktor 0.8 gekennzeichnet. Diese Multiplikatoren werden in dem Modell direkt an die Berechnung der infektionsgünstigen Stunden gekoppelt. Auf eine ähnliche Art erfolgte die Integration von schlagspezifischen Faktoren bereits in anderen Prognosemodellen, wie zum Beispiel dem Halmbruchmodell SIMCERC und dem Echten Mehltau Modell SIMERY (SIEBRASSE, 1982; SiebrasSE \& FeHRMANN, 1986; KRAATZ, 1994; KLEINHENZ et al., 1998a; WEINERT et al., 2005).

An die Simulation der Befallshäufigkeit wurde eine quantitative Erfassung der durch $S$. sclerotiorum verursachten Ertragsverluste angeschlossen. Diese basiert auf einer BefallsVerlust-Relation, die in dreijährigen Feldversuchen aus den Jahren 2002-2004 von DuNKER (2000) erarbeitet wurde und in das Prognosemodell SkleroPro integriert wurde. Unter einer wirtschaftlichen Schadensschwelle versteht man die zu einem gegebenen Zeitpunkt vorhandene Befallsdichte eines Schadorganismus oder das Ausmaß der Erkrankung oder Verunkrautung, die bei Nichtbekämpfung Schäden gleicher Höhe verursachen würden, wie an Kosten für die Behandlungsmaßnahme entstehen (DIERCKS \& HEITEFUSS, 1994). Exakte, auf Befalls-Verlustanalysen beruhende Schwellenwerte für die gezielte Bekämpfung von verschiedenen Schädlingen und Unkräutern in der Pflanzenpathologie sind nur mit umfangreichen experimentellen Untersuchungen möglich und wurden nur in wenigen Arbeiten veröffentlicht (BLASZYK, 1970; KÜST et al., 1989; LASSAK, 1993; BRUNS, 1996). Ein Beispiel ist das an der Universität Göttingen entwickelte Modell CeBrUS, welches auf verschiedenen Schadenschwellen für Unkräuter basiert. Dieses Modell soll künftig als internetgestütztes Beratungsmodell für die Unkrautbekämpfung im Raps und Getreide zur Verfügung stehen (WERNER et al., 2002). 
Nach FREIER et al. (1994) können Schadensschwellen aus biologischer, ökologischer und ökonomischer Sicht keinen einzigen Befallswert annehmen, sondern angesichts vieler Variablen wie Befalls-Schadens-Relation, Populationsdynamik und anderen ökonomischen Parametern einen größeren Wertebereich einnehmen. Erste Ansätze zur Ermittlung von Befalls-Verlust-Relationen für $S$. sclerotiorum wurden von KRÜGER \& STOLTENBERG (1983) durchgeführt. Schon in diesen frühen Untersuchungen stellte sich heraus, dass sich bei einer geringen Befallshäufigkeit von bis zu 12\% eine Fungizidapplikation gegen $S$. sclerotiorum als nicht wirtschaftlich erweist. Auch bei einem mittleren Befall von 13-24\% ist die Wirtschaftlichkeit einer Behandlungsmaßnahme bedenklich und richtet sich je nach den verwendeten Fungiziden und Arbeitsbreiten. Der berechnete Schwellenwert der Befallshäufigkeit in SkleroPro ist keine feste Größe, sondern richtet sich nach verschiedenen individuellen Eingabegrößen wie den Fungizidkosten, Rapspreis, Ertragserwartung und den Überfahrtskosten. Der prozentuale Anteil der Durchfahrtsverluste von 2,6\%/ha wurde als fester Wert angenommen (DUNKER, 2005). Bei einer Ertragserwartung von 30 bis $50 \mathrm{dt} / \mathrm{ha}$ beträgt die in SkleroPro berücksichtigte Schadensschwelle von S. sclerotiorum Befallshäufigkeiten zwischen 25 und 15\%.

\subsection{Validierung von SkleroPro}

Bevor Prognosemodelle in die Praxis übernommen werden, sollten sie den praktischen Erfordernissen angepasst sein. Durch die zunehmende Entwicklung von Prognosemodellen im Pflanzenschutz sollte nach TENG (1980) auch das Anstreben nach der Überprüfung der Zuverlässigkeit solcher Modelle im Vordergrund stehen, nach wie vor werden immer noch viele Modelle ohne den Beweis ihrer Zuverlässigkeit oder Überprüfung der Gültigkeit der Parameter veröffentlicht.

Da Simulationsmodelle eine Vereinfachung bzw. Abstraktion von verschiedenen Entwicklungsprozessen darstellen, die zum Teil auf empirischen oder statistisch abgesicherten Daten beruhen und diese nie eine ,absolute Wahrheit“" der in der Natur beobachteten Prozesse widerspiegeln können, sind Überprüfungen der Zuverlässigkeit von Prognosemodellen von besonderer Bedeutung. Im Rahmen einer gründlichen Modelleinschätzung von SkleroPro wurden neben der Überprüfung der Berechnung von verschiedenen Komponenten, wie zum Beispiel der Rapsentwicklung und der 
Vorhersagegenauigkeit der Befallshäufigkeit, insbesondere die Tauglichkeit und die Zuverlässigkeit der Behandlungsentscheidung in Bezug auf die Wirtschaftlichkeit geprüft.

Bei der Anwendung von Vorhersagemodellen im Pflanzenschutz ist es besonders wichtig, dass eine Unterschätzung des Befalls oder der Behandlungsempfehlung vermieden wird. Die Auswertungen von 689 Feldversuchen mit 3814 Blütenbehandlungen des amtlichen Pflanzenschutzdienstes von 1981-1991 zeigten, dass insgesamt 73\% der Fungizidapplikationen gegen S. sclerotiorum unwirtschaftlich waren (WAHMHOFF, 2000). In einer anderen Studie konnte DUNKER (2004) ebenfalls feststellen, dass die Wirtschaftlichkeit der Blütenbehandlung (anhand von Feldversuchen des amtlichen Pflanzenschutzdienstes von 1992-2004) bei nur 68\% liegt. In den eigenen Untersuchungen aus Feldversuchen der Pflanzenschutzdienste der Länder von 1994-2005 konnte ebenfalls festgestellt werden, dass sich nur in $65 \%$ der Flächen eine Routinebehandlungen als wirtschaftlich erwies. Anhand dieser Tatsache kann entnommen werden, dass ein großes Einsparungspotential bei der Sclerotinia-Behandlung vorhanden ist. Der für eine wirtschaftliche Fungizidmaßnahme mindestens zu erbringende Ertragsgewinn wird in verschiedenen Untersuchungen der letzten Jahre auf 4-7 dt/ha angesetzt (LOR, 1995; SCHMIDT \& KÖPPL, 1995; STEINBACH \& BROSCHEWITZ, 1997). Übereinstimmend dazu konnte auch in der vorliegenden Arbeit ein durchschnittlicher Ertragsgewinn von 4-6 dt/ha aus den Versuchsjahren sowie aus den vergangenen Jahren festgestellt werden.

Die Validierung von Prognosemodellen basiert häufig auf der Überprüfung der Vorhersagegenauigkeit verschiedener Entwicklungsprozesse, des Befallsauftretens oder der Behandlungsentscheidung. Die Aufgabe der Überprüfung von Prognosemodelle wird im Rahmen der ZEPP übernommen (JÖRG \& KLEINHENZ, 1996; JÖRG \& ROSSBERG, 1998; HANSEN et al., 2001; RACCA et al., 2002). Insbesondere bei der Weiterentwicklung von Modellen konnte eine deutliche Verbesserung in der Vorhersagegenauigkeit erreicht werden. So wurde die Trefferquote verschiedener Entwicklungsprozesse von SIMLEP 2 zu SIMLEP 3 von 6-74\% auf 63-94\% verbessert (JÖRG \& ROSSBERG, 1998). Eine erste Validierung des Prototyps von CERCBET 3 ergab eine Zuverlässigkeit der Prognose von 50\% (RACCA et al., 2002). Durch die Optimierung verschiedener Verlaufsfunktionen und die Integration von schlagspezifischen Parametern konnte die Vorhersagegenauigkeit der Terminprognose für das Überschreiten der Bekämpfungsschwelle auf 90\% erhöht werden (RACCA et al., 2004). In den eigenen Untersuchungen konnten übereinstimmende Ergebnisse festgestellt werden. So lagen die Trefferquoten beim Modell SKLERO nur bei 
48\%. Die ersten Veränderungen von SKLERO in Bezug zum Infektionsgeschehen und durch den Verzicht einiger Berechnungen von verschiedenen Entwicklungsprozessen wie z. B. dem Apothezienaufwuchs und dem Sporenflug führten dazu, dass mit dem Prototyp eine Verbesserung der Vorhersage auf 57\% erreicht werden konnte. Durch die Weiterentwicklung zu einem schlagspezifischen sowie befalls- und schadensbezogenen Modell konnte eine Verbesserung der Vorhersagegenauigkeit der Behandlungsentscheidung von $81 \%$ erzielt werden.

Anhand der Vorhersagegenauigkeit wird die Qualität und die Praxistauglichkeit von Prognosemodellen bestimmt, die meisten der angewandten Modelle besitzen eine Trefferquote von 60 bis 90\% (RACCA et al., 2004; JÖRG \& KLEINHENZ, 1996). Eine absolute Trefferquote von 100\% kann durch Vorhersagen von Modellen nicht erreicht werden, da die Entwicklungs- und Infektionsprozesse von Schaderregern durch eine Vielzahl von Faktoren beeinflusst werden. Aber nicht nur allein die Vorhersagegenauigkeit spielt bei der Validierung von Modellen eine wichtige Rolle, sondern auch die wirtschaftliche Betrachtung der Behandlungsentscheidung sollte in die Validierung einbezogen werden. Eine wirtschaftliche Betrachtung der Zuverlässigkeit der Prognoseentscheidung wurde nur in Ansätzen in verschiedenen Arbeiten beschrieben. Bei der Analyse der Wirtschaftlichkeit von SIMCERC anhand von 56 Feldversuchen aus den Jahren 1994-1997 konnte im Vergleich zu einer Routinebehandlung in allen Jahren höhere Erlöse bei der SIMCERC Variante erzielt werden. Die Erträge der SIMCERC Variante lagen aber in allen Jahren knapp unter denen der Routinebehandlungen (KLEINHENZ et al., 1998). Ein weiteres in ISIP integriertes Modell SIMPHYT besteht aus zwei verbundenen Prognosemodellen. SIMPHYT I berechnet den Behandlungsbeginn und SIMPHYT II simuliert den Befallsverlauf. Die Validierung des SIMPHYT I Modells auf 86 Flächen ergab eine Zuverlässigkeit von 97\%. Die Überprüfung von SIMPHYT II ergab im Vergleich zu einer ortsüblichen Behandlung dieselben Bekämpfungserfolge bei geringerem Pflanzenschutzmittelaufwand, aber etwas höheren Endbefallsstärken als in der ortsüblichen Variante (JÖRG \& KLEINHENZ, 1996).

In den eigenen Untersuchungen konnte bei der Praxiseinführung von SkleroPro anhand von 32 Versuchen im Jahr 2005 ein Mehrerlös im Vergleich zur Routinebehandlung von $44 € /$ ha erzielt werden, wobei es im Durchschnitt über alle Versuche zu einer Ertragminderung von $0.5 \mathrm{dt} / \mathrm{ha}$ bei SkleroPro kam. Im Hinblick auf die geringen Befallshäufigkeiten im Jahr 2005 und des daraus resultierenden hohen Anteils 
unwirtschaftlicher Routinebehandlungen erwies sich das Modell SkleroPro als durchaus viel versprechend für den praktischen Einsatz. Durch die Anwendung von SkleroPro konnte eine Reduzierung der Blütenbehandlungen von $75 \%$ erzielt werden, ohne dabei ein Risiko der Unterschätzung des Befalls bzw. der Behandlung einzugehen. Mit einer Vorhersagegenauigkeit von $81 \%$ konnte damit auch gezeigt werden, dass dieses Modell sogar in extremen Jahren mit sehr geringem Befallsdruck nicht zu einer übermäßigen Überschätzung des Befalls bzw. der Behandlungen neigte, sondern den Befall real prognostiziert und damit sichere Ergebnisse liefert.

Eine rückwirkende Analyse der Vorhersagegenauigkeit von SkleroPro aus den Jahren 1994-2003 mit den Validierungsergebnissen aus den Jahren 2004-2005 haben gezeigt, dass im Vergleich zu einer Routinebehandlung durch die Anwendung des Modells eine Reduzierung des Fungizideinsatzes von 47\% erzielt werden konnte. Ebenfalls konnte in einer weiteren Untersuchung gezeigt werden, dass durch die Behandlungsentscheidung ein Mehrertrag von 0,1 dt/ha und ein Mehrerlös von 23 Euro/ha im Vergleich zur Routinebehandlung erreicht werden konnte. Bei einem Verzicht der Blütenbehandlung aufgrund der Prognose konnten Verluste von 50 Euro/ha eingespart werden. Dies ermöglicht dem Landwirt nicht nur eine umweltschonendere Bewirtschaftung seiner Flächen, sondern auch eine Verringerung der Bekämpfungskosten kann durch den gezielten Einsatz der Fungizide nach der Behandlungsentscheidung eines geeigneten Prognosemodells erzielt werden. Im Sinne des integrierten Pflanzenschutzes treten mit Hilfe des Prognosemodells an die Stelle von prophylaktischen Routinespritzungen gezielte Behandlungen auf der Basis von Befalls-Verlustanalysen (BURTH et al., 1994).

In der Literatur gibt es wenige Informationen zum optimalen Zeitpunkt der Blütenblattbehandlungen. Um möglichst alle Infektionen mit Fungiziden zu erfassen, werden die meisten Behandlungen zum Stadium der Vollblüte (BBCH 65) eingesetzt (HARTLEB et al., 1999; GARBE, 2000). In einem weiteren Versuch wurde überprüft, ob die exakte Terminierung der Blütenbehandlung von SkleroPro einen Einfluss auf die Wirtschaftlichkeit hat. Hierfür wurden an 18 Feldversuchen aus den Pflanzenschutzdiensten der Länder in dem Jahr 2004 die behandelten Flächen mit 0,5 1/ha Cantus ${ }^{\circledR}$ (BASF) der beiden Modelle SkleroPro und SKLERO miteinander verglichen. Im Vergleich zu SKLERO konnte durch das neue Prognosemodell SkleroPro bei Verwendung des gleichen Fungizids und der gleichen Menge ein Mehrertrag von 0,3 dt/ha erzielt werden, womit ein Mehrerlös von 13 Euro/ha erbracht wurde. Dies zeigt, dass allein durch 
einen gezielten terminierten Einsatz der Blütenblattbehandlung höhere Erlöse erzielt werden können.

\subsection{Bewertung verschiedener Verfahren zur Abschätzung der Behandlungs- notwendigkeit von S. sclerotiorum im Hinblick auf SkleroPro}

In den letzen Jahren wurden weltweit Ansätze für die Entwicklung von Prognoseverfahren für die Bekämpfung von $S$. sclerotiorum unternommen. Aufgrund der Tatsachse das $S$. sclerotiorum zuerst die Blütenblätter befällt und erst dann der Stängel der Rapspflanze infiziert wird (JAMAUX et al., 1995), wurden Verfahren zum Nachweis von S. sclerotiorum auf Blütenblätter entwickelt, um daraus den späteren Befall im Feld abzuleiten. In zahlreichen Arbeiten wurde mit Hilfe eines Agarmediums, dem so genannten Petaltest und der darauf festgestellten Anzahl infizierter Blütenblätter, der Fungizideinsatz zur Blüte vorhergesagt (Gugel \& Morall, 1986; Turkington \& Morrall, 1993; Bom \& BOLAND, 2000). Laut Angaben der Autoren konnte unter Praxisbedingungen aber nicht immer eine enge Beziehung zwischen den infizierten Blütenblättern und dem späteren Befall im Feld festgestellt werden (TURKINGTON \& MORRALL, 1993). Nur in Jahren mit hohem Infektionsdruck konnte eine enge Korrelation festgestellt werden. Eine eindeutige Vorhersage des $\mathrm{zu}$ erwartenden Befalls und infolgedessen eine gezielte Behandlungsentscheidung für die Praxis ist anhand dieser Methode nicht möglich. Dies bestätigen auch die eigenen Untersuchungen mit dem $\mathrm{pH}$-Indikator-Test. Der Petaltest gibt jedoch einen Hinweis über das Aufwachsen von Apothezien und den aktuellen Sporenflug bis zum Zeitpunkt der Probeentnahme. Ebenso konnten mit der Entwicklung eines $S$. sclerotiorum spezifischen ELISA-Tests (JAMAUX et al., 1995) und einer spezifischen PCR (FREEMAN et al., 2002) bis heute noch keine zufrieden stellenden Ergebnisse zur Befallsvorhersage erzielt werden. Die höheren Kosten solcher Verfahren und der erhöhte Arbeitseinsatz machen einen großflächigen Einsatz dieser Methoden nicht praktikabel.

Einen anderen Ansatzpunkt zur Befallsvorhersage bietet der von AHLERS (1989) entwickelte Fragebogen. Durch die Bewertung von verschiedenen schlagspezifischen Angaben wird anhand der Gesamtpunktzahl die Notwendigkeit einer Behandlungsmaßnahme abgeleitet. Laut AHLERS (1989) erreichte der Fragebogen bei einer zweijährigen Anwendung eine Trefferquote von 60\%, wobei besonders in trockenen Jahren mit geringem Befall ein Überschätzen vorherrscht. In Übereinstimmung dazu 
konnte auch THÜRWÄCHTER (1991) eine Überschätzung des Fragebogens feststellen. Ähnliche Erfahrungen wurden auch in Österreich bei der Anwendung des Fragebogens zur Erprobung eines Sclerotinia-Warndienstes unter Berücksichtigung von Witterungsdaten aus Messstationen erreicht (KÖPPL \& SCHMIDT, 1993). Aufbauend auf der Fragebogenmethode von AHLERS (1989) wurde in Schweden eine Risikopunkt-Tabelle entwickelt (TwENGSTRÖM et al., 1998). Die Auswertungen von 48 Versuchsstandorten in den Jahren 1996 und 1997 zeigten, dass sich für den Schwellenwert, der in einem Wertebereich zwischen 40 und 50 Punkten liegt, eine sehr unsichere Prognose ergibt, wobei es sowohl zu Überschätzungen als auch Unterschätzungen des Befalls kommen kann. Auf nichtbehandelten Feldern konnten Befallshäufigkeiten von 25-30\% beobachtet werden. Der Vorteil der Fragebogenmethode ist, dass es sich um ein sehr kostengünstiges und leicht durchzuführendes Verfahren handelt. Aufgrund der fehlenden Betrachtung von exakten Witterungsparametern zur Blüte kommt es aber nur zu geringen Treffergenauigkeiten und damit nur $\mathrm{zu}$ einer unzureichenden Einschätzung der Behandlungsnotwendigkeit, was dieses Verfahren nur bedingt als Entscheidungshilfe brauchbar macht.

Viele Vorhersagen zum Auftreten von S. sclerotiorum basieren auf dem Aufwachsen von Apothezien. In einer Weiterentwicklung der Bewertungstabellen wurde von AHLERS und HINDORF (1987) ein mathematisches Verfahren, basierend auf einer Diskriminanzanalyse, erarbeitet. In diesem Modell wird von einem festen Schwellenwert von 10\% tolerierbarem Befall ausgegangen, weiterhin wird mit Hilfe von Sklerotiendepots, das Auskeimen der Sklerotien beobachtet und aufbauend auf diesen Ergebnissen die Bekämpfungswürdigkeit zum Zeitpunkt der Blüte berechnet. Allein auf der Grundlage von Sklerotiendepots und schlagspezifischen Parametern wurde die Behandlungswürdigkeit von S. sclerotiorum in Schweden abgeleitet. Die ersten Untersuchungen im Feld lieferten keine ausreichenden Ergebnisse für einen großflächigen praktischen Einsatz (AHLERS \& HINDORF, 1987).

In Versuchen von NORDIN et al. (1991) wurde anhand der Entwicklung der Apothezien in gesondert angelegten Depots, der Bestandesdichte und des Vorjahresbefalls die Notwendigkeit einer Fungizidmaßnahme abgeleitet. Obwohl diese Methode in Befallsjahren zu wirtschaftlichen Behandlungen geführt hat, konnte in Jahren mit geringem Infektionsdruck kein Mehrertrag durch eine Behandlungsvorhersage ermittelt werden. Als besonders nachteilig erweist sich sowohl bei dem Modell von AHLERS \& HINDORF (1987) als auch bei NORDIN et al. (1991) die Anlage und Auswertung von Sklerotiendepots und 
Sporenfallen. Der hohe Zeitaufwand der Datengewinnung ist aus heutiger Sicht nicht mehr praktikabel.

In England wurden weitere Untersuchungen zur Erarbeitung eines Vorhersagemodells zur Ermittlung der Sklerotienkeimung von S. sclerotiorum in Salat entwickelt (CLARKSON et al., 2005). Sowohl unter Laborbedingungen als auch im Feld konnte ein enger Zusammenhang zwischen Bodentemperatur und Keimungsrate sowie der endgültigen Anzahl an aufgewachsenen Apothezien festgestellt werden. Die in den Boden eingegrabenen Sklerotien keimten in einem Temperaturbereich von $5-25^{\circ} \mathrm{C}$, bei einem Matrixpotential von $>-100 \mathrm{kPa}$. Oberhalb von $26^{\circ} \mathrm{C}$ konnte keine Keimung beobachtet werden. Aus diesen Beobachtungen wurde ein Modell entwickelt, welches auf der Basis von Schwellenwerten für die Bodentemperatur sowie des Feuchtegehalts im Boden die Anzahl an gekeimten Sklerotien berechnet. In einer weiteren Studie wurde in England ein Prognosemodell zur Ermittlung der Ascosporeninfektion von S. sclerotiorum an Salat entwickelt (Young et al., 2005). Anhand der Temperatur, der rel. Luftfeuchte und der Sporenkonzentration wird das zeitliche Auftreten der Krankheit und die Befallshäufigkeit vorhergesagt. Eine Validierung des Modells oder eine Anwendung in der Praxis wurde bisher noch nicht durchgeführt. In naher Zukunft soll dieses Modell mit dem Modell für die Vorhersage der Sklerotienkeimung verknüpft werden (CLARKSON et al., 2005; PHELPPS et al., 2005). Aufgrund der fehlenden Validierung der beiden Modelle sind noch keine Aussagen über die Vorhersagegenauigkeit bezüglich der Sklerotienkeimung und der Infektion durch Ascosporen zu treffen. Es scheint jedoch fraglich, ob eine exakte Prognose der Sklerotienkeimung durch den sehr breiten Temperaturbereich von $5-25^{\circ} \mathrm{C}$ möglich ist, da diese Temperaturen gerade in der kritischen Zeit von April bis Mai fast täglich überschritten werden. Als nachteilig erweist sich ebenso die aufwändige Kontrolle der Sklerotiendepots.

Zusammenfassend kann an dieser Stelle noch einmal darauf hingewiesen werden, dass sowohl durch die Vorhersage der Keimung der Sklerotien als auch durch geeignete Nachweismethoden des Blütenblattbefalls mit Ascosporen keine eindeutige Prognose für den zu erwartenden Befall gegeben werden kann. Da mit Hilfe dieser Parameter nicht die eigentliche Infektion des Stängels vorhergesagt wird, sondern vielmehr vorgeschaltete Infektionsparameter, wie Inokulummenge und Sporenkonzentration prognostiziert werden. Die Vorhersage dieser Parameter führt aber laut einiger Autoren zu einer starken Überschätzung des Befalls (NORDIN et al., 1991; TURKINGTON \& MORRALL, 1993; KRUSE, 
2004). Mit Hilfe aufwändiger Messungen der Sporenausschleuderung über einem Sklerotiendepot, konnte trotz gemessener Sporenfreisetzung kein Befall im Feld festgestellt werden (WoHLleBen, 2001). Ebenso führte auch der Nachweis von $S$. sclerotiorum auf Blütenblättern, besonders in befallsarmen Jahren zu einer Überschätzung des Befalls (KRUSE, 2004). Demnach ist allein durch die Vorhersage der Sporenfreisetzung keine Einschätzung der Behandlungsnotwendigkeit möglich. Eine gesicherte Prognose des zu erwartenden Befalls im Feld kann nur über die Vorhersage der Stängelinfektion gegeben werden. Aus diesem Grund müssen vermehrt die Infektionsbedingungen für eine Ascosporenkeimung sowie die Dauer bis zur Infektion des Stängels berücksichtigt werden. Aufgrund der Bewertung anderer weltweit entwickelter Vorhersagemodelle für die Abschätzung der Behandlungswürdigkeit von S. sclerotiorum ist auch eine kritische Betrachtung des in dieser Arbeit beschriebenen Modells SkleroPro vorzunehmen. Die Validierungsergebnisse von 2005 haben gezeigt, dass die Fehlerquote bei der Betrachtung der Vorhersagegenauigkeit $19 \%$ beträgt, wobei hier allein eine Überschätzung der Behandlung vorherrscht. Diese Ungenauigkeiten in der Prognose können zu einem großen Teil durch die Entfernung der Wetterstationen zum Feld erklärt werden. Durch das dünne Netz der Wetterstationen in einigen Gebieten Deutschlands besteht die Gefahr, dass nicht für alle Prognosestandorte eine Wetterstation in der Nähe liegt und demnach auf Stationen in über $70 \mathrm{~km}$ Entfernung ausgewichen werden muss. Diese Entfernungen können zu abweichenden Ergebnissen bezüglich der Witterungsdaten und demnach zu ungenauen Prognosen führen. Zudem beinhaltet die Vorhersage des Niederschlages durch den DWD eine gewisse Fehlerquote (KLEINHENZ, 2005), die zu unpräzisen Vorhersagen führen kann. Die Überschätzung der Behandlungen 19\% kann jedoch vernachlässigt werden, wenn man durch die Anwendung des Modells eine Einsparung der Blütenbehandlungen von 75\% erzielt.

Im Hinblick auf andere wetterbasierte Prognosemodelle für S. sclerotiorum ist SkleroPro ein sehr einfach strukturiertes Modell, welches auf nur wenigen Berechnungen, Gleichungen und Formeln beruht. Die Validierung von SKLERO und die Bewertung anderer Modelle hat gezeigt, dass durch die komplexe Darstellungsweise des Entwicklungsverlaufes von S. sclerotiorum die Fehlerrate in den einzelnen Berechnungen ansteigen und es somit zu erhöhten Fehlaussagen kommen kann. Der einfache Aufbau von SkleroPro führt demzufolge zu einer leichten Handhabung in der Praxis, aufwändige 
Erhebungen im Feld fallen ganz weg. Im Gegensatz dazu müssen einige schlagspezifische Daten für die Berechnung der Prognose eingegeben werden.

Durch die Einbindung von flexiblen Schadensschwellen ist SkleroPro derzeit das einzige praxisreife Modell für die Behandlungsentscheidung bei S. sclerotiorum, welches nicht nur die erwartete Befallshäufigkeit vorhersagt, sondern auch auf eine wirtschaftliche Behandlungsentscheidung ausgerichtet ist. 


\section{Ausblick}

Mit der Intensivierung des Rapsanbaus ist in allen Anbaugebieten ein ansteigender Krankheitsdruck der Weißstängeligkeit zu beobachten. Derzeit wird diese von bodenbürtigen Dauerkörpern (Sklerotien) ausgehende Krankheit überwiegend routinemäßig durch eine Fungizidbehandlung zum Zeitpunkt der Rapsblüte bekämpft. Verschiedene Untersuchungen belegen inzwischen, dass eine Vielzahl dieser nichtzielgerichteten Behandlungen gegen S. sclerotiorum unwirtschaftlich sind und somit ein hohes Einsparpotenzial für den Fungizideinsatz im Raps besteht. Mit Hilfe des am Institut für Pflanzenpathologie und Pflanzenschutz entwickelten Prognosemodells SkleroPro besteht nun die Möglichkeit den Fungizideinsatz gezielt nur auf den Flächen einzusetzen, auf denen ein höherer Infektionsdruck zu erwarten ist und demnach sich eine Behandlung als wirtschaftlich erweist. Durch die Einsparung von Fungiziden wird dem Landwirt nicht nur eine umweltschonendere Bewirtschaftung seiner Flächen, sondern auch eine maßgebliche Verringerung der Bekämpfungskosten ermöglicht.

Als Grundlage für einen erfolgreichen Einsatz von SkleroPro ist es notwendig, das Modell weiterhin unter möglichst unterschiedlichen Klima- und Standortbedingungen und auch über mehrere Jahre zu überprüfen, um bei eventuellen Veränderungen das Modell zu aktualisieren und optimieren zu können.

Zur Erweiterung des Modells wird zusätzlich der Sortenfaktor näher betrachtet werden. Aufgrund von Auswertungen aus Feldversuchen in Göttingen der letzten drei Jahre kann geschlossen werden, dass die Sorte einen Einfluss auf den Befall mit S. sclerotiorum ausübt, darüber hinaus können in näherer Zukunft tolerante oder sogar resistente Sorten auf den Markt kommen, die eine Berücksichtigung in dem Modell zur Folge haben müssen. Des Weiteren wird die Verwendung des biologischen Präparates Contans WG® (Prophyta $\mathrm{GmbH}$ ) einen Einfluss auf die Notwendigkeit einer Blütenbehandlung ausüben. Es ist daher weiterhin zu überprüfen, inwiefern sich diese Faktoren auf den Befall und damit auf die Bekämpfungswürdigkeit von S. sclerotiorum auswirken.

Aufgrund der weltweiten Bedeutung von S. sclerotiorum ist ebenso zu überprüfen, inwieweit sich dieses Modell auf andere Länder und eventuell auch für andere Kulturen mit anderen Klimavoraussetzungen und Bedingungen übertragen lässt. 


\section{Zusammenfassung}

Die Intensivierung des Rapsanbaus hat dazu beigetragen, dass sich die Weißstängeligkeit durch den Erreger S. sclerotiorum in den letzten Jahren stark ausgedehnt hat. Aufgrund fehlender Prognosemöglichkeiten und um einen Ertragsverlust entgegenzuwirken, werden in den traditionellen Rapsanbaugebieten die Blütenbehandlungen routinemäßig durchgeführt.

Im Rahmen dieser Arbeit wurden neben der Erstellung eines schlagspezifischen und schadensbezogenen Prognosemodells verschiedene Verfahren zum Nachweis von $S$. sclerotiorum auf Blütenblättern optimiert und getestet. Ziel war es mit Hilfe dieser Nachweisverfahren eine frühe Erfassung des zu erwartenden Befalls geben zu können.

Die Erprobung des pH-Indikator-Tests erwies sich als eine kostengünstige und einfache Methode, um den Befall auf den Blütenblättern nachzuweisen. Eine genaue Quantifizierung und eine exakte Vorhersage der Befallshäufigkeit im Feld konnte nicht abgeleitet werden. Der ELISA lieferte in vitro gute Ergebnisse zur Befallseinschätzung von S. sclerotiorum auf Blütenblättern. Ein Nachweis auf fest an der Blüte haftenden Blütenblättern aus dem Feld war aufgrund geringer positiver Reaktionen nur schwer möglich. Zudem kam es bei der Untersuchung von abgefallenen Blütenblättern zu falschpositiven Reaktionen. Ein sicherer Nachweis von S. sclerotiorum auf Blütenblättern konnte mit der spezifischen Real-time PCR erzielt werden. Die Nachweisgrenze lag bei diesem Verfahren bei 5 Ascosporen. Insgesamt konnte durch den Nachweis von Ascosporen auf Blütenblättern mit Hilfe der verschiedenen Verfahren keine Vorhersage der zu erwartenden Befallshäufigkeit im Feld vorgenommen werden und somit nicht als Entscheidungshilfe für eine Blütenbehandlung genutzt werden.

Neben der Überprüfung verschiedener Nachweismethoden wurde in den Jahren 2002-2004 das rechnergestützte und wetterbasierte Prognosemodell SkleroPro zur schlagspezifischen Befallsvorhersage der Weißstängeligkeit entwickelt und erstmalig im Jahr 2005 in Feldversuchen der Pflanzenschutzdienste der Länder überprüft. Als Grundlage wurde das Modell SKLERO vom DWD genutzt.

In einem ersten Schritt wurde das Arbeitsmodell SKLERO ausführlich validiert. Hierbei zeigte sich, dass das Modell insgesamt die Behandlungsnotwendigkeit überschätzt. Bei einer näheren Betrachtung der einzelnen Funktionen stellte sich heraus, dass die Vorhersagegenauigkeit des Erscheinens der Apothezien zum Teil sehr stark von dem 
tatsächlichen Auftreten im Feld abweicht. Unterschiede bis zu 25 Tage konnten im Feld beobachtet werden. Des Weiteren konnte festgestellt werden, dass die Berechnung des Sporenflugs keinen Einfluss auf das Infektionsgeschehen ausübt. Auch in der Berechnung der täglichen Rapsentwicklung während der Blüte konnte nicht immer eine Übereinstimmung mit der aktuellen Entwicklung im Feld festgestellt werden. Zwischen Prognose und tatsächlichem Entwicklungsstand im Feld wurden Abweichungen bis zu 14 Tagen beobachtet. Über die Berechnung der infektionsgünstigen Stunden und des Infektionsdrucks konnte keine Beziehung zur Befallshäufigkeit im Feld hergestellt werden.

Für die Erstellung eines neuen Modells wurden in einem weiteren Schritt die Bedingungen für eine Infektion mit Ascosporen überprüft. Die Minimumtemperatur lag bei diesen Untersuchungen bei $7^{\circ} \mathrm{C}$ und die optimalen Temperaturen zwischen $16-22^{\circ} \mathrm{C}$.

Für die Einbeziehung schlagspezifischer Daten in das Prognosemodell wurden von den einzelnen Pflanzenschutzdiensten der Länder aus den Jahren 1994-2004 die Versuchsergebnisse der Sclerotinia-Flächen ausgewertet und varianzanalytisch berechnet. Für die statistische Analyse zur Überprüfung des Einflusses von verschiedenen Schlagfaktoren auf den Befall mit S. sclerotiorum wurde der Datensatz nach verschiedenen Bundesländern regionalisiert und die einzelnen Gebiete separat untersucht. Die statistische Analyse ergab, dass die Faktoren Fruchtfolge, Sorte, Bodenart, Aussaattermin und Vorfrucht einen signifikanten Einfluss auf die Befallshäufigkeit von S. sclerotiorum ausüben. In Übereinstimmung mit der Literatur wurde als erster schlagspezifischer Faktor die Fruchtfolge in das Modell integriert. Anhand der statistischen Auswertung wurde die Fruchtfolge mit den Faktoren 0,8 für eine mehrjährige, 1.0 für eine dreijährige und 1.3 für eine zweijährige Fruchtfolge bewertet. Der Fruchtfolgefaktor wurde im Modell direkt an die Berechnung der infektionsgünstigen Stunden gekoppelt.

Neben der Eingliederung der Fruchtfolge in das neue Sclerotinia-Modell wurden unter anderem auch Veränderungen in der Berechnung der infektionsgünstigen Stunden vorgenommen. Mit Hilfe der im Boxentest ermittelten optimalen Temperaturen und Mindesttemperatur für eine Ascosporeninfektion wurde die Gleichung für die Berechnung der infektionsgünstigen Stunden verändert. Die Bedingungen für eine Infektion werden durch Kombination von rel. Luftfeuchte und Temperatur beschrieben. So wird in SkleroPro eine gelungene Infektionsstunde erst beim Überschreiten von $7^{\circ} \mathrm{C}$ und einer rel. Luftfeuchte von $86 \%$ erreicht oder bei einer rel. Luftfeuchte von mindestens $80 \%$ und einer Temperatur von $11^{\circ} \mathrm{C}$. Eine gelungene Infektion im Feld wird erst bei einer Anzahl von 23 
ununterbrochenen infektionsgünstigen Stunden vom Modell herausgegeben. Ebenso fand eine Anpassung der Berechnung der Ontogenese des Rapses während der Blüte statt. Durch die Integration neuer Gleichungen und die Veränderung einiger Parameter konnte eine verbesserte Vorhersage der Rapsentwicklung während der Blüte erreicht werden.

Durch die Einbindung einer flexiblen Schadensschwelle für S. sclerotiorum kann eine schadensbezogene Behandlungsentscheidung kalkuliert werden. Hierfür müssen verschiedene Daten in das Modell eingegeben werden, wie Ertragserwartung, Rapspreis, Fungizidkosten und Überfahrtskosten.

Begleitend wurden in den Versuchsjahren 2004 und 2005 deutschlandweit Feldversuche in Winterraps zur Überprüfung des Modells angelegt. Die Praxiseinführung von SkleroPro im Jahr 2005 ergab in Bezug auf die Vorhersagegenauigkeit, dass insgesamt 81\% der Behandlungsentscheidungen wirtschaftlich waren, wobei es zu keiner Unterschätzung der Behandlungsnotwendigkeit kam. Bei der retrospektiven Anwendung des Modells mit historischen Daten wurde eine Vorhersagegenauigkeit von 73\% erzielt. In 5\% der Flächen wurde die Behandlung unterschätzt.

Im Vergleich zur Routinebehandlung konnten bei der Anwendung von SkleroPro im Versuchsjahr 2005 Einsparungen im Fungizideinsatz von 82\% erzielt werden. Dies führte zu einem durchschnittlichen Mehrerlös von 44,2 Euro/ha bei einer Ertragsreduzierung von durchschnittlich 0,5 dt/ha. Bei einer rückwirkenden Anwendung von SkleroPro mit historischen Daten aus den Jahren 1994-2004 konnte eine Reduzierung der Blütenbehandlungen von $71 \%$ im Vergleich zu einer praxisüblichen- bzw. Routinebehandlung erzielt werden. In diesen Jahren konnte durch die Anwendung von SkleroPro ein durchschnittlicher Mehrerlös von 23 Euro/ha und ein Mehrertrag von 0,1 $\mathrm{dt} /$ ha erbracht werden.

Eine nähere Betrachtung der wirtschaftlichen Aspekte der Vorhersage auf 75 Flächen aus den Jahren 1994-2004 zeigte, dass durch die Behandlungsempfehlung von SkleroPro ein Mehrertrag von durchschnittlich $5 \mathrm{dt} / \mathrm{ha}$ auf den behandelten Flächen erzielt werden konnte. Auf Flächen, auf denen das Modell keine Behandlung empfohlen hat, aber trotzdem eine Blütenblattbehandlung durchgeführt wurde, konnte nur ein Mehrertrag von 1,5 dt/ha erreicht werden. Dies verursachte durchschnittliche Verluste von 50 Euro/ha.

Das Prognosemodell SkleroPro wurde zum Ende des Versuchsjahrs 2004 in die Internetplattform ISIP integriert und wird dort ab 2006 sowohl den Beratern als auch den Landwirten zur Verfügung stehen. 


\section{Literaturverzeichnis}

Abawi, G. S. \& Grogan R. G. (1979): Epidemiology of diseases caused by Sclerotinia species. Phytopathology 69, 899-904.

AdAms, P. B. \& Ayers, W. A. (1979): Ecology of Sclerotinia species. Phytopathology 69, 896-899.

AHLERS, D. \& HindoRF H. (1987): Epidemiologische Untersuchungen über den Schaderreger Sclerotinia sclerotiorum an Winterraps im Hinblick auf eine Prognose. Nachrichtenblatt Deutscher Pflanzenschutzdienst 39, 113-119.

AHLERS, D. (1986): Untersuchungen über den Erreger der Weißstengeligkeit Sclerotinia sclerotiorum (Lib.) de Bary an Winterraps - Sortenresistenz - Epidemiologie Krankheitsverlauf - Prognose. Dissertation, Universität Bonn.

AHLERS, D. (1989): Integrierter Pflanzenschutz bei Pilzkrankheiten an Winterraps. Gesunde Pflanze 41 (9), 306-311.

ANONYM (2000): Beschreibende Sortenliste 2000. Getreide, Mais, Ölfrüchte, Leguminosen (großkörnig), Hackfrüchte (außer Kartoffeln). Landbuchverlag, Hannover, 37-38.

BAtes, J. A.; TAYlor, J. A; Kenyon, D. M.; Thomas, J. E. (2001): The application of realtime PCR to the identification, detection and quantification of Pyrenophora species in barley seed. Molecular Plant Pathology 2 (1), 49-57.

BÄUMER, K. (1992): Allgemeiner Pflanzenbau. 3. Auflage, Verlag Eugen Ulmer, Stuttgart.

BÄUMLER, S. (2004): Entwicklung und validierung von molekularen Markersystemen für Qol-Fungizidresistenzen bei pilzlichen Pathogenen. Dissertation, Technische Universität München.

BENTE, D. A. (2003): Evaluierung konventioneller und real time RT-PCR-Protokolle für die spezifische Diagnose des Virus der Klassischen Schweinepest. Dissertation, Tierärztliche Hochschule Hannover.

BIEBER, F. (1990): Biotinylierung monoklonarer Antikörper. In: Peters, J. H. \& Baugarten, H. (Hrsg.): Monoklonare Antikörper. Springer-Verlag, Berlin. 
BLASZYK, P. (1970): Zur Problematik von Schadensschwellenwerten von Schadorganismen landwirtschaftlicher Kulturpflanzen. Zeitschrift für Pflanzenkrankheiten und Pflanzenschutz 77 (11/12), 628-637.

BockeY, D. (2003): Der Biodieselmarkt wächst. Raps 21, 81-84.

Boland, G. J. \& Hall, R. (1988a): Epidemiology of Sclerotinia stem rot of soybean in Ontario. Phytopathology 78, 1241-1245.

Boland, G. J. \& HALL, R. (1988b): Relationships between the spatial pattern and number of apothecia of Sclerotinia sclerotiorum and stem rot of soybean. Plant Pathology 37, 329-336.

Boland, G. J. \& HALL, R. (1994): Index of plant hosts of Sclerotinia sclerotiorum. Canadian Journal of Plant Pathology 16, 93-108.

Bom, M. \& Boland, G. J. (2000): Evaluation of disease forecasting variables for Sclerotinia stem rot (Sclerotinia sclerotiorum) of canola. Canadian Journal of Plant Science 80, 889-898.

BRADEN, H. (1995): The model AMBETI. A detailed description of a soil-plantatmosphere model. Berichte des DWD, Nr. 195.

BRADFORD, M. M. (1976): A rapid and sensitive method for the quantitation of microgram quantise of protein utilising the principle of protein-dye binding. Anal. Biochem. $72,248-254$.

BRUNS, J. B. (1996): Untersuchungen zur wetterbasierten Befallssimulation und Verlustprognose von Echtem Mehltau (Erysiphe graminis D. C. f. sp. tritici Marchal) an Winterweizen. Dissertation, Universität Göttingen.

Burth, U.; Freier, B.; Pallutt, B.; Gutsche, V. (1994): Anforderungen an den integrierten Pflanzenschutz im Ackerbau. Nachrichtenblatt Deutscher Pflanzenschutzdienst 46 (1), 16-18.

CASPER, R. \& MENDGEN, K. (1979): Quantitative serological estimation of a hyperparasite: Detection of Verticillium lecanii yellow rust infected wheat by ELISA. Phytopathologische Zeitschrift 94, 89-91.

Caesar, A. J. \& Pearson, R. C. (1983): Environmental factors affecting survival of ascospores of Sclerotinia sclerotiorum. Phytopathology 73, 1024-1030. 
CERNUSKO, R. (1995): Entwicklung und Erprobung enzymatischer und immunologischer Nachweismethoden für Verticillium dahliae Kleb. im Raps (Brassica napus L.). Dissertation, Univeristät Göttingen.

Cessna, S. G.; Sears, V. E.; Dieckmann, M. B.; Low, P. S. (2000): Oxalic acid, a pathogenicity factor for Sclerotinia sclerotiorum, suppresses the oxidative burst of the host plant. The Plant Cell 12, 2191-2199.

Christen, O. \& Sieling, K. (1999): Vorfruchtwert von Raps. Ist nach der Agenda 2000 eine Neubewertung nötig? Raps 17 (2), 65-67.

Clark, M. F. \& ADAMS, A. N. (1977): Characteristics of the microplate method of enzyme-linked immunosorbent assay for the detection of plant viruses. Journal of General Virology 34, 475-783.

Clarkson, J. P.; Phelps, K.; Whipps, J. M.; Young, C .S.; Smith, J. A.; Watling, M. (2004): Forecasting Sclerotinia disease on lettuce: toward developing a prediction model for carpogenic germination of Sclerotia. Phytopathology 94, 268-279.

Clarkson, J. P.; Phelps, K.; Whipps, J. M.; Young, C. S.; Smith, J. A.; Watling, M. (2005): Prediction carpogenic germination of Sclerotinia sclerotiorum sclerotia: effects of soil temperature, water potential and conditioning. $13^{\text {th }}$ International Sclerotinia Workshop, Monterey, USA.

Delanoy, M.; Slamon, M.; Kummert, J.; Lepoivre, P. (2002): Development of real-time PCR for the rapid detection of episomal Banana steak virus (BSV). Plant Disease, 87 (1), 33-38.

DeUtSChER WeTterdienst (2004): Profil der Agrarmeteorologischen Forschung des Deutschen Wetterdienstes in Braunschweig. http://argarmet.de

DiePenbrock, W.; Fischbeck, G.; Heyland, K.-U.; Knaus, N. (1999): Spezieller Pflanzenbau. Eugen Ulmer Verlag, Stuttgart.

DiercKs, R. \& Heitefuss, R. (1994): Gezielter chemischer Pflanzenschutz. In: DiercKs, R. \& Heitefuss, R. [Hrsg]: Integrierter Landbau. BLV Verlagsanstalt, München, 152-170.

Dunker, S. \& V. Tiedemann, A. (2004): Disease yield loss and analysis for Sclerotinia stem rot in winter oilseed rape. IOBC Vol. 27 (19), 59-65. 
DUNKER, S. (2005): mündliche Mitteilungen.

Dunker, S. \& V. Tiedemann, A. (2005): Zur Ertragserwartung von Pilzkrankheiten im Winterraps. Raps 23 (1), 16-19.

Edwards, S. G.; O'Callighan, J.; Dobson, D.W. (2002): PCR-based detection and quantification of mycotoxigenic fungi. Mycological Research 106 (9), 1005-1025.

Ferraz, L. C. L.; CAfe Filho, A. C.; NAsser, L. C. B.; Azevedo J. (1999): Effects of soil moisture, organic matter and grass mulching on the carpogenic germination of sclerotia and infection of bean by Sclerotinia sclerotiorum. Plant Pathology 48, 7782.

Ferris, R.S.; Stuckey, R. E.; Gleason, M. L.; Siegel, M.R. (1987): Effects on Seed Qualitiy, Seed Treatment, Soil Sourc, and Initial Soil Moisture on Soybean Seedling Performance. Phytopathology 77, 140-148.

ForTNAGEL, B. (1994): Herstellung poly- und monoklonaler Antikörper gegen phytopathogene Pilze am Beispiel von Polymyxa betae Keskin und Verticillium dahliae Kleb. Dissertation, Universität Gießen.

Freeman, J.; Ward, E.; Calderon, C.; McCartney A. (2002): A polymerase chain reaction (PCR) assay for the detection of inoculum of Sclerotinia sclerotiorum. European Journal of Plant Pathology 108: 877-886.

Freier, B. \& Rossberg, D. (2001): Simulationsmodelle als Erkenntnismittel in der Agrarökologie. Arbeitsbericht; Interdisziplinäre Arbeitsgruppe Naturwissenschaft und Technik und Sicherheit.

Freier, B; Pallutt, B.; Hommes, M. (1994): Zur Anwendung von flexiblen Schwellenwerten im integrierten Pflanzenschutz. Nachrichtenblatt Deutscher Pflanzenschutzdienst 46 (8), 170-175.

FRIESLAND, H. (1998). Ein agrarmeteorologisches Vorhersageverfahren für den Rapskrebs (Sclerotinia sclerotiorum) in Winterraps. Mitteilungen der Biologischen Bundesanstalt für Land- und Forstwirtschaft 357, 64.

Friesland, H. (2000): Agrarmeteorologisches Verfahren zur Prognose von Rapskrebs. Raps 18 (1), 14-17. 
GARBE, V. (1999): Krankheiten im Winterraps in Europa. Wo steht der integrierte Pflanzenschutz? Raps 17 (2), 68-71.

GARBE, V. (2000): Fungizide im Winterraps. Raps 18 (2), 60-65.

GENTELMAN, R. \& IHAKA, R. (1997): http://www.r-project.org/

Germeier, C.; HedKe, K.; V. Tiedemann, A. (1994): The use of pH-indicators in diagnostic media for acid-producting plant pathogens. Zeitschrift für Pflanzenkrankheiten und Pflanzenschutz 101 (5), 498-507.

GIEFFERS, W. (2001): Methodik der quantitativen Resistenzprüfung. Max-Planck-Institut für Züchtungsforschung. Labor-Arbeitspapier.

Gracia-Garza, J. A.; Neumann, S.; Vyn, T. J.; Boland, G. J. (2002): Influence of crop rotation and tillage on production of apothecia by Sclerotinia sclerotiorum. Canadian Journal of Plant Pathology 24, 137-143

Gugel, R. K. \& Morall, R. A. A. (1986): Inoculum-disease relationships in Sclerotinia stem rot of rapeseed in Saskatchewan. Canadian Journal of Plant Pathology 8, 8996.

Gutsche, V. (1992): Stand und Tendenzen der deutschen Pflanzenschutzforschung auf dem Gebiet der Prognose und Modellierung. Mitteilungen aus der Biologischen Bundesanstalt für Land- u. Forstwirtschaft 279, 45-56.

Hansen, J. G.; Kleinhenz, B.; JörG, E.; Wander, J. G. N.; Spits, H. G.; Dowley, L. J.; Rauscher, E.; Michelante, D.; Dubois, L.; Steenblock, T. (2001) Results of validation trials of Phytophthora DSSs in Europe, 2001. Sixth Workshop of an European Network for development of an Integrated Control Strategy of potato late blight Edinburgh, Scotland, 26-30 September 2001.

HAN-ZHONG, W.; GUI-HUA;L.; YUAN-BEN, Z.; XIN-FA, W.; QING, Y. (2003): Breedding of Brassica napus cultivar Zhongshuang No. 9 with high-resistance of Sclerotinia sclerotiorum and dynamics of its important defense enzyme activity. Proceedings, $11^{\text {th }}$ International Rapeseed Congress, Copenhagen, Denmark, 12-15.

HaO, J. J.; SubbaraO, K. V.; DuniWAy J. M. (2003): Germination of Sclerotinia minor and S. sclerotiorum sclerotia under various soil moisture and temperature combination. Phytopathology 93, 443-450. 
Hartleb, H., WolfF, C.; RÜCKer, P. (1999): Fungizideinsatz im Winterraps- eine schwierige Entscheidung. Raps 17 (2), 72-75.

HAU, B. (1990): Analytic models of plant disease in changing environment. Annual Review Phytopthology 28, 221-245.

HAU, B. (1995): Entwicklung von Simulationsmodellen für Pflanzenkrankheiten. Mitteil. BBA 311, 36-44.

HEDKE, K. (1992): Weiterführende Untersuchungen zum mycoparasitischen Abbau von Sklerotien von Sclerotinia sclerotiorum (LIB.) de Bary in Gewächshaus und Feld. Institut für Pflanzenpathologie und Pflanzenschutz der Georg-August-Universität Göttingen, Diplomarbeit.

Hegedus, D. D. \& Rimmer, S. R. (2005): Sclerotinia sclerotiorum: When „to be or not to be“ a pathogen? FEMS Microbiology Letters 251, 177-184.

Henson, J. M. \& FRENCH R. (1993) The polymerase chain reaction and plant disease diagnosis. Annual Review Phytopathology 31, 81-109.

HePPNER, C. (1994): Nachweis von Verticillium dahliae Kleb. im Boden mit Plattengussverfahren und ELISA (enzyme-linked immunosorbent assay) sowie Untersuchungen zur Auswirkung des Inokulums auf den Befall von Winterraps (Brassica napus ssp. Olifera Metzg.) Dissertation, Universität Göttingen.

HEROLD H. \& SACHS E. (1987): 10 jährige Erfahrungen bei der EDV-gestützten zentralen Überwachung des Schaderregerauftretens in der DDR. Nachrichtenblatt Deutscher Pflanzenschutzdienst 41 (1), 1-4.

Honermeier, B.; Behele-SchalK, L.; Gaudchau, M. (2002): Vorfruchtwirkung von Winterraps. Raps (3), 108-110.

HoRNIG, H. (1983): Zur Epidemiologie und Bekämpfung der Weißstengeligkeit (Sclerotinia sclerotiorum (Lib.) de Bary) - Einige Fragestellungen, Resultate und ungelöste Fragen. Raps 1 (1), 31-34.

ISIP (2005): http://www.isip.de

JamauX, I.; Gelie, B.; LAMARQUe, C. (1995): Early stages of infection of rapeseed petals and leaves by Sclerotinia sclerotiorum revealed by scanning electron microscopy. Plant Pathology 44, 22-30 
JAMAUX, I. \& SPIRE D. (1994): Development of a polyclonal antibody-based immunoassay for the early detection of Sclerotinia sclerotiorum in rapeseed petals. Plant Pathology 43, 847-862.

JamauX-DespreauX, I. \& SpIRE, D. (1999): Comparison of responses of ascospores and Myzelium by ELISA with anti-mycelium and anti-ascospore antisera for the development of a method to detect Sclerotinia sclerotiorum on petals of oilseed rape. Annual Applied Biology 134, 171-179.

JEGER, M. J. (1986): The potential of analytic compared with simulation approaches to modeling in plant disease epidemiology - See. Ref. 47, 255-281.

JIANG, L. (2001): A mutant with apetalous flowers in oilseed rape (Brassica napus): Mode of inheritance and influence on crop physiology and Sclerotinia infection. Dissertation, Universität Göttingen.

JÖRG, E. \& KLEINHENZ, B. (1996): Zweimal weniger spritzen. DLG- Mitteilungen 4, 46-48.

JÖRG, E. \& ROSSBERG, D. (1998): Entwicklung von SIMLEP 2 zur schlagspezifischen Kartoffelkäferprognose. Mitteilungen aus der Biologischen Bundesanstalt für Landund Forstwirtschaft, Heft 357, 100.

JÖRG, E.; FAlke, K.; Rossberg, D. (2005) "Ein neues Modell erspart Ihnen Fahrt zum Feld". DLG-Mitteilungen 4, 60-61.

JunG, M.; Much, M.; LuKOwsKY, A.; JunG, K.; LoEnING, S. A. (2001): Dimethyl sulfoxide as additive in ready-to-use reaction mixtures for real-time polymerase chain reaction analysis with SYBER Green I Dye. Analytical Biochemistry 289, 292-295.

KLeINHEnZ, B. \& JÖRG, E. (1998): Integrierter Pflanzenschutz - Rechnergestützte Entscheidungshilfen. Schriftenreihe des Bundesministeriums für Ernährung, Landwirtschaft und Forsten, Heft 473.

KLeINHEnZ, B. \& RÖHRIG, M. (2003): Pflanzenschutzberatung unter www.isip.de. Getreide Magazin 8 (1), 36-39.

KLeinhenZ, B. \& Rossberg, D. (2000): Structure and development of decision-support systems and their use by the state Protection Services in Germany. OEPP Bulletin /EPPO Bulletin, 93-97.

KLEINHENZ, B. (2005): mündliche Mitteilungen. 
KleinhenZ, B.; JÖRG, E.; Schietinger, R. (1998): Umsetzung der Verwaltungsvereinbarungen der Länder vom 01.10.97 über die gemeinsame Entwicklung und Pflege EDV-gestützter Entscheidungshilfen (ZEPP). Mitteilungen aus der Biologischen Bundesanstalt für Land- und Forstwirtschaft, Heft 357, 201.

Koch, S. \& VON TIEDEMANN, A. (2004): Entwicklung eines schadensbezogenen Prognosemodells zur Bekämpfung der Weißstängeligkeit in Winterraps. Mitteilungen aus der Biologischen Bundesanstalt für Land- und Forstwirtschaft, Heft 396, 190.

Koch, S. \& von Tiedemann, A. (2005): Den Spritztermin richtig absichern. DLGMitteilungen 3, 44-46.

Koch, S. \& von Tiedemann, A. (2005): Mit SkleroPro auf der sicheren Seite. Neue Strategien im Pflanzenschutz. Land und Forst, Schriftenreihe Pflanzenschutz, 2830 .

KoHN, L. M. (1979): Delimitation of the economically important plant pathogenic species. Phytopathology 69 (8), 881-886.

KoOpmanN, B. (1995): Entwicklung und Erprobung von DNA-Sonden und Anwendung der Polymerase-Kettenreaktion zur Differenzierung und zum Nachweis der getreidepathogenen Pilze Fusarium culmorum (W.G.Sm.) Sacc., Fusarium graminearum Schwabe und Fusarium avenaceum (Fr) sacc. im pflanzlichen Gewebe. Dissertation, Universität Göttingen.

KöpPL, H. (1993): Erprobung eines Sclerotinia-Warndienstes. Raps 11 (2), 66-69.

Kora, C; McDonald M. R.; Boland G. J. (2005): Epidemiology of sclerotinia rot of carrot caused by Sclerotinia sclerotiorum. Canadian Journal of Plant Pathology 27 (2), 245-258.

KRAATZ, M. (1994): Auswertung von Erhebungsdaten einer amtlichen Schaderregerüberwachung zur Abhängigkeit der Halmbruchkrankheit von Standortfaktoren und anderen Einflussfaktoren. Dissertation, Universität Göttingen.

KRANZ, J. (1996): Epidemiologie der Pflanzenkrankheiten: Eine Einführung. Verlag Eugen Ulmer, Stuttgart.

Krostitz, J. (1998): Weißstängeligkeit. Wie ernst ist sie zu nehmen? Raps 16 (2), 52-56. 
KURSE, T. (2004): Epidemiologie, Bedeutung und integrierte Bekämpfungsmöglichkeiten von Leptosphaeria maculans (Phoma lingam) sowie weiterer pilzlicher Krankheitserreger im schleswig-holsteinischen Winterrapsanbau (Brassica napus L. var. napus). Dissertation, Universität Kiel.

KRÜGer W. \& STOLtenberg J. (1983): Bekämpfung von Rapskrankheiten II. Maßnahmen zur Befallsverringerung von Sclerotinia sclerotiorum unter Berücksichtigung ökonomischer Faktoren. Phytopathologische Zeitschrift 108, 114-126.

KRÜGER W. (1976): Untersuchungen zur Beeinflussung der Apothezien-Entwicklung von Sclerotinia sclerotiorum (Lib.) de Bary. Nachrichtenblatt Deutscher Pflanzenschutzdienst 28, 129-135.

KRÜGER, W. (1975A): Die Beeinflussung der Apothezien- und Ascosporenentwicklung des Rapskrebserregers Sclerotinia sclerotiorum (Lib.) de Bary durch Umweltfaktoren. Zeitschrift für Pflanzenkrankheiten und Pflanzenschutz 82, 101-108.

KRÜGER, W. (1975B): Influence of the weather on attack of rape by Sclerotinia sclerotiorum (Lib.) de Bary. Nachrichtenblatt Deutscher Pflanzenschutzdienst 27, $1-6$.

KRÜGER W. (1977): Einfluss abiotischer Faktoren auf den Erreger des Rapskrebses und dessen Bekämpfung. Kali Briefe 13, 1-12.

Kull, L. S.; Vuong, T. D.; Powers, K. S.; Eskridge, K. M.; Steadman, J. R.; HartmanN, G. L. (2003): Evaluation of Resistance Screening Methods for Sclerotinia Stem Rot of Soybean and Dry Bean. Plant Disease 87, 1471-1476.

Kurle, J. E.; Grau, C. R.; Oplinger, E. S.; Mengistu, A. (2001): Tillage, Crop Sequence and Cultivar Effects on Sclerotinia Stem Rot Incidence and Yield in Soybean. Agronomy Journal 93, 973-982.

KÜst, G.; WAhmhoff, W.; Heitefuss, R. (1989): Schadenschwellen für Unkräuter im Winterraps. Raps 7, 122.

LASSAK, V. H. (1993): Befalls-Verlust-Relation von Echtem Mehltau (Erysiphe graminis D. C. f. sp. tritici Marchal) an Winterweizen; Ermittlung, Anwendung und Überprüfung mit einem Programm zur Verlustprognose. Dissertation, Universität Göttingen. 
Le Tourneau, D. (1979): Morphology, cytology, and Physiology of Sclerotinia Species in Culture. Phytopathology 69, 887-890.

Lefol, C. \& MorRall R. A. A. (1996): Immunofluorescent staining of Sclerotinia ascospores on canola petals. Canadian Journal of Plant Pathology 18, 237-241.

Li; G.; Wu, X.; Shengqui, F.; Cuilian, C.; Tang, H. (2003): The establishment of Sclerotinia sclerotiorum resistant near isogenic lines. Proceedings, $11^{\text {th }}$ International Rapeseed Congress, Copenhagen, Denmark, 52-56.

LIS J. T. \& SCHLEIF R. (1975): Size fractionation of double-stranded DNA by precipitation with polyethylene glycol. Nucleic Acids Research 2, 383-389.

LOR, H.-J. (1995): Ist der Einsatz von Fungiziden in Raps noch wirtschaftlich? Raps 13 (2), $62-63$.

Lutze, G.; Kluge, E.; Enzian, S.; Schultz, A. (1990): Forschungsschwerpunkt "Überwachung, Prognose, Entscheidungsfindung“ -Beiträge zum umweltgerechten Pflanzenschutz. Nachrichtenblatt Pflanzenschutz DDR 44, 286-289.

McCartney, H. A.; Lacey, M. E.; LI, Q.; Heran A. (1999): Airborne ascospores concentration and the infection of oilseed rape and sunflowers by Sclerotinia sclerotiorum. Proceedings of the $10^{\text {th }}$ International Rapeseed Congress, Camberra, Australia.

McDonald, M. R. \& Boland, G. J. (2004): Forecasting disease caused by Sclerotinia spp. In eastern Canada: fact or fiction? Canadian Journal of Plant Pathology 26, 480488.

MCQuilken, M.P.; Mitchell, S. J.; ARChER, S. A. (1994): Origin of early attacks of Sclerotinia stem rot on winter oilseed rape (Brassica napus sup. Sp. oleifera var. biensis) in the UK. Journal of Plant Pathology, 140 (3), 179-186.

MEIER, U. (1997): Growth stages of Mono- and Dicotyledonous plants. Federal biological research centre for agriculture and forestry. Blackwell Wissenschafts- Verlag Berlin-Wien.

Merriman, P. R.; Pywell, M.; Harrison, G.; Nancarrow, J. (1979): Survival of sclerotia of Sclerotinia sclerotiorum and effects of cultivation practices on disease. Soil Biology and Biochemistry 11, 567-570. 
MielKe, T. (2005): Perspektiven der Rapsproduktion durch wachsende Food- und NonFood-Märkte. Raps 23 (2), 79-82

Mila, A. L.; CARriQuiry A. L.; YANG X. B. (2004): Logistic Regression Modeling of Prevalence of Soybean Sclerotinia Stem Rot in North-Central Region of the United States. Phytopathology 94, 102-110.

Mitchell, S. J. \& WheELER, B. E. J. (1990): Factors affecting the production of apothecia and longevity of sclerotia of Sclerotinia sclerotiorum. Plant Pathology 39, 70-76.

Mueller, D. S.; Hartmann G. C.; Pedersen W. L. (2002): Effect of crop rotation and tillage system on sclerotinia stem rot on soybean. Canadian Journal of Plant Pathology 24, 450-456.

MÜLleR H.-J. (2001): PCR - Polymerase - Kettenreaktion. Spektrum-Akademischer Verlag. Heidelberg-Berlin.

Murray, M. G. \& ThOMPSON, W. F. (1980): Rapid isolation of high molecular weight plant DNA. Nucleic Acids Research 8, 4321-4325.

NABIZAdEH-ARDEKANI, F. (1999): Nachweis bakterieller Krankheiten der Tomate durch die Polymerase-Kettenreaktion oder serologische Methoden und Bestimmung des Rassespektrums von Pseudomonas syringae pv. tomato in der Türkei. Dissertation, Universität Göttingen.

NASSER, L. C. B. (1995): Influence of crop residues and soil moisture on Sclerotinia sclerotiorum from the Cerredos region in Brazil. Canadian Journal of Plant Pathology 17, 360-361.

Nicholson, P.; Simpson, D. R.; Weston, G.; Rezanoor, H. N.; Lees A. K.; PARry D. W.; JoYGE, D. (1998): Detection and quantification of Fusarium culmorum and Fusarium graminearum in cereals using PCR assays. Physiological and Molecular Plant Pathology 53, 17-37.

NichOLL, D. S. T. (2002): Gentechnische Methoden. 2. Auflage, Spektrum Akademischer Verlag.

Nordin, K.; SigVald R.; Svensson C. (1992): Forecasting the incidence of Sclerotinia stem rot on springsown rapeseed. Zeitschrift für Pflanzenkrankheiten und Pflanzenschutz 99, 245-255. 
PARKHOMENKO, S. (2003): Ein Vergleich der weltweit wichtigsten Anbauregionen für Ölsaaten. Endbericht für die Union zur Förderung von Öl- und Proteinpflanzen e.V. http://www.ufop.de/downloads/Weltoelsaaten_deutsch.pdf.

Paul, V. H. (2003): Raps Krankheiten, Schädlinge, Schadpflanzen. Verlag Th. Mann, Gelsenkirchen-Buehr.

Paul, V. H.; Henneken, M.; LiU, Y.; Föller, I. (2000): Rapsjahr 2000 - Jahr der Weißstängeligkeit? Raps 18, (4), 184-187.

Paul, V. H.; LiU, Y.; Brandau, K. (2005): Neue Rapsfungizide im Test gegen Rapskrankheiten- Erste Laborergebnisse. Raps, 23 (2), 60-62

Phelps, K.; Clarkson, J.P.; Whipps, J. M.; Young, C. S.; Smith, J. A.; Watling M. (2005): Prediction carpogenic germination of Sclerotinia sclerotiorum sclerotia: field validation of a simulation model. $13^{\text {th }}$ International Sclerotinia Workshop, Monterey, USA.

PHILLIPS A. J. L. (1994): Influence of fluctuating temperatures and interrupted periods of plant surface wetness on infection of bean leaves by ascospores of Sclerotinia sclerotiorum. Annals of Applied Biology 124, 413-427.

Peters, J. H. \& Baumgarten, H. (1990): Monoklonale Antikörper. Springer Verlag, Berlin.

Pope, S. J.; VArney, P. L., Sweet, J. B. (1989): Susceptibility of cultivars of oilseed rape to Sclerotinia sclerotiorum and the effect of infection on yield. Aspects of Applied Biology 23, 451-456.

PURDY, L. H. (1979): Sclerotinia sclerotiorum: History, disease and symptomatology, host range, geographic distribution, and impact. Phytopathology 69, 875-880.

QUENTIN, U. (2004): Weißstängeligkeit erfolgreich bekämpfen. Raps 22 (3), 100-102.

RaccA, P.; Jörg, E.; Mittler, S.; Petersen, J. (2002): CERBET 3- ein flexibles Modell zur Prognose von Bekämpfungsschwellenüberschreitungen bei Cercospora beticola. Mitteilungen aus der Biologischen Bundesanstalt für Land- und Forstwirtschaft, Heft 390, 218-219.

RaccA, P.; JÖrG, E.; Mittler, S.; Petersen, J. (2004): CERBET 3- als Entscheidungshilfe zur Bekämpfung von ein Cercospora beticola in Zuckerrüben- 
Behandlungsstrategie und Fungizidwirkung. Mitteilungen aus der Biologischen Bundesanstalt für Land- und Forstwirtschaft, Heft 396, 166.

RAPOOL: http//:www.rapool.de

REUTER, L. B. (2003): Der Rapsmarkt auf einen Blick. Raps 21, 192-193.

REWERTS, T. (2003): Entwicklung und Validierung von Methoden zum Screening der Anfälligkeit von Winterraps gegenüber Sclerotinia sclerotiorum. Masterarbeit, Universität Göttingen.

RÖHrig, M. \& KleInHENZ, B. (2002): Internetbasierte Pflanzenproduktionsberatung im ISIP - Status und Funktionsweise, 53. Deutsche Pflanzenschutztagung. Mitteilungen aus der Biologischen Bundesanstalt für Land- und Forstwirtschaft, Heft 390, 216.

RÖHRIG, M. \& SANDER, R. (2004): ISIP - zweijährige Erfahrungen mit der Online-Beratung der Pflanzenschutzdienste, 54. Deutsche Pflanzenschutztagung. Mitteilungen aus der Biologischen Bundesanstalt für Land- und Forstwirtschaft, Heft 396, S. 249.

Rollins, J. A. \& DickMAn, M. B. (2001): pH signaling in Sclerotinia sclerotiorum: Identification of pacC/RIM1 homolog. Applied and environmental microbiology 67 (1), 75-81.

ROßBERG, D.; JÖRG, E.; FALKE, K. (2004): SIMONTO- ein neues Ontogenesemodell für Wintergetreide und Winterraps. Mitteilungen aus der Biologischen Bundesanstalt für Land- und Forstwirtschaft, Heft 396, 163.

ROßBERG, D.; JÖRG, E.; FALKE, K. (2005): SIMONTO- ein neues Ontogenesemodell für Wintergetreide und Winterraps. Nachrichtenblatt Deutscher Pflanzenschutzdienst 57 (4), 74-80.

SACHS, L. (1992): Angewandte Statistik. Anwendung statistischer Methoden. 7. Auflage, Springer-Verlag, Berlin Heidelberg.

SALM, H. \& GEIDER K. (2004): Real-time PCR for detection and quantification of Erwinia amylovora, the causal agent of fireblight. Plant Pathology 53, 602-610.

SAUR, R. (1983): Versuche mit Sporenfallen zur Terminbestimmung bei der Bekämpfung von Sclerotinia sclerotiorum an Winterraps. Zeitschrift für Pflanzenkrankheiten und Pflanzenschutz 90 (3), 225-231. 
SCHMIDT, C. (1990): Gewächshausscreening für Sklerotienparasiten von Sclerotinia sclerotiorum (LIB.) de Bary. Institut für Pflanzenpathologie und Pflanzenschutz der Georg-August-Universität Göttingen, Diplomarbeit

SchmiedL, J. \& KöPPL, H. (1996): Lohnt sich der Fungizideinsatz im Raps? Raps 14 (1), 16-19.

Siebrasse, G. \& FeHRMANN H. (1986): Ein erweitertes Modell zur praxisgerechten Bekämpfung des Erregers der Halmbruchkrankheit Pseudocercosporella herpotrichoides in Winterweizen. Zeitschrift für Pflanzenkrankheiten und Pflanzenschutz 94 (2), 137-149.

SIEBRASSE, G. (1982): Zur Entwicklung eines mathematischen Modells für ein praxisgerechtes Halmbruchwarnsystem in Winterweizen. Dissertation, Universität Göttingen.

Singh U. P. \& Singh R. B. (1983): The effect of soil texture, soil moisture and depth of soil on carpogenic germination of Sclerotinia sclerotiorum. Zeitschrift für Pflanzenkrankheiten und Pflanzenschutz 90 (6), 662-669.

Singh, U. P.; Singh R. B.; Gupta S. (1985): Effect of temperature on sclerotia germination, growth and sclerotia formation in Sclerotinia sclerotiorum. Zeitschrift für Pflanzenkrankheiten und Pflanzenschutz 92 (3), 281-287.

Steadman, J. R. (1983) White mould - a serious yield limiting disease of bean. Plant Disease 67, 346-350.

SteinBACH, P. \& BRoschewitz, B. (1997): Ertragssicherung durch Krankheitskontrolle und/oder Wachstumsregulierung? Raps 15(2), 62-66.

Steventon, L. A.; Fahleson, J.; QIONG, H.U.; DiXelius, C. (2002): Identification of the causal agent Verticillium wilt of winter oilseed rape in Sweden, V. longisporum. Mycological Research 106 (5), 570-578.

Sun, P. \& YANG X. B. (2000): Light, temperature and moisture effects on apothecium production of Sclerotinia sclerotiorum. Plant Disease 84 (12), 1287-1293.

TENG, P. S. (1981): Validation of computer models of plant disease epidemics: A review of philosophy and methodology. Zeitschrift für Pflanzenkrankheiten und Pflanzenschutz 88 (1), 49-63. 
TeO, B. K.; Morrall, R. A. A.; Verna, P. R. (1989): Influence of soil moisture, seeding date and canola cultivars (Tobin and Westar) on the germination and rotting of sclerotia of Sclerotinia sclerotiorum. Canadian Journal of Plant Pathology 11, 393399.

Tischner, H. (1998): Entscheidungs- und Prognosesysteme im Pflanzenschutz. Gesunde Pflanze 50 (8), 237-245.

Turkington, T. K. \& Morall, R. A. A. (1993): Use of petal infestation to forecast Sclerotinia stem rot of canola: the influence of inoculum variation over the flowering period and canopy density. Phytopathology 83, 682-689.

THÜRWÄCHTER, F. (1991): Bestimmung der Infektionswahrscheinlichkeit durch Sclerotinia sclerotiorum (Lib.) de Bary- Prognoseansatz unter Berücksichtigung von Bestandesklimadaten. Diplomarbeit, Universität Göttingen.

Twengström, E.; Sigvald, R.; Svensson, C.; Yuen, J. (1998): Forecasting Sclerotinia stem rot in spring sown oilseed rape. Crop Protection 17 (5), 405-411.

UFOP (2005): http://www.ufop.de/1640.htm

Ulrich, J. \& SchröDTER, H. (1966): Das Problem der Vorhersage des Auftretens der Kartoffelkrautfäule (Phytophthora infestans) und die Möglichkeiten seiner Lösung durch eine Negativprognose. Nachrichtenblatt Deutscher Pflanzenschutzdienst 13, 33-40.

UNGER, J.-G. (1989): Entwicklung und Erprobung eines Erprobung eines ELISA (Enzymelinked Immunosorbent Assay) zum Nachweis von Fusarium culmorum (W:G.Sm.) Sacc. und Pseudocercosporella herpotrichoides (Fron.) Deigh. in Weizen. Dissertation, Universität Göttingen.

VAn MAanen, A. \& XU, X.-M. (2003): Modeling plant disease epidemics. European Journal of Plant Pathology 109, 669-682.

VAN DER Plank, J. E. (1982): Host-Pathogen Interactions in Plant Disease. Academic press New York, 207.

VENETTE, J. (1998): Sclerotinia spore formation, transport and infection. Proceedings of the Sclertotinia workshop. Fargo North Dakota. 
Volk, T. \& Herbert, K. G. (2002): Pflanzenschutz-Informationsdienste: Aktuelle und zukünftige Praxisanforderungen sowie technische Möglichkeiten. Nachrichtenblatt Deutscher Pflanzenschutzdienst 57 (4), 74-80.

VOLKE, B. (1999): Leptosphaeria maculans, der Erreger der Wurzelhals- und Stängelfäule an Raps: Verbreitung verschiedener Pathogenitätsgruppen in Europa, Quantifizierung des Befalls- und Schadwirkung im Freiland. Dissertation, Universität Göttingen.

VON SchWARZENBERG, K. (1984): Entwicklung eines immunologischen Tests zum Nachweis von Gerlachia nivalis in pflanzlichem Gewebe unter Anwendung des ELISA-Verfahren. Diplomarbeit, Universität Göttingen.

Von Tiedemann, A. (2004): Aktuelle Krankheiten. Welche Lösungen zeichnen sich ab? Raps (22) 2, 56-59.

von Tiedemann, A.; Hedke, K.; Mögling, R. (2000): Biologische Bekämpfung der Sclerotinia-Weißstängeligkeit. Raps (18) 1, 10-13.

von Tiedemann, A.; Hedke, K.; MöGling, R. (2001): Abbauverhalten von Sklerotien der Weißstängeligkeit bei Einsatz von Contans. Raps (19) 1, 21-23.

WAgGOner, P. E.; Horsfall, J. G. (1969): EPIDEM, a simulator of plant disease written for a computer. Conn. Agric. Exp. Stn. Bull. 698, 1-80.

WAHMHOFF, W. (2000): Integrierter Rapsanbau: Untersuchungen zur Entwicklung integrierter Produktionsverfahren am Beispiel des Winterrapses (Brassica napus L.). Erich Schmidt Verlag.

Wahmhoff, W.; Hedke, K.; v. Tiedemann, A.; Nitzsche, O.; Ulber, B. (1999): Zum Einfluß von Fruchtfolge und Bodenbearbeitung auf die Entwicklung wichtiger Schaderreger des Winterrapses. Zeitschrift für Pflanzenkrankheiten und Pflanzenschutz 106, 57-73.

WALKER, A. (1997): ModelMaker, 4.0 edn. Cherwell Scientific, Oxford, UK.

WaAlwijk, C.; Van der Heide, R.; De VRIes, I.; Van der Lee, T.; Schoen, C.; Corainville, G.; Häuser-Hahn, I.; Kastelein, P.; Köhl, J.; Lonnet, P.; Demarquet, T.; Kema, G. H. J. (2004): Quantitative detection of Fusarium species in wheat using TaqMan. European Journal of Plant Pathology 110, 481-494. 
Weber, E. \& BleiHOlder H. (1990): Erläuterungen zu den BBCH-Dezimal-Codes für die Entwicklungsstadien von Mais, Raps, Faba-Bohne, Sonnenblume und Erbse- mit Abbildungen. Gesunde Pflanze (9) 42, 308-321.

Weinert, J.; Kleinhenz B.; Racca P. (2005): Prognose jetzt für jeden Acker. DLGMitteilungen 3, 54-57.

Werner, B.; De Mol, F.; GerowitT, B. (2002): Unkraut mit der Maus erwischen. DLGMitteilungen 9, 52-56.

WeisS, A.; KeRR, E. D.; STEAdMAn, J. R. (1980): Temperature and moisture influences on development of white mold disease (Sclerotinia sclerotiorum) on great northern beans. Plant Disease 64 (8), 757-759.

White, T. J.; Bruns, S.; LeE, S.; TAYLOR, J. (1990) Amplification and direct sequencing of fungal ribosomal $\mathrm{RNa}$ genes for phylogenetics. In: Innis M.A., Gelfand D.H., Sninsky J.J. and White T.J. (eds) PCR Protocols. A Guide to Methods and Applications (315-322) Academic Press, San Diego, USA.

Williams, J. R. \& Stellfox, D. (1979): Dispersal of ascospores of Sclerotinia sclerotiorum in relation to Sclerotinia stem rot of rapeseed. Plant Disease Reporter 63, 395-399.

Williams, R. H.; WaRd, E.; McCARTNeY H. A. (2001): Methods for integrated air sampling and DNA anlaysis for detection of airborne fungal spores. Applied and Environmental Microbiology, 67 (6), 2453-2459.

WoHlleBen, S. (2001): Epidemie- und Schadensdynamik von pilzlichen Krankheitserregern (Leptosphaeria maculans, Sclerotinia sclerotiorum, Verticillium dahliae) an Winterraps (Brassica napus L. var. napus) in SchleswigHolstein. Dissertation, Universität Kiel.

WOLF (2003): mündliche Mitteilung

Wolf, P. F. J., Weis, F.J., Verreet, J.-A., BÜrcky, K., Maier, J., Tischner, H. (1998): IPS (Integriertes Pflanzenschutzsystem)- Modell Zuckerrübe - Entwicklungsschritte und Einführung in die Praxis. Gesunde Pflanze 50 (8), 264-272.

Young, C. S.; Clarkson, J. P.; Smith, J. A.; Watling, M.; Phelps, K.; Whipps, J. M. (2004): Environmental conditions influencing Sclerotinia sclerotiorum infection and disease development in lettuce. Plant Pathology 53, 387-397. 
Young, C. S.; Fawcett, L. E.; Anthony, S. G.; Smith, J. A. Watling, M.; Clarkson, J. P.; WhIPPS, J. M. (2005): Forecasting Sclerotinia disease in field-grown lettuce. $13^{\text {th }}$ International Sclerotinia Workshop, Monterey, USA.

ZEPP (2005): http://www.zepp.info

Zhao, J.; Peltier, A. J.; Meng, J.; Osborn, T. C.; Grau, C. R. (2004): Evaluation of Sclerotinia stem rot resistance in oilseed Brassica napus using a petiole inoculation technique under greenhouse conditions. Plant Disease 88, 1033-1039.

ZHAO, Q.; JIANG, J.; BECKER, H. C.; WOLF, G. A. (2002): Untersuchungen zur Anfälligkeit blütenblattloser Rapslinien gegenüber Sclerotinia sclerotiorum und anderen Rapsstängelkrankheitserregern mit Hilfe von serologischen Verfahren. 53. Deutsche Pflanzenschutztagung, Bonn. Mitteilungen aus der Biologischen Bundesanstalt für Land- und Forstwirtschaft 390, 441-442. 


\section{Danksagung}

Ich möchte mich ganz herzlich bei Herrn Prof. Dr. A. von Tiedemann für die Überlassung des Themas, die ständige Diskussionsbereitschaft und die stets gewährte Unterstützung bei der Durchführung dieser Arbeit bedanken. Herrn Prof. Dr. H. Becker danke ich für die Übernahme des Korreferates.

Weiterhin bedanke ich mich ganz herzlich bei Herrn Friesland für die Kooperationsbereitschaft und Bereitstellung des Prognosemodells SKLERO.

Den Mitarbeitern der ZEPP und ISIP, insbesondere Herrn Dr. Kleinhenz, Frau Keil und Herrn Dr. Röhrig danke ich für die ständige Hilfsbereitschaft in allen Fragen der Modellierung und der Wetterdatenbereitstellung.

Besonderer Dank gilt auch den Pflanzenschutzdiensten der Länder und der Biologischen Bundesanstalt, die an dem Projekt teilgenommen haben. Ohne die tatkräftige Unterstützung und Hilfsbereitschaft der zum Teil doch sehr arbeitsaufwendigen Probennahmen und Betreuung der Versuchsanlagen wäre diese Arbeit nicht möglich gewesen.

Danken möchte ich auch Herrn Prof. Dr. G. A. Wolf für die Bereitstellung der Antiseren für den ELISA sowie Herrn Prof. Dr. P. Karlovsky für die Unterstützung bei allen PCR Arbeiten.

Außerdem möchte ich mich ganz herzlich bei der "Sclerotinia-Arbeitsgruppe“ insbesondere bei Isabel Müller, Michaela Meyer und Sarah Dunker für die Unterstützung, das freundliche Arbeitsklima und die stete Hilfsbereitschaft bedanken.

Des Weiteren gilt mein Dank allen Mitarbeitern des Instituts und insbesondere der Arbeitsgruppe von Prof. von Tiedemann für die freundliche Arbeitsatmosphäre und die stete Hilfsbereitschaft. In diesem Zusammenhang möchte ich mich auch ganz herzlich bei Frau Bode und dem Sekretariat für die große Unterstützung und Hilfe bei den administrativen Aufgaben bedanken.

Zum Schluss möchte ich mich noch ganz besonders bei meinen Eltern, meiner Familie und Hubertus bedanken, die mir immer mit viel Verständnis zur Seite standen und auch in schwierigen Zeiten immer ein offenes Ohr für mich hatten.

Ein besonderer Dank gilt auch dem Bundesministerium für Landwirtschaft, Ernährung und Forsten und der Bundesanstalt für Umwelt, die mir diese Arbeit finanziell ermöglicht haben. 


\section{Persönliche Daten:}

Name: $\quad$ Simone Koch

Geburtsdatum: $\quad$ 12.06.1978 in Alfeld

\section{Schulbildung:}

1984 - $1988 \quad$ Grundschule Limmer

1988 - $1997 \quad$ Jugenddorf - Christophorus - Schule - Elze

Abschluss: Allgemeine Hochschulreife

\section{Hochschulstudium:}

10/1997 - 07/1999 Studium der Agrarwissenschaften an der Christian - Albrecht - Universität zu Kiel

10/1999 - 12/2001 Studium der Agrarwissenschaften an der Georg - August - Universität zu Göttingen Fachrichtung: Pflanzenbau

12/2001 Abschluss: Master of Science in Agriculture „Untersuchungen zum Vegetationsmanagement in Mulchsaaten mit glyphosattoleranten Zuckerrüben“"

03/2002 - 12/2005 Promotionsstudium und Anfertigung einer Dissertation am Institut für Pflanzenpathologie und Pflanzenschutz

\section{Praktische Tätigkeiten:}

08/1998 - 09/1998 Praktikum auf dem Lehr- und Forschungsgut der Tierärztlichen Hochschule Hannover in Ruthe

08/2000 - 09/2000 Praktikum bei Bayer Vital GmbH in Hannover

02/2001 - 05/2001 Studentische Hilfskraft am Institut für Zuckerrübenforschung in Göttingen

\section{Berufstätigkeit:}

03/2002-02/2005 wissenschaftliche Mitarbeiterin am Institut für Pflanzenpathologie und Pflanzenschutz der Universität Göttingen

05/2005 - 05/2006 wissenschaftliche Mitarbeiterin am Dienstleistungszentrum ländlicher Raum Rheinhessen-Nahe-Hunsrück 


\section{Eidesstattliche Erklärung}

Hiermit erkläre ich eidesstattlich, dass diese Dissertation selbstständig und ohne unerlaubte Hilfe angefertigt wurde.

Göttingen, Dezember 2005 